\title{
KEY LABOUR MARKET ISSUES AND DECENT WORK IN DEVELOPING AND EMERGING COUNTRIES
}

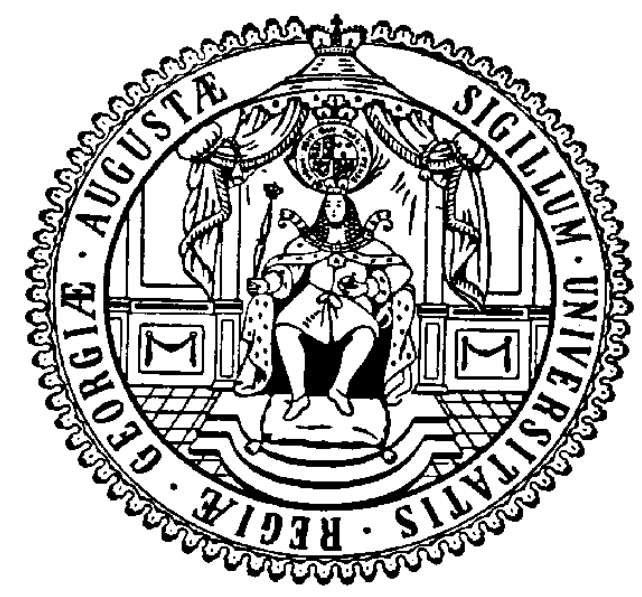

\section{DISSERTATION}

Submitted in accordance with the requirements

for the doctoral degree in economic sciences

at the Georg-August-Universität Göttingen

by

Martin Ostermeier

Born in Munich, Germany

June 2020 


\section{Thesis Committee}

First supervisor: Apl. Prof. Dr. Jann Lay

Second supervisor: Prof. Stephan Klasen, Ph.D.

Third examiner: Prof. Dr. Renate Hartwig

Date of submission: 04 June 2020 


\section{Acknowledgements}

I am grateful to my first supervisor, Jann Lay, for his continued support throughout this dissertation project, for his academic advice and professional guidance, and for his encouragement and patience. I also thank Stephan Klasen and Renate Hartwig for their helpful comments and suggestions and for giving me the opportunity to seek advice.

I would like to thank my co-authors Claire Harasty, Jann Lay, Sarah Wiegel, Kerstin Nolte and Sebastian Prediger for their many insightful discussions and excellent collaboration. I very much enjoyed working with you.

This dissertation was partly compiled at the German Institute of Global and Area Studies (GIGA), which provided me with a fertile research environment and access to excellent resources. I am thankful for the abundant learning opportunities offered by the GIGA Doctoral Programme and for the helpful comments from, and inspiring exchanges with, my fellow students at both the GIGA and the University of Göttingen. In the same vein, I would like to thank my colleagues at the International Labour Organization for sharing their expertise and supporting me with help and advice.

This dissertation was finalized during the "Great Lockdown", i.e. during the global COVID-19 pandemic of early 2020. It was a particularly lonely time, when social interactions were massively reduced or even stopped almost entirely. I am therefore particular grateful to all my friends who regularly checked on me, made sure I was well cared for and were there for me when I needed them.

Last but not least, my deepest gratitude goes to my family. There was a time when none of us knew where my journey might take me. Not only did you allow me to navigate my own path, you also never stopped supporting me because you always believed in me. Thank you. 


\section{Contents}

Acknowledgements

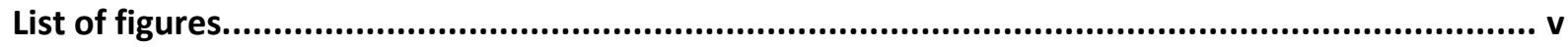

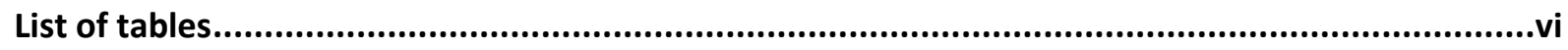

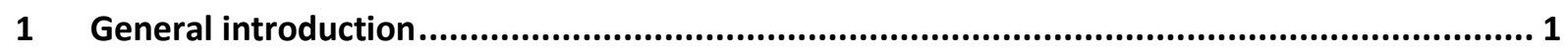

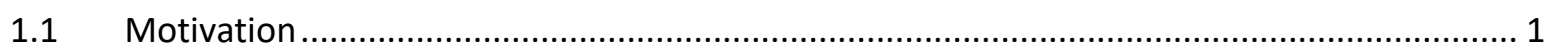

1.2 Key labour market trends in developing and emerging countries ...................................... 3

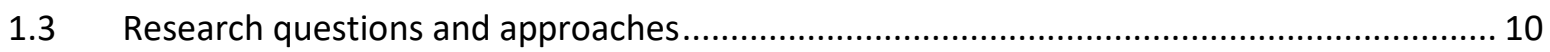

2 SMARTer indicators for decent work in a post-2015 development agenda: A proposal.......... 15

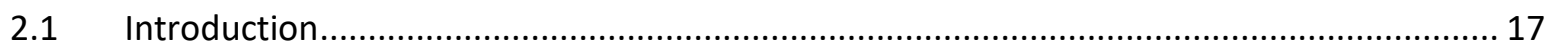

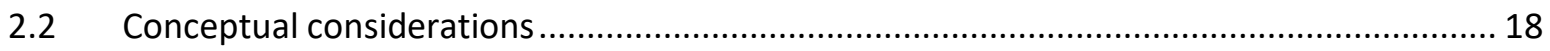

2.2.1 Foundations and challenges of employment-related development targets ............... 18

2.2.2 The relationship between employment and social protection ................................... 19

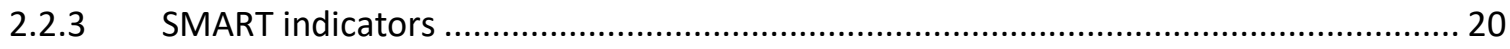

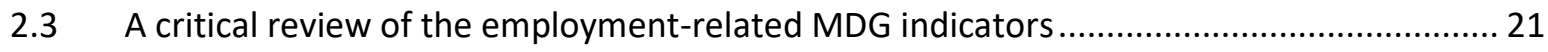

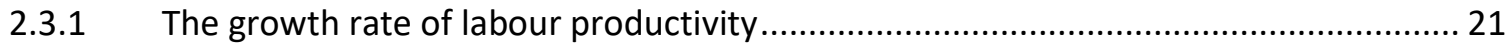

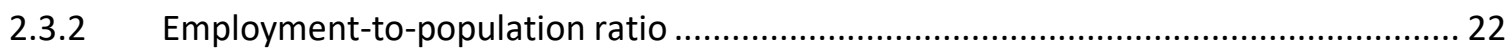

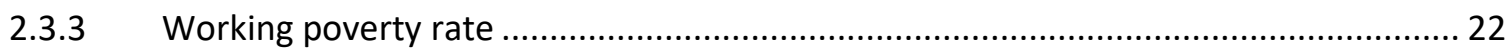

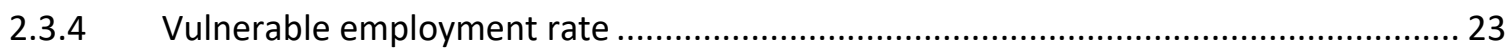

2.3.5 Share of women in wage employment in the non-agricultural sector ......................... 24

2.4 Proposal for a new employment target and set of indicators ......................................... 25

2.4.1 Indicator 1: Growth of labour value added per worker ............................................ 26

2.4.2 Indicator 2: Working poverty rate

2.4.3 Indicators 3a and 3b: Proportions of workers earning less than an absolute and a relative

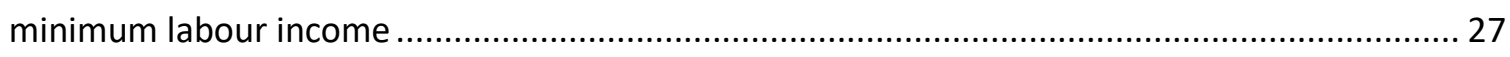

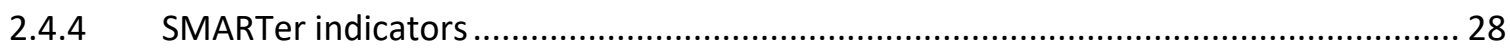

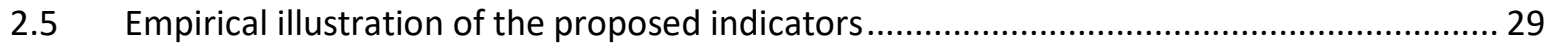

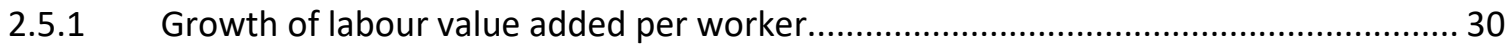


2.5.3 Workers earning less than absolute and relative minimum labour incomes

2.6 Conclusion

3 Labour Market Effects of Large-Scale Agricultural Investment: Conceptual Considerations and Estimated Employment Effects 37

3.1 Introduction 39

3.2 Rural labour markets and labour productivity 41

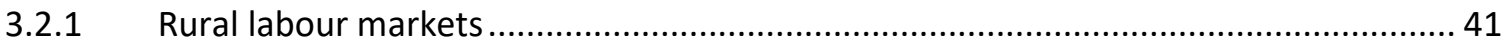

3.2.2 Agricultural labour productivity and labour intensity .......................................42

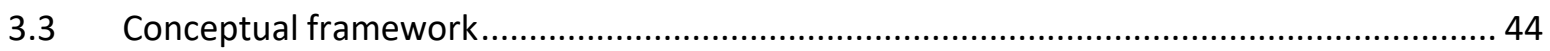

3.3.1 Scenarios for brownfield investments........................................................... 47

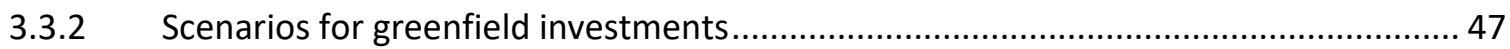

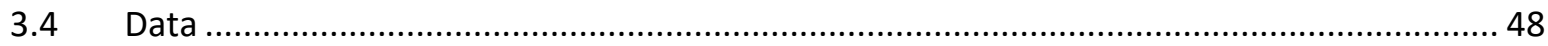

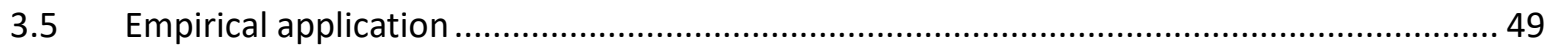

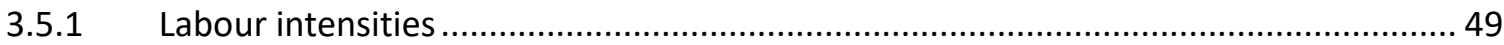

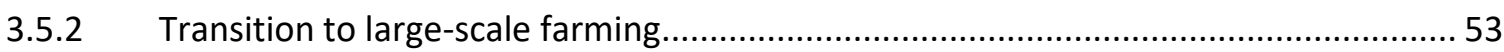

3.5.3 Estimation of labour creation potential through LSAls ......................................... 58

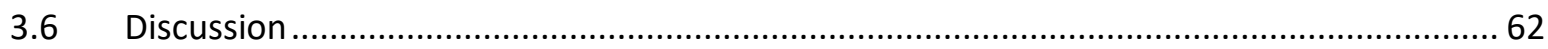

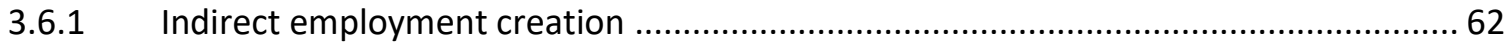

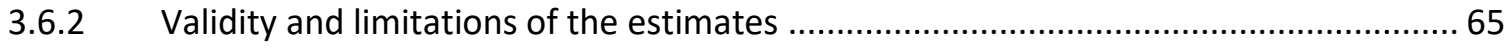

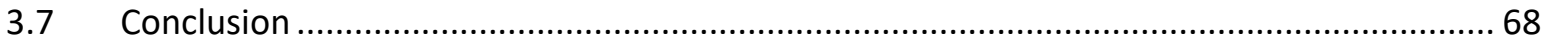

4 Population Ageing: Alternative Measures of Dependency and Implications for the Future of

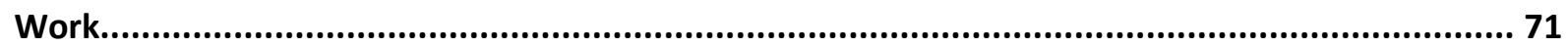

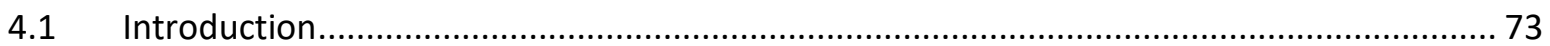

4.2 Population ageing and labour force trends among older age cohorts ............................74

4.2.1 The world is getting older: more than three quarters of countries will either be ageing or already aged by 2050 75

4.2.2 The proportion of older workers in the labour force is increasing worldwide 78 
4.2.3 Trend reversal in older workers' labour force participation rates across development level 80

4.3 Alternative economic dependency measures based on employment and decent work...... 81

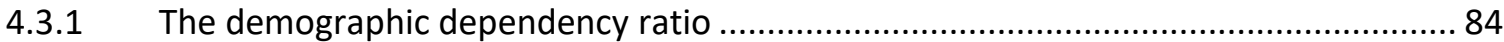

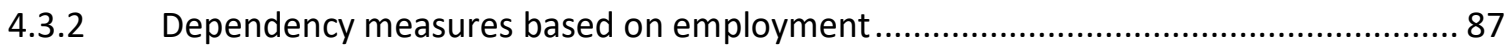

4.3.3 Dependency measures based on productive employment ..........................................97

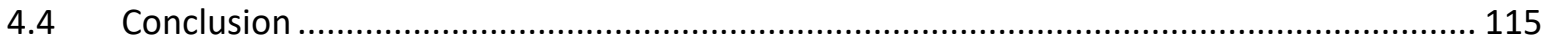

5 Scarred Youth: School-to-work Transitions and Income Scars in Times of Crisis....................120

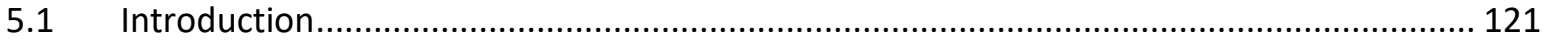

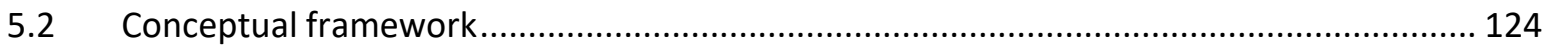

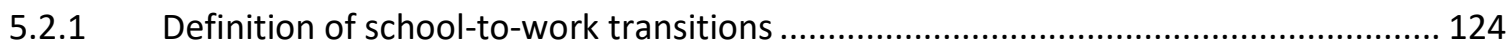

5.2.2 Empirical literature review of scarring effects ........................................................ 126

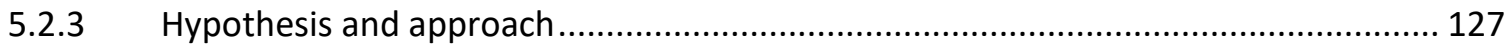

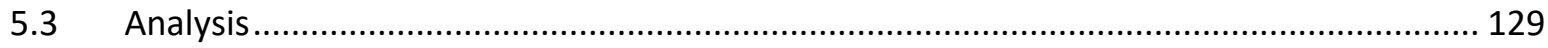

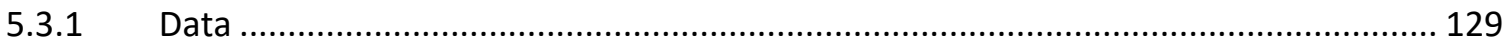

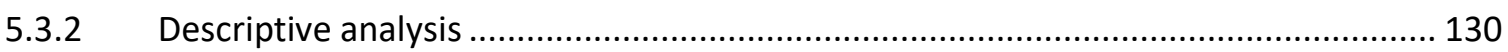

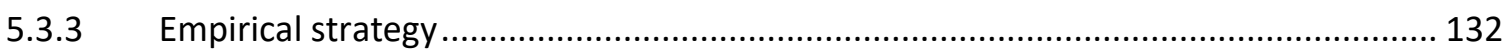

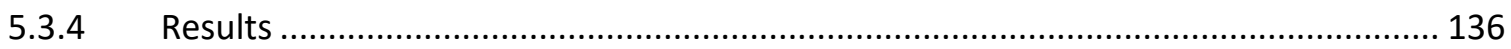

5.3.5 Discussion of findings and further research .......................................................... 143

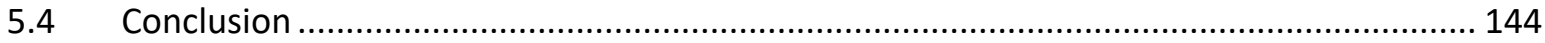

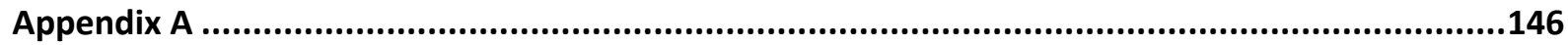

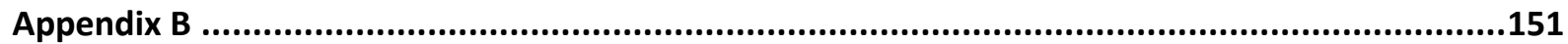

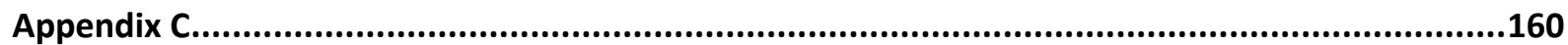

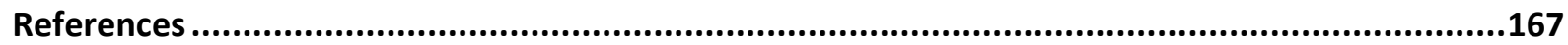

Versicherung bei Zulassung zur Promotionsprüfung ................................................................186

Erklärung über den geleisteten Eigenanteil der Arbeit ..............................................................187 


\section{List of figures}

Figure 3.1. Labour intensities for major annual and perennial crops

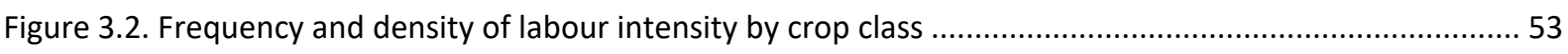

Figure 3.3. Regional perspective according to the key determinants

Figure 4.1. Global ageing status in 2020, 2030 and 2050: share of population aged 65 and over in total

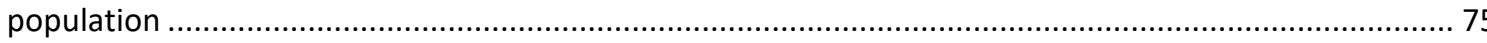

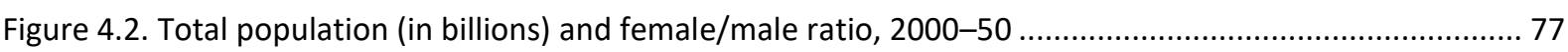

Figure 4.3. Population aged 55 years and over (in millions), by sex and income group, 2000-30 .................... 78

Figure 4.4. Composition of the labour force (in billions) and share of older workers, by sex and income group, 2000-30.

Figure 4.5. Labour force participation rate (in \%) and gender gaps (percentage points), by income and age group, 2000-30

Figure 4.6. Demographic dependency ratio (DDR), by income group, 1991-2030

Figure 4.7. Activity-based dependency ratio (ABDR), by income group, 1991-2030 ..... 89

Figure 4.8. Employment-based dependency ratio (EBDR), by income group, 1991-2024 . 93

Figure 4.9. Labour underutilization dependency ratio (LUDR), by income group, 2005-24

Figure 4.10. Working poverty-based dependency ratio (WPDR), by income group, 2000-24 102

Figure 4.11. Breakdown of the WPDR over time, by income group, 2000-24 104

Figure 4.12. Vulnerable employment-based dependency ratio (VEDR), by income group, 1991-2024 .... 109

Figure 4.13. Breakdown of the VEDR over time, by income group, 1991-2024

Figure 5.1. Labour force participation rates (LFPR) and female-male ratio by income groups (1998-2018) .... 122

Figure 5.2. Zero-inflated and dispersed school-to-work transition duration...... 


\section{List of tables}

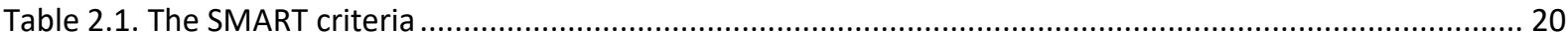

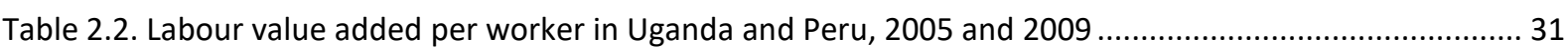

Table 2.3. Working poverty rates in Uganda and Peru, 2005 and 2009 (percentages) ................................... 32

Table 2.4. Workers earning less than absolute/relative thresholds in Uganda and Peru, 2005 and 2009 .......... 35

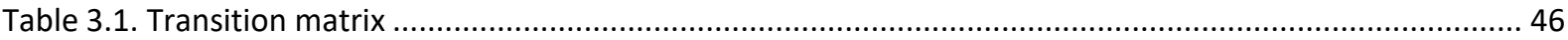

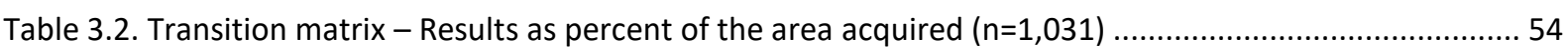

Table 3.3. Employment creation through LSAls for selected countries (scenarios $2 a-2 d)$...............................6 60

Table 4.1. Comparison of demographic-, activity-, and employment-based dependency ratios, by income

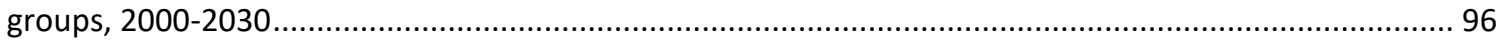

Table 4.2. Comparison of different dependency ratios, by income group, 2000-30 .................................. 114

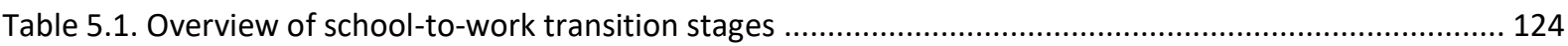

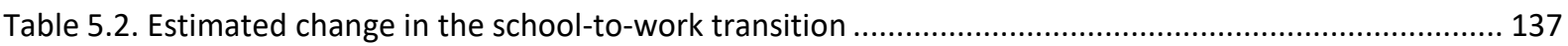

Table 5.3. Estimated impact of the GFC on the school-to-work transition............................................... 139

Table 5.4. Results of the maximum likelihood estimation on labour income............................................ 142

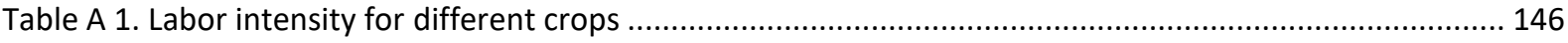

Table A 2. Different scenarios and actual areas under contract in hectares ................................................. 150

Table B 1. Ranking of countries and territories by ageing status (population aged 65 and over as \% of total

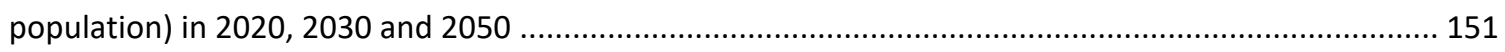

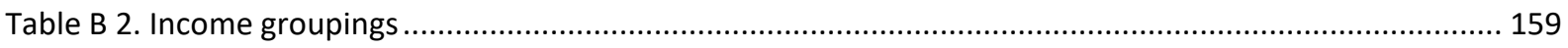

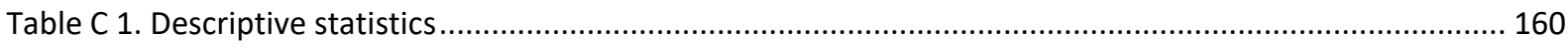

Table C 2. Selection of treatment and control group based on real GDP growth......................................... 161

Table C 3. Estimated change in the school-to-work transition (full output, model comparison) ...................... 164

Table C 4. Estimated impact of the GFC (full output, model comparison) .................................................... 165 


\section{General introduction}

\subsection{Motivation}

Si vis pacem, cole justiciam

(If you desire peace, cultivate justice)

The above words were carved into the foundation stone of the first headquarters of the International Labour Organization (ILO). They reflect the shared vision of the ILO's founders, as laid down in the Preamble to the ILO's Constitution, that "universal and lasting peace can be established only if it is based upon social justice". Work plays an important role in achieving social justice: it provides us with the means to meet our material needs. In fact, for the largest part of the society, it is essential for survival. But work goes beyond material needs alone: it also gives people an identity and fosters social inclusion and cohesion. The workplace itself is a place for socializing with others - something one tends to forget until the workplace is no longer available or accessible. Work also equips us with the capabilities we need to expand our choices in life.

However, work can also contribute to social injustice. Some jobs are poorly paid and thus do not allow workers to lift themselves above the poverty line. Some workers are forced into labour and deprived of their fundamental principles and rights at work ${ }^{1}$. Workplaces can be exclusive and restrictive; sometimes, they can even be places of harassment. Work can be hazardous and make people ill or leave them with a disability. It can also kill, whether as a result of a fatal accident or simply through being overworked - a phenomenon known as karōshi in Japan.

What sets good work that promotes social justice apart from bad work that threatens the achievement of social justice is captured by the concept of decent work. In the absence of a clear-cut definition, the concept can be described in the following terms:

Decent work sums up the aspirations of people in their working lives. It involves opportunities for work that is productive and delivers a fair income, security in the workplace and social protection

\footnotetext{
${ }^{1}$ Adopted in 1998, the ILO Declaration on Fundamental Principles and Rights at Work sets out principles and rights in four categories: freedom of association and the effective recognition of the right to collective bargaining, the elimination of forced or compulsory labour, the abolition of child labour and the elimination of discrimination in respect of employment and occupation.
} 
for families, better prospects for personal development and social integration, freedom for people to express their concerns, organize and participate in the decisions that affect their lives and equality of opportunity and treatment for all women and men. (ILO 2020d)

The concept and the importance of decent work have been acknowledged by the international community, and the four pillars of the ILO's Decent Work Agenda - employment promotion, social protection, fundamental rights at work and social dialogue - have become integral elements of the 2030 Agenda for Sustainable Development (UNGA 2015). The notion of decent work features in several of the Sustainable Development Goals (SDG), most prominently in Goal 8, which calls for the promotion of "sustained, inclusive and sustainable economic growth, full and productive employment and decent work for all" (ibid.).

It is difficult to find the positive side of the COVID-19 pandemic: its impact on people's lives and livelihoods is just so devastating. However, two possible avenues for recovering from the crisis are open to us: either we try to return to our "old" lives and continue with business as usual, or we try to do things differently and have the courage to pursue more of a "business as unusual" approach. History has shown that previous crises and economic shocks have actually exacerbated rather than reduced social inequality; we allowed social justice to slip further off into the distance. It is in our hands to ensure that we do not waste this opportunity again: we must see this crisis as an opportunity to rethink our current development path. This is our chance to rebuild our economies on a more sustainable foundation. This is our chance to revitalize multilateralism and global solidarity. This is our chance to reinvigorate the social contract and put people back at the centre of economic and social policymaking. In short: this could be our chance to create fairer and more equal societies and to make a giant leap towards achieving social justice.

The remainder of this dissertation is organised as follows: the next sub-chapter (1.2) sets the scene for the dissertation and provides an overview of key labour market trends in emerging and developing countries. It elaborates on different aspects and dimensions of labour market participation and labour income, and touches on trends that are expected to become increasingly important in the future. The issues identified in this overview are then addressed in the subsequent chapters. Sub-chapter 1.3 contains a summary of the four stand-alone articles of this thesis, introduces their respective research questions and demonstrates how the articles are interconnected and build on each other: Chapter 2 discusses the conceptual 
considerations for measuring decent and productive work and proposes a set of indicators. Chapter 3 takes up the notion of productive work and analyses the impact of large-scale agricultural investments on rural labour markets in low and middle income countries. Measuring economic dependency is the focus of chapter 4, which analyses global demographic trends and their impact on future labour markets. The last article of this dissertation (chapter 5) brings us back to the here and now and looks at the long-term consequences of economic crises for youth. Each article concludes with a summary of the key findings and indicates further areas for research.

\subsection{Key labour market trends in developing and emerging countries}

The following chapter provides an overview of important labour market trends in developing and emerging economies. The country groupings applied in this overview have been defined in accordance with the World Bank's country income classifications, which are based on gross national income (GNI) per capita (in current US\$) in 2019. Accordingly, developing countries are classified as low income countries with a GNI per capita of less than US\$1,026. Emerging countries are comprised of lower-middle (US\$1,026 to US\$3,995) and upper-middle income (US\$3,996 to US\$12,375) countries (World Bank 2019). Unless otherwise stated, all data presented in this section is extracted from the modelled estimates and projection series of the ILO's statistical database (ILOSTAT) (ILO 2020b; 2017a). Wherever applicable, data is presented for youth (aged 15 to 24 years) and adults ( 25 years and over) and disaggregated by sex. The aim of this assessment is not only to identify current challenges but also to highlight the tremendous progress that has been made over the past two decades.

One of the most frequently consulted indicators for assessing developments in the labour market is the unemployment rate. In developing countries, the share of the unemployed in the total labour force declined by around 5 per cent between 2000 and 2019, and currently stands at around 3 per cent for adults and 6.5 per cent for youth. This decline was more significant for men than for women. In emerging countries, an opposing trend was observed, with rising unemployment rates for both adults and youth. Although this increase was slightly more pronounced for adults (16 per cent) than for youth (14 per cent) in lower-middle income countries, it was considerably stronger for youth (26 per cent) in upper-middle income countries than for adults (12 per cent). Generally speaking, youth are disproportionately affected by unemployment: in upper-middle income countries, the unemployment rate for 
youth is around three times higher than it is for adults; in lower-middle income countries, it is more than five times higher. Turnham and Eröcal (1990) argue that lower unemployment rates in developing countries reflect the reality that poorer workers cannot afford to be without a job; as a result, unemployment is a reflection of the search for better paid jobs by those who can afford the associated job-search costs. This may be particularly true when one considers the low rates of coverage of social protection systems in developing countries, which all but eliminates joblessness as an option. In fact, only 45 per cent of the global population is effectively covered by at least one form of social protection benefit, and the rate is much lower in low and middle income countries (ILO 2017b). During times of economic crisis, in particular, the lack of social protection coverage for those who lose their income owing to sickness or unemployment poses a serious threat to people's livelihoods (ILO 2020e).

The youth-adult differentials in unemployment can be traced back to young people's comparably low levels of work-related skills and competences and their lack of work experience (Pastore 2018; Verick 2009), but also their lower ability to access finance in order to start their own business (O'Higgins 2001).

Despite the progress made in bringing more people into employment, the unemployment rate for youth is stagnating at a high level. The adverse effects of unemployment on a young person's future employment trajectory include a lower probability of finding a job in the future (Petreski, Mojsoska-Blazevski, and Bergolo 2016), a higher likelihood of dropping out of the labour force (Helbling and Sacchi 2014), and a lower future labour income level (ibid).

A second indicator for the analysis of labour markets is the labour force participation rate (LFPR). Over the past 20 years, the LFPR has declined in both developing and emerging countries. This decline has been much more pronounced for youth than for adults: in developing countries, the rate has dropped by 9 per cent for youth and by 3 per cent for adults; whereas, in emerging countries, it has decreased by 24 per cent and 5 per cent respectively. While the overall reduction in the rate is similar within the group of emerging countries, the current LFPR for persons aged 15 years and over differs by some 10 percentage points in lower-middle ( 55 per cent) and upper-middle income countries (65 per cent). Men have an overall higher LFPR compared to women, but the LFPR of women is declining stronger. This difference is more pronounced in emerging countries.

Business cycles are often identified as the cause of short-term fluctuations in the LFPR. However, a deep recession coupled with a slow labour market recovery can turn into a 
hysteresis and create persistent structural problems (Blanchard, Cerutti, and Summers 2015; Aaronson et al. 2006). Discouraged by long-term unemployment and poor employment prospects, workers may drop out of the labour force and become economically inactive (Krause and Sawhill 2017). While these factors are assumed to be driving the changes in the LFPR for adult workers, there are additional determinants for youth, such as increasing educational attainment. Indeed, according to the UNESCO Institute for Statistics (UIS 2020), the gross enrolment ratio in tertiary education, for instance, doubled in low- and lower-middle income countries and even tripled in upper-middle income countries between 2000 and 2018. This is a very positive development since it implies that the current lower LFPR should lead to a higher skilled labour force of the future.

In addition to the higher educational attainment, there seems to be another driver behind the comparably lower youth LFPR: the proportion of youth not in employment, education or training (NEET). Around one in five young persons in low and upper-middle income countries, and more than three out of every four youth in lower-middle income countries, are classified as NEETs. Despite the fact that the international community agreed, in target 8.6 of the SDGs, to substantially reduce the NEET rate by the year 2020, little progress has been made (ILO 2019c). Between 2005 and 2018, the total NEET rate fell by less than 2 percentage points in developing and emerging countries. Although the gender gap in the NEET rate closed slightly over the same period, women remain disproportionately affected and are on average twice as likely to experience NEET spells than their male counterparts. While unemployment is the main reason behind the male NEET rate, family responsibilities, such as household chores and care responsibilities, are often why women become NEETs (Elder 2015). The disappointing pace of reducing the share of NEETs is particularly problematic because NEETs are, by definition, neither acquiring work experience nor enhancing their skills. Just one of these factors, never mind both in combination, represents a significant obstacle to a young person's transition into the labour market and impairs their future employment and income prospects (Helbling and Sacchi 2014; Samoilenko and Carter 2015; Crawford et al. 2011).

Beyond the social imperative to ensure equal opportunities for women and men in the labour market, several studies have also demonstrated the economic imperative: unlocking the potential of women's increased LFPR has a clear and positive impact on economic growth (Klasen and Lamanna 2009; Verick 2014; Tsani et al. 2013). 
A common feature of labour markets in developing and emerging countries is the stark prevalence of informal sector employment. Developing and emerging countries account for around 83 per cent of total global employment but for 93 per cent of all informal sector employment (ILO 2018c). Almost 7 in 10 workers in developing and emerging countries are employed in the informal economy, mostly as own-account or contributing family workers. The age distribution is u-shaped and shows a high incidence of informality among young workers (86 per cent), lower rates of around 68 per cent for prime-age workers, and elevated rates again of up to 89 per cent for older workers (ibid.). While men (63 per cent) are generally more likely than women ( 58 per cent) to be engaged in the informal economy, this trend is reversed in the higher age brackets (ibid.). In addition to criticism about the definition of and methodology used to derive informal employment figures, especially regarding the dualistic labour market approach and the assumed homogeneity of the informal sector (c.f. Fields 2007; Melamed, Hartwig, and Grant 2011; Chen and Vanek 2013), there is also a debate about voluntary and involuntary informal sector employment (see, for instance, Günther and Launov 2012 for an overview). Employees in the informal economy are thought to be more vulnerable and to face restrictions on the exercise of their fundamental principles and rights at work. For instance, they are less protected against exploitative working conditions; experience lower levels of social protection, if any; and have less access to redress (ILO 2018c; 2013b; Schlyter 2002). However, entering into informal work can also be a choice made voluntarily in order to maximize personal utility, gain an individual competitive advantage or even as a last resort to escape involuntary unemployment (Rosenzweig 1988; Maloney 2004). The self-employed in the informal economy, on the other hand, often lack access to finance, are excluded from public transfer and support schemes and face fewer opportunities for contract enforcement (Slonimczyk 2014). At the same time, operating in the informal economy allows them to reduce their administrative costs and avoid tax payments (Araujo and Rodrigues 2016). This links back to the burden of informal employment that is carried by the wider society: in addition to an oftentimes inefficient allocation of goods and services caused by corruption, the loss of tax revenues puts a further strain on the already limited fiscal space in developing and emerging countries (Joshi, Prichard, and Heady 2014; O'Hare and Curtis 2017).

The adverse consequences for (involuntary) informal workers and for society require that action is be taken. Facilitating the transition of workers from the informal into the formal economy represents a great challenge. However, several studies have shown that it is an 
endeavour that could pay off. Tightening up regulatory frameworks, for instance, could increase wages, total output and welfare (Meghir, Narita, and Robin 2015); it could even decrease unemployment (Kolm and Larsen 2003).

The share of informal employment tends to decrease with economic development (Schneider and Enste 2000; Loayza, Oviedo, and Serven 2005; Loayza 2016). One of the drivers behind this decrease is the change in the sectoral composition of economies during their development. Two decades ago, the agricultural sector employed the largest share of workers in low, lowermiddle and upper-middle income countries, at 70.8 per cent, 53.8 per cent and 40.6 per cent respectively. The modernization of the agricultural sector and the further expansion of the industry and services sectors led this share to decrease, while other sectors gained in importance in terms of the distribution of workers. Between 2000 and 2019, the share of the population working in agriculture decreased by around 15 per cent in low income countries and by around 30 per cent and 50 per cent in lower- and upper-middle income countries respectively. Low income and upper-middle income counties seemed to leapfrog the industrial sector and gained more employment directly in the services sector, while lowermiddle income countries experienced the strongest increase in the industry sectors (Blimpo et al. 2017).

One strategy for modernizing the agricultural sector, as observed in many low- and middle income countries, is by means of the inflow of foreign direct investment in farming, which mostly comes from high income countries (Lay and Nolte 2018; Giger et al. 2019). These largescale agricultural investments often bring about an upgrade in technology and knowledge, which can lead to human labour being largely substituted by technology and, hence, the mostly small-scale farmers being squeezed out of the market. Considering the large number of agricultural workers in low and middle income countries, this can have a significant impact on the labour market, particularly if the industries upstream and downstream are not able to absorb the excess labour supply.

Participation in the labour market is only part of the picture: employment quality also matters. One dimension of decent work is labour income. Although data on real wages is scarce, we can get an idea of how incomes are changing by looking at the Group of 20 (G20) countries. Emerging G20 countries $^{2}$ have experienced strong wage growth in recent decades: between

\footnotetext{
${ }^{2}$ Argentina, Brazil, China, India, Indonesia, Mexico, Russian Federation, South Africa and Turkey.
} 
1999 and 2017, real wages almost tripled in emerging G20 countries, whereas they grew moderately by around 9 per cent in advanced G20 countries (ILO 2018b). However, not everybody seems to be benefiting equally from the growth in wages: the gender pay gap in emerging G20 countries currently stands at 21.7 per cent, which represents an increase of around 4.5 per cent between 2010 and 2016 (ILO 2019a). However, the nine emerging G20 countries are not representative of all emerging countries and certainly not of developing countries. In the absence of observed wage data, the share of workers earning an income considered insufficient to lift themselves and their dependants above the poverty line (otherwise known as working poverty) could provide further insight. Today, around 38 per cent of workers in developing countries are living in extreme poverty - that is to say, they are living in a household with a daily per capita consumption or income of less than US\$1.90 in terms of purchasing power parity (PPP). This rate drops to 10 per cent in lower-middle income countries and to less than 1 per cent in upper-middle income countries. Two decades ago, the situation was very different: in the year 2000, the working poverty rate was around 37 per cent higher in developing countries, 71 per cent higher in lower-middle income countries and even 97 per cent higher in upper-middle income countries (ILO 2020b). Across these country groupings, we find considerably larger working poverty rates for youth than for adults. In terms of gender discrepancies, adult women in low income and in upper-middle income countries experience a slightly higher incidence of working poverty, while this holds true for both female youth and female adults in lower-middle income countries (ibid.).

The overall picture alters considerably if we apply the moderate poverty line and look at workers living on an income of between US\$1.90 and US\$3.20 per day (PPP). Although we can still observe a decline in both lower- and upper-middle income countries (-20 and -80 per cent respectively), we note an increase of around 27 per cent in low income countries (ILO 2019e). The slower reduction rates and the increase in low income countries point to a "bunching up" of workers just above the extreme poverty line, as identified by Chen and Ravallion (2008). Most of the decline can be attributed to China, which managed to translate its high economic growth rates into poverty alleviation ${ }^{3}$. However, we also note that the pace of the annual rate of poverty reduction has slowed considerably, from around 14 per cent in 2013 to less than 2 per cent in 2019 (ILO 2019b).

\footnotetext{
${ }^{3}$ See ILO (2019e) and Liu (2017) for a detailed discussion on China's role in decreasing working poverty.
} 
Low-income jobs are the most obvious cause of working poverty (Feder and Yu 2020). Several studies demonstrate the adverse consequences of low-income jobs, such as lower future employment and earning prospects (Stewart 2007; Schnabel 2016) and limited upward social mobility (Grimshaw 2011), which may push workers into poverty and trap them there. Lowpaid jobs are mostly located in developing countries, and the further "slicing up of global value chains" (M. P. Timmer et al. 2014) in favour of more advanced countries will only increase competition for the already scarce supply of decent jobs. This situation is expected to be further exacerbated as large numbers of young people enter the labour market in low and middle income countries in the coming years. If the creation of decent work opportunities cannot keep pace with this development, the likelihood of achieving SDG Goal 1, on ending poverty in all its forms everywhere, fades into the distance - despite the remarkable progress so far made in reducing working poverty.

While most advanced countries are confronted with rapid population ageing, low and middle income countries have populations that are still characterized by a large share of youth. As discussed earlier, the policies that are pursued will dictate whether this youthfulness becomes a dividend or a burden. Even so, it has already been determined that this upsurge in the youth population will disappear over time, and that low and middle income countries will join the rest of the world in the demographic ageing process. In fact, in most middle income countries this process is already in motion: today, persons aged 65 years and over account for 3.3 per cent in low income countries, and for 5.9 per cent and 10.8 per cent in lower- and uppermiddle income countries. These shares are projected to double in all country groupings by the year 2050 (UNDESA 2019b). The ageing process will directly translate into a growing number of older workers in the labour force.

In conclusion, an increasing number of new entrants is creating pressure at one end of the labour market; while, at the other end, the rising share of older workers who are remaining economically active for longer is only adding to that pressure. The ongoing demographic shift from youthful to ageing societies could therefore threaten the financial sustainability of the often already beleaguered social protection systems, especially with regard to healthcare and pension systems (ILO 2018a; Behrendt and Nguyen 2018). In other words, a decreasing number of economically active persons will have to provide for an increasing number of beneficiaries of social protection. This is captured by measures of economic dependency. 
This section outlined current labour market trends in developing and emerging economies. Admittedly, it provides only a snapshot: there are certainly many more labour market challenges and success stories to be told. It is clear, however, that the real test lies in not only creating enough new jobs but creating jobs of good quality. This would, in turn, lead to a fairer and more equal society and bring us closer to the goal of social justice.

\subsection{Research questions and approaches}

This dissertation is comprised of four stand-alone research articles, which are presented in chapters 2 to 5 . While all four contributions can be read and understood individually, they are all connected thematically and each article builds on the previous ones. The following section briefly introduces each contribution, states the respective research questions covered and outlines the analytical approaches taken.

\section{Chapter 2}

The first article discusses the conceptual considerations for measuring decent work and proposes a set of empirically tested indicators. The article was written in 2015, just as the Millennium Development Goals (MDG) were coming to a close and the debate about a potential post-2015 Development Agenda was in full swing. This potential post-2015 agenda became the current 2030 Agenda for Sustainable Development.

Among the MDGs was Target 1.B, on achieving full and productive employment and decent work for all, including women and young people, which consisted of four quantitative indicators for assessing progress towards MDG Goal 1, on eradicating extreme poverty and hunger. Another employment-related indicator was located under MDG Goal 3, which was aimed at promoting gender equality and empowering women.

The first part of the article discusses the conceptual foundation of decent work by analysing the individual components of Target 1.B. The second part evaluates each of the five employment-related MDG indicators based on the SMART criteria. ${ }^{4}$ This evaluation concludes that all of the assessed indicators suffer from major shortcomings, such as ambiguous interpretability, the inappropriate use of aggregate statistics, and measurement problems. One major concern that is identified relates to the fact that these indicators contain a number

\footnotetext{
${ }^{4}$ SMART is an acronym that stands for specific, measurable, achievable, relevant and timely/time-bound.
} 
of strong assumptions that lack any firm empirical basis and hence often do not hold true in the context of developing countries. This critique is followed by a proposal for alternative indicators that overcome most of the weaknesses of the employment-related MDG indicators. The conceptual validity of the proposed indicators is checked against the SMART criteria, and their derivation is guided by the elements of Target $1 . B$ and amended by an equity dimension. The proposed indicators are: (i) the growth of labour value added per worker, (ii) the working poverty rate, and (iii) the share of workers receiving (a) less than an absolute labour income and (b) less than 60 per cent of the median labour income. Each proposed indicator is tested in an empirical illustration, using national household survey data from Uganda and Peru.

The main research questions that chapter 2 seeks to address are:

- What are the key components of decent work?

- Which dimensions of decent work can be quantified in an internationally comparable way?

Although our proposal was not directly incorporated into the indicator framework of the SDGs, our article made an important contribution to the general discourse about how to measure decent work. Furthermore, the empirical illustration revealed substantial decent-work deficits in low and middle income countries that are often related to structural problems. In strongly agriculture-based economies, such structural problems include a high incidence of informality among smallholders and a low labour productivity rate due to outdated production methods in the agricultural sector.

\section{Chapter 3}

Building on the findings of the previous chapter, the second article analyses the impact of large-scale agricultural investments (LSAIs). As detailed in sub-chapter 1.2, LSAls are considered as a means to initiate the modernization of the agricultural sector.

The article begins with a description of the nature of LSAIs, then discusses the concepts of labour productivity and intensity in the context of rural labour markets. It notes that smallholders and family farmers account for the largest share of farmers in low and middle income countries. Their production methods are somewhat labour intensive. Large-scale farmers, on the other hand, have the ability to replace labour with capital - and often do so. The next section then explains the direct labour market effects that occur when a large-scale 
farm has been set up. Three key determinants are identified as being decisive to the employment creation potential of LSAIs: (i) the previous land-use type, (ii) the crop cultivated, and (iii) the production model applied. These determinants build the conceptual framework, illustrated in a transition matrix, which is used for the empirical analysis. This analysis is carried out in three steps: first, the labour-intensity differential between small- and large-scale farmers is assessed; second, different scenarios are developed, based on the transition matrix; and third, data is added to the model and estimates of the net employment effect are derived for LSAls on former smallholder land in selected countries.

The main research questions that chapter 3 seeks to address are:

- What effects does the establishment of a large-scale farm have on the rural labour market in low and middle income countries?

- Do large-scale agricultural investments create or destroy employment?

The article concludes that LSAIs can indeed result in small-scale farmers being squeezed out of the market, and the estimated net employment effect identified in the empirical application demonstrates the magnitude of this effect. It can be inferred that a considerable number of these farmers - particularly those who are older in years - will drop out of the labour force because their skills may not (or no longer) match the demand in the non-agricultural labour market. Even if they remain in the labour force, the odds of them obtaining decent employment may be low due to the increasing number of jobseekers in the immediate surrounding of the newly established large-scale farm. The capacity of the rural labour markets to absorb these squeezed-out farmers will therefore dictate whether they become dependent upon the support of others.

\section{Chapter 4}

Chapter 4 begins where the previous chapter left off and looks at the changing relationship between economically dependent and independent persons. Economic dependency can occur as a result of joblessness, as explained in chapter 3, or because of a lack of decent and productive employment, as demonstrated in chapter 2 . The article in chapter 4 , however, begins with a different form of dependence: demographic dependence.

As discussed in chapter 1.2, as a consequence of demographic changes the labour markets in low and middle income countries are subject to pressure on two sides. Due to the inability of 
many low and middle income economies to provide a sufficient number of decent jobs, many jobseekers end up in lower-productivity jobs or even drop out of the labour force altogether. As a result, they become part of the economically dependent group of persons.

To begin with, the article assesses the most commonly used measure of economic dependency: the demographic dependency ratio. It then introduces several alternative indicators, of which two are based on employment status and another three are based on fullpotential and productive employment. The functioning of each indicator is illustrated empirically, followed by a discussion of the indicator's validity.

The main research questions that chapter 4 seeks to address are:

- What impact does an ageing society have on the labour markets?

- How can economic dependency be measured?

The assessment of the alternative measures reveals that each indicator has advantages over the others, but that no one indicator alone is able to fully capture all the dimensions of economic dependence; and hence of decent work deficits. Instead, they form a toolbox of measures that allows for a deeper analysis of economic dependence in different contexts.

\section{Chapter 5}

The last article of this thesis returns to the notion of decent work and addresses two of its main components: employment prospects and stability, and labour income. More precisely, it shows how the employment prospects and labour incomes of young labour market entrants are impacted by an economic crisis. The transition from school to work is a crucial step in a young person's life. While some youth are able to transition almost seamlessly into a first job, others have a tougher time of it. Tensions and greater competition in the labour market, as described in sub-chapter 1.2, can impede or even block this transition. Entering the labour market during an economic recession is thought to make this transition even more difficult.

The article in chapter 5 begins with an introduction of the school-to-work transition concept and its connection to scarring effects. Based on a literature review of employment and income scars for youth, the empirical strategy discusses various approaches to estimate these scars. 
The main research questions that chapter 5 seeks to address are:

- Does an economic crisis such as the global financial crisis affect the school-to-work transition time of a young person (employment scar)? If so, which youth are most affected?

- Does an economic crisis affect future labour incomes (income scar)? If so, who is most affected and how persistent are these effects?

The results show that a crisis can leave both employment and income scars on the fledgling careers of young labour market entrants. This highlights the need for large-scale policy responses to prevent long-term damage in terms of future labour market prospects for youth. 


\section{SMARTer indicators for decent work in a post-2015 development agenda: A proposal}

Martin Ostermeier, Sarah Linde, Jann Lay and Sebastian Prediger*

This chapter appeared as:

OSTERMEIER, M., LINDE, S., LAY, J. and PREDIGER, S. (2015), SMARTer indicators for

decent work in a post-2015 development agenda: A proposal. International Labour Review, 154: 285-302. doi:10.1111/i.1564-913X.2015.00035.x

\footnotetext{
*The authors gratefully acknowledge funding by the Federal Ministry for Economic Cooperation and Development (BMZ) within the framework of the project "Employment, Empowerment and Living Standards", implemented in cooperation with the German Development Bank (KfW). Additional financial support by the European Union (EU) under the 7th Research Framework Programme (Nopoor project, Theme SSH.2011.1, Grant Agreement No. 290752) is also gratefully acknowledged. The authors wish to thank Holger Seebens and Julia Kubny for discussions on an earlier draft of this article, and participants in the Nopoor project, the ICDD Annual Thematic Conference 2014, the PEGNet Conference 2014, and the internal GIGA seminar for their helpful comments. The findings, interpretations and conclusions presented in this article are entirely those of the authors and do not necessarily represent the views of $\mathrm{BMZ}, \mathrm{KfW}$ or the EU.
} 


\section{Abstract}

The MDG employment indicators suffer from major shortcomings, including measurement problems, inappropriate use of aggregate statistics, ambiguous interpretability, and assumptions that do not apply to developing countries. Based on this critique, the authors propose a new set of four indicators for productive employment and decent work, namely: the growth of labour value added per worker, the working poverty rate, the share of workers receiving less than an absolute minimum labour income, and the share of workers receiving less than 60 per cent of the median labour income. They demonstrate the empirical application of these indicators using the country cases of Uganda and Peru. 


\subsection{Introduction}

Employment is the main determinant of living standards (World Bank 2012). It is also of paramount importance for economic development. Quantitative analyses confirm that rising labour earnings are the largest contributor to poverty reduction (Azevedo et al. 2013). Beyond its fundamental and immediate contribution to household income, employment also affects other dimensions of individual and societal well-being, including self-esteem, mental and physical health, and social cohesion.

Recognizing that decent and productive work is central to human and economic development, a new employment target was incorporated into the Millennium Development Goals (MDGs) in 2008 (Target 1.B). Four quantitative indicators were developed to measure progress towards this target. A fifth employment-related indicator relates to Target 3.A, on the promotion of gender equality and women's empowerment. With the MDG deadline approaching, the international community has been intensively discussing the structure and content of the Sustainable Development Goals (SDGs), which will build upon the MDGs and converge with the post-2015 development agenda (ECOSOC 2014). For the purposes of this article, the most relevant SDG proposal is the one made by the United Nations Open Working Group on Sustainable Development Goals (2014), whose Goal 8 aims to "promote sustained, inclusive and sustainable economic growth, full and productive employment and decent work for all". Besides the Open Working Group, several other institutions and development practitioners have formulated proposals for employment-related targets and indicators in a post-2015 development agenda (see, for example, Bates-Earner et al. 2012; ILO 2012; 2013; Martins and Takeuchi 2013).

This article contributes to the debate by proposing indicators for the measurement of employment outcomes in a post-2015 framework. To this end, it discusses the conceptual foundations of decent work and critically reflects on the current MDG indicators related to employment (ILO 2009; Sparreboom 2011). Measurement problems, the inappropriate use of aggregate statistics, ambiguous interpretability, and assumptions which often do not hold true in the context of developing countries are identified as major shortcomings of the MDG indicators. In particular, we argue that the discrimination against self-employment and family employment, implicit in the ILO's definition of vulnerable employment and in the MDG indicators, is misplaced and not based on firm empirical grounds. This is also one of the 
reasons why social protection would be better dealt with as a separate goal focusing on population coverage by basic social security benefits. Although social protection is one of the pillars of the ILO's Decent Work Agenda, it does not necessarily have to be considered in the context of employment.

Our critique is followed by a proposal for a new employment-related target and corresponding indicators for the post-2015 development agenda. Such a target should focus on the quality of employment and include an equity component. It should be operationalized through indicators that are specific, measurable, achievable, relevant and time-bound. The proposed four indicators are (i) the growth of labour value added per worker, (ii) the working poverty rate and (iii) the share of workers receiving less than (a) an absolute and (b) a relative minimum labour income. Their empirical application is illustrated using the country cases of Uganda and Peru.

\subsection{Conceptual considerations}

This section relates the MDG employment targets to some of the main dimensions of employment and decent work, as understood by the ILO. Our discussion highlights different properties of employment that should ideally be captured by indicators. Particular attention is paid to the definition of vulnerable employment and the possibilities of linking employment with social protection in the post-2015 development agenda. We then present a set of technical requirements for formulating conceptually valid and feasible indicators.

\subsubsection{Foundations and challenges of employment-related development targets}

Under MDG 1, Target 1.B seeks to "achieve full and productive employment and decent work for all, including women and young people" (UNSTATS 2008). This target incorporates three aspects of employment:

- quantity of employment: full employment for all,

- quality of employment: productive employment and decent work, and

- equity of employment opportunities: including women and young people (Martins and Takeuchi 2013).

Full employment is a standard economic concept which requires that all people who are available, capable and willing to work are able to do so. Yet, the quantity aspect of employment also refers to participation in the labour market: some people, particularly 
women, may not even be actively seeking work - the prerequisite for being considered unemployed and thus participating - despite being available, capable and willing to work. In general, the importance of both of these quantitative dimensions of employment - i.e. labour force participation and unemployment - depends on a country's level of development and country-specific labour market conditions. ${ }^{5}$

The quality of employment is described by the attributes "productive" and "decent". Productive employment can be defined as "employment yielding sufficient returns to labour to permit the worker and her/his dependents a level of consumption above the poverty line" (ILO 2012, 3). Thus, the productive employment deficit is comprised of the unemployed and the working poor, who are unable to attain a minimum consumption level despite being employed. Decent work is a more comprehensive concept and is understood as "productive work in which rights are protected, which generates an adequate income, with adequate social protection" (ILO 1999, 13). Under social protection the ILO subsumes the coverage and effectiveness of social security schemes, and labour protection "which comprises decent conditions of work, including wages, working time and occupational safety and health" (ILO 2014, 1).

Finally, the MDG employment target considers equity aspects, stressing the exclusion of specific groups - here women and the young - from full and productive work. While this is doubtless relevant, the focus on the inequality of opportunities rather than outcomes is too narrow. Indeed, feedback mechanisms from outcomes to opportunities - e.g. low wages that cause little investment in human capital - require that an employment target should also take account of the distribution of outcomes, such as equality of labour earnings.

\subsubsection{The relationship between employment and social protection}

Non-decent employment conditions can place people at economic and personal risk. Thus, there is a rationale for linking employment and social protection in the post-2015 development agenda, and many proposals do indeed incorporate measures of social

\footnotetext{
${ }^{5}$ This article uses the definitions of work and employment adopted by the 19th International Conference of Labour Statisticians in 2013 (ILO 2013a). In previous statistical practice (applied when the MDGs were drafted), persons engaged in the production of economic goods and services for own and household consumption were considered to be in self-employment and, therefore, employed, whereas persons (notably women) doing household work were considered not to be in the labour force. Under the current rules, both groups are defined as outside the labour force, but in the "potential labour force".
} 
protection. Yet, from a conceptual point of view, including social security (e.g. coverage by health, old-age and/or un- employment benefits) under an employment goal is appropriate only if related measures provide direct information about the decency of work. This is the case if social security benefits are directly tied to the employment relationship. However, this typically applies only to workers in wage employment. Another, more practical problem is the diverse and context-specific nature of social protection systems and working arrangements.

\subsubsection{SMART indicators}

The challenge in measuring decent work is to find indicators that can meaningfully capture all three dimensions of the employment target by combining relevance in terms of decent work with practical realism (particularly in terms of actually collecting and managing the required data). A widely used and internationally recognized set of formal requirements to assess the quality of indicators is the so-called SMART criteria. These are presented in Table 2.1.

\section{Table 2.1. The SMART criteria}

\begin{tabular}{|c|c|}
\hline Specific & $\begin{array}{l}\text { The indicator must ensure a clear and unambiguous interpretation and should be a } \\
\text { true translation of the target so that the changes measured by the indicator } \\
\text { genuinely express the targeted improvement. }\end{array}$ \\
\hline Measurable & $\begin{array}{l}\text { The indicator must be (easily) measurable and deliver reliable (hence replicable) } \\
\text { data, no matter who conducts the measurement. It should rely on common data } \\
\text { already collected within the scope of the country's statistical strategy (e.g. national } \\
\text { household surveys or labour force surveys). For inter-temporal and cross-country } \\
\text { comparability it is essential that the data sources, collection and preparation } \\
\text { methods, and the final analysis comply with international standards. Moreover, } \\
\text { definitions and methodologies have to be consistent over time. }\end{array}$ \\
\hline Achievable & $\begin{array}{l}\text { The set aspiration level of the indicator must be achievable. Unduly low target } \\
\text { values can suggest evident results but are not useful for measuring the effectiveness } \\
\text { of the project, programme or policy. }\end{array}$ \\
\hline Relevant & $\begin{array}{l}\text { The information provided by the indicator must deliver important information for } \\
\text { decision-makers. In the case of employment-related indicators, this refers primarily } \\
\text { to national governments, but also to the international community and individual } \\
\text { workers or trade unions. }\end{array}$ \\
\hline
\end{tabular}


Timely/Time- The indicator must specify a deadline or time frame.

bound

Source: authors' compilation after European Commission (2004) and UNDP (2009).

\subsection{A critical review of the employment-related MDG indicators}

\subsubsection{The growth rate of labour productivity}

The first employment-related indicator of the MDGs addresses the creation of productive employment by measuring the annual growth rate of GDP per person employed. ${ }^{6}$ The rationale for including labour productivity in the set of MDG indicators is its close and positive relationship with wages. According to neo-classical theory, wages equal marginal labour productivity. Empirical studies confirm a close - albeit far from perfect - relationship between wages and labour productivity (Luebker 2011).

Nevertheless, labour productivity growth presents several drawbacks that limit its validity as a measure of productive employment. Most importantly, in a significant number of developing economies, other production factors - particularly natural resources and land - generate a considerable share of value added, with factor income being earned by their respective owners. In more developed economies with high capital-to-labour ratios, gross domestic product (GDP) growth may be driven mainly by capital accumulation (not necessarily higher returns), and the earned factor incomes then typically accrue to capital owners. This implies that levels of labour productivity - not to mention growth rates - can only be meaningfully compared across economies that share similar factor endowments and sectoral compositions.

Furthermore, labour productivity only makes a relevant measure of decent pay if there are no large differences in labour productivity and corresponding wages between workers. Many poor economies, however, may employ highly productive labour with high wages in some sectors (e.g. mining), while a large share of their workforce is engaged in low-productivity and low-wage occupations, such as subsistence agriculture and work in the urban informal sector. Wide wage differentials may also occur within sectors. In consequence, GDP growth rates may

\footnotetext{
${ }^{6} \mathrm{~A}$ general problem in linking production and employment is the possible discrepancy between output measured by national accounts and people in work (but not employed) who generate output. While housework (unpaid, at home) is neither considered as employment nor measured in national accounts, this may be different for the self-employed and (part of) their produce. For example, smallholder production - though it may (partially) be for household consumption - is within the national accounts production boundary.
} 
increase without any improvement of labour productivity and wages across large segments of the workforce.

\subsubsection{Employment-to-population ratio}

The employment-to-population ratio (EPR) is the share of a country's working-age population that is actually employed. This indicator measures an economy's ability to provide employment for those people who are able to work, i.e. the extent to which full employment is achieved. The ILO (2009) suggests a value range from 50 to 75 per cent. Yet the lack of a clear target value or even a guideline for the EPR renders the interpretation of this indicator difficult and ambiguous, particularly in the context of developing economies. For example, a high EPR may result from a low unemployment rate, which might, in turn, be the sign of a well-functioning and rapidly clearing labour market. However, low registered unemployment can also be a reflection of the lack of social support systems, let alone unemployment insurance, as is the case in many poor economies. People in such circumstances cannot afford to be unemployed and have to work for survival. Whether their work is counted as "employment" will then depend on the market orientation of what they do for a living, i.e. whether it is done in exchange for pay or profit. Similarly, in economies dominated by smallholder agriculture, a high rate of labour market participation and, consequently, a high EPR do not signal ample labour market opportunities, but rather that all available labour is required to operate the household farm. Finally, an EPR may also be low because a substantial share of the working-age population is out of the labour force attending school or university. Taken together, these ambiguities make the EPR a dubious indicator that can hardly be expected to provide reliable information on progress towards full employment.

\subsubsection{Working poverty rate}

The ILO (2009) defines the working poverty rate (WPR) as the proportion of employed people living in a household with a per capita income below the nationally defined poverty line (or the international poverty lines of Int. \$1.25 or 2 per day). The WPR provides a measure of productive employment by linking poverty and employment data. It represents the share of workers whose jobs do not generate sufficient income to lift them and their families out of poverty. Although this indicator explicitly considers only the income dimension of decent work, it implicitly provides a broader picture: it is reasonable to assume that jobs which provide people with insufficient means to meet their basic needs are unlikely to fulfil other 
requirements of decent work (ILO 2009). Yet, working poverty may be caused by factors other than low pay (e.g. number of dependants), while other sources of income might mask low labour earnings (e.g. remittances and government transfers).

In principle, the WPR can be readily computed from micro data sets that provide information on poverty status at the household level and employment at the individual level. In practice, however, the WPR has often been calculated using aggregate statistics, as the product of the poverty rate and the labour force participation rate (macroeconomic approach). This simplification has been justified by a lack of micro data, but entails important drawbacks. The neglect of differences in demographic composition and labour force participation rates among poor and non-poor households results in biased estimates of the country-level incidence of working poverty. Using data for 15 sub-Saharan African countries, Kapsos (2011) finds an average difference of 8.6 percentage points between the macro- and the micro-based WPR estimates. Finally, this indicator suffers from the general drawbacks of a headcount index in that it does not account for intra-household inequality or for the depth of poverty. It is also plagued by the problems related to the definition of national and (more so) international poverty lines. $^{7}$

\subsubsection{Vulnerable employment rate}

According to the ILO (2009), the vulnerable employment rate is the proportion of own-account and contributing family workers in total employment. Based on their employment status, these two categories of workers are termed vulnerable because they are believed to face high economic risks. Own-account workers and contributing family workers are assumed to be less likely to have formal work arrangements, and thus often to lack elements of decent work, such as adequate social security and effective social dialogue mechanisms (Sparreboom 2011). Additionally, own-account workers in developing countries are typically perceived to earn a low and irregular income since they are mostly subsistence farmers and small-scale entrepreneurs operating in the informal economy. Indeed, in many cases, contributing family

\footnotetext{
${ }^{7}$ The literature has identified challenges arising from different consumption patterns across countries/regions, the 2005 PPP factors based on 1988-2005 prices and changing basic needs, the strong bias towards African countries (only two out of the 15 poorest countries are in Asia), and urban bias because internationally comparable services and goods are mainly found in urban areas. For a detailed critique and the implications for Asian poverty calculations, see ADB (2014).
} 
workers receive neither payment in cash nor remuneration in kind, but benefit indirectly from an increased household income.

However, the assumption that self-employed (family) workers are per se more vulnerable than employees is problematic, thus calling into question the specificity and relevance of the "vulnerable employment" indicator. Own-account workers and the associated category of contributing family members form a very heterogeneous group in developing countries. It includes not only those engaged in agricultural and urban informal subsistence activities, but also those running productive and profitable micro enterprises. In fact, research has shown that self-employment is often - albeit not always, and conditional on context - chosen voluntarily (Maloney 2004). Furthermore, in many developing countries wage workers (not to mention casual or seasonal workers) are not covered by social protection and do not have legally enforceable contracts of employment, which might render their conditions just as precarious as those of some own-account and contributing family workers. Thus, vulnerable employment would better be defined in terms of employment conditions, rather than employment status.

\subsubsection{Share of women in wage employment in the non-agricultural sector}

This last employment-related indicator of the MDGs is part of the gender equality goal and can be found under Target 3.A, which aims to "eliminate gender disparity in primary and secondary education, preferably by 2005 , and in all levels of education no later than 2015 ". The share of women in paid employment in the non-agricultural sector is expressed as the percentage of female workers in total non-agricultural wage employment.

The ratio of women in wage employment in the manufacturing and service sectors is meant to provide an indication of the extent to which female workers have access to the modern monetary economy and thus benefit from the structural transition of the economy. The underlying assumption is that women in such wage employment enjoy greater autonomy and self-reliance in personal development and decision-making (ILO 2009). While there is indeed some evidence that wage employment outside agriculture improves the situation of women (Kabeer 2005), the general discrimination against self-employment is subject to the same criticism as that expressed above in regard to "vulnerable employment". Furthermore, the indicator ignores the value that women may attach to the flexibility afforded by work on a household farm or in a household enterprise. Indeed, wage employment may not only bring 
about positive changes in women's lives. Since women typically continue to be responsible for domestic work and childcare, gender inequalities in work burdens may intensify (ibid.).

\subsection{Proposal for a new employment target and set of indicators}

In general, the multidimensional formulation of both the MDG employment target and the Open Working Group's current proposal is an important strength. It avoids some of the criticisms levelled at other MDG targets, such as a lack of focus on quality (e.g. Target 2.A on full primary education) and the general absence of (any) equity considerations. Accordingly, a future employment target should cover quantity, quality and equity aspects. These dimensions can be subsumed into a target to "achieve full and productive employment and decent work for all". The implicit weightings given to the different aspects of this employment target will eventually be determined by the chosen indicators.

While full employment should be explicitly mentioned in the target, our conceptual considerations and assessment of the EPR demonstrate that the underlying drivers participation and unemployment - would give rise to ambiguities if quantitative aspiration levels were to be formulated. This may preclude the establishment of specific indicators of full employment.

For most qualitative components of decent work, such as wages or occupational safety and health, there are no such ambiguities (although decent working time does raise ambiguities similar to those surrounding labour force participation). However, more practical problems arise when it comes to operationalizing the quality of employment, particularly in regard to occupational safety and health, which may be very industry-specific. While good data collection practices can be found, say, in the European Union (Burchell et al. 2014), there are almost no data available for developing countries.

In the light of these problems, the indicators proposed below deliberately focus on the income component of decent work. We implicitly assume that income is often highly correlated with non-monetary dimensions of decent work, particularly with occupational safety and health. As regards social protection, we have argued above in favour of setting a separate social protection goal rather than including elements of social protection in an employment target. The corresponding indicators would then not be directly tied to a person's employment 
relationship, but provide information about the total population's coverage by social security schemes.

Regarding equity, the proposed indicators emphasize relative labour earnings inequality. While equal pay for equal work is considered to be important as well, any such indicator would need to identify "pairs of equal work" unambiguously, for comparison. While there are techniques for doing this, their sophistication implies that such an indicator would hardly be suitable for the SDG agenda.

Our proposed indicators are an attempt to overcome some of the weaknesses of the current employment indicators and explicitly to introduce an equity dimension. They are not only conceptually valid but also feasible indicators that allow for the quantitative measurement of progress (or regress) on specific and important aspects of productive employment and decent work. Applying the SMART criteria results in a catalogue of four indicators for our proposed target of "achieving full and productive employment and decent work for all", namely: the growth of labour value added per worker, the working poverty rate, the share of workers receiving less than an absolute minimum labour income, and the share of workers receiving less than 60 per cent of the median labour income.

All four indicators can be disaggregated by sex, age (for a focus on youth) and other groups of interest. Whether other disadvantaged groups - e.g. persons with disabilities or migrants should be explicitly considered under an employment target is also a question of the general design of the SDGs. Alternatively, cross-cutting issues of discrimination against specific groups could be dealt with under separate targets. This may limit the risk of overloading the "thematic" target (in this case employment). Finally, we suggest that target values should be set nationally in order adequately to reflect country-specific employment challenges and development contexts.

\subsubsection{Indicator 1: Growth of labour value added per worker}

Labour value added is defined as total labour compensation (including income from selfemployment) over total employment. It captures both the productivity of the worker and the share of production accruing to labour through factor income earned. The growth of labour value added per worker is driven by higher wages, which may, in turn, be the result of higher productivity. The indicator reduces the problem of non-labour income being taken as a sign 
of productive work. Single industries with large shares of income generated by natural resources or capital do not bias it. A decline in labour value added per worker unambiguously indicates that wages and/or employment creation have not kept pace with economic growth. In countries where labour value added is not provided frequently enough by the national accounts system, it can be approximated by GDP minus factor payments for capital and land, taxes, and tariff revenues. Labour value added can also be calculated from nationally representative household data by dividing total labour earnings by total employment. This microeconomic approach can be considered to yield an upper bound estimate since it includes profits from self-employment under total labour income. ${ }^{8}$ The proposed indicator would be used to increase labour value added by a certain country-specific percentage by 2030 .

\subsubsection{Indicator 2: Working poverty rate}

The working poverty rate captures the concept of decent work fairly well in terms of enabling workers and their families to earn a decent livelihood. In addition to using national poverty lines, it should also be reported by reference to the international poverty lines of Int. \$1.25 and 2 in order to allow for cross-country comparisons. Regarding its operationalization, the working poverty rate should be computed by using household or labour force survey data. The indicator would be used to reduce the incidence of working poverty by a certain countryspecific percentage by 2030 .

\subsubsection{Indicators 3a and 3b: Proportions of workers earning less than an absolute and a relative minimum labour income}

These two indicators of decent pay represent the proportions of working-age people receiving a labour income below nationally or internationally defined minimum income levels ("minimum labour earnings"). These minimum labour income levels should be specified both in absolute terms (i.e. by reference to the international or national poverty lines) and in relative terms (i.e. 60 per cent of the median labour income). Using an absolute threshold allows for an unambiguous interpretation: labour income levels directly affect one's material livelihood; and, ceteris paribus, higher earned income is preferred over lower earned income. In addition, defining a relative "decent labour income threshold" as a certain percentage of

\footnotetext{
${ }^{8}$ Note that household survey data are known to produce much lower estimates of income compared to national accounts. So while the inclusion of capital income from self-employment induces an upward bias, the very use of micro data implies a downward bias.
} 
mean or median labour income puts more emphasis on equity since the indicator will not respond to labour income increases that do not affect the distribution of labour earnings.

Conceptually, the mean labour income would be the preferred reference for a relative indicator. It is more sensitive than the median to income gains by the richer segments of the employed workforce. In practice, however, estimates of mean incomes from household or labour force survey data are prone to errors, in particular because of reporting biases in higher incomes. This is why the median labour income is the more robust reference, although the resulting indicator will not respond to changes in the income distribution above the median. We propose to use 60 per cent of the median as the relative threshold; this choice is motivated by the fact that the European Union, for example, considers people below this threshold to be "at risk of poverty". Some caution is warranted when interpreting the proposed relative indicator, particularly when comparing it across countries, because the meaning of the reference income, the median labour income, crucially depends on the shape of the labour income distribution in combination with the structural features of each specific economy. In a country where the median earner is a subsistence farmer or entrepreneur (e.g. in many subSaharan African economies), the income distribution below the median will be very flat: probably only a small fraction of people will earn less than 60 per cent of the median labour income because there is little inequality of labour income among a large and fairly poor population. Indeed, there may be preferable situations in terms of well-being when inequality among those below the median labour income is wider, hence the advisability of the proposed combination of absolute and relative indicators.

For the absolute indicator, established per capita poverty thresholds - i.e. national and international poverty lines - can be used as a proxy for minimum labour income thresholds. The two indicators would thus be used to reduce the share of workers below the absolute and relative thresholds by a country-specific percentage by 2030.

\subsubsection{SMARTer indicators}

Labour value added growth and the working poverty rate lend themselves to clear, unambiguous interpretation and straightforward formulation of the corresponding countryspecific aspiration levels. The same goes for the share of workers earning less than a specified absolute minimum labour income, but not for the relative, "equity" indicator. Any such indicator necessarily entails a value judgement on the weight assigned to the welfare of 
individuals at different quantiles of the distribution of labour earnings. Since only those earning below 60 per cent of the median are taken into account, the implied weight given to the distributional distance to earners of very high incomes is zero.

All of our proposed indicators can be measured using available data (e.g. living standard measurement surveys, national household surveys or labour force surveys). It would certainly be desirable better to reflect working conditions in the SDG indicators (with regard to health, safety and hours of work). Yet, it is not conceivable that the necessary data would be available for a sufficient number of countries in the short term. The lack of detailed comparable data on working conditions thus also explains our focus on income.

Finally, the proposed indicators are clearly relevant, as they can deliver important information for decision-makers. If based on micro data, all four indicators can be broken down, say, by occupation, sector, sex, education, and migration status. This can help to identify groups that are particularly affected by non-decent working conditions. Conditional on the overall set-up of the SDGs, specific subgroup indicator values could be derived for each indicator. The indicators relating to labour income can also inform policy interventions, such as the setting of a national minimum wage.

\subsection{Empirical illustration of the proposed indicators}

This section illustrates the application of the proposed indicators using the examples of Uganda and Peru. These two cases are indeed well suited to the purpose of illustrating the advantages and challenges associated with the proposed indicators in different settings.

Specifically, some of Uganda's characteristics make it a suitable representative of the world's low-income economies, particularly in regard to the predominance of the agricultural sector, largely informal urban employment, and a high labour force participation rate. Despite an impressive growth performance in the past 20 years compared to the African average, Uganda is still a low-income country. Income poverty has been reduced considerably, from over 70 per cent of the population in the early 1990s to about 38 per cent in 2009 (headcount ratio applying the PPP poverty line of Int. \$1.25) (World Bank 2010). According to our calculations based on the Ugandan National Household Survey (UNHS), agricultural and non-agricultural self-employment have played an important part in this process, as they account for more than two-thirds of the country's employment. This does not include other contributing household 
members on and off the farm, which account for a further 20 per cent of the workforce. While the share of urban population has been increasing, it was still below 15 per cent in 2010 . The illustrations given below draw on UNHS data for the years 2005/06 and 2009/10, based on survey samples of about 7,400 households with more than 41,200 individuals in 2005/06, and 6,775 households with more than 36,400 individuals in 2009/10.

Peru is an upper-middle-income economy. Like Uganda, it has enjoyed a good growth performance over the past 15 years, together with a steady decline of its poverty ratio, from 12.4 per cent in 2000 to 4.9 per cent in 2010 (World Bank 2016). Compared to Uganda, the share of self-employment is lower in Peru and has been decreasing slightly since the mid2000s, but over 54 per cent of the workforce was still self-employed in 2009. In terms of sectoral composition, Peru has a fairly large service sector accommodating more than 55 per cent of total employment, while Uganda's economy is largely dominated by agricultural activities (73 per cent). These basic characteristics of the Peruvian labour market are comparable not only to those of other Latin American economies with large shares of selfemployment, such as Mexico or Colombia, but also to the labour market characteristics of Asian middle-income economies, including Indonesia and Thailand. For Peru, we use household data from the Encuesta Nacional de Hogares (ENAHO) for the years 2005 and 2009. This survey comprised more than 25,600 households (with almost 93,000 individuals) in 2005, and 26,600 households (with over 96,000 individuals) in 2009.

\subsubsection{Growth of labour value added per worker}

Labour value added per worker is computed as the sum of all wages and net profits divided by the number of persons employed. ${ }^{9}$ Table 2.2 shows the growth in labour value added per worker in Uganda and Peru between 2005 and 2009. The estimates are well in line with the overall economic performance of both countries. In Peru, labour value added per worker (in constant $\mathrm{LCU}^{10}$ ) grew by about 9 per cent annually between 2005 and 2009 (from a 2005 baseline of Int. $\$ 3,424$ in PPP), while the annual growth rate of gross national income (GNI) per capita was 6.3 per cent (World Bank 2016). In Uganda, with a per capita income of only Int. $\$ 353$ in 2005, the estimated annual growth of labour value added per worker (in constant

\footnotetext{
${ }^{9}$ We count all smallholders in both Uganda and Peru as employed. While this may partially conflict with the new labour statistics practices, it is in line with the definitions used when the surveys were carried out. Yet, it should be noted that - even in Uganda - the majority of smallholders produce for the market.

${ }^{10}$ Local currency units, i.e. Peruvian nuevo soles and, for Uganda, Ugandan shillings.
} 
LCU) was 14.1 per cent over the period - considerably higher than the economy's per capita GNI growth rate of only 4.8 per cent (ibid.). Closer inspection of the Ugandan data reveals that this strong growth was driven by labour value added in agriculture, while labour value added per worker in non-agricultural self-employment actually declined.

Table 2.2. Labour value added per worker in Uganda and Peru, 2005 and 2009

\begin{tabular}{llll}
\hline Country & 2005 & 2009 & Annual growth
\end{tabular}

\begin{tabular}{lccc}
\hline Uganda & & & \\
In constant 2005 Int. \$ & 353 & 451 & 6.3 \\
In constant LCU & 263,009 & 446,320 & 14.1 \\
\hline Peru & & & \\
In constant 2005 Int. $\$$ & 3,424 & 4,504 & \\
In constant LCU & 5,650 & 7,656 & \\
\hline
\end{tabular}

Note: LCU refers to local currency units (Ugandan shillings and Peruvian nuevo soles).

Source: Authors' calculations based on UNHS 2005/06 and 2009/10 and ENAHO 2005 and 2009.

Technically, the differences between the PPP-adjusted values and the values in local currency for Uganda are noteworthy. The much lower growth rate of labour value added in constant Int. $\$$ can be explained by major changes in the PPP conversion factors. While the figures in Int. \$ are useful for cross-country comparisons, the analysis of within-country changes over time should be complemented by indicators measured in local currency. Finally, this exercise also illustrates that a meaningful aspiration level for this indicator might be the projected growth rate of GNI per capita.

\subsubsection{Working poverty rate}

In the next step, we compute the incidence of working poverty in Uganda and Peru. Table 2.3 shows the headcount poverty ratios and the WPRs for both countries in 2005 and 2009, using different approaches. The results of calculations based on national conventions are contrasted with those obtained from the World Bank's approach to computing the internationally comparable poverty rates (applying the $1.25 \mathrm{Int}$. \$/day poverty line to monitor MDG 1 ). For 
the purposes of its official national poverty statistics, Uganda uses a consumption aggregate per adult equivalent and regional poverty lines that further distinguish between rural and urban areas. Peru bases its estimates on consumption per capita and also uses regional poverty lines. The regional poverty lines can differ considerably: in Peru, the highest is 52 per cent higher than the lowest, and in Uganda it is four times higher. Depending on the context, the consideration of equivalence scales and regional price differences is known to matter for measuring poverty and, accordingly, working poverty. While these are only two of the problems raised by the calculation of internationally comparable (working) poverty rates, a more extensive discussion of the issues goes beyond the scope of this article. Yet, we consider the advantage of having internationally comparable indicators to outweigh those disadvantages.

Table 2.3. Working poverty rates in Uganda and Peru, 2005 and 2009 (percentages)

\begin{tabular}{lcccc}
\hline & \multicolumn{2}{c}{ Uganda } & \multicolumn{3}{c}{ Peru } \\
& 2005 & 2009 & 2005 & 2009 \\
\hline Poor (headcount - national poverty line) & 29.3 & 24.5 & 55.6 & 33.5 \\
Poor (headcount - Int. \$1.25) & 44.6 & 35.7 & 5.6 & 2.2 \\
Poor (headcount - Int. \$2) & 70.1 & 64.4 & 16.8 & 8.7 \\
LFPR & 77.0 & 77.7 & 71.7 & 76.9 \\
Total number of persons employed & $9,799,816$ & $11,432,223$ & $13,107,577$ & $15,418,822$ \\
WPR (national poverty line) & 27.9 & 22.5 & 55.7 & 32.0 \\
WPR (Int. \$1.25) & 45.9 & 29.7 & 5.5 & 2.0 \\
WPR (Int. \$2) & 73.3 & 60.2 & 17.0 & 8.2 \\
\hline
\end{tabular}

Note: LFPR and WPR refer to the labour force participation rate and the working poverty rate, respectively.

Source: Authors' calculations based on UNHS 2005/06 and 2009/10 and ENAHO 2005 and 2009.

Table 2.3 shows that poverty decreased in both countries, and the results illustrate the importance of the choice of applied methods and poverty lines. Uganda's national poverty statistics suggest a moderate decline in the headcount ratio between 2005 and 2009. Using the international poverty lines, however, the reduction of extreme poverty (less than Int. 
$\$ 1.25$ per capita per day) appears to have been much more pronounced than that of poverty according to the higher poverty line (less than Int. \$2 per capita per day). In Peru, the national poverty line is much higher than the international poverty lines. Albeit at different levels, however, all of the country's poverty indicators show a drastic decline over the period under consideration.

Some very interesting patterns emerge with regard to the WPR, illustrating the possible value of this indicator as a complement to poverty measures. For Peru, the WPR is very close to the headcount ratio, i.e. the share of poor workers among all workers is similar to the share of poor people in the overall population. This holds for all indicators and both years, implying that progress in poverty reduction correlates with progress in workers' incomes. In Uganda, in contrast, this only applies to 2005; in 2009, the WPR was between two and six percentage points lower than the headcount ratio. This means that the working population fared better than the non-working population and that income from work enables people to escape poverty more effectively than do other sources of income. This is consistent with the above finding of a considerable increase in labour value added per worker in Uganda; it is also likely to reflect the country's higher labour force participation rate, with more household members contributing to household income with their labour. In general, the fact that overall poverty rates in Uganda are higher than the country's working poverty rates - while being similar in Peru - is likely to be related to differences in the composition of household income sources between the two countries. In particular, non-labour incomes (e.g. old-age pensions and other transfers), which partially sustain households without employed individuals, are more common in Peru than in Uganda. In other words, in economies without social support programmes people are more dependent on decent labour income.

\subsubsection{Workers earning less than absolute and relative minimum labour incomes} As explained above, established per capita poverty thresholds - i.e. national and international poverty lines - are used as proxies for absolute minimum labour income thresholds. To estimate the proportions of employed people earning less than the Int. \$1.25 threshold and the proposed relative threshold of 60 per cent of median labour income, we first calculate the total monthly labour income for each employed person. In a developing country context, this poses a number of challenges. One of them is the high incidence of unpaid family workers in household firms (and farms), which is an important feature not only of the Ugandan economy 
but also of many other developing countries. Unfortunately, the intra-household allocation of profits accruing from such household-level economic activities is not known. In order to obtain income measures for unpaid family workers, we divide household business and farm incomes equally among all household members involved in the productive activity.

Table 2.4 reports both countries' median monthly labour incomes in 2005 and 2009, as well as the shares of workers aged 15 years and above earning less than the respective thresholds. In line with our previous observations on changes in labour value added and the incidence of working poverty, the figures show that labour earnings increased substantially in both countries in the period under review, although Ugandan workers still had low earnings by the end of the period. Indeed, Uganda's monthly median labour income was Int. \$25.8 in 2009, which implies that more than 57 per cent of workers earned less than the absolute threshold of Int. \$1.25 per day. This share is down from 64 per cent in 2005, so some progress can also be seen in individual labour earnings in this country. This also holds for Peru, where the share of workers earning less than Int. $\$ 1.25$ per day declined from 18 to 11.3 per cent over the period. Yet, what is noteworthy in the Peruvian case is that these shares are relatively high when compared to the WPR (5.5 and 2 per cent in 2005 and 2009, respectively). This implies that employed persons with very low labour earnings live in households that have additional sources of income (either other workers with higher labour income or social transfer payments). The difference between the working poverty rate and the minimum labour income indicator is somewhat less pronounced in Uganda. 
Table 2.4. Workers earning less than absolute/relative thresholds in Uganda and Peru, 2005 and 2009

\begin{tabular}{|c|c|c|c|c|c|}
\hline & & \multicolumn{2}{|c|}{ Uganda } & \multicolumn{2}{|c|}{ Peru } \\
\hline & & 2005 & 2009 & 2005 & 2009 \\
\hline \multirow{3}{*}{$\begin{array}{l}\text { Total monthly labour } \\
\text { income per employed } \\
\text { person - median }\end{array}$} & Int. \$ & 19.5 & 25.8 & 159 & 228 \\
\hline & $\begin{array}{l}\text { Constant LCU } \\
\text { (base }=2005 \text { ) }\end{array}$ & 14,500 & 25,492 & 263 & 388 \\
\hline & Int. \$ & 11.7 & 15.5 & 95 & 137 \\
\hline $60 \%$ of the median & $\begin{array}{l}\text { Constant LCU } \\
\text { (base }=2005 \text { ) }\end{array}$ & 8,700 & 15,295 & 158 & 233 \\
\hline \multicolumn{6}{|l|}{ Share of workers below... } \\
\hline ...Int. $\$ 1.25$ (PPP) per day & in $\%$ & 63.9 & 57.7 & 18.0 & 11.3 \\
\hline ...60\% of median income & in $\%$ & 37.3 & 36.4 & 36.7 & 36.5 \\
\hline
\end{tabular}

Note: LCU refers to local currency units.

Source: Authors' calculations based on UNHS 2005/06 and 2009/10 and ENAHO 2005 and 2009.

Table 2.4 also reports our estimates of the proportions of workers earning less than 60 per cent of the median incomes in both countries. Somewhat surprisingly, the proportions are very similar in both countries - about 36 per cent - and remained relatively constant over time. In Uganda, however, the relative income threshold was very low - at Int. \$11.7 in 2005 and Int. \$15.5 in 2009 - so the fact that more than a third of all workers fell below this threshold is striking. Yet, even those with extremely low earnings appear to have benefited from general income growth. At least, their relative position is not deteriorating. There is nonetheless obvious room for improvement, as more than a third of workers earn less than 60 per cent of median earnings in countries where the median earner already earns well below the average.

\subsection{Conclusion}

This article contributes to the discussion of employment-related targets and indicators for the post-2015 development agenda. We propose to measure progress towards a target to "achieve full and productive employment and decent work for all" by using four indicators, 
namely: the growth of labour value added per worker; the working poverty rate; the share of workers receiving less than an absolute minimum labour income; and the share of workers receiving less than 60 per cent of the median labour income. The suggested target and indicators overcome most of the major limitations of the indicators currently in use and put special emphasis on equity - an aspect that was largely neglected in the MDG agenda. The proposed indicators are conceptually valid according to the SMART criteria and allow for the quantitative measurement of progress (or regress) on important aspects of productive employment and decent work. Moreover, the setting of targets at the national level and the possibility of disaggregating each of our proposed indicators by sex, age and other variables of interest to decision-makers allow for the incorporation of additional dimensions of equity and inclusion. Nonetheless, the multidimensionality of decent work implies that neither the currently applied employment-related indicators nor those proposed by us are able to capture all of its facets.

A major challenge in measuring decent work stems from the quality, scope, coverage, and periodicity of data collection, since these factors typically impede cross-country comparisons to a large extent. Our proposed indicators are income-focused not because we think that income is a perfect proxy for the quality of work, but because data on conditions of work e.g. working time and occupational safety and health - are simply not available for a sufficient number of countries. Hence the urgent need to expand the scope of household and labour force surveys and to harmonize them internationally as they are the main data source for employment indicators. This will require further strengthening of the capacities of national statistical institutes. 


\title{
3 Labour Market Effects of Large-Scale Agricultural Investment: Conceptual Considerations and Estimated Employment Effects
}

\author{
Kerstin Nolte \& Martin Ostermeier*
}

This chapter appeared as:

NOLTE, K. and OSTERMEIER, M. (2017), Labour Market Effects of Large-Scale Agricultural Investment: Conceptual Considerations and Estimated Employment Effects. World Development, 98: 430-446. doi: 10.1016/j.worlddev.2017.05.012.

\footnotetext{
*We wish to thank Jann Lay, Simone Gobien, Anne Hoss (all GIGA), Martin Petrick (IAMO), and two anonymous reviewers for their excellent input. Further, we are grateful for the feedback received by participants of seminars within the GIGA Doctoral Programme and at the University of Göttingen, and attendees at the workshop on large-scale land transactions at the University of Michigan (2016), the IAMO Forum in Halle (2016), the World Bank Conference on Land and Poverty (2016), and the Development Economics Conference at the Göttinger Schule, Göttingen (2016). We also thank our colleagues at the Land Matrix Initiative for their constructive and close collaboration over the last few years. This work was supported by the Federal Ministry for Economic Cooperation and Development (BMZ) within the scope of the Large-Scale Land Acquisitions: Data, Patterns, Impacts, and Policies project.
} 


\section{Abstract}

Large-scale agricultural investments (LSAIs) in general and their socio-economic implications in particular have been heavily debated in recent years. While some claim that LSAIs are an important catalyst for development in neglected rural areas, others caution that they pose a risk to rural communities' livelihoods. The extent to which LSAls provide benefits for local communities is hence still contested.

This paper sets out to conceptually understand what effects the establishment of a large-scale farm has on the rural labour market in low- and middle-income countries. In addition, we empirically address the question of whether large-scale farming as recorded in the Land Matrix creates or destroys employment. We develop a transition matrix to identify several scenarios based on key determinants of the direct employment creation potential of LSAIs, namely the former land use, the crop type and the production model. We empirically assess the actual importance of these scenarios and the employment creation to be expected from this sample of LSAls based on labour intensities. We further look into the net employment effects for land formerly used by smallholder farmers. Our analysis shows that LSAIs massively crowd out smallholder farmers, which is only partially mitigated through the cultivation of labour intensive crops and the application of contract farming schemes. This holds true for all regions targeted by LSAIs, although regional differences are found in terms of magnitude.

The paper concludes that these effects tend to be large on the local scale (i.e., in the immediate surroundings of the investment site) but small in relation to total national employment in agriculture. However, indirect employment creation related to LSAIs, which is discussed but not empirically addressed in this paper, needs to be taken into account to have the full picture. 


\subsection{Introduction}

The demand for land suitable for agricultural production is growing globally (Lambin and Meyfroidt 2011). A major driver is the increased demand for food and energy of growing populations worldwide (Scheidel and Sorman 2012). In this context the expansion of largescale commercial farming is seen as a potential solution ${ }^{11}$ to satisfy this demand (Deininger 2013). In the last decade investors have been increasingly acquiring land in developing countries for huge farming operations (Nolte, Chamberlain, and Giger 2016). The media have coined this phenomenon "land grabbing"; a more neutral term is "large-scale agricultural investments" (LSAIs). The term "LSAI"12 is also more precise since it excludes cases of speculation and only considers land acquisitions that result in an operational farm.

Such investments, in general, and the socio-economic implications of these investments, in particular, have been heavily debated in recent years (Ali, Deininger, and Harris 2017; Baumgartner et al. 2015; Collier and Venables 2012; Cotula 2013; German, Schoneveld, and Mwangi 2013; Herrmann 2017; Kleemann and Thiele 2015; Messerli et al. 2014). The implications such investments have for target countries' agricultural sectors and, more specifically, for rural employment are still contested. The creation of jobs is one of the most important and common pledges investors make to local communities and governments when acquiring land; although, the actual realization of this commitment is often debated: while some see potential for employment creation (Baumgartner et al. 2015; Kleemann and Thiele 2015), others fear that the most vulnerable parts of society will lose their means of existence (Li 2011). Obviously, whether and to what extent these investments turn out to benefit host countries critically hinges on the potential for employment creation, particularly for those who lose their land without compensation. Although past experiences with large farms have been largely negative, recent changes in the context conditions have given reason to believe that large farms may have a future (Deininger and Byerlee 2012) and may actually contribute to

\footnotetext{
${ }^{11}$ Another view is that smallholder farming is still the backbone of global food security in the developing world. Tscharntke et al. (2012) therefore suggests that there is a need to link agricultural intensification with biodiversity conservation and hunger reduction instead of conventional intensification.

${ }^{12}$ We use the terms LSAls and large-scale farms interchangeably. We believe that the size of a farm best distinguishes the different production models; i.e., large-scale commercial and (often) mechanized farming, and less mechanized smallholder farming. We acknowledge that smallholder farmers not only produce for own consumption but may also produce commercially for the market (see also footnote 15).
} 
increased welfare and poverty reduction due to employment creation (Deininger and Xia 2016; Herrmann 2017; Van den Broeck, Swinnen, and Maertens 2017).

Moreover, generating employment is a key component of economic and social development and, thus, of poverty alleviation (World Bank 2012) - an issue ranked high on most national development agendas. However, development processes typically go hand in hand with declining shares of agricultural sectors' gross domestic product (GDP) contributions and decreasing employment in agricultural sectors (Chenery and Syrquin 1975; A. D. Foster and Rosenzweig 2007; Kuznets 1957; Üngör 2013). In other words, the shift from agriculture-based economies toward industrialized or service oriented economies seems to be a necessary precondition for development. In many poor countries, the agricultural sector continues to be the backbone of the economy and employs a large share of the population. Development processes often focus on urban areas and leave rural populations behind (Headey, Bezemer, and Hazell 2010). Against this logic, largescale farms in rural areas could hence shoulder the burden of creating agricultural wage employment, for instance, by (i) satisfying labour demand by directly employing former land users and (ii) stimulating the local economy and creating employment opportunities outside the agricultural sector through sectoral linkages. Moreover, establishing a largescale farm might have further implications for the local economy, such as lower food prices and greater access to new technologies, to name but a few. Depending on the extent to which these effects materialize, they could alleviate poverty (Irz et al. 2001; Maertens and Swinnen 2009).

This paper seeks to conceptually understand the effects the establishment of a large-scale farm has on the rural labour market in low- and middle-income countries. Moreover, it addresses the question of whether large-scale farming creates or destroys employment when compared with the previous activity carried out on the land in question (e.g., smallholder farming). To do this, we provide relevant background information on rural labour markets in general and the labour productivities and intensities in the agricultural sector in particular in section 3.2. In section 3.3 we elaborate on the direct labour market effects that occur once a large-scale farm is set up. For these direct effects, we identify and discuss three key determinants which are decisive for the employment creation potential of LSAIs: (i) the former land-use type, (ii) the crop cultivated, and (iii) the production model applied. Based on these determinants, we develop different scenarios and illustrate them in a transition matrix. In 
section 3.4 we present the data for our empirical application. In section 3.5 we empirically assess the employment creation in three steps: First, we assess small-scale and large-scale labour intensities based on data from the Land Matrix Global Observatory ${ }^{13}$ and the FAO smallholder data portrait. Second, we assess which scenarios are actually occurring in reality and derive implications for the labour market. Third, we estimate the net employment effect for LSAls on former smallholder land in selected countries. In section 3.6 we elaborate on further indirect effects and discuss the validity and limitations of our findings, before concluding in section 3.7 .

\subsection{Rural labour markets and labour productivity}

\subsubsection{Rural labour markets}

In rural areas of low- and middle-income countries, agriculture is the main source of employment and income (Rosenzweig 1988). In 2010, 24 per cent of the workforce in low and middle-income countries was employed in agriculture, while agriculture's contribution to GDP was at 10 per cent (World Bank 2016). In those countries heavily targeted by foreign agricultural investments, the share of workers in the agricultural sector is even higher - for instance, 73 per cent in Ethiopia and 72 per cent in Uganda in 2013 (World Bank 2016). ${ }^{14}$

Over two-thirds of farming activities are performed by self-employed individuals (Gindling and Newhouse 2014); wage and salary employees are mainly found in the processing industry. Agricultural wage employment opportunities exist predominantly only for casual and seasonal workers, which can be explained by the seasonality of agricultural production. For most crops, there are clear seasonal peaks (e.g., toward harvest times) during which times labour demand is high (Nolte and Subakanya 2016; Rosenzweig 1988). In addition to being limited in terms of quantity, those temporary jobs are also limited with regard to quality. Major differences

\footnotetext{
${ }^{13}$ The Land Matrix Global Observatory is a global and independent land monitoring initiative that promotes transparency and accountability in decisions regarding land and investment. It records land acquisitions of 200 hectares and more in low- and middle-income countries that have occurred since the year 2000. Further information can be found at http://www.landmatrix.org/.

${ }^{14}$ These figures might even be underestimated since many surveys only focus on the primary occupation of the respondent. Agricultural activities, however, are often pursued as secondary or tertiary occupations and therefore not captured by survey. Especially on family farms it is common for household members to work on the farm in addition to their main job in the industrial or service sectors. Consequently, the importance of farm activities might be understated (Haggblade, Hazell, and Reardon 2010).
} 
between regular and irregular wage employment can be found in the working conditions, social protection, and entitlements and benefits for workers (ILO 2003).

Labour supply in rural areas is considered to be infinite. Even in areas where new labour opportunities open up, the supply remains high due to people migrating into these areas (Taylor and Martin 2001). A major constraint in rural areas is that the workforce typically lacks the training to perform high-skill tasks (Collier and Dercon 2014).

Jobs created by LSAls are often earmarked for wage workers. In some cases self-employment opportunities are provided through contract farming. A smallholder farmer's decision on whether to switch from self- to wage employment is mainly driven by the social opportunity costs of the self-employed (shadow wages). Smallholders will only decide to enter wage employment or release family members to work on a largescale farm if the drop in profits is compensated by the wage earned on the large-scale farm. More precisely, wages paid on large-scale farms have to be equal to or exceed the marginal revenue product of smallholder farmers (Barrett, Sherlund, and Adesina 2007).

Another aspect of wage employment created on large-scale farms is that it contributes to the formalization of the agricultural sector, from self-employed smallholder farming to wage employment. This in turn increases the fiscal revenue of an economy since larger holdings are more likely to be formally registered and hence taxable compared to smallholders (Irz et al. 2001); this is despite the fact that investors in agriculture enjoy considerable tax benefits in many countries (Cotula et al. 2009).

\subsubsection{Agricultural labour productivity and labour intensity}

As countries develop, their agricultural sectors lose importance. This can be illustrated by comparing the share of people employed in agriculture and the sector's contribution to GDP in low- and middle-income countries over time. During 2000-10, the share of the workforce engaged in agriculture almost halved from 45 to 24 per cent. Within the same period the agricultural sector's contribution to GDP only decreased by 23 per cent (from 13 to 10 per cent) (World Bank 2016). The sharp drop in agricultural employment compared with the more modest decrease in agriculture's GDP contribution clearly points to increased labour productivity. In other words, less labour input is required to produce the same level of output. 
Labour productivity measures employment efficiency and is defined as output per unit of labour input during a period of time.

Generally speaking, (agricultural) labour productivity varies largely across countries. In 2015 the agriculture value added per worker (in constant 2010 USD) in Norway was more than four hundred times higher (USD 98,950) than that in Burundi (USD231) (World Bank 2016). These differences in agricultural productivity can be explained by a variety of factors: First, policies that distort farm size may lead to a misallocation of farmland and impair productivity (Adamopoulos and Restuccia 2014). Second, the self-selection of low-skilled workers into the agricultural sector in developing countries is considered to decrease agricultural productivity (Gollin, Lagakos, and Waugh 2014; Lagakos and Waugh 2013). Third different agro-ecological conditions (e.g., rainfall and soil quality) determine agricultural productivity and explain differences (Gallup and Sachs 2000). And fourth, differences in agricultural productivity are particularly stark between countries in diverse states of development. The last point is often rooted in contrasting models of agricultural production. For instance, large-scale agriculture accounts for the majority of agricultural production in industrialized countries, whereas smallholder and family farming ${ }^{15}$ play an important role in developing countries. Large-scale farms and smallholder farms also differ in terms of their capital and labour endowments. While smallholders largely depend on labour, large-scale farmers often substitute labour with capital. The extent to which such a substitution can take place depends on, inter alia, the crop itself. The crop determines the labour intensity, i.e., the amount of labour needed in a production process (Deininger and Byerlee 2011). The cropping practice related to these different labour and capital intensities of production further affects agricultural productivity (Bustos, Caprettini, and Ponticelli 2016).

In agricultural science it is common to use a labour input measure (labour intensity) instead of an output measure (labour productivity). Labour intensity (LI) is defined as the amount of

\footnotetext{
15 There is no universal definition of "smallholder" or "family farmer" (HLPE 2013). Smallholder farming refers to the size of the farms; however, the understanding of what is "small" depends very much on the context. Most commonly, an upper threshold of two hectares is used to identify smallholders. Family farming in turn refers to who owns and works the land. Thus, farms that principally rely on a family labour supply are considered family farms. While both concepts overlap, they are not the same (Lowder, Skoet, and Raney 2016). We use the term smallholder farming in the following to distinguish smaller (often, but not necessarily, family-operated) farms from large-scale farming operations; the latter are identified by their size of two hundred hectares or more.
} 
labour needed in a production process and is calculated as the number of workers required to cultivate one hectare of a specific crop:

$$
L I=\frac{\text { Number of } \text { workers on the farm }}{\text { Area in production (hectare) }}
$$

Two main crop classes are often distinguished based on their cultivation patterns: annual crops and perennial crops. Annual crops (e.g., wheat, corn, and soya beans) perform an entire life cycle in one season and have to be replanted every year. Since the process from planting to harvest can be largely performed with the aid of machinery, annual crops are considered capital intensive. Subsequently, there is a great deal of scope for capital to replace labour. On the contrary, perennial crops (e.g., tea, coffee, and bananas) persist for many growing seasons. Planting, caring for, and harvesting these (typically tree) crops require more labour input. They thus provide less scope to substitute labour for capital and are considered rather labour intensive. Therefore, in terms of labour input, there are significant differences between crops for which labour can easily be substituted by capital. For instance, Deininger and Byerlee (2011) find that oil palm and (manual) sugar cane generate 10-30 times as many jobs compared with mechanized grain farming. Hence, for perennials, key operations potentially vary little between large-scale and smallholder farms and, accordingly, labour intensities are similar. This is not the case for mechanized grain production, where large differences exist between smallholder and large-scale farms (Deininger and Byerlee 2011). In these cases a hectare under smallholder production is typically thought to employ more people than a hectare under mechanized large-scale farming.

\subsection{Conceptual framework}

The establishment of a new large-scale farm implies the transition from a certain former land use to large-scale farming. This has far-reaching consequences on the rural labour market. We distinguish direct and indirect employment creation: Direct employment creation can be directly linked to the operation on the farm. These effects typically become visible immediately with the farm establishment. Indirect employment creation, in turn, concerns employment creation that is triggered by the farm operation but does not occur on the actual farm. These effects can occur immediately but typically occur in the medium- and long-term 
when sectoral changes become effective (forward- and backward linkages). In our conceptual framework and the empirical application we focus on changing labour requirements due to direct employment creation and discuss the indirect employment effects in section 3.6.1.

In order to conceptualize how the establishment of a large-scale farm in a rural context can directly affect the labour market, we illustrate different scenarios (1a-5d) in a transition matrix (Table 3.1). Accordingly, the direct employment effects depend on three factors: (i) the former land-use, as it determines whether and to what extent crowding out of labour takes place, (ii) the type of crop cultivated, as labour intensity differs between crops, and (iii) the production model, which could mitigate the crowding out of smallholder farmers. The labour demands of new farms vary over time. In the initial stages land preparation and infrastructure development contribute to employment creation. But once the farm is operational, the crops produced and the production model applied are the decisive factors behind further employment creation. We are interested in longer-term employment prospectives and thus only consider the employment creation of operational farms.

The former land use determines the loss of employment. A newly established farm leads to a change in land use and all former income-generating activities on the land cease to exist. We distinguish between investments on farmland already used for large-scale agriculture (1a-1d, brownfield) and the establishment of an entirely new farm (greenfield) on land formerly used for smallholder agriculture (2a-2d), pastoralism (3a-3d), forestry (4a-4d), or conservation $(5 a-5 d)$.

Labour requirements for the new large-scale farm largely depend on the crops or, more precisely, on the labour and capital intensity of crop production (as discussed in section 3.5.1). Accordingly, we differentiate between labour-intensive and capital-intensive crops in our transition matrix.

We further account for different production models in that we distinguish between investors who introduce contract farming schemes (CF) and those who do not (no CF). Contract farming schemes are thought of as a solution to preserve smallholder employment and achieve considerable social benefits for participating farmers (Deininger and Byerlee 2012; Kleemann and Thiele 2015). The term "contract farming" refers to agreements between a farmer and a firm. Under such an agreement, a farmer is required to provide a certain quantity and quality 
of commodity that is either produced on the farmer's own land or on land acquired by the investor but worked by the farmer. In turn, the investor provides production support and processes the farmer's produce or puts it on the market (Eaton and Shepherd 2001). Regardless of whether leased or non-leased, in both cases jobs are largely maintained and depending on the specific contract arrangements - production conditions might improve, for instance, through the provision of credit; agricultural inputs in the form of seeds, fertilizer, and pesticides; and training in production methods. Contract farming is a highly debated practice in the literature (Baumann 2000; Simmons 2002). On the one hand, such arrangements are criticized because of the unequal power relationship between the smallholder and the investor, which could lead to the latter exploiting the former. On the other hand, it is considered an opportunity to include local farmers in development processes in the context of large-scale land investments (De Schutter 2011; Robertson and PinstrupAndersen 2010).

Table 3.1. Transition matrix

\begin{tabular}{|c|c|c|c|c|c|}
\hline & & & Comm & l farm & \\
\hline & & Labor & ensive & $\begin{array}{r}\text { Capita } \\
\end{array}$ & nsive \\
\hline Former l & d use & no $C F$ & $C F$ & no $C F$ & $C F$ \\
\hline $\begin{array}{l}\text { Brownfield } \\
\text { investments }\end{array}$ & Commercial agriculture & $1 \mathrm{a}$ & $1 \mathrm{~b}$ & $1 c$ & $1 d$ \\
\hline & Smallholder agriculture & $2 \mathrm{a}$ & $2 b$ & $2 c$ & $2 \mathrm{~d}$ \\
\hline$n+\rho \mid \alpha$ & Pastoralists & $3 a$ & $3 b$ & $3 c$ & $3 d$ \\
\hline investments & Forestry & $4 a$ & $4 \mathrm{~b}$ & $4 \mathrm{c}$ & $4 d$ \\
\hline & Conservation & $5 a$ & $5 b$ & $5 c$ & $5 d$ \\
\hline
\end{tabular}

Source: author's compilation.

Note: $C F=$ contract farming. 


\subsubsection{Scenarios for brownfield investments}

For scenarios 1a-1d, we would expect new investments to take over existing farms. In this case there would be no crowding out of smallholder agriculture or other income-generating activities of local communities; although employees of the previous farm might still be released. Therefore, the net employment effect is strongly driven by the labour intensity of the cultivated crops and the question of whether contract-farming schemes are applied or not. If the investor decides to plant more labour-intensive crops $(1 a+1 b)$, we would expect a more positive employment effect than if the investor were to opt for capital-intensive crops $(1 c+1 d)$ under high mechanization. This positive effect might be further stimulated if the investor implements contract-farming schemes, which would offer employment opportunities to smallholder farmers in the region.

\subsubsection{Scenarios for greenfield investments}

If new farms are established on land that was not formerly used for large-scale agriculture, former land use plays a more pronounced role since jobs connected to the land's former use will be lost. This holds particularly true for investments in scenarios $2 a-2 d$, which target land that was formerly used for smallholder agriculture. Accordingly, we expect displacements and massive crowding out of smallholder employment. In the scenarios 3a-3d we expect pastoralists to be crowded out, while in scenarios $4 a-4 d$ we expect labour engaged in forestry to be crowded out. Conservation areas often serve various purposes, such as hunting, fishing, and gathering of firewood. Therefore, these activities would be expected to cease in scenarios 5a-5d. Generally speaking, we expect low crowding out of former employment on land formerly used for forestry and conservation (scenarios $4 a-5 d$ ) due to the relatively low labour demand for forestry, which ranges between 0.02 and 0.04 workers per hectare (Bustos, Caprettini, and Ponticelli 2016; Deininger and Byerlee 2011).

Similar to brownfield investments, employment is created according to the crops that are cultivated and the business model: labour intensive crops ( $a+b$ of scenarios $2-5)$ are more likely to preserve existing jobs or even generate additional employment opportunities, which could lead to net employment creation. With capital-intensive crops ( $c+d$ of scenarios $2-5)$, the newly created employment might not compensate the employment that was crowded out in the first place. Some investment projects implement contract-farming schemes $(b+d$ of 
scenarios 2-5), which could - similarly to labour-intensive crops - mitigate the crowding out of employment linked to different former land uses.

In sum, the net employment effect is driven by the combination of these three aspects in each acquisition, ranging from massive crowding out and very few new employment opportunities to hardly any crowding out mitigated by contract-farming schemes and many new jobs. The negative effects are prone to be strongest for former greenfields which experienced high crowding out of former employment - specifically, former smallholder farms. The cultivation of labour-intensive crops might mitigate the loss through substantive labour demand, while capital-intensive crops are expected to generate only limited employment. If contract-farming schemes are implemented, the crowding out of former employment can be reduced and smallholder farmers can partake in the development process of the region.

\subsection{Data}

In our empirical analysis we mainly draw on two databases. For LSAIs, we use data from the most comprehensive database on large-scale land acquisitions, the Land Matrix (retrieved on 1 August 2016). We include all concluded agricultural deals (both oral agreement and signed contract) above two hundred hectares. ${ }^{16}$ Our data sample contains 1,346 deals amounting to 35.2 million hectares. The Land Matrix contains comprehensive information on individual large-scale farming projects with exact figures for the acquired area. In particular, it feeds the transition matrix with information on the (i) former land use, (ii) the type of crop cultivated including its respective current size under production and current number of workers, and (iii) the production model by capturing contract-farming schemes (with information on the area used for contract farming and the respective number of contract farmers, either inside or outside of the land acquired by an investor).

The land acquired by investors often contains multiple entries for several of these categories. If the share of these different entries is not given, we assume equal shares for each entry. For those cases of contract farming, where the actual area for contract farming is not given, we assume that contract farmers cultivate the entire acquired area.

\footnotetext{
${ }^{16}$ Land Matrix data also record "intended" and "failed" deals and include deals for other purposes, including mining and tourism. We hence use a subset of 1,346 deals included in the Land Matrix. We also include deals below two hundred hectares if the leased area combined with the area under contract farming amounts to more than two hundred hectares.
} 
To assess the employment loss from the former land use smallholder farming we draw on the FAO's Smallholder Farmers' Dataportrait ${ }^{17}$ - a standardized smallholder-specific database that consists of Living Standards Measurement Study (LSMS) survey data and FAO Rural Income Generating Activities (RIGA) data. We use this to estimate the labor intensity of smallholder farmers (see section).

To allow for the assessment of the net employment creation potential (see 3.5.3), we use five African low- and middle-income countries covered by the Smallholder Farmers' Dataportrait: Ethiopia, Kenya, Nigeria, Tanzania, and Uganda. For these countries, Land Matrix and FAO data overlap and provide a solid basis for a cross-country comparison.

\subsection{Empirical application}

\subsubsection{Labour intensities}

In the first step of our empirical analysis, we derive and compare the labour intensities of large-scale and smallholder farmers. This allows us to distinguish labour and capital intensive crops which is an important precondition to study actual employment effects. Based on the labour intensities, we can estimate the loss of employment from land formerly used for smallholder farming as well as the employment creation on now commercially farmed land.

\section{(i) Smallholder agriculture}

For smallholder agriculture, labour intensity is derived from the number of workers (family and hired workers) on a smallholder farm and the size of the farm as reported in FAO's Smallholder Farmers' Dataportrait. Both measures are median-weighted averages aggregated on country level. Because of its level of aggregation, the smallholder data do not account for individual crops, former uses, or production models. However, since the data set is derived from national labour surveys and household surveys and only addresses smallholder farmers, it reflects country-specific cropping patterns - that is, the data capture the typical crops cultivated and the respective labour intensity level for each crop. Therefore, the derived estimate can be considered - in the country context - a good estimate of smallholder labour intensity.

\footnotetext{
17 Available at: http://www.fao.org/economic/esa/esa-activities/esasmallholders/dataportrait/farm-size/en/ (visited 26/09/2016).
} 
Based on the FAO data, we consider smallholder labour intensities to range between 1.13 and 3.77 workers per hectare (see also Table 3.3 below in section 3.5.3), with a mean of 1.77 and a median of 1.26 .

\section{(ii) Large-scale agriculture}

For our large-scale agriculture labour intensity estimate per $\operatorname{crop}^{18}$, we use Land Matrix data. To cater for the differing labour demand under contract farming arrangements, we calculate intensities for such cases separately. ${ }^{19}$

In the following, we look at the labour intensities of some key crops, determined by their frequency in the Land Matrix. We assume that labour intensities are similar across world regions. This is a strong supposition given that agro-ecological conditions, such as rainfall and soil quality, vary largely across world regions. Our assumption, however, may be justified given (i) the highly mechanized mode of production in largescale agriculture, which is comparable across the globe, and (ii) the fact that agro-ecological conditions predetermine cropping patterns - for example, certain crops are only cultivated if the operation is thought to be profitable. We consider the derived estimates to be a valid approximation of differences in the labour intensities of various crops but are fully aware that one overall value will not be able to precisely reflect labour demands across the world.

Figure 3.1 shows labour intensities for annual and perennial crops and confirms that indeed annual crops have lower intensities. Nevertheless, there is some variance and hence some exceptions to this rule. For instance, rice shows a rather high labour demand of over 0.6 workers per hectare despite being considered a capital-intensive annual crop. However, this is not due to the natural characteristic of the plant but rather due to the way it is commercially cultivated. Although a perennial crop by nature, rice is usually replanted every year in order to generate higher yields. Similarly, cotton is cut down every year to prevent disease and pest

\footnotetext{
${ }^{18}$ Here we explicitly use the labour per area under production and not per acquired area. This takes into account that the acquired area (i.e., the area under contract) usually exceeds the area actually used for production since investors typically do not immediately enter into the production phase on the entire area acquired. Missing values in the size under production are imputed by a simple mean imputation based on the ratio of the size under contract and the respective size in production for all cases that have this information.

${ }^{19}$ If the labour intensity of contract farmers was not available, we used large-scale farmers' intensity. The rationale here is that contract farmers' labour intensity falls somewhere between that of smallholder farmers and large-scale farmers, depending on their access to improved technologies. Accordingly, we consider the labour demand of a large-scale farmer to be a lower-bound estimate.
} 
infestation even though it can survive several growing seasons. We also find heterogeneity in terms of labour intensities among perennial crops. Typically, such perennials are commercially produced on plantations. Due to their physical characteristics, some of these crops (e.g., tea, bananas, and coffee) are indeed quite labour intensive, while others (e.g., rubber, cocoa, and palm oil) are less labour intensive (ILO 1994). In the latter group of crops it is easier to substitute labour with capital.

Figure 3.1. Labour intensities for major annual and perennial crops
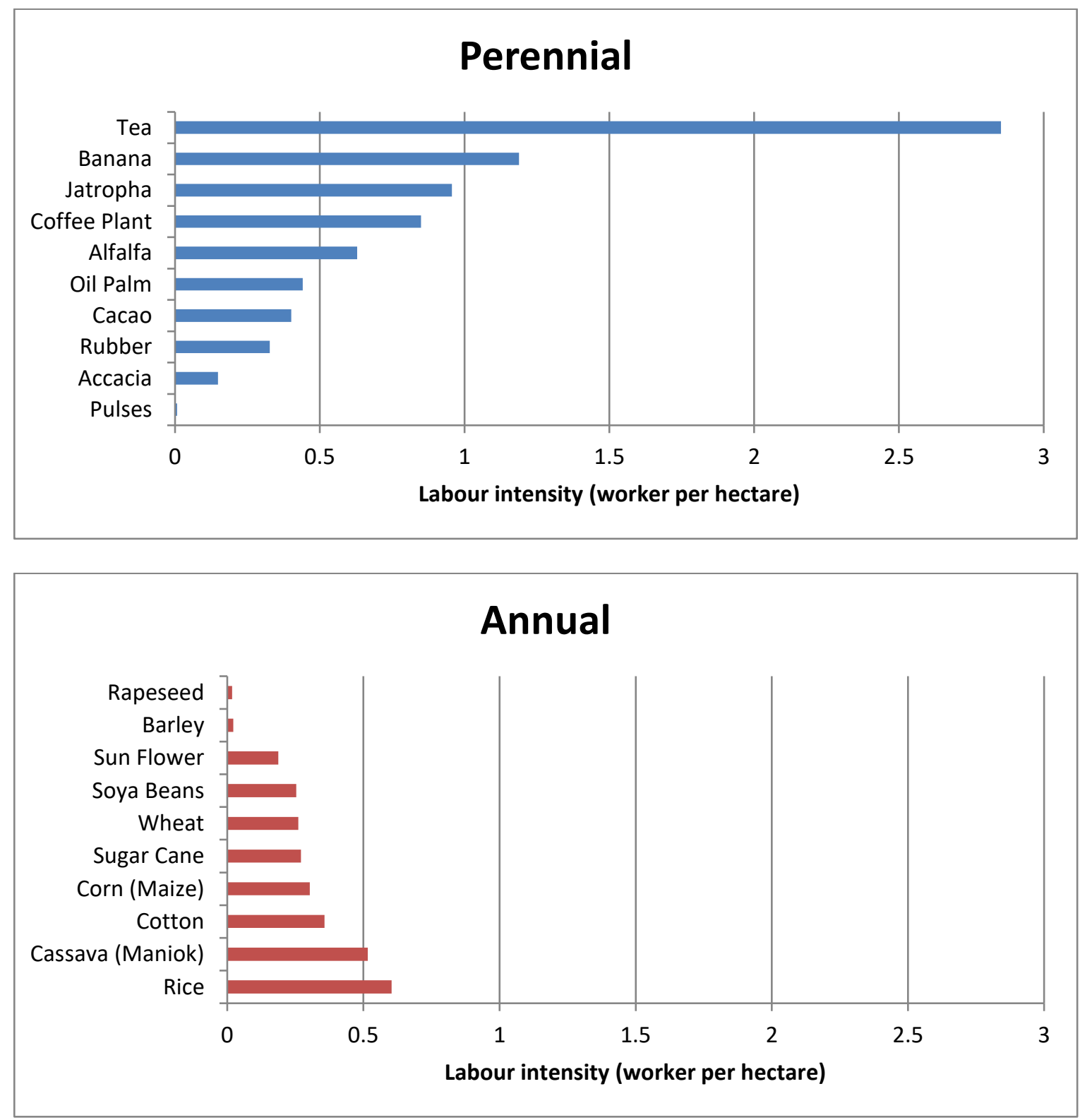

Source: author's calculation based on the Land Matrix Global Observatory (2016). 
We check the labour intensities derived from Land Matrix data against reports on labour intensity in the literature (see Appendix A, Table A 1). Generally speaking, we find similar labour intensities.

These empirical findings show that the classification of annuals and perennials reflects potential labour intensity quite well, although not perfectly. In the following empirical applications we hence do not use strict annual versus perennial crops as categories but categorize crops as either labour intensive or capital intensive. In general, the labour-intensive category consists of perennial crops; however, we also include those annual crops which are more labour intensive and exclude those perennial crops which, relatively speaking, are less labour intensive. The capital-intensive category typically comprises annual crops, though some labour-intensive annuals are excluded, while some perennial crops with low labour intensities are included.

To now distinguish labour-intensive from capital-intensive crops, we feed labour intensities of annual and perennial crops derived from the Land Matrix into a non-parametric estimation (kernel density). The point of intersection is used to derive the threshold between labour and capital intensity. Figure 3.2 shows that this point is at a labour intensity of 0.576 workers per hectare. Consequently, we define all crops above 0.576 workers per hectare as labour intensive, and all crops below that threshold as capital intensive. 
Figure 3.2. Frequency and density of labour intensity by crop class

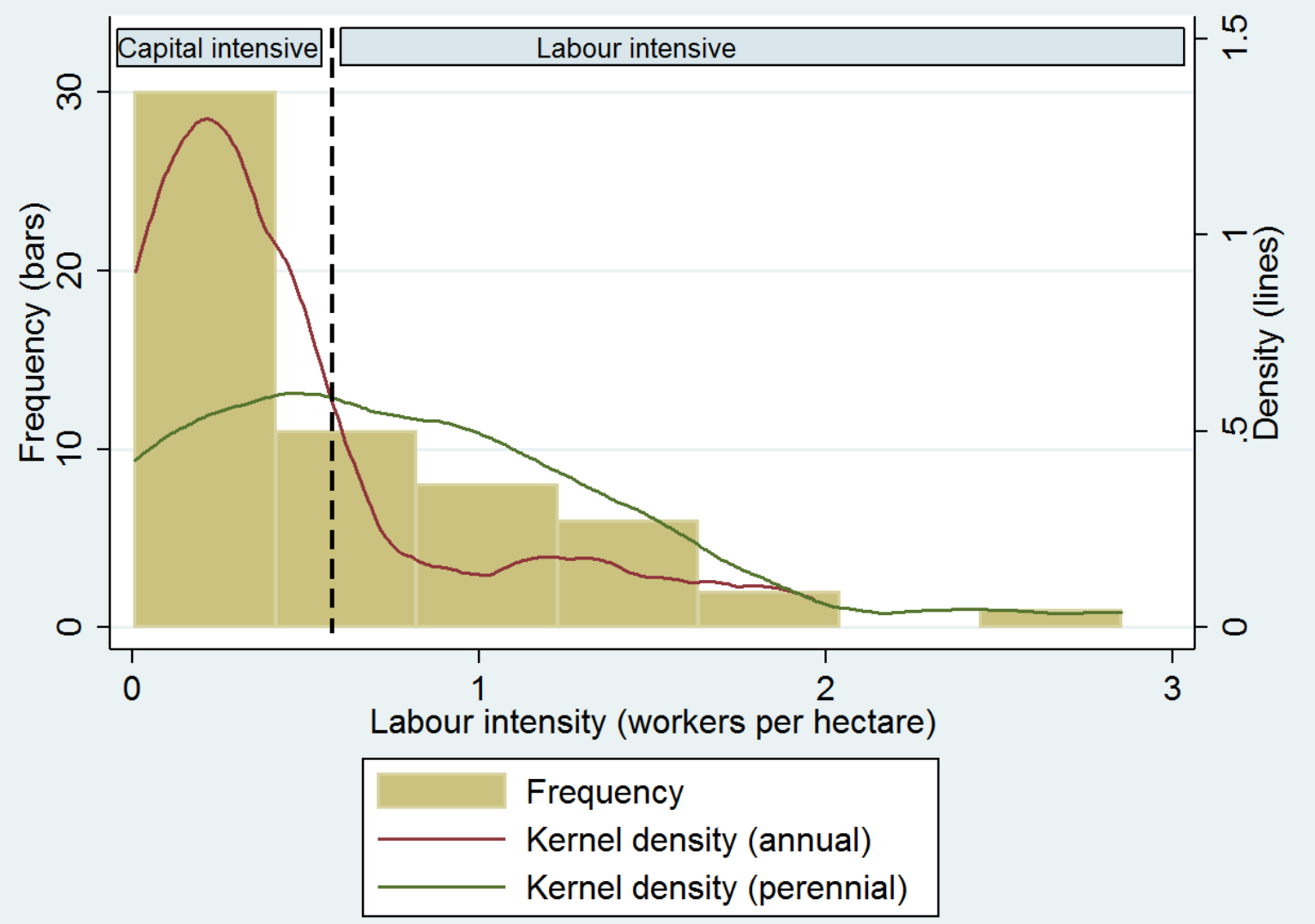

Source: author's calculation based on the Land Matrix Global Observatory (2016).

\subsubsection{Transition to large-scale farming}

\section{(i) Global overview on different scenarios}

We now address the transition from the former land use to large-scale farming by using the transition matrix (introduced in section 3.3) to illustrate how the total acquired area is distributed across each of the following three key factors: (i) the former land-use (large-scale agriculture, smallholder agriculture, pastoralists, forestry, and conservation); (ii) the labour intensity of the crop cultivated (labour intensive, capital intensive; see section 3.5.1); and (iii) the production model applied (contract farming, no contract farming). As a result, we can estimate the area that is transformed from the respective former land use to large-scale farming, taking into account the crops planted and the production models applied. Table 3.2 shows the transition matrix with the former land-use and the respective final land-use based on Land Matrix data. We use the acquired area (expressed as percentage of the total acquired area) as a measure; the areas' sizes in hectares can be found in Appendix A, Table A 2. 
Table 3.2. Transition matrix - Results as percent of the area acquired $(n=1,031)$

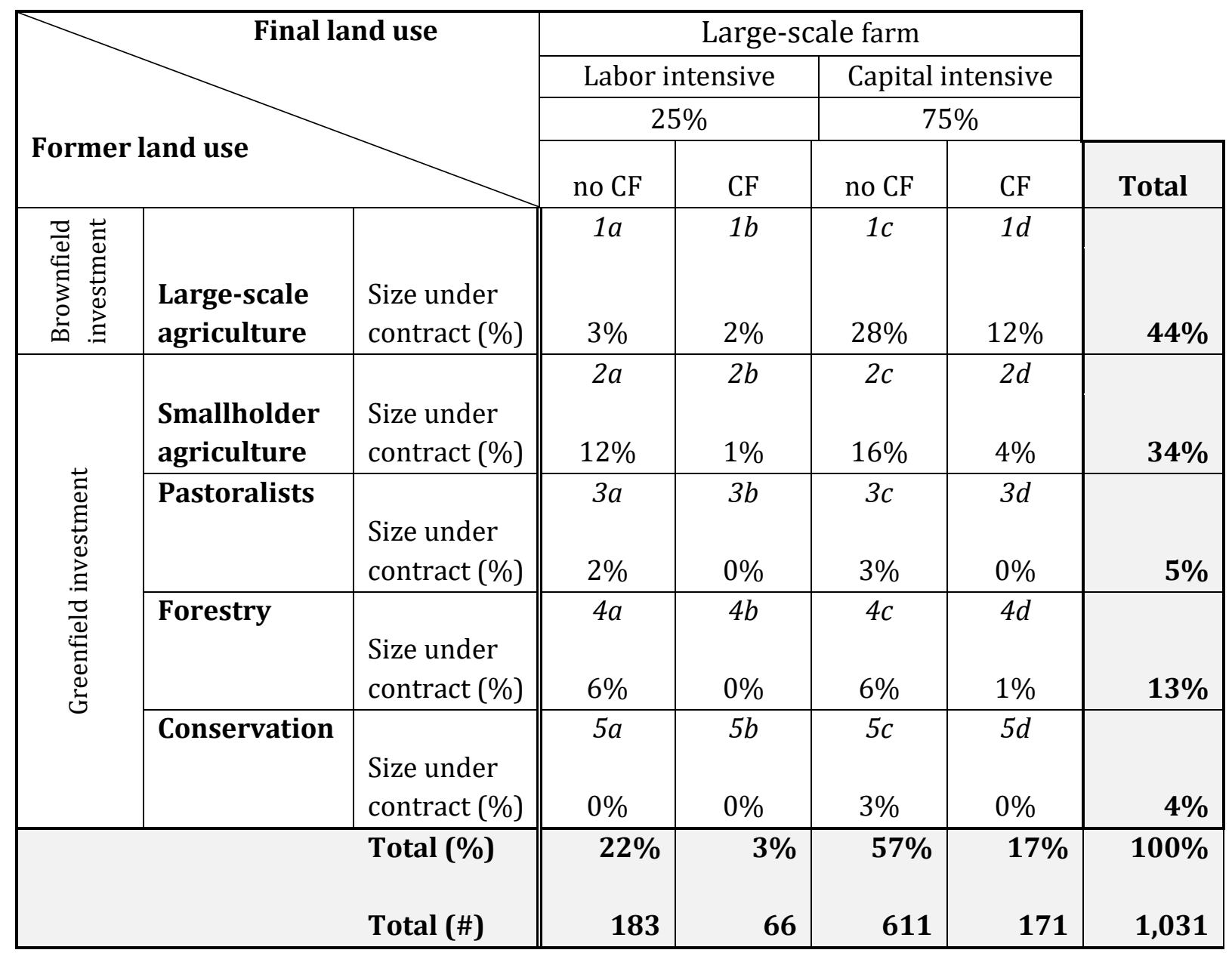

Source: author's calculation based on the Land Matrix Global Observatory (2016).

Note: Total can vary due to rounding.

Relating the derived estimates to the potential employment effect of each key determinant reveals that over three-quarters of the land acquired has previously been used for agriculture - 44 per cent for large-scale agriculture and another 34 per cent for smallholder agriculture. Meanwhile, 13 per cent of the land targeted was formerly used for forestry; 5 per cent, by pastoralists; and 4 per cent, for conservation. This global overview on former land use suggests that investors do not primarily target "idle" land. Instead, targeted land has usually been used for agriculture before suggesting that crowding out of former employment can be expected. ${ }^{20}$ Looking at the crop type, we find a clear majority of the area used to cultivate capital-intensive crops (75 per cent). This suggests a rather low employment creation potential for most LSAls as capital-intensive crops indicate a highly mechanized production with low labour inputs.

\footnotetext{
20 This also confirms the findings of Messerli et al. (2014): Based on detailed insights into the geographical contexts of land acquisitions, they question the often postulated idea that targeted land is "idle" or "marginal".
} 
In total, LSAls only implement contract-farming schemes on 2 out of every 10 hectares. This is more often the case for capital-intensive crops (17 per cent) compared to labour intensive crops (3 per cent).

We now look into the different scenarios of the transition matrix. For brownfield investments, i.e., land formerly used by large-scale farms ( $1 \mathrm{a}-1 \mathrm{~d}, 44$ per cent), we do not expect a crowding out of former employment. The share of capital-intensive crops (40 per cent, with and without contract farming) is eight times higher than the share of labour-intensive crops (5 per cent). In contrast to other former uses, contract-farming schemes are relatively common and applied on almost one-third of the area formerly used for large-scale agriculture (adding up the percentages of labour intensive and capital intensive crops, see explanation on within group comparisons ${ }^{21}$ ), especially for capital-intensive crops. Given that crowding out of former employment is considered limited, positive employment effects might occur in this scenario even in the dominating case with capital-intensive crops, especially if contract farming schemes are applied.

Over one-third of the land area has previously been used by smallholder farmers $(2 a-2 d)$, implying a potential crowding out of this former employment. This crowding out is only partially mitigated through the cultivation of labour-intensive crops (41 per cent) or through contract-farming schemes (15 per cent). We hence expect that potential employment losses are rather high in the majority of cases where land formerly used by smallholders is targeted. This specific scenario will be looked at in greater detail in section 3.5.3.

On former pastoralist land ( $3 a-3 d, 5$ per cent) it is likely that pastoralists will be crowded out once the land is transferred to a large-scale farmer. According to our findings, capital-intensive crops dominate (66 per cent) - which impairs the (new) employment generation - and there is almost no evidence of contract farming (4 per cent). Therefore, we expect the majority of deals on former pastoralist land to result in employment losses.

We find capital-intensive crops on more than half of the land (57 per cent) formerly used for forestry (4a-4d, 13 per cent). Moreover, only a small share (12 per cent) of former forestry land is farmed under contract-farming schemes. However, considering the generally low

${ }^{21}$ Sample calculation for within group comparison: $\frac{C F_{\text {labour }}+C F_{\text {capital }}}{\text { Total }_{\text {former }} \text { use }}=\frac{2 \%+12 \%}{44 \%}=31.8 \%$ 
labour requirements of the former forestry land, on those areas where labour-intensive crops are cultivated (43 per cent) and where contract farming is applied, we expect rather positive employment creation potential.

The same holds for former conservation land (5a-5d, 4 per cent), which is typically characterized by a rather low labour intensity and does hence not imply a large crowding out of former employment. The predominant cultivation of capital-intensive crops without contract farming indicates very limited employment creation, which might however be positive if there is indeed no crowding out of former employment.

\section{(ii) Regional perspective}

In order to provide a more realistic picture, regional differences have to be taken into account.

Figure 3.3 shows that the three key determinants differ across regions.

Figure 3.3. Regional perspective according to the key determinants

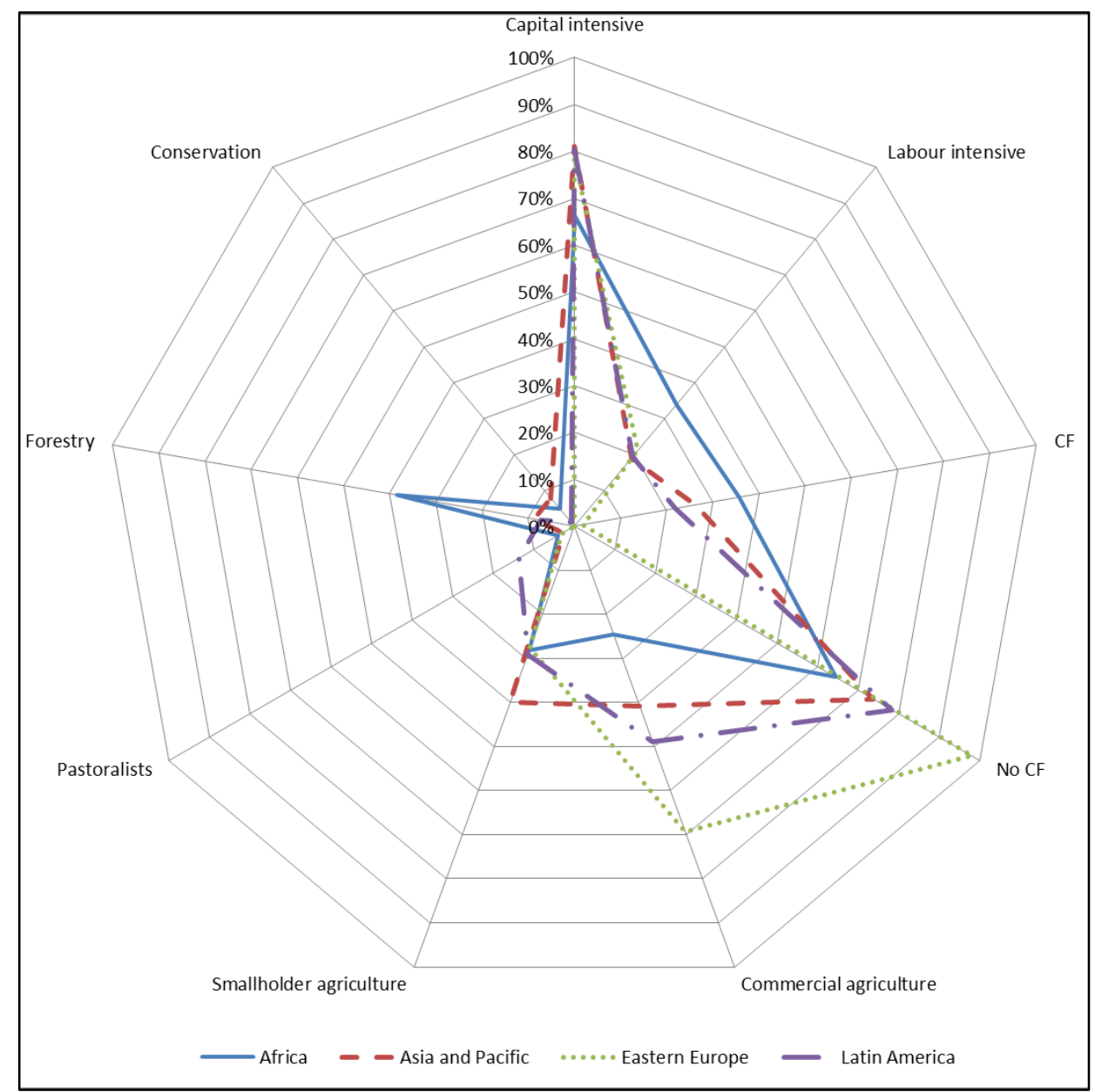

Source: author's calculation based on the Land Matrix Global Observatory (2016).

Note: $\mathrm{CF}=$ Contract farming. This figure also includes deals which lack the information of the former use but do have information on the crop and/or the production mode. 
On the African continent, half of the LSAIs are set up on agricultural land that had been primarily used by smallholders (28 per cent) and we also find the largest share of former forestry land (39 per cent) compared to other regions. Former pastoralist land and conservation areas only constitute 4 and 5 per cent, respectively. LSAIs in Africa have a clear preference for capital-intensive crops (66 per cent); however, contract-farming schemes (36 per cent) are also often applied compared to other regions. The considerable share of labourintensive crops (33 per cent) in combination with the frequent occurrence of contract farming (36 per cent) has the potential to - at least partly - mitigate the crowding out of smallholders and pastoralists in Africa.

The Asia and Pacific region has the highest share of investments on former smallholder land (40 per cent) and hence entails the greatest risk of crowding out. A similar share of the acquired area was formerly used for large-scale agriculture. Less labour-intensive forestry and conservation activities were each carried out on less than 10 per cent of the area. Pastoralists are less common in the region, accounting for only 3 per cent of the land. Similar to Africa, though more pronounced, investors in the Asia and Pacific region concentrate on capitalintensive crops (81 per cent). The high level of crowding out and the low level of labourintensive crops point to negative net employment creation in the region; although the considerable share of contract farming ( 26 per cent) might partly mitigate this.

Two thirds of LSAls in Eastern Europe target former largescale farms, followed by former smallholder land (28 per cent). Similar to patterns in Africa and the Asia and Pacific region, capital-intensive crops (79 per cent) are favoured over labour-intensive crops (21 per cent). Contract-farming schemes are irrelevant, accounting for only 2 per cent of the acquired area. Although most of the investments target large-scale farms, the choice of crops and production mode make mitigation of the considerably high crowding out of smallholders unlikely.

As in Eastern Europe, albeit less pronounced, most investors in Latin America target existing large-scale farms (49 per cent). Smallholder land accounts for 29 per cent of LSAls in the region; pastoralists, 14 per cent (the largest share across all regions); forestry, 7 per cent; and conservation areas, 1 per cent. The crowding out of smallholders and pastoralists is further accelerated by the prevailing cultivation of capital-intensive crops ( 81 per cent). Contractfarming schemes, which are in place on about one out of every five hectares, could cushion, 
without eliminating, the negative effects. Thus, overall net employment is expected to be negative.

This regional analysis shows that crowding out of former smallholder farmers is a serious problem across all regions, particularly in the Asia and Pacific region, where as the crowding out of pastoralists is most marked in Latin America. The creation of new employment and therewith the mitigation of crowding out through cultivating labour-intensive crops are, generally speaking, rather low but slightly higher in Africa. Contract farming might be able to mitigate crowding out to some degree - especially in Africa and to a lesser extent in Latin America and the Asia and Pacific region but not in Eastern Europe.

Given the preceding empirics of the three determinants in the different world regions, we see very little scope for a positive direct employment effect across all regions; rather, we expect high crowding out of existing jobs and relatively few new jobs to emerge.

\subsubsection{Estimation of labour creation potential through LSAIs}

Finally, we assess the net employment creation potential for those countries where Land Matrix and FAO data overlap. We provide estimates for both smallholder and large-scale farmers for each of the five African countries by multiplying the acquired area with the previously derived labour intensities (crop-specific in the case of large-scale agriculture and country-specific in the case of smallholder agriculture). This estimate is based on the size of the acquired area to show the number of jobs potentially created for each recorded LSAl if the entire area was cultivated. The difference between the number of jobs created by large-scale farmers and the number of jobs formerly required by smallholders is the potential net employment effect. We then relate this effect to the total number of people employed in agriculture in the respective country. These estimates are meant to give an idea about the dimensions of potential employment creation but entail important uncertainties, which we discuss in detail in section 3.6.2. To derive the respective net employment effect, we contrast the gross employment of large-scale holdings with the former form of employment, only looking at land formerly used for smallholder agriculture (i.e., scenarios $2 a-2 d$ of the transition matrix; see Table 3.1).

The net employment effect $E E_{n e t}$ is defined as the difference between the number of jobs created on a newly established large-scale farm and the number of jobs derived from the 
former land-use type (here, smallholder agriculture) expressed as a percentage of the former use:

$$
E E_{\text {net }}=\frac{J o b s_{\text {commercial }}-\text { Jobs }_{\text {former use }}}{\text { Jobs } s_{\text {former use }}}
$$

Table 3.3 shows the estimated net employment effect with respect to the three key determinants in the transition matrix, focusing on land formerly used by smallholders. To put the total value in specific national contexts, we further report the employment effect as a percentage of overall employment in agriculture in the respective country. 
Table 3.3. Employment creation through LSAls for selected countries (scenarios 2a-2d)

\begin{tabular}{|c|c|c|c|c|c|c|c|}
\hline & & \multicolumn{2}{|c|}{ Labor intensive } & \multicolumn{2}{|c|}{ Capital intensive } & \multirow[b]{2}{*}{ Total } & \multirow[b]{2}{*}{$\begin{array}{c}\text { As \% of employment } \\
\text { in agriculture }\end{array}$} \\
\hline Country(a) & & no $\mathrm{CF}$ & $\mathrm{CF}$ & no $\mathrm{CF}$ & $\mathrm{CF}$ & & \\
\hline \multirow{3}{*}{$\begin{array}{c}\text { Ethiopia } \\
(L I=1.24 ; n=43)\end{array}$} & $\begin{array}{l}\text { Gross employment } \\
\text { creation through new } \\
\text { large-scale farm }\end{array}$ & 106,775 & 529 & 31,445 & 9,329 & 148,078 & $0.48 \%$ \\
\hline & $\begin{array}{l}\text { Crowding out of former } \\
\text { smallholders on acquired } \\
\text { area }\end{array}$ & 137,000 & 458 & 149,034 & 29,760 & 316,252 & $1.03 \%$ \\
\hline & Net employment effect & $-22 \%$ & $16 \%$ & $-79 \%$ & $-69 \%$ & $-53 \%$ & $-0.55 \%$ \\
\hline \multirow{3}{*}{$\begin{array}{c}\text { Kenya } \\
(\mathrm{LI}=3.77 ; \mathrm{n}=6)\end{array}$} & $\begin{array}{l}\text { Gross employment } \\
\text { creation through new } \\
\text { large-scale farm }\end{array}$ & 76,507 & 7,179 & $\mathrm{n} / \mathrm{a}$ & 687 & 84,373 & $0.39 \%$ \\
\hline & $\begin{array}{l}\text { Crowding out of former } \\
\text { smallholders on acquired } \\
\text { area }\end{array}$ & 301,600 & 16,965 & $\mathrm{n} / \mathrm{a}$ & 10,682 & 329,247 & $1.53 \%$ \\
\hline & Net employment effect & $-75 \%$ & $-58 \%$ & $n / a$ & $-94 \%$ & $-74 \%$ & $-1.14 \%$ \\
\hline $\begin{array}{c}\text { Nigeria } \\
(L I=1.43 ; n=32)\end{array}$ & $\begin{array}{l}\text { Gross employment } \\
\text { creation through new } \\
\text { large-scale farm }\end{array}$ & 23,450 & 28,272 & 9,870 & 113,449 & 175,042 & $1.18 \%$ \\
\hline
\end{tabular}




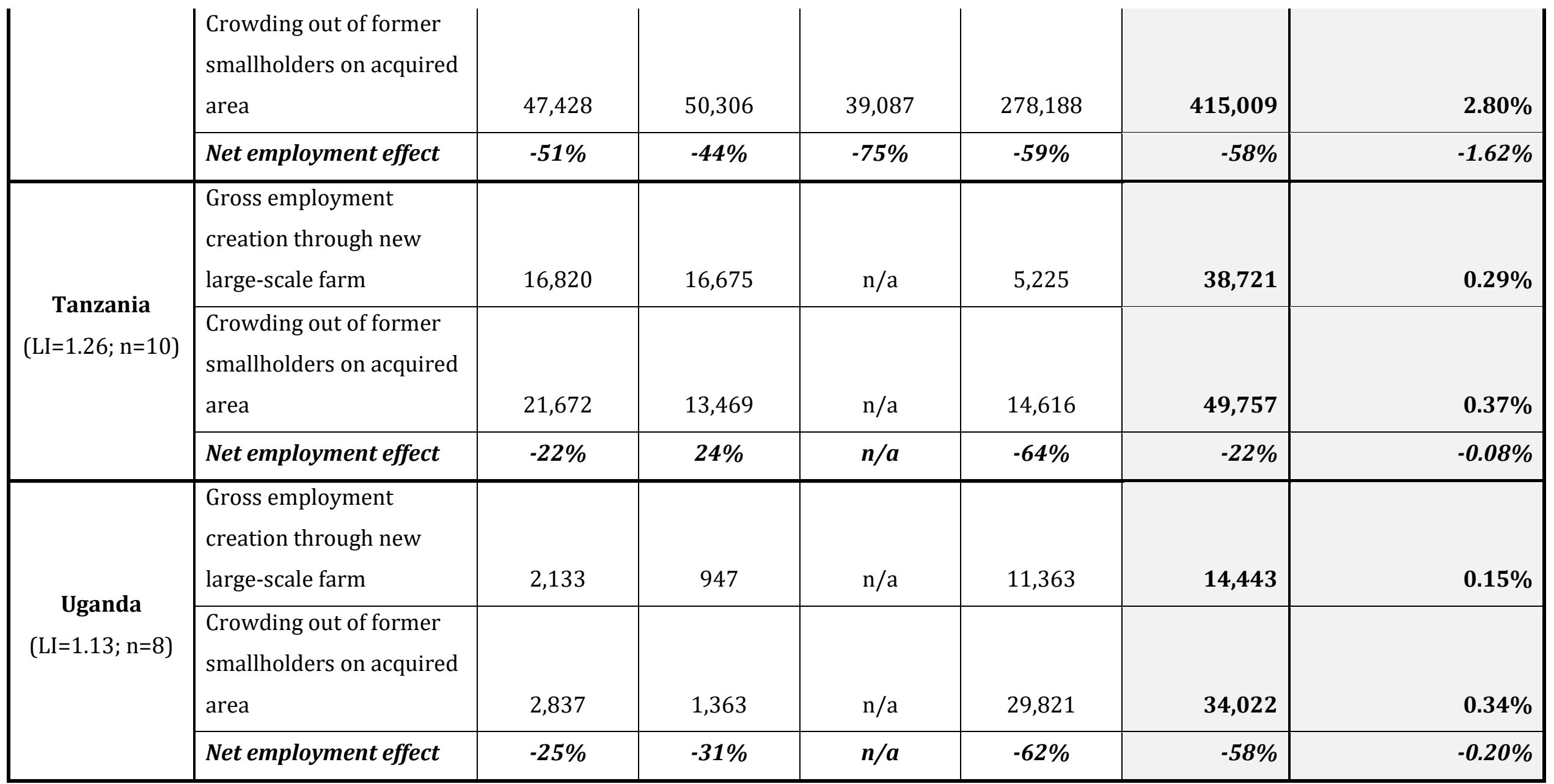

Source: author's calculation based on the Land Matrix Global Observatory (2016) and ILO (2016).

Notes: (a) Labor intensities (LI) of smallholder farmers and number of LSAIs (n) per country in parenthesis.

(b) The figures on employment in agriculture correspond to the latest available year per country. 
Across all countries we encounter a strong negative net employment effect if a large-scale farm is established on land formerly used for smallholder agriculture, which is due to high crowding out. The effect ranges between 22 per cent (Tanzania) and 74 per cent (Kenya). As expected, farms cultivating capital-intensive crops suffer greater job losses than do farms cultivating labour-intensive crops. Looking into the net employment effects of labourintensive crops, the mitigation potential of contract farming is clearly evident. In fact, we even identify net employment creation of 16 to 24 per cent for Tanzania and Ethiopia, respectively. We also find lower employment losses for farms cultivating capital-intensive crops if contract farming is used.

The last column of Table 3.3 gives an indication on the magnitude of the net employment effect in the respective country. The employment losses expressed as a percentage of overall agricultural employment through LSAls are relatively small and range between 0.1 per cent (Tanzania) and 1.6 per cent (Nigeria). This shows that on a global and national scale, the crowding out of smallholder farmers and the accompanying net employment losses are rather small. However, they can be substantial in the immediate proximity of the investment, especially if there are no other employment opportunities available in the respective local labour markets.

\subsection{Discussion}

Large-scale agricultural investments cause a significant loss of employment on the local level considering the direct employment creation only. This is mainly due to the crowding out of former employment, which can only be partially mitigated. In this section we also elaborate on the indirect employment creation of LSAls and discuss the validity and limitations of our estimates.

\subsubsection{Indirect employment creation}

Establishing a large-scale farm does not only have direct employment effects, as empirically assessed in the preceding sections, it also has indirect effects that may result in employment creation not directly linked to farming. One such effect is related to the inflow of capital, which makes new technologies available (e.g., inputs such as seeds, fertilizer and pesticides, and machinery). Improved technologies typically increase labour productivity; this is particularly the case for agricultural workers on large-scale farms. Depending on the potential of the spillover effects, advanced technologies might also reach smallholder farmers, resulting in 
productivity gains for them, too. Such productivity gains do three things: First, they increase the availability of food if food is produced, which in turn reduces the market price. The reduction of food prices relative to farm workers' incomes frees up shares of households' budgets, which can then be used to purchase non-food goods and services. The resulting increase in demand for industrial goods and services fosters the growth of these respective sectors (Dorward 2013). Second, they release labour from agriculture to other sectors (Dorward 2013; C. P. Timmer 1988). In short, capital inflow into agriculture is expected to change the sectoral composition from employment in agriculture toward employment in industry and services. Third, they result in higher total labour incomes (FAO 2016; Satchi and Temple 2009).

However, empirical studies show that technological changes are not labour saving per se and hence do not always trigger a sectoral shift. For example, Bustos et al. (2016) study two technological changes in Brazil: the introduction of genetically engineered soy and the introduction of a second harvesting season. The former is strongly labour-saving and fosters industrialization processes and a shift of employment toward the industry and service sectors (as expected). In contrast, a second harvesting season is land-augmenting and can hinder industrialization. In this case, technological change did not lead to a shift of employment from agriculture toward other sectors. Kouser, Abedullah, and Qaim (2015) examined the technological change of introducing insect-resistant bacillus thuringiensis (Bt) cotton in Pakistan. They found that rather than reducing agricultural labour demand due to less spraying of chemical pesticides, the introduction of Bt cotton resulted in a 55 per cent increase in the demand for hired labour mainly due to the need to harvest larger yields.

Another effect is related to the potential of large-scale farms to build productive relationships with other industrial branches over time (Larson and Shaw 2001). A common distinction of these relationships is backward and forward linkages. In the agricultural context backward linkages describe the interconnection of a large-scale farm with the industrial branch supplying it with inputs (e.g., seeds, fertilizer, and pesticides). The increased demand for such inputs - induced by large-scale farms - might trigger the expansion of the upstream industry and present new employment opportunities. Forward linkages, on the other hand, comprise all downstream industries processing the farms' output - for instance, the processing, packing, and shipping industries. In this case the increased output of large-scale farmers might lead to 
an expansion of the processing industry - if processing is done in the target country - and hence more jobs in the industrial sector. The fact that labour is released from the agricultural sector due to productivity gains is conducive to establishing these linkages.

For backward linkages, there is hardly any causal evidence available in the literature. In cases where a newly established farm procures inputs locally, we expect jobs to be created through backward linkages. However, with a highly competitive and increasingly concentrated supply side for the main agricultural inputs and technologies (for instance, seeds, fertilizer and machinery) dominated by a few global players, the establishment of domestic input supply industries for agriculture is unlikely. Jobs would hence mainly be created through the (usually locally rooted) service sector - for instance, trade intermediaries and logistic and shipping companies which facilitate access to agricultural inputs.

Forward linkages bear potential for the development of the local industry. The growing output triggered by higher productivity requires adequate processing facilities. In one out of three deals according to Land Matrix data, the produced commodities are exported unprocessed. For this one-third of deals hardly any employment creation is expected through forward linkages, whereas the opposite might be the case for the remaining two-thirds of deals. A key determinant for unlocking the potential of forward linkages lies in the capital intensity of the processing industry. This is nicely illustrated by the examples of Brazil and Thailand. In Brazil large-scale mechanized farming substituted capital for labour, resulting in low employment creation and growing inequalities. In Thailand agricultural commercialization took a different turn as off-farm enterprises did not have access to subsidized credit and, therefore, could not afford labour-displacing technologies. This consequently generated massive employment, especially in the processing industry (World Bank 2009).

In sum, from a theoretical stance we would clearly expect a change from a smallholderdominated labour market to a labour market dominated by industry and service. Empirically, the picture is less clear as the literature also reports cases in which technological changes have increased the demand for agricultural labour. Employment creation in the industrial sector through backward and forward linkages depends on the specific country and sector contexts. 


\subsubsection{Validity and limitations of the estimates}

The validity of our results heavily hinges on the quality of the Land Matrix data. While Land Matrix data were criticized when first published (see, for instance, Bräutigam and Zhang 2013; Edelman 2013; Oya 2013), the data are now widely used by researchers (see, for instance, Arezki, Deininger, and Selod 2015; Messerli et al. 2014; Osabuohien 2014). The Land Matrix Initiative is transparent about potential biases in the data and does not claim to provide a realistic representation of reality (The Land Matrix Global Observatory 2016). In fact, due to the opaqueness surrounding many LSAIs, the Land Matrix data are likely to underestimate the phenomenon. Accordingly, the acquired areas as reported in the Land Matrix can be considered a conservative estimate of the overall phenomenon. Despite certain biases, we consider Land Matrix data to be the most accurate information available and well suited to highlighting overall global trends.

The conceptual framework incorporates three key determinants, which require some assumptions and simplifications in their empirical application. First, input for the labour intensities would ideally be calculated on an individual level or, more precisely, on the basis of man-hours per hectare and per crop. Because such disaggregated figures are not available, we use the total employment numbers of each holding as reported in the Land Matrix. Although the Land Matrix differentiates the type of employment, only one out of five cases explicitly state the number of seasonal workers. For the remaining cases, we assume that seasonal workers are included in the total employment figures. A conversion factor could be used to translate these seasonal-employment figures into full-time equivalents in order to account for the fact that seasonal labourers only work part of the year. However, we consider such a factor to be too arbitrary to account for the variation in working hours of seasonal workers and instead treat seasonal labour as full-time equivalents. In contrast, FAO's Smallholder Farmers' Dataportrait accounts for the heterogeneity to a certain extent by calculating labour input as the total number of person-days divided by the number of workdays in a year. However, also person-days per workdays can be only considered as a second best solution to address the labour input compared to man-hours. More precisely, it lacks the detail to distinguish between part-time and full-time during a workday and therefore fails to fully capture time-related underemployment; a reality often found on smallholder farms owned by families which would overstate the actual labour input. As a result of these different approaches, the labour input and therewith the estimated labour intensities derived 
from Land Matrix data could be overestimated. Although both overestimations are likely to cancel each other out, the gross employment generation estimated in Table 3.3 should be considered an upper bound estimate.

Second, we assume that the whole area acquired by an investor was to be cultivated. This is meant to give an idea of how many jobs could potentially be created on the land acquired. In reality, investors often lack the capacity to cultivate all the land acquired, and, usually, not all of the land acquired is suitable for production; hence, only a fraction of the land will be cultivated. This also adds to the overestimation of gross employment generation through large-scale farms in Table 3.3. However, we equally pretend the whole area was formerly under production and thus overestimate the crowding out of former employment. This is particularly important for land formerly used by smallholder farmers. Consequently, the estimate for employment losses of former smallholders is also an upper-bound estimate.

Third, we cannot account for the quality of newly created employment. Employment quality plays an important role as there might be a huge difference between a self-employed smallholder and a wage employee in terms of decency. One important aspect in this context is that self-employed smallholders usually operate in the informal economy and are hence excluded from social security systems and lack adequate representation. On the contrary, formal wage employees ideally have access to these systems and are also able to express their concerns through workers' organizations. However, the transformation from smallholder farming to wage employment can heavily impact the social relations in communities and within households. Ethnographic research on Vietnam (Dao 2016) and Indonesia (Julia and White 2012) shows that employment on plantations is often perceived as a downgrade. Households that have lost agricultural self-employment have the possibility to compensate for their lost income by switching into wage employment. Although fewer employment opportunities are expected to emerge, overall compensation is still feasible since many lowpay jobs are replaced by fewer better paid jobs.

Fourth, in terms of multi-cropping patterns and multiple former land uses, we assume that the total area of a holding - and hence the labour input - is equally distributed across each former land-use type and crop. As we do not know the real share of an area attributed to various former land uses or crops, this is a necessary assumption even though it can potentially introduce biases. For instance, cases reporting two different crops are difficult to determine. 
It could be different plots of land used for each crop or it could be multi-cropping - that is, both crops sharing one plot through intercropping or succession planting. In the first case, the area could be equally or unequally distributed across the crops, whereas in the case of multicropping the same plot of land is used for both crops, meaning that an equal distribution across the two crops is very likely. In both cases labour intensity is increased compared to single-cropping, either through higher yields or through an additional growing cycle in one season. However, when comparing the labour intensities of single-entry cases with multiple entry-cases in our data, there are no major differences.

Fifth, in terms of production models there is obviously more diversity than just contract farming and non-contract farming. Moreover, even contract-farming arrangements exist in different forms and context conditions. The effects of contract farming on participating farmers are diverse and a source of controversial debate in the literature (Bijman 2008; Minot 2007). Different contractual arrangements, diverse context conditions, and an unequal power balance between the firm and farmers may explain the variance in outcomes. We neglect these variances in our analysis and only consider the sheer prevalence of such agreements. However, we do use - whenever available - labour intensities for contract-farming arrangements and thereby attempt to capture the importance of different production models with data based on real contract-farming schemes.

Sixth, our analysis of net employment effects is limited to land formerly used by smallholders as we lack information on the crowding out of former employment for other types of land use. On the one hand, the acquisition of former smallholder land is highly relevant as it concerns more than a third of the acquired land, which is of major concern to opponents of LSAls. Hence, there certainly is a rationale to focus on former smallholder land. On the other hand, we have to bear in mind that we expect the largest degree of crowding out to occur on these areas and smaller degrees to happen on land with other uses. Thus, our net employment estimates cannot be transferred to other former land-use types. The effects are expected to be more positive in the other scenarios due to less destruction of former employment.

Last, we deliberately choose to focus on employment effects and thus neglect other effects associated with establishing a large-scale farm. We do so to understand the very complex effects on the labour markets. At the same time, we are aware of the profound and diverse effects of large-scale farms on the economic and social spheres of local communities as well 
as on the environment (for instance, see Oberlack, Tejada, Messerli, Rist, and Giger (2016) for a meta-analysis of case studies on livelihood outcomes of large-scale land acquisitions).

With all of these caveats in mind, the above-described empirical exercise provides an empirical assessment of the potential employment effects of LSAIs. We provide a simple but powerful tool to assess the direct employment creation of investments by taking three decisive - albeit simplified - factors into account. Using Land Matrix data implies that we underestimate the overall phenomenon as the area acquired is probably much larger. However, we believe that Land Matrix data reveal accurate trends concerning these three factors. Certain assumptions (e.g., about land distribution or the complete use of the acquired land) and simplifications of complex issues (e.g., contract farming) are necessary, though they lead to an upward bias in labour intensities and demand of large-scale farmers. As a result, we tend to overestimate large-scale farms' gross employment creation that we consider to be upper bounds. Accordingly, the predicted values for net employment creation might - despite the negative values - even be too optimistic.

We therefore consider these net employment effects for land formerly used by smallholders as a conservative estimate of employment losses. However, it is important to bear in mind that this is hugely driven by the crowding out of smallholder farmers (for which we also use an upper-bound estimate) and that net employment effects are more likely to be positive for other land-use types. Although our estimates should not be taken at face value, they indicate overall trends of the direct employment effects of the different scenarios in our transition matrix.

\subsection{Conclusion}

This paper debates the employment effects of large-scale agricultural investments (LSAIs). It contributes to the debate by providing and empirically testing a conceptual framework on direct employment effects. To this end, we identified and discussed key determinants of these direct employment effects: (i) the former land-use, (ii) the crop cultivated, and (iii) the production model applied. We summarize these key determinants in a transition matrix to illustrate scenarios that could potentially occur in the course of transitioning from the former land use to large-scale farming. 
In our empirical application, we use Land Matrix data to assess which scenarios actually occur in reality and then derive implications for employment creation. The largest generation of direct net employment is expected for investments that do not entail massive crowding out of former income-generating activities and cultivate labour-intensive crops under contractfarming schemes. However, Land Matrix data show that this scenario only applies to a very small amount of the acquired area. Instead, we find that over a third of land targeted was formerly used by smallholder farmers and that contract-farming schemes are only used on 2 out of every 10 hectares. This implies that crowding out of former smallholder farmers is a serious issue. Moreover, capital-intensive crops are clearly dominating, which hints at investors focusing on highly mechanized farming with low labour demand. Accordingly, direct net employment creation for the great majority of LSAls is limited, and high hopes for massive direct employment creation through LSAls are clearly misplaced.

Crowding out of smallholder farmers is a severe problem in all regions, with some nuances. For instance, crowding out of smallholders is most pronounced in the Asia and Pacific region while pastoralists are particularly affected in Latin America. Only about 20 per cent of land is used to cultivate labour-intensive crops, which is generally low; only in Africa is this share slightly higher. Africa also reveals the highest amount of mitigation potential through contract-farming schemes.

We then derived the net employment effects for land formerly used by smallholders for selected countries. We find a massive loss of employment (ranging between 28 and 75 per cent), with the highest losses stemming from the cultivation of capital-intensive crops. However, in few cases, we identified a positive net employment effect associated with the cultivation of labour- intensive crops in combination with contract farming, suggesting that LSAls may actually be capable of creating net employment if a specific combination of key determinants is in place. Although these results hint at large losses for individual farming operations, the overall impact on the population employed in agriculture at the national level is for our sample below 1.5 per cent and hence relatively small.

To assess employment creation triggered by large-scale farms, it is essential to look into indirect effects, which typically occur in the medium- and long-term. Such effects are usually linkages to other sectors, but they also include price and wage effects on local markets. Price and wage effects foster growth of the non-agricultural sector, which can absorb the released 
labour force with a certain time lag. New employment opportunities might also emerge through backward and forward linkages. However, these indirect effects cannot be directly attributed to the setting-up of large-scale farms and are hence difficult to empirically assess. The indirect employment creation would need to be empirically addressed in order to reveal the full employment potential of LSAIs.

Another aspect that deserves further attention is the formalization of the labour market. While smallholder farming is, in most cases, informal employment, large-scale farms provide wage employment and usually pay taxes. This is linked to the quality of employment. Further research is required to assess the quality and decency of the employment opportunities created. In particular, to address the question of what extent the wage-employment opportunities created are able to compensate for the income lost by self-employed farmers.

The employment effects of LSAIs depend on the specific project. Looking at the overall picture, mechanized largescale farming creates (gross) employment but is unable to absorb all the labour released from former income-generating activities, in particular smallholder farmers. This requires targeted policy responses in order to reach an inclusive and sustainable development process. We recommend three measures. First, it is essential to support alternative employment opportunities. Such measure might include creating employment in the service and processing industries as well as providing vocational training to released labourers in order to smooth their transition into alternative employment. Key to this is supporting local industries, for instance the processing industry. In this context, a social safety net is crucial to ensure a socially responsible transition. Second, our analysis showed that some LSAls use more inclusive business models and hence increase the potential to include local communities in development processes. It is necessary to conduct further research on which business models are successful in including local communities and important that there is greater political support for such models. Third, in certain contexts, for instance in areas with high population densities and smallholder agriculture or pastoralism as key income generation strategies, LSAls are likely to lead to massive employment destruction with little or no scope for mitigation. In these cases, governments are well advised not to lease or sell land without having well-elaborated active labour market policies and alternative employment opportunities for crowded out land users. 


\section{Population Ageing: Alternative Measures of Dependency and Implications for the Future of Work}

Claire Harasty \& Martin Ostermeier*

This chapter appeared as:

HARASTY, C., OSTERMEIER, M. (2020), Population ageing: Alternative measures of dependency and implications for the future of work, ILO Working Paper 5 (Geneva, ILO).

\footnotetext{
*We would like to thank our colleagues Eléonore D'Achon, Sara Elder and Aurelio Parisotto for their careful review of this working paper and Dorothea Schmidt-Klau for her insightful input at various stages of its development. We are grateful to the participants of the Sixth Regulating for Decent Work Conference who provided valuable feedback and additional insights. We are most grateful to Deborah Greenfield for her final comments and for her full support in finalizing this paper. The final product would not have seen the light of day without the excellent technical assistance provided by Carole Turcato and the thorough editing provided by Laurie Munslow.
} 


\section{Abstract}

The world's population is getting older, a phenomenon that has important implications for the future of work. Persons aged 55 years and over are expected to outnumber all children aged 0 to 14 years by 2035 and the entire child and youth population aged 0 to 24 years by 2080 . As a direct consequence of population ageing, the number of older workers aged 55 to 64 years is increasing and is set to equal one quarter of the global labour force by 2030 .

This paper examines the projected labour force participation trends of older workers to 2030 and discusses the future of economic dependency for developing, emerging and developed countries. It introduces five alternative measures of economic dependency to account for the fact that persons of working age may not be working or may be facing employment conditions that compromise their capacity to support themselves and others. Such conditions include scenarios where workers are unable to work as many hours as they would like, or where they are in situations of vulnerable employment or working poverty. These alternative measures therefore not only take into account demographic and quantitative labour market characteristics, such as age structure, activity status and unemployment, but also consider qualitative dimensions such as underemployment, labour income and vulnerability.

Using a very rich ILO data set that provides a consistent series of labour market data for all countries with forecasts to 2024 and beyond, the paper provides estimates for these new dependency measures and makes a number of policy recommendations to address the impact of ageing on decent work. 


\subsection{Introduction}

The world's population is getting older, a phenomenon that has important implications for the future of work. In 2014, persons aged 55 years and over outnumbered young persons aged 15 to 24 years, and they are expected to outnumber all children aged 0 to 14 years by 2035 and the entire child and youth population aged 0 to 24 years by 2080 (UNDESA 2019b). In this context, it is important to analyse the ways in which future demographic shifts will impact the labour markets.

First, smaller cohorts of young persons and larger groups of older persons will call for adjustments in the labour market, with consequences for the labour force participation of older women and men. With greater numbers of older workers in the labour force, workplaces will need to adapt in terms of occupational safety and health, working hours and work organization in order to enable the continuing participation of these workers in the labour market. Active ageing policies, including targeted retraining, reskilling and upskilling, will become necessary in order to retain the employability of older workers.

Second, there will be an increased need for workers, services and industries to care for the elderly population. Large numbers of new jobs and enterprises will be created in sectors such as healthcare and long-term care (ILO 2018a), pharmaceuticals and housing adapted to the needs of older citizens. These new employment opportunities will require the acquisition of new skills, and these types of careers will need to be promoted.

Third, the public debate places considerable attention on the impact that these demographic shifts will have on dependency rates, that is, the ratio of persons who are not of working age ( 0 to 14 years and 65 years and over) to that of the working-age population (15 to 64 years). These ratios are expected to rise in countries with ageing societies. As a result, a growing number of non-working-age persons will increasingly depend upon a shrinking number of persons of working age. This could slow down economic growth, generate lower tax revenues and threaten the financial sustainability of social protection systems. However, it is becoming increasingly apparent that the standard age-based dependency measure does not adequately capture the situation. 
This paper is structured as follows: the first chapter takes a closer look at global population ageing and the labour force participation trends of older workers, ${ }^{22}$ based on the projections of the International Labour Organization (ILO) and the United Nations Department of Economic and Social Affairs (UNDESA). In the second chapter, alternative measurements of dependency are proposed that take into account the fact that many working-age persons either do not participate in the labour market or face employment conditions that compromise their economic independence. Such conditions include situations where workers are unable to support any dependants or do not contribute through taxes and wealth creation to the financing of education, healthcare and social protection. These alternative measures are disaggregated by sex and based on age-specific indicators of labour market activity and unemployment, as well as on qualitative components of employment, such as income, working hours and vulnerability. In a demographic context of an ageing labour force, these new measures indicate possible policy directions for avoiding unsustainable dependency rates, which would undermine economic and social development. The report concludes with a summary of our findings and specific policy options.

\subsection{Population ageing and labour force trends among older age cohorts}

As a population ages, so does the workforce. Globally, the share of older workers aged 55 to 64 years in the total labour force has been increasing since 2000 and will continue to rise significantly until 2030. This trend will be particularly marked in emerging and developed countries, where it will reach 13.2 per cent and 17.7 per cent of the workforce respectively, compared to 7.9 per cent in developing countries (ILO 2019f). In total, between 2000 and 2030 , the share of older workers in the labour force will have increased by 2.5 per cent in developing nations, by 76 per cent in developed economies and by 80 per cent in emerging countries.

We use the ILO 2019 Labour Force Estimates and Projections (LFEP) database to analyse ageing trends globally and by broad income groups ${ }^{23}$ and to assess their impact on labour force participation rates for women and men.

\footnotetext{
22 In this paper, older workers are defined as workers aged 55 years and over.

${ }^{23}$ The income groups utilized in this paper are based on the new ILO classification of countries by level of income, where the "developing countries" group corresponds to the World Bank low-income countries classification, the "emerging countries" group includes both lower- and upper-middle-income countries, and the "developed
} 


\subsubsection{The world is getting older: more than three quarters of countries will either}

be ageing or already aged by 2050

The following figures show the projected proportion of the population aged 65 years and over in the total population at country level for the years 2020 (Figure 4.1 (a)), 2030 (Figure 4.1 (b)) and 2050 (Figure 4.1 (c)). Drawing from Oizumi et al. (2006), a country is categorized as an "aged" society when the share of persons aged 65 years and over reaches 14 per cent or more of the total population, as "ageing" when it accounts for between 7 and 14 per cent, and as "not aged" when it constitutes less than 7 per cent of the total.

Figure 4.1. Global ageing status in 2020, 2030 and 2050: share of population aged 65 and over in total population

(a) Global ageing status in 2020 (share of population aged 65 and over in total population)

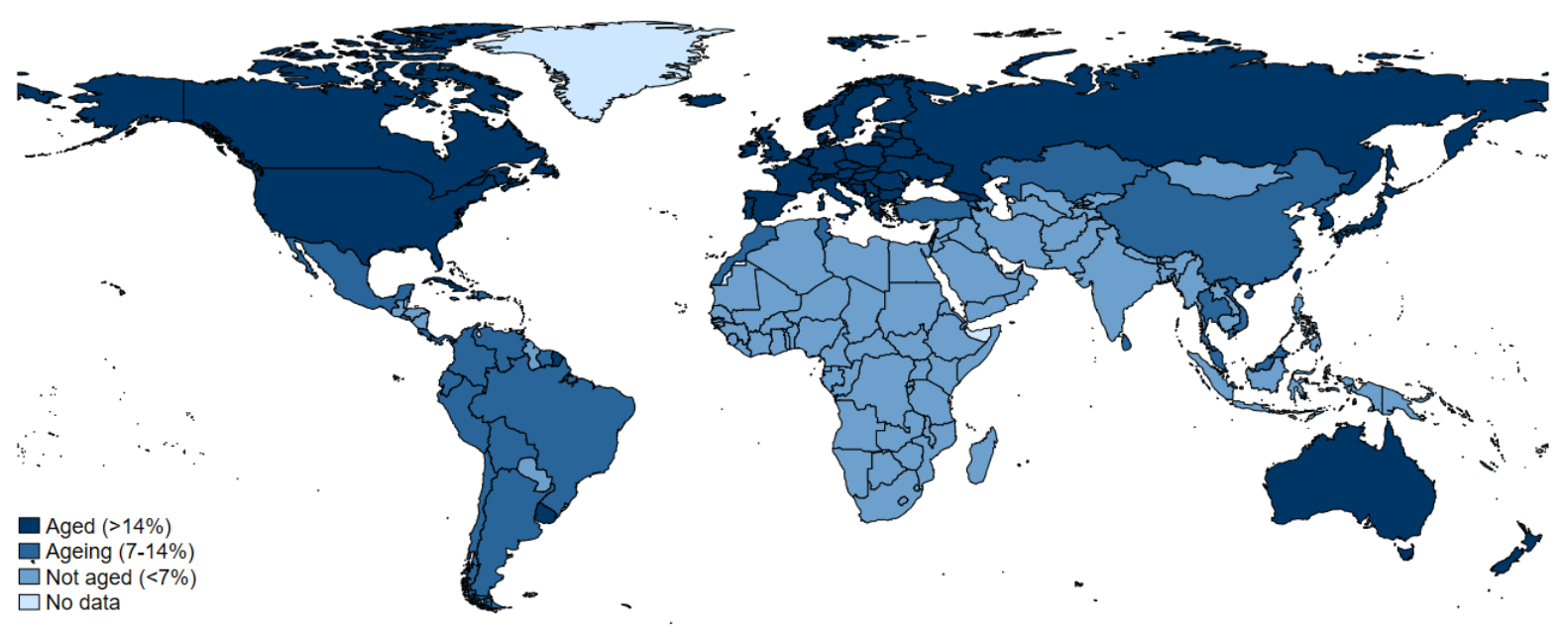

(b) Global ageing status in $\mathbf{2 0 3 0}$ (share of population aged 65 and over in total population)

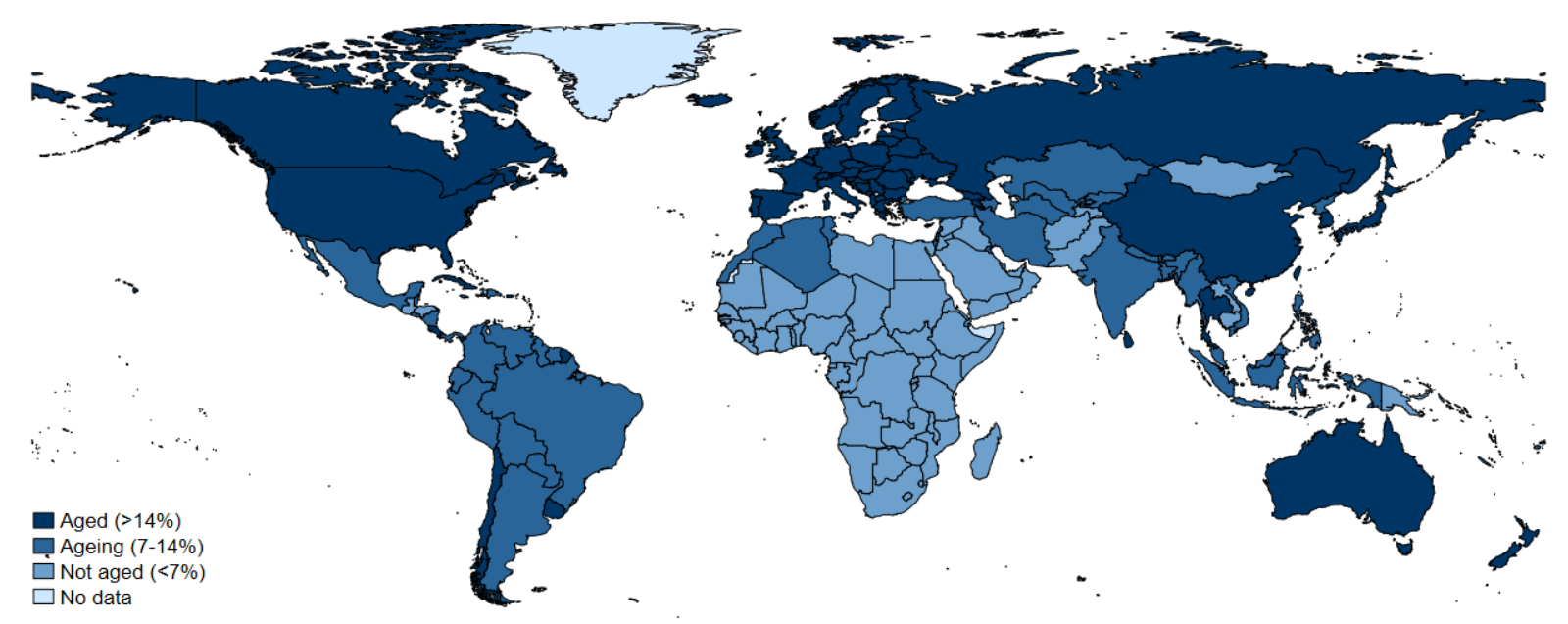

countries" group corresponds to high-income economies. See details of these income groupings in Appendix B, Table B 2. 
(c) Global ageing status in $\mathbf{2 0 5 0}$ (share of population aged 65 and over in total population)

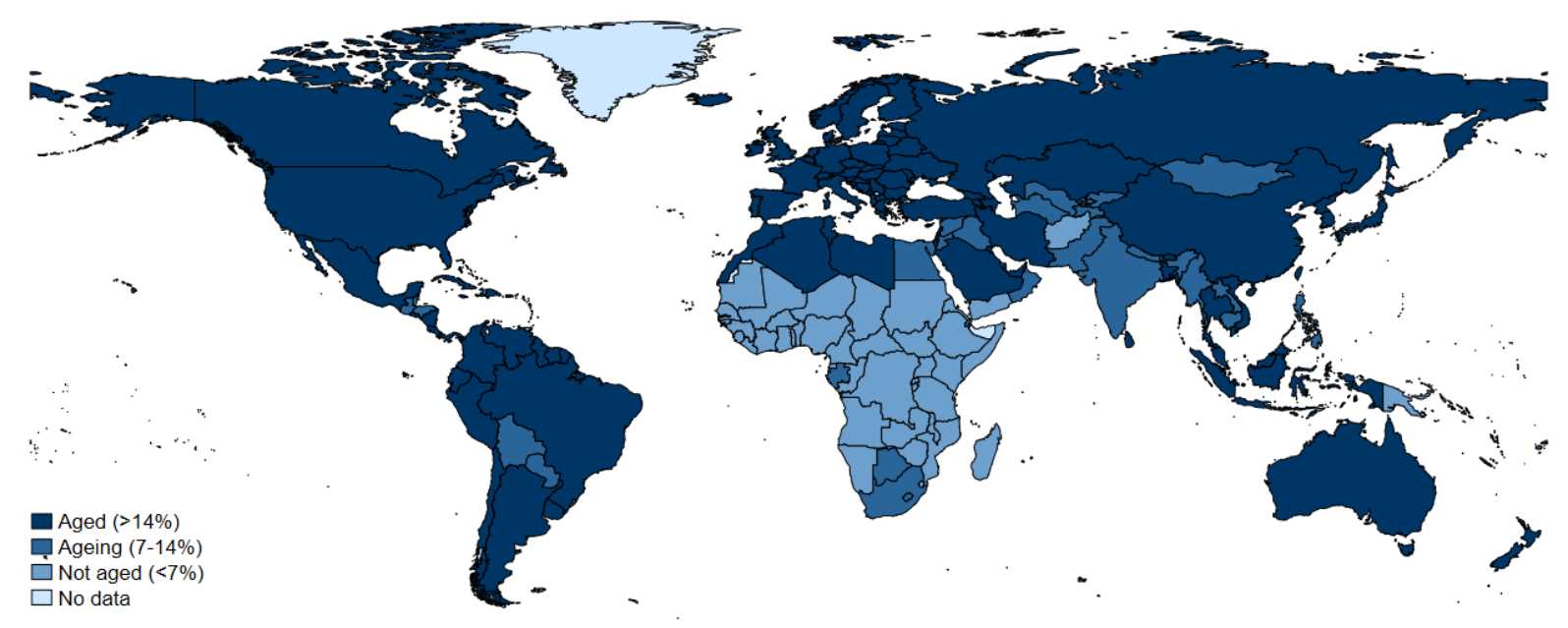

Source: calculations based on UNDESA World Population Prospects 2019.

In 2020,54 countries are classified as aged societies, most of them developed countries (72 per cent), while another 42 predominantly emerging countries (79 per cent) are deemed to be ageing. By 2030, 51 countries will be ageing and 67 will be aged; in 2050, the ageing phenomenon will have progressed further, with 36 ageing and 111 aged societies. As a result, the number of countries immediately concerned by population ageing will increase significantly from 96 in 2020 to 147 in 2050 - that is, more than three quarters of all countries and around 87 per cent of the global population. The 16 most aged countries will have very high shares of older persons, who will account for more than 30 per cent of the total population. Sub-Saharan Africa will be home to the world's most youthful populations, since more than 85 per cent of the region's countries will not have begun this demographic transition, while Europe and Central Asia will have the oldest populations, as almost 92 per cent of countries in the region will have aged (see Appendix B, Table B 1 for a detailed overview by region).

The latest UNDESA (2019b) population projections to 2050 indicate that the global population will reach 9.7 billion, with major increases in emerging and developing countries (see Figure 4.2). Overall, the numbers of women and men are about equal, although the female-male ratio is slightly smaller in emerging countries, with around 97 women per 100 men. At older ages, women outnumber men owing to their longer average life expectancy (UNDESA 2019a). However, the projected rise in life expectancy for men, which reflects improvements in 
economic and health conditions, will rebalance this situation over time, especially in developed countries.

Figure 4.2. Total population (in billions) and female/male ratio, 2000-50

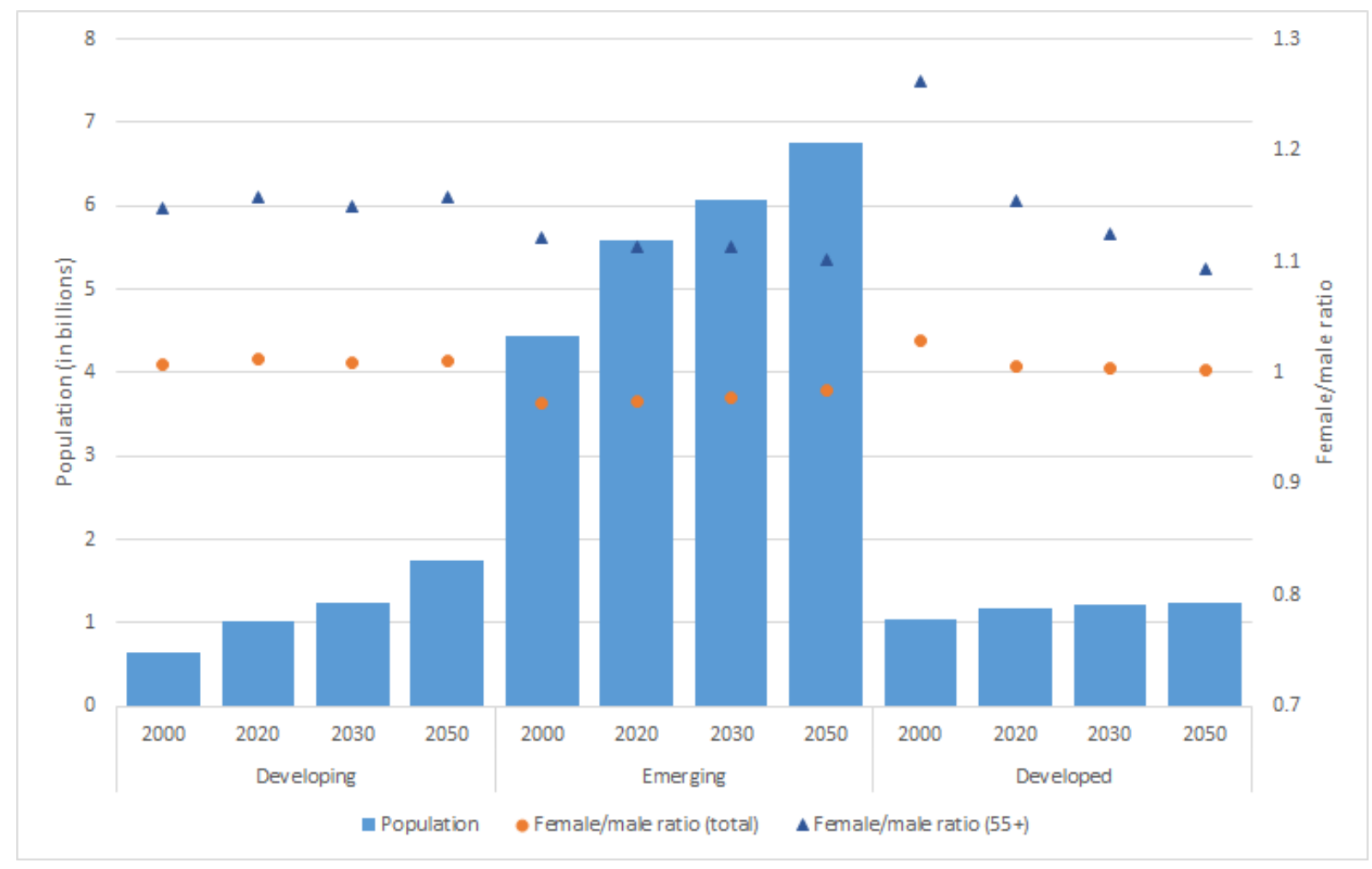

Source: calculations based on UNDESA World Population Prospects 2019.

The vast majority of persons aged 55 years and over will be located in emerging countries, where almost 1.9 billion persons will be over 55 years of age in 2050 (see Figure 4.3). However, the strongest increase in the over-55 population is expected to be seen in developing countries, where it will almost triple between 2020 and 2050 from a small base in absolute numbers. Over the same period, the over-55 age group will double in emerging countries and grow by a factor of 1.3 in developed countries. Compared to the total population, the share of the older cohort will be highest in developed economies (40 per cent), followed by emerging (28 per cent) and developing countries (14 per cent). 
Figure 4.3. Population aged 55 years and over (in millions), by sex and income group, 2000-30

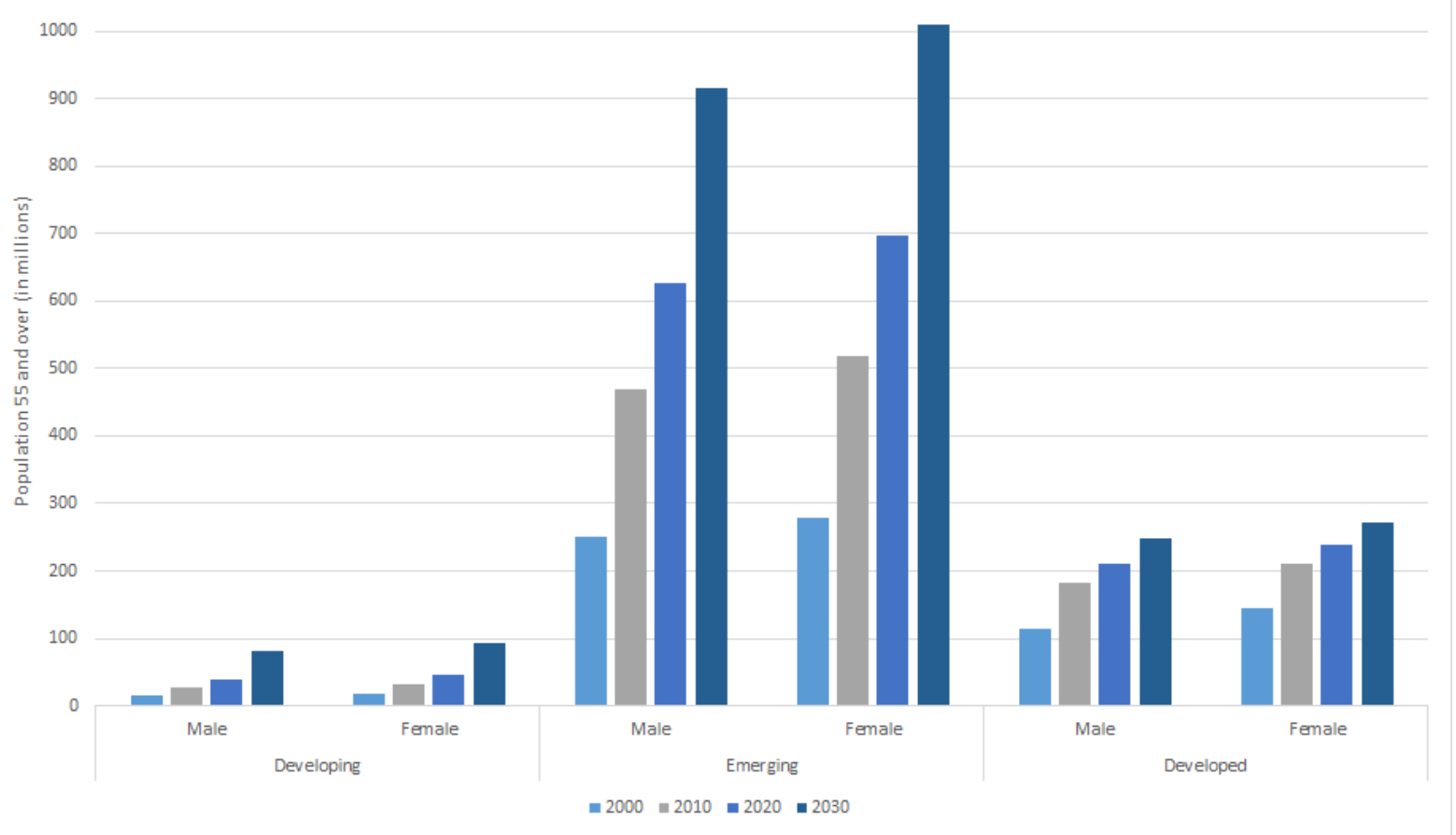

Source: calculations based on UNDESA World Population Prospects 2019.

\subsubsection{The proportion of older workers in the labour force is increasing worldwide} As a direct consequence of the population ageing process, there will be a growing number of older workers in the future labour force. It is common practice to define older workers as the share of the labour force aged 55 years and above (Samorodov 1999). Current data and projections show increasing trends in these numbers (see Figure 4.4). 
Figure 4.4. Composition of the labour force (in billions) and share of older workers, by sex and income group, 2000-30

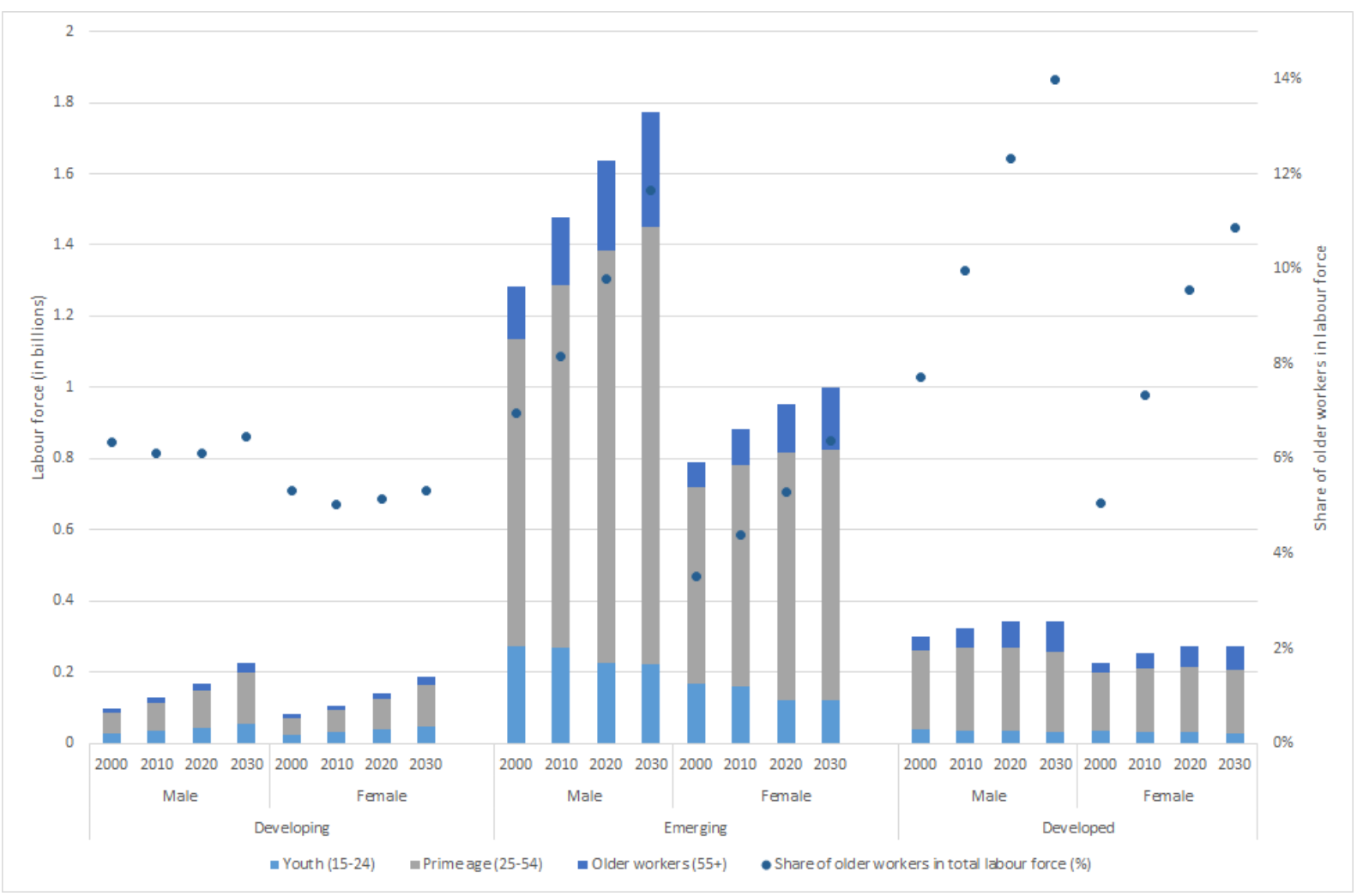

Source: calculations based on ILO LFEP database, July 2019 update.

Indeed, the labour force aged 55 years and over will grow consistently, with the highest growth rate occurring between 2020 and 2030 in developing countries (40 per cent), followed by emerging ( 28 per cent) and developed countries (14 per cent).

Emerging countries account for the highest absolute number of older workers: by 2030, some half a billion workers will be over the age of 55 years, accounting for around 18 per cent of the total labour force.

Around one quarter of all workers in developed countries will be over 55 years of age in 2030, making this the group with the largest share of older workers in the total labour force globally.

The picture is slightly different for developing countries, where both the absolute numbers and the shares of older workers remain modest but are projected to rise steadily over the coming years to reach 48.5 million, or 12 per cent of the labour force, by 2030.

Although there are no major gender differences in the expected increase in the proportion of older workers in the total labour force, there is a considerable levelling effect between women and men. Despite women making up the majority of the total over-55 age group (see Figure 
4.2), women's participation in the labour force will continue to be lower than men's. This trend holds true for developed and emerging countries alike.

\subsubsection{Trend reversal in older workers' labour force participation rates across development level}

Breaking down the labour force participation rates (LFPRs) of older persons by age group reveals some interesting patterns. An early study of the LFPRs of older workers in 151 countries concluded that "countries with high national income per capita tend to have lower participation rates for older men and women" (Clark and Anker 1990, 21). As shown in Figure 4.5, this pattern seems to be changing. While LFPRs are decreasing in developing countries, they are strongly increasing in developed countries, where they will overtake the levels seen in developing countries by 2030. In emerging countries, these rates are only falling for the 65 years and over cohort, remaining relatively stable for the other age groups.

Figure 4.5. Labour force participation rate (in \%) and gender gaps (percentage points), by income and age group, 2000-30

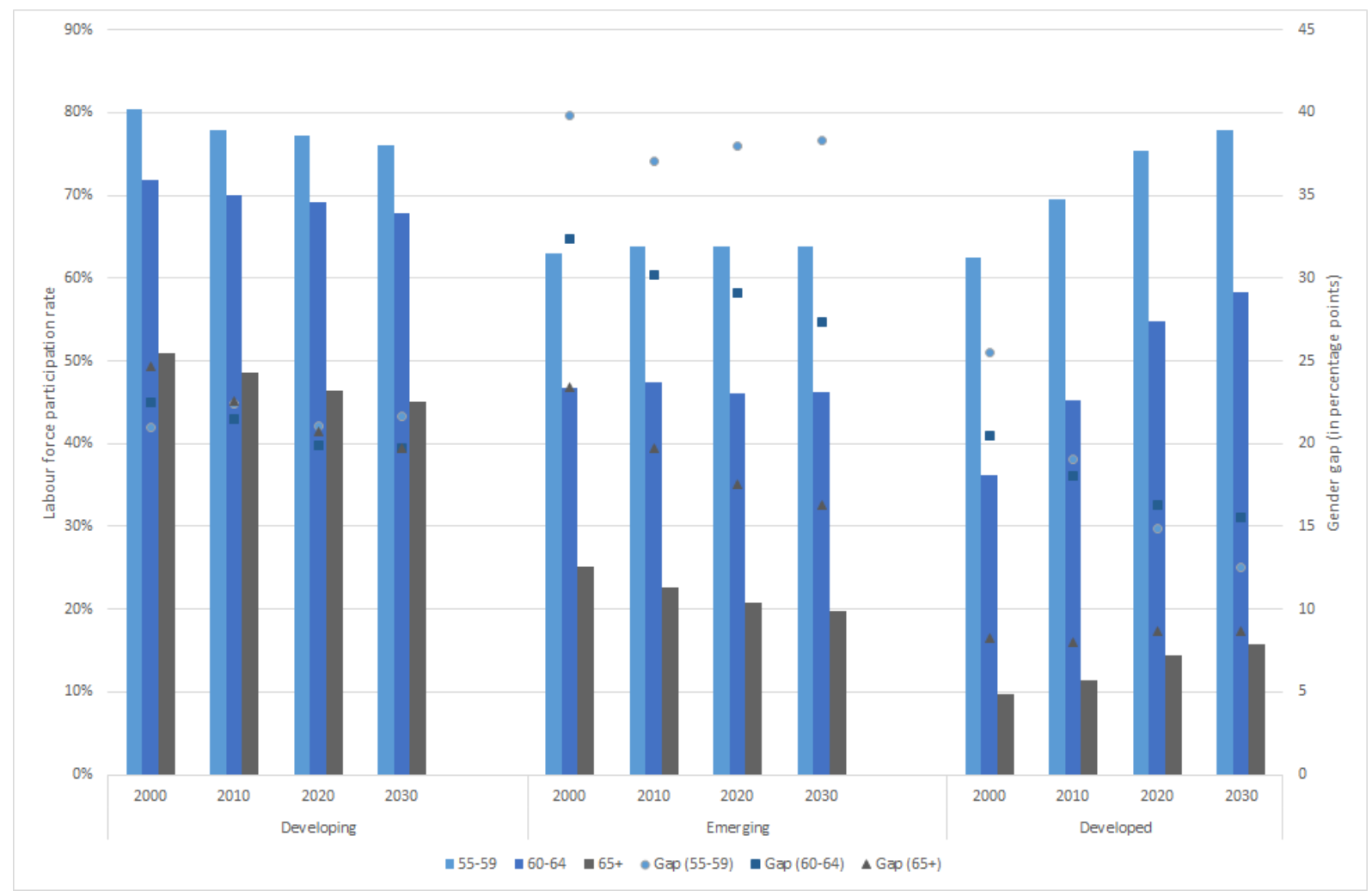

Source: calculations based on the ILO LFEP database, July 2019 update.

The decrease in LFPRs in developing countries can be attributed to the advances made in terms of pension system coverage and other social transfer systems (ILO 2017b), which gives older workers greater choice in deciding whether to remain in the labour market. Even so, the 
share of older workers in the labour force remains high in these countries: many work in the informal economy (ILO 2018c) and are not covered by any social protection benefits that would enable them to stop working while still receiving an income.

The increase in LFPRs in developed countries can be explained by two main factors. First, several countries have raised the statutory retirement age in recent decades, a trend that is likely to continue (OECD 2017). This translates almost automatically into a longer working life (Vogel, Ludwig, and Börsch-Supan 2017). Second, the implementation of employment policies that promote active ageing, foster the retention and recruitment of older workers by enterprises, and address age discrimination has succeeded in keeping more workers aged 55 years and over in the labour market.

Gender gaps in labour force participation rates are high across all levels of development, reflecting the persistence of occupational and sectoral gender segregation and the uneven distribution of unpaid household and care work, even at older ages (ILO 2016a).

In developing countries, the gender gap in labour force participation lingers at around 20 percentage points across all age categories. Emerging economies reveal the highest gaps in LFPRs for workers aged 55 to 59 years (around 38 percentage points) and 60 to 64 years (around 30 percentage points). The gap is expected to decrease for workers aged 60 years and over but will remain high for those aged 55 to 59 years.

In developed countries, equal access to education, anti-discrimination laws and activation policies, such as the provision of childcare and maternity benefits, have enabled and encouraged women to participate in the labour market. The consequent narrowing of the gap in LFPRs is most significant for the 55 to 59 years age group, where it is expected to drop by 12 percentage points by 2030, compared to a projected decrease of five percentage points for the 60 to 64 years cohort. However, the gap is expected to increase slightly for workers aged 65 years and over.

\subsection{Alternative economic dependency measures based on employment and decent work}

Age dependency ratios provide information about how the demographic structure of a country impacts the proportion of non-working and working persons. In this definition of dependency, dependents are all persons under the age of 15 years or over the age of 64 years, 
while the working-age population comprises persons aged 15 to 64 years (Notestein et al. 1944; cited in Sanderson and Scherbov 2015, 691). Those who work are assumed to contribute to the financing of public services, such as education, health and pensions, through taxes and social security contributions. Those who do not work or who no longer work still make a contribution to the public financing system - through indirect taxes, for example - but are thought largely to benefit from the contributions made by the working population. Several variations of the age dependency ratio exist, such as the adult dependency ratio, which takes prolonged working lives into account by removing the upper threshold and hence defining dependency as the proportion of inactive persons (aged 0 to 14 years) compared to active persons (aged 15 years and over) in the population (Bussolo, Koettl, and Sinnott 2015).

The problem is that these standard age dependency ratios disregard the fact that not all persons aged 15 to 64 years actually work. Some may still be in education; others may already have retired; and still others may be unemployed or may have chosen not to work for various reasons, such as those who may have become discouraged after unsuccessfully looking for work over a long period of time. Moreover, some children below the age of 15 years and some older persons over the age of 64 years may be part of the labour force, while many persons of working age may not. To address these limitations, alternative measurements have been developed, such as the economic dependency ratio (Wöss and Türk 2011), the labour-marketadjusted dependency ratio (Zuleeg 2007; Guerzoni and Zuleeg 2011) and the employmentbased dependency ratio (Loichinger et al. 2014). These divide the number of potentially dependent persons - such as the unemployed, pensioners (old-age, early retirement, disability), homemakers and discouraged persons - by the number of persons in paid employment (Eurofound 2012a).

While these alternative measurements of dependency provide a more accurate picture of the relationship between the economically active and inactive populations in quantitative terms, they still ignore important factors related to job quality - productivity and income levels, for instance - that determine whether a person can actually support dependants. In other words, economic dependency not only depends on the effective employment of the working-age population, but also on the quality of this employment and its contributive capacity. Informal employment that does not contribute to social security, and working poverty or subsistence 
self-employment that provide very low incomes and do not generate tax revenues, should not be considered as work that reduces the dependency burden.

In this paper, we present five new measures of employment-related dependency that not only take into account the demographic structure of the population, but also consider differences in the age and gender-specific characteristics of the labour market. Our measures include quantitative (activity status and unemployment) and qualitative (labour income, working hours and vulnerability) labour market dimensions. In combination with the standard agebased dependency ratio, these alternative dependency ratios allow us to analyse the causes of dependency in greater detail. A critical evaluation of each measure demonstrates that there is no single indicator which can fully capture all dimensions of economic dependency. Each proposed indicator has advantages over the others but also some limitations. They are therefore meant to provide researchers and policy makers with a set of measures, which allow for deeper analyses that provide insights into the most relevant policy areas for offsetting the effect of ageing on economic dependency in different contexts.

We use the ILO Labour Force Estimates and Projections (LFEP) database (July 2019 version), which provides a consistent series of labour market indicators for all United Nations' Member States, with forecasts to $2030 .{ }^{24}$ These indicators can be disaggregated by age and sex to provide additional information on the characteristics of dependents and non-dependents. It also allows us to present results based on the broad income groups of developing, emerging and developed economies.

In line with the work of Loichinger et al. (2014) and Loichinger and Skirbekk (2016), this global analysis of demographic, economic and employment-based dependency ratios reveals the importance of age- and gender-specific employment levels, as well as their determinants, when discussing the challenges associated with population ageing. In this way, the consequences of high youth unemployment, low female labour force participation, old-age poverty, significant vulnerable employment and the high incidence of working poverty are highlighted and provide the basis for policy recommendations aimed at alleviating the economic burden of population ageing.

\footnotetext{
${ }^{24}$ See ILO (2017a) for details of the LFEP database and the methodology applied.
} 


\subsubsection{The demographic dependency ratio}

The demographic dependency ratio is the most commonly used measure of dependency. The young-age dependency ratio reveals the number of persons below the age of 15 years compared to those aged 15 to 64 years, while the old-age dependency ratio shows the proportion of persons aged over 64 years relative to those aged 15 to 64 years. The sum of both ratios is the total demographic dependency ratio (DDR).

$$
D D R=\frac{\text { non working age population }}{\text { working age population }}
$$

where:

working-age population is the number of persons aged 15 to 64 years;

non-working-age population is the number of persons aged 0 to 14 years and those aged 65 years and over.

This ratio assumes that children and the elderly are economically dependent upon persons aged 15 to 64 years. As the ratio increases, there may be an increased burden on the population in the labour force in order to maintain the upbringing and pensions of economically dependent persons.

In developing countries, the total demographic dependency ratio decreased from 0.93 in 1991 to 0.81 in 2020 and is expected to further decrease to 0.72 by 2030 (see Figure 4.6). This is due to a significant reduction in the child dependency ratio, although the old-age dependency ratio has been increasing slightly over time.

In emerging countries, the total demographic dependency ratio decreased by one quarter from 0.66 in 1991 to 0.50 in 2015 owing to a decline in the share of children in the total population. Since 2015, the ratio has remained stable and is expected to stay that way to 2030 due to a growing older population, which will offset the decrease in child dependency.

Developed countries experienced a slight decrease in the total dependency ratio - from 0.50 in 1990 to 0.49 in 2010 - largely driven by a shrinking younger population. Since 2010 , the total ratio has started to rise again and is poised to grow by one quarter to the year 2030 . This increase can be almost entirely explained by a rapidly ageing society, with the further shrinking of the child dependency ratio playing a minor role. 
Figure 4.6. Demographic dependency ratio (DDR), by income group, 1991-2030

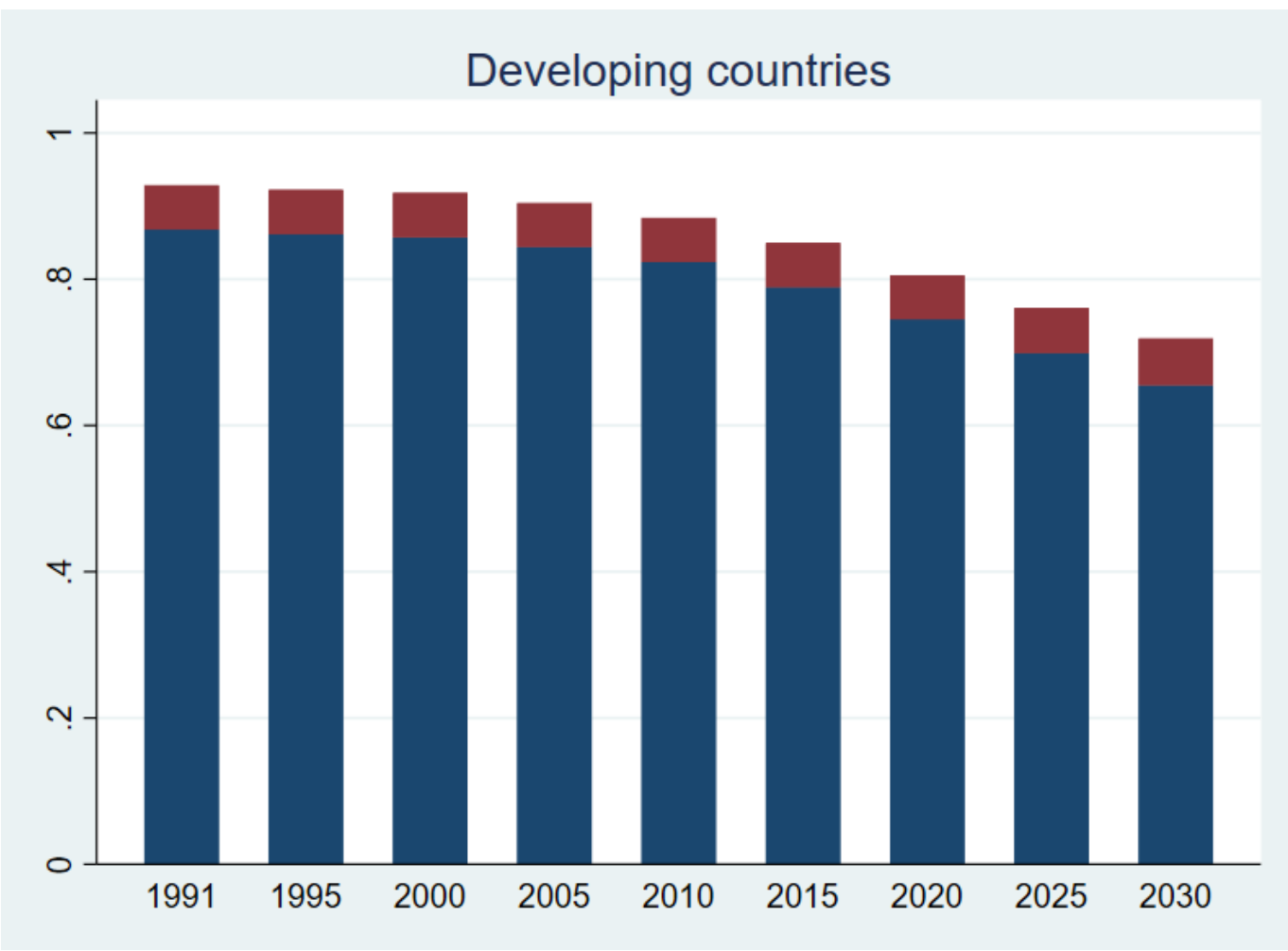

Emerging countries

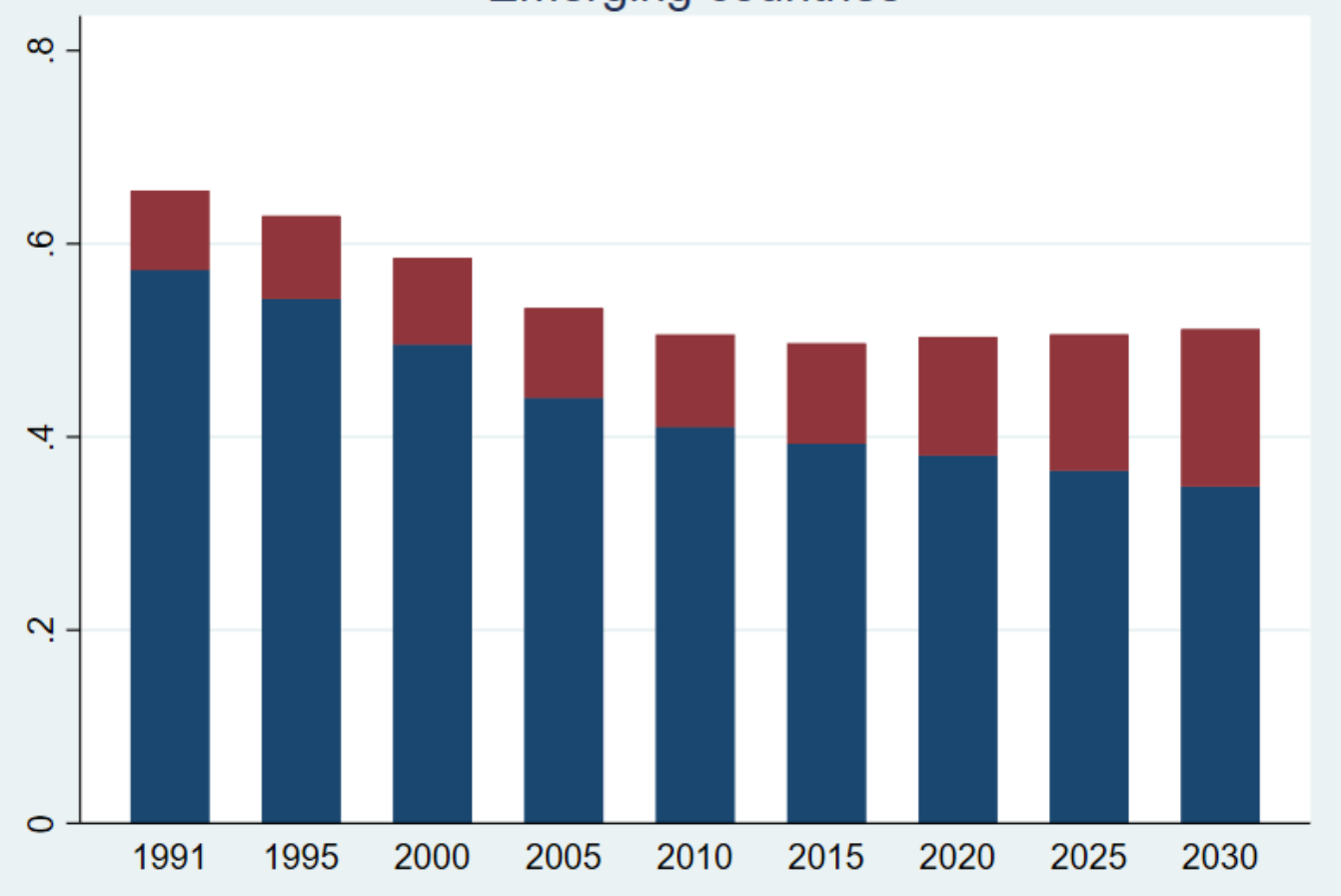




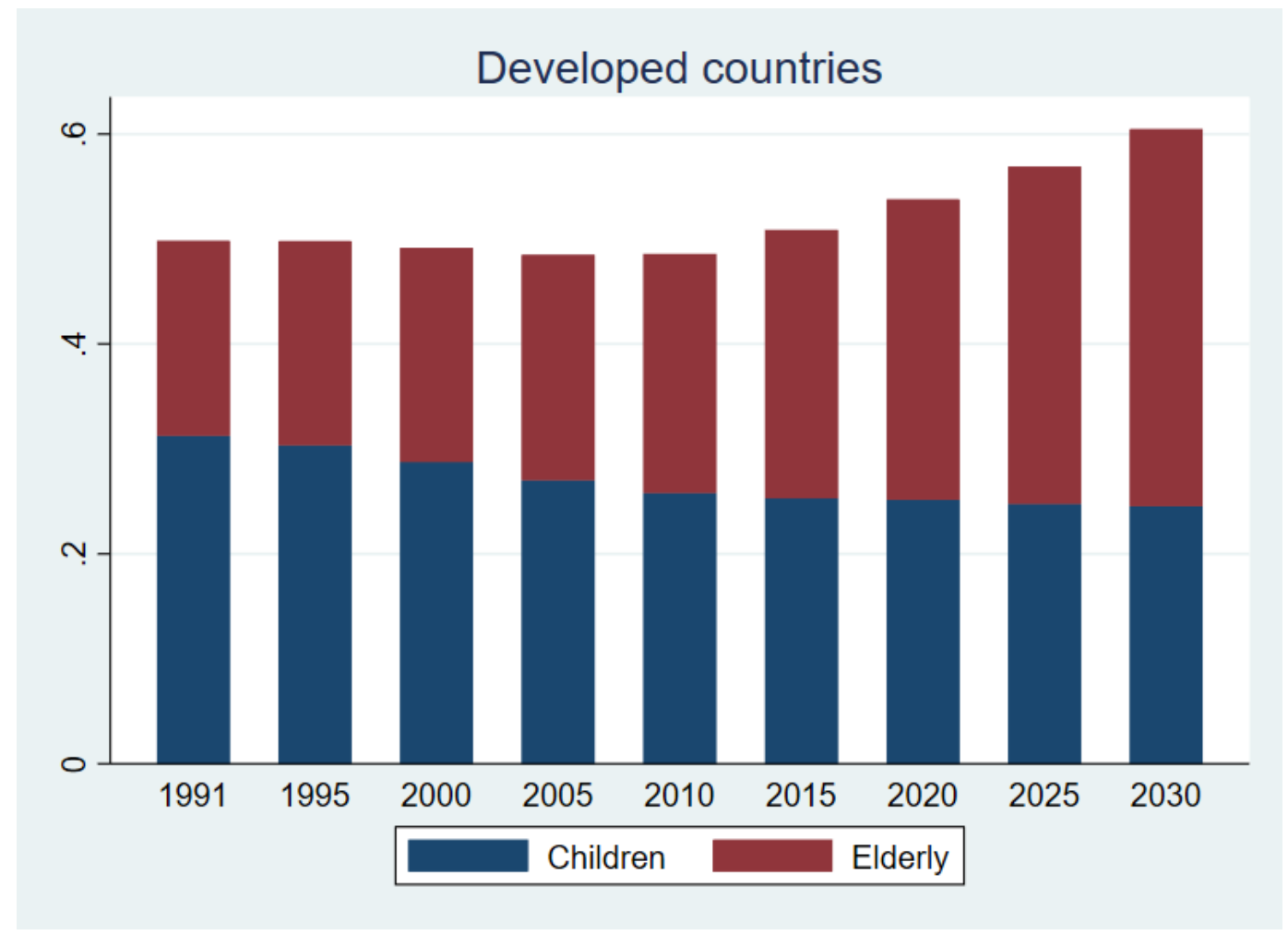

Source: calculations based on the ILO LFEP database, July 2019 update.

The DDR provides a good starting point for forecasting and discussing dependency burdens, especially in the context of shrinking youth and growing older populations worldwide. Its calculation is straightforward and requires only basic demographic information (i.e. age and sex) to be available for almost all countries. Moreover, the composition of the population changes slowly. This indicator therefore allows for accurate short- and medium-term projections of the data, especially with regard to the population aged 15 years and over.

However, there is no universal definition of the working-age population. The age thresholds usually correspond to societal standards for education and work eligibility and are anchored in national legislation. In order to enable international comparability, the ILO usually defines the working-age population as all persons aged 15 years and older. Furthermore, the demographic dependency ratio ignores the actual economic behaviour of persons aged between 15 and 64 years, such as age of entry to and exit from the labour market, employment status, and level of labour income. Instead, this ratio simply assumes fixed age limits in the labour markets and does not allow for a more sophisticated economic interpretation. 


\subsubsection{Dependency measures based on employment}

\subsubsection{Activity-based dependency ratio}

The first alternative measure of dependency is based on the economic activity status of the working-age population. Not everyone of working age is part of the labour force (i.e. working or available and seeking work) for a variety of reasons: young people may still be in school; adults may have taken early retirement or have chosen to stay at home due to care responsibilities, such as childcare or elderly care; while others may not work for reasons of disability or long-term illness, or because they simply do not wish to work. ${ }^{25}$

This alternative dependency measure, called the activity-based dependency ratio (ABDR), restricts the "universe" of persons that support dependents to those that are in the labour force, namely all employed and unemployed persons, thus excluding those persons of working age who are not covered by these two statuses. As a result, the dependent population for the ABDR consists of: (a) children below the age of 15 years, (b) persons aged 15 to 64 years who are outside the labour force, and (c) older persons aged 65 years and over.

$$
A B D R=\frac{\text { non working age }+ \text { outside the labour force }}{\text { labour force }}
$$

where:

non-working-age is the number of persons aged under 15 years or over 64 years;

outside the labour force is the population aged 15 to 64 years that is not engaged in the labour force, i.e. neither employed (in paid employment or in self-employment) nor unemployed;

labour force is the population aged 15 to 64 years that is engaged in the labour force, i.e. either employed or unemployed.

We divide the ratio into six sub-ratios based on the characteristics of the inactive population: a child dependency ratio (under 15 years of age); a sex-disaggregated dependency ratio for the youth population (aged 15 to 24 years) outside the labour force; a dependency ratio for

\footnotetext{
${ }^{25}$ This also includes persons outside the labour force who may be involved in forms of work other than paid employment (e.g. own-use production work, volunteer work and unpaid traineeships), and therefore contribute to national production and to households' livelihoods and well-being.
} 
the adult population (aged 25 to 64 years) outside the labour force, for both women and men; and an elderly dependency ratio (aged 65 years and over). This breakdown allows us to gain a more detailed picture of those working-age persons who are outside the labour market and are therefore likely to be dependent upon the support provided by those who are in the labour force.

As shown in Table 4.1, the activity-based dependency ratio (ABDR) is much higher than the total demographic dependency ratio (DDR) for all three income groups. When all those who are outside the labour market are included, economic dependency doubles on average in developing and developed countries - by a factor of 1.9 and 2.0 respectively - and increases by a factor of 2.7 in emerging countries in 2020. This strong divergence between the two measures highlights the inaccuracy of the DDR as an indicator of economic dependency.

The ABDR is highest in developing countries (see Figure 4.7). It remained stable between 1991 (1.56) and the early 2000s (1.55), at which point it started to fall, with the exception of a slight peak in 2010, probably in the aftermath of the 2007-08 global financial crisis. The ABDR for developing countries is expected to reach 1.41 in 2030. The main determinant of the ABDR in these countries remains the very high child dependency rate, which has been decreasing since 1991. The elderly dependency ratio is small: many of the countries in this group have not yet entered the ageing phase and will only do so in around 2030 (see section 4.2). The other subratios - youth and adults outside the labour force, disaggregated by sex - are also relatively small, illustrating the fact that, in the absence of any form of social protection, all those who are capable of working can and do undertake some form of economic activity. When it comes to gender, it is interesting to note that the share of adult women outside the labour force is on average three times higher than that of men. This could reflect the uneven distribution of household and care responsibilities between women and men, including at younger ages.

The ABDR in emerging countries fell from 1.36 in 1991 to 1.27 in 2005, mainly because of the sharp decrease in the child dependency ratio. However, it has been increasing ever since and is projected to reach 1.40 in 2030, just above the 1991 rate. While the increasing elderly dependency ratio is certainly the strongest driver of this change, the share of persons outside the labour market is also on a clear upward trend. This trend is most pronounced for adult women who are more likely than adult men to be outside the labour force. 
Although the ABDRs in emerging and developing countries are expected to converge by 2030, the $A B D R$ in emerging countries tends to be slightly lower than in developing countries because of a considerably lower child dependency ratio. At the same time, this effect is partly offset by higher income levels and better social protection systems, which enable people to remain outside the labour market if they so wish.

In developed economies, the ABDR decreased from 1.14 in 1991 to 1.08 in 2010 and started rising again as of 2015 to reach 1.18 in 2030 - slightly higher than the level in 1991. While child dependency is declining, the elderly dependency rate has increased sharply since the 1990s, overtaking the child dependency ratio around the year 2015. The proportion of women outside the labour force has been decreasing significantly since 1991, a trend that is expected to continue, albeit at a slower pace. While this increase in the women's activity rate partly explains the fall in the ABDR, it is not sufficient to counterbalance the sharp rise in the elderly dependency ratio.

Figure 4.7. Activity-based dependency ratio (ABDR), by income group, 1991-2030

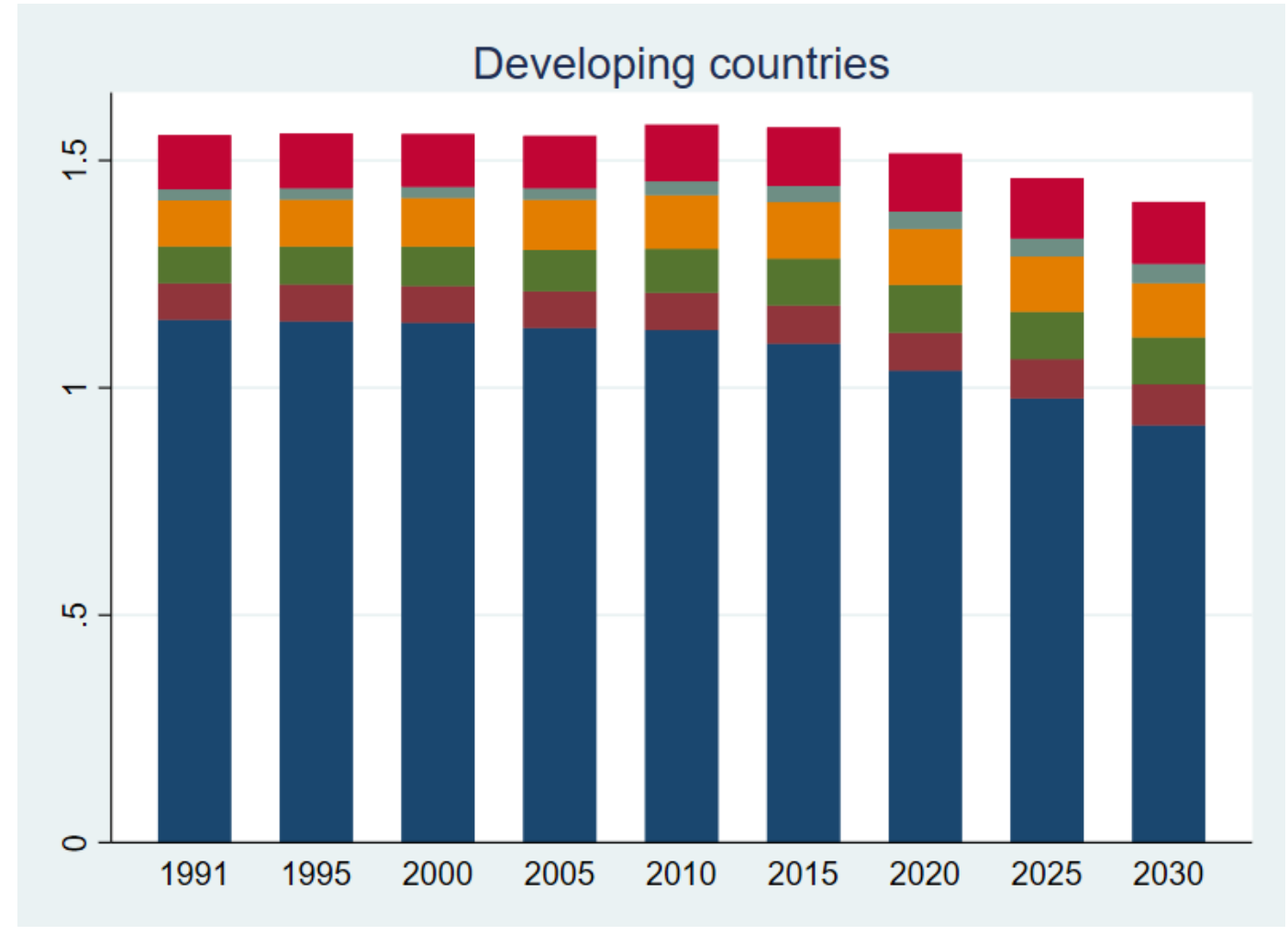



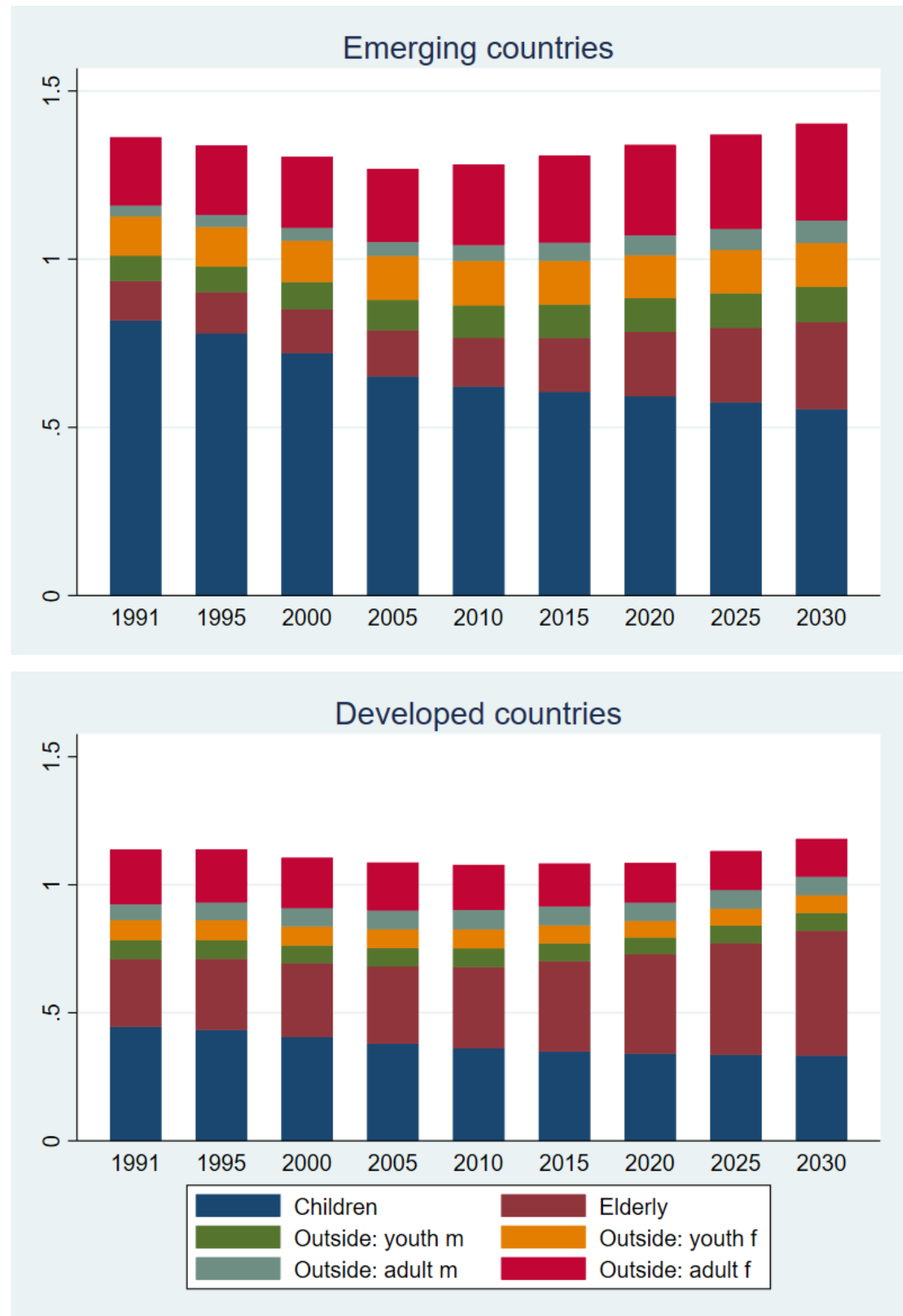

Source: calculations based on the ILO LFEP database, July 2019 update.

The ABDR provides a finer measure of economic dependency than the demographic dependency ratio. By factoring in the effective labour market participation of working-age persons, disaggregated by sex and age group, it provides analysts and policymakers with more 
detailed information about how labour market participation levels influence dependency rates.

Since it is based on basic demographic and labour market information, data is available for a large number of countries and enables cross-country comparisons to be made. However, the simplicity of the data requirements, and in particular the binary nature of either being inside or outside the labour force, comes at a price: the ABDR does not provide any indication of the quality of employment for those persons who are in the labour force or any rationale as to why other persons are outside the labour force. Furthermore, it counts unemployed persons as non-dependents, which is misleading. Even assuming the existence of effective social security systems, such as unemployment benefits, unemployed persons are receiving transfers from other groups in society. And where such systems do not exist, even when unemployed persons draw on personal savings, they usually still depend on family members for their basic needs.

\subsubsection{Employment-based dependency ratio}

Our second employment-based alternative measure of dependency includes unemployed persons as dependents, in addition to persons outside the labour force. It thus assumes that those who are unemployed benefit from transfers from those who are employed. Such transfers can either be direct - through intrahousehold reallocations, for example - or indirect, such as through social security or public redistribution schemes. The denominator of the employment-based dependency ratio (EBDR) is limited to the employed population, while the numerator, or the dependent population, consists of: (a) children below the age of 15 years, (b) persons aged 15 to 64 years who are outside the labour force, (c) all unemployed persons aged 15 years and over, and (d) older persons aged 65 years and over.

$$
E B D R=\frac{\text { non working age }+ \text { outside the labour force }+ \text { unemployed }}{\text { total employed }}
$$

where:

non-working-age is the number of persons aged under 15 years or over 64 years;

outside the labour force is the population aged 15 to 64 years that is not engaged in the labour force; 
unemployed is all persons aged 15 years and over ${ }^{26}$ who are seeking and are available to start working for pay or profit in specified reference periods;

total employed is all persons aged 15 to 64 years who are in work, either in paid employment or in self-employment.

We divide this ratio into eight sub-ratios based on the characteristics of the inactive population and the unemployed: a child dependency ratio; a sex-disaggregated dependency ratio for the youth population (aged 15 to 24 years) outside the labour force; a dependency ratio for the adult population (aged 25 to 64 years) outside the labour force, for both women and men; an unemployed ratio, also for women and men; and an elderly dependency ratio. This enables us to see the proportion of employed persons that is providing support to the other cohorts.

As Table 4.1 shows, the employment-based dependency ratio (EBDR) is higher than the activity-based dependency ratio (ABDR), although the difference is small. This is mainly a reflection of relatively low shares of unemployed persons compared to persons outside the labour market, especially in emerging and developed countries.

In developing countries, the EBDR remained stable at around 1.6 until 2015, when it started to decrease and is expected to fall to 1.52 in 2024 (see Figure 4.8). The demographic component (child dependency and elderly dependency) clearly drives the dependency ratio, especially the child component. The addition of unemployed persons to the group of potential dependents plays only a minor role.

In emerging countries, the EBDR decreased from 1.43 in 1991 to 1.37 in 2010. It has been increasing ever since and is expected to reach 1.45 in 2024. The demographic component is behind this trend: there has been a strong decline in the child dependency ratio throughout the entire period and a marked increase in the elderly dependency ratio since 2005 . Hence,

\footnotetext{
${ }^{26}$ It should be noted that the ILO does not apply an upper-age threshold to its unemployment statistics. Therefore, persons aged 65 and over could be counted in both the non-working-age and the unemployed population groups. This could introduce an upwards bias and lead to an overestimation of the EBDR. However, this bias is thought to be rather small, since national legal retirement ages are projected to remain at around 65 years of age (see OECD 2017, for instance).
} 
ageing is and will continue to be an important determinant of dependency in these countries. Unemployment also plays a more pronounced role in this group of countries.

In developed countries, the EBDR has been fluctuating at around 1.22, reaching a low of 1.13 in around 2020. The latest projections suggest a slight tendency upward between now and 2024. The demographic component accounts for some three quarters of the dependency ratio, with the elderly component increasingly gaining in significance. Unemployment constitutes the smallest contributing factor.

Figure 4.8. Employment-based dependency ratio (EBDR), by income group, 1991-2024

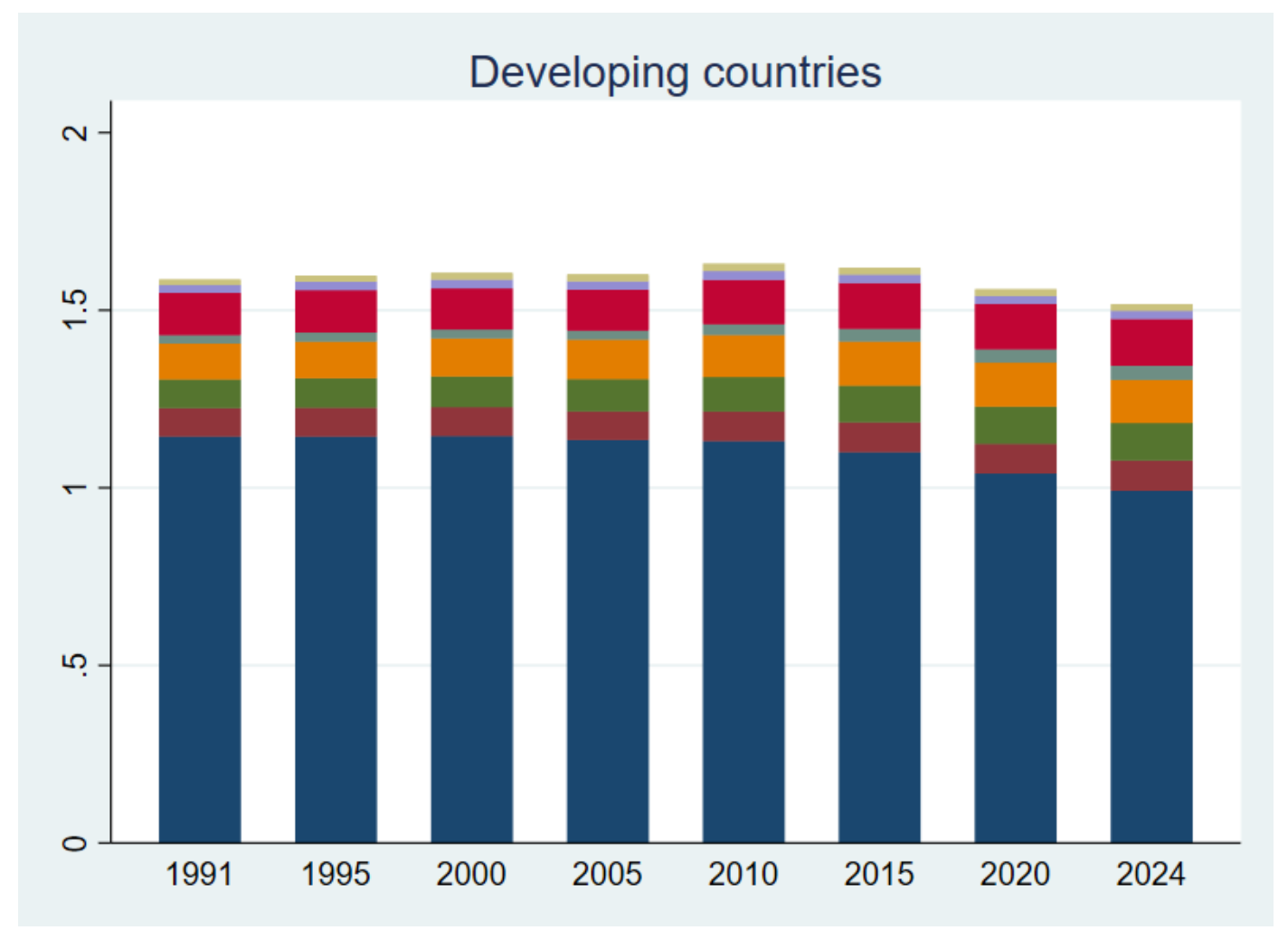



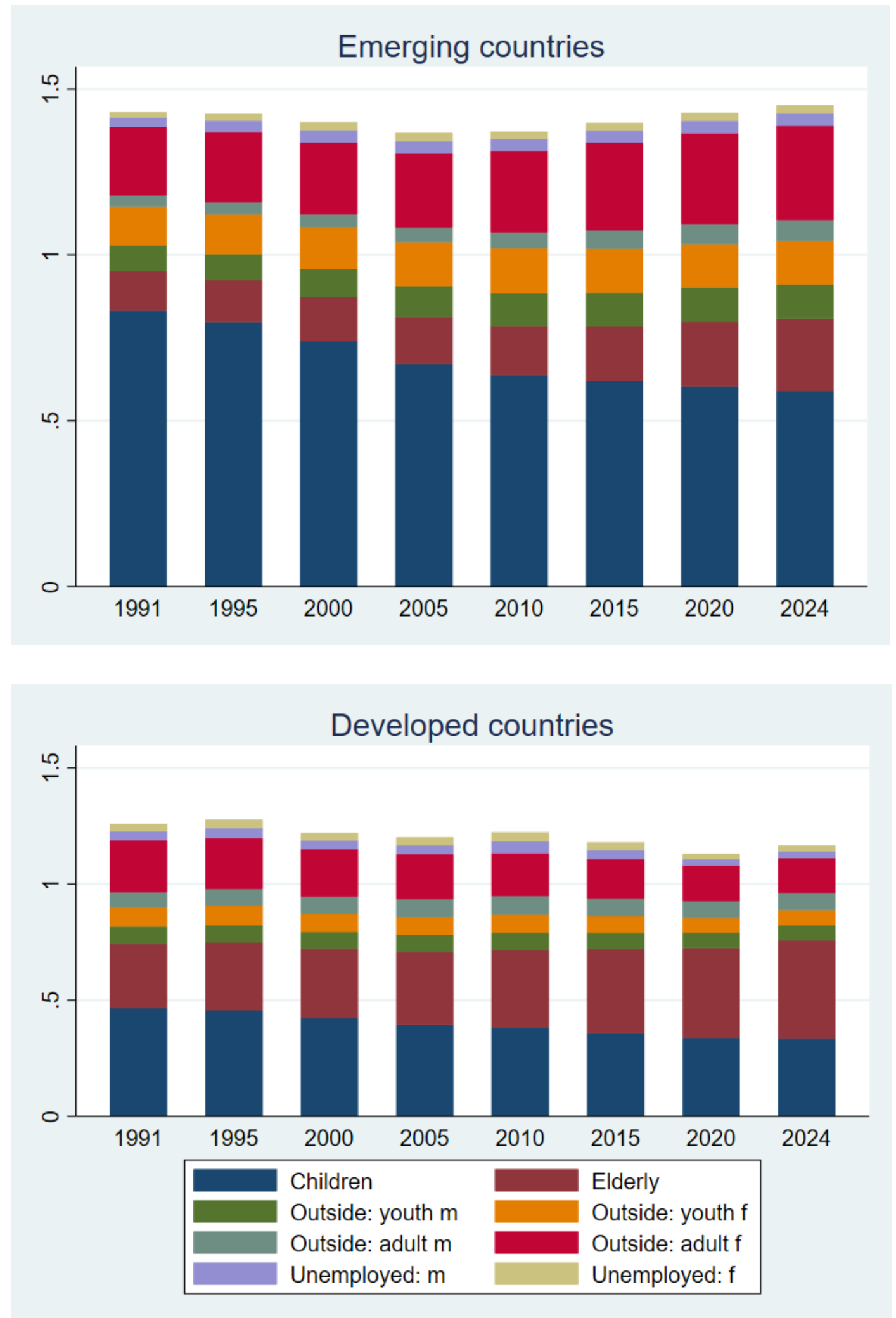

Source: calculations based on the ILO LFEP database, July 2019 update.

The EBDR offers valuable insights into the composition and distribution of potential dependents. From a conceptual point of view, it makes sense to include unemployed persons in the group of dependents. In addition to the problems discussed in relation to the ABDR in 
the previous section, however, the EBDR suffers from a major shortcoming in the data: both the employment and unemployment rates are influenced by a large variety of factors that make it difficult to predict trends accurately, especially for the more distant future. ${ }^{27}$ While the explanatory power of the EBDR decreases for distant future predictions, it may still be an adequate indicator for policymakers to assess labour market needs in the nearer future. Nevertheless, the EBDR does not give any indication of the job quality of those in employment and assumes them to be non-dependents.

${ }^{27}$ See ILO (2019e Appendix B) for more information on the ILO Labour Force Estimates and Projections. 
Table 4.1. Comparison of demographic-, activity-, and employment-based dependency ratios, by income groups, 20002030

\begin{tabular}{|c|c|c|c|c|}
\hline & & DDR & ABDR & EBDR \\
\hline \multirow{3}{*}{2000} & $\begin{array}{l}\text { Developing } \\
\text { countries }\end{array}$ & 0.92 & 1.56 & 1.61 \\
\hline & $\begin{array}{l}\text { Emerging } \\
\text { countries }\end{array}$ & 0.59 & 1.3 & 1.4 \\
\hline & $\begin{array}{l}\text { Developed } \\
\text { countries }\end{array}$ & 0.49 & 1.11 & 1.22 \\
\hline \multirow{3}{*}{2010} & $\begin{array}{l}\text { Developing } \\
\text { countries }\end{array}$ & 0.88 & 1.58 & 1.63 \\
\hline & $\begin{array}{l}\text { Emerging } \\
\text { countries }\end{array}$ & 0.51 & 1.28 & 1.37 \\
\hline & $\begin{array}{l}\text { Developed } \\
\text { countries }\end{array}$ & 0.49 & 1.08 & 1.22 \\
\hline \multirow{3}{*}{2020} & $\begin{array}{l}\text { Developing } \\
\text { countries }\end{array}$ & 0.81 & 1.52 & 1.56 \\
\hline & $\begin{array}{l}\text { Emerging } \\
\text { countries }\end{array}$ & 0.5 & 1.34 & 1.43 \\
\hline & $\begin{array}{l}\text { Developed } \\
\text { countries }\end{array}$ & 0.54 & 1.09 & 1.13 \\
\hline \multirow{3}{*}{2024} & $\begin{array}{l}\text { Developing } \\
\text { countries }\end{array}$ & 0.77 & 1.47 & 1.52 \\
\hline & $\begin{array}{l}\text { Emerging } \\
\text { countries }\end{array}$ & 0.51 & 1.36 & 1.45 \\
\hline & $\begin{array}{l}\text { Developed } \\
\text { countries }\end{array}$ & 0.56 & 1.12 & 1.17 \\
\hline \multirow{3}{*}{2030} & $\begin{array}{l}\text { Developing } \\
\text { countries }\end{array}$ & 0.72 & 1.41 & . \\
\hline & $\begin{array}{l}\text { Emerging } \\
\text { countries }\end{array}$ & 0.51 & 1.4 & . \\
\hline & $\begin{array}{l}\text { Developed } \\
\text { countries }\end{array}$ & 0.6 & 1.18 & . \\
\hline
\end{tabular}

Notes: DDR: demographic dependency ratio; ABDR: Activity-based dependency ratio; EBDR: Employment-based dependency ratio. Projections of employment and unemployment figures based on econometric models are only available to the year 2024. As a result, estimates for the EBDR are not included for all years.

Interpretation: A ratio of 1.5 of the EBDR, for instance, can be interpreted as meaning that 15 persons not in employment (i.e. children below the age of 15 years, persons aged 15 to 64 years outside the labour force, unemployed persons aged 15 years and over, and older people aged 65 years and over) are thought to be economically dependent upon 10 persons in employment.

Source: calculations based on the ILO LFEP database, July 2019 update. 


\subsubsection{Dependency measures based on productive employment}

In the following section, we are introducing three indicators based on the notions of fullpotential and productive employment. Full-potential employment reflects the ability of an economy to utilize the available human resources to the full extent. Productive employment is defined as "employment yielding sufficient returns to labour to permit the worker and her/his dependents a level of consumption above the poverty line" (ILO 2012).

\subsubsection{Labour underutilization as a proxy for non-productive employment}

Even when workers are in employment, they may find themselves in a situation where they wish to work more paid hours; that is, they are time-related underemployed. The income generated by such involuntary part-time employment may not be sufficient to cover basic needs and may be a cause of in-work poverty (Warren 2015; McBride, Smith, and Mbala 2018). Alongside the unemployed and the inactive populations, persons in time-related underemployment form the underutilized labour force group. If we define productive employment as employment that generates an income sufficient to keep workers and their families above the poverty line, then we can use the labour underutilization indicator as a proxy for non-productive employment.

This alternative dependency measure can therefore be defined as the labour underutilization dependency ratio (LUDR), where the denominator is those persons who are fully employed all employed persons who are not in time-related underemployment - and the numerator comprises the following dependents: (a) children below the age of 15 years, (b) persons aged 15 to 64 years who are outside the labour force, (c) all unemployed persons aged 15 years and over, (d) older persons aged 65 years and over, and (e) time-related underemployed persons aged 15 years and over.

$$
\begin{aligned}
& L U D R \\
& =\frac{\text { non working age }+ \text { outside the labour force }+ \text { unemployed }+ \text { underemployed (iv) }}{\text { full }- \text { potential employment }}
\end{aligned}
$$

where:

non-working-age is the number of persons aged under 15 years or over 64 years;

outside the labour force is the population aged 15 to 64 years that is not engaged in the labour force; 
unemployed is all persons aged 15 years and over who are seeking and are available to start working for pay or profit in specified reference periods;

underemployed is all persons in employment who want to work additional hours, whose working time in all their jobs is below a specified threshold of hours and who are available to work additional hours if they are given the opportunity to do so;

full-potential employment is the total number of employed persons minus the underemployed.

The breakdown of the LUDR follows the same metrics as the EBDR but includes involuntarily underemployed women and men. As expected, this increases the dependency ratio across all income levels (see Table 4.2), most notably in developing countries, where it is on average 25 per cent higher than the EBDR. This reflects the reality of many workers in developing countries who cannot afford to be without employment and hence accept any kind of work, often with piece-rate or daily contracts.

The LUDR in developing countries is projected to decrease from 2.0 in 2015 to 1.9 in 2024 (see Figure 4.9). The contribution of the time-related underemployed to the overall dependency ratio remains stable at levels that are much higher than for unemployment. Thus, underemployment is a more relevant indicator of dependency than unemployment in developing countries.

The LUDR in emerging countries is increasing and is expected to reach 1.56 in 2024 . This increase is largely being driven by population ageing, while the underemployment share is shrinking. Men seem to be more affected by time-related underemployment than women.

The LUDR is lowest in developed countries, where it is trending upward and is projected to reach 1.23 in 2024. Women are on average a third more likely to be in involuntary part-time employment than men. 
Figure 4.9. Labour underutilization dependency ratio (LUDR), by income group, 2005-24
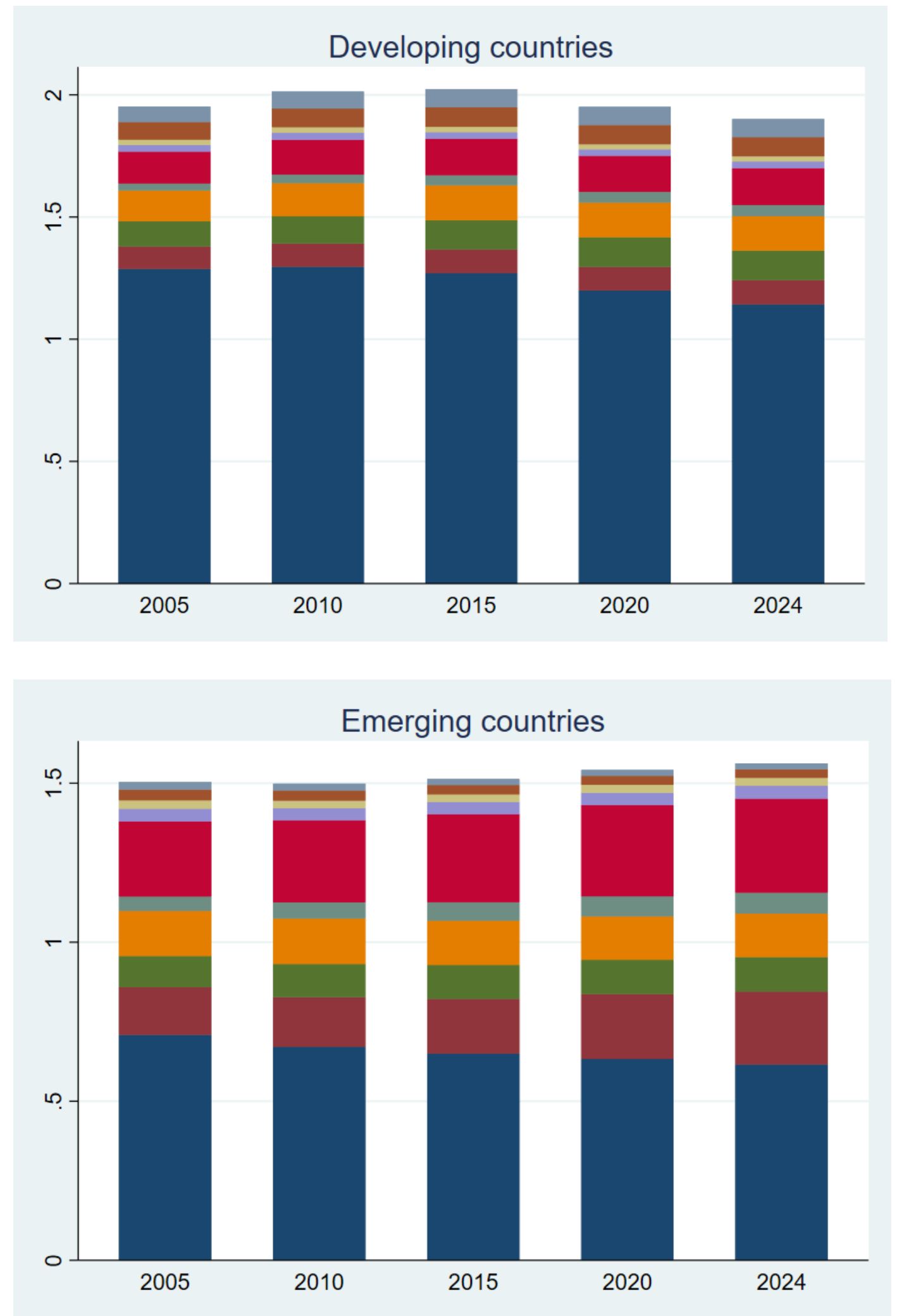


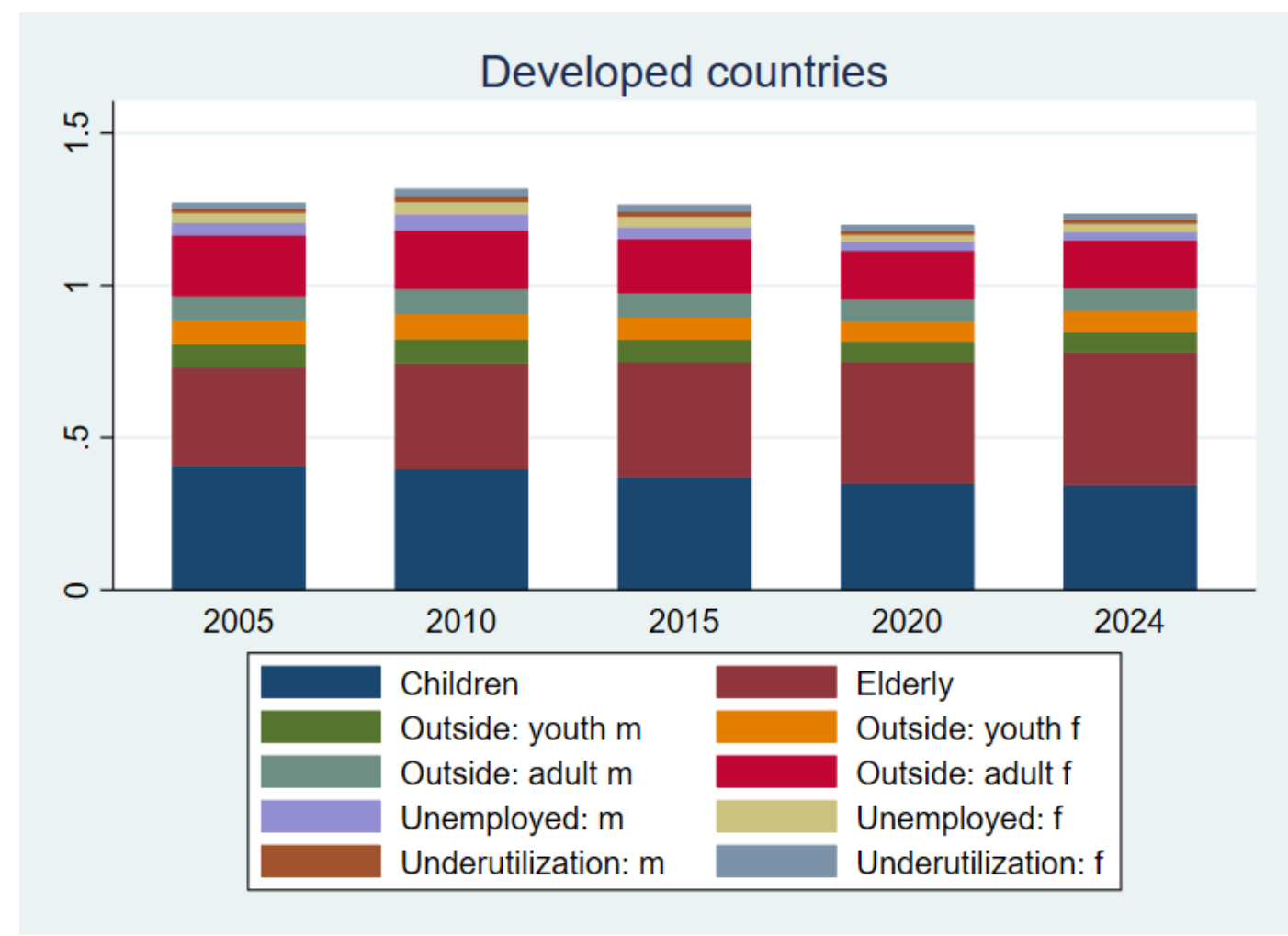

Source: calculations based on the ILO LFEP database, July 2019 update.

While unemployment and inactivity indicate a lack of available jobs, time-related underemployment suggests a lack of available paid hours. The LUDR therefore sheds more light on the supply side of the labour market and demonstrates the untapped opportunities of the potential labour force, especially regarding women and youth not in employment, education or training (NEET). In terms of data, this measure shares the same limitations as the EBDR but is further constrained when it comes to historical data points.

The assumption that involuntary part-time workers are essentially dependents may not hold true in all cases. Nevertheless, time-related underemployment is a common feature of in-work poverty. The LUDR unites three key dimensions of labour force underutilization, and the breakdown and disaggregation by age and sex provides valuable information to enable policymakers to formulate targeted responses. Yet, labour underutilization is an imperfect proxy for unproductive employment. It doesn't capture the fact that workers can be employed full-time, but earn too little to keep themselves and their families above the poverty line. The working poverty rate as well as the rate of vulnerable employment therefore provide additional insights that may be useful to inform policy-making. 


\subsubsection{Working poverty as a proxy for non-productive employment}

Not all of those who work are productively employed. Some workers in paid employment or self-employment may not earn enough to lift themselves and their families above the poverty line. In this case, they can be considered as being economically dependent, meaning that they rely on social or family transfers to live a decent life and cannot support others through their earned income. We define this type of dependency as the working poverty-based dependency ratio (WPDR), with the dependent population consisting of: (a) children below the age of 15 years, (b) persons aged 15 to 64 years who are outside the labour force, (c) all unemployed persons aged 15 years and over, (d) older persons aged 65 years and over, and (e) the working poor aged 15 years and over.

$$
\begin{aligned}
& \text { WPDR } \\
& =\frac{\text { non working age }+ \text { outside the labour force }+ \text { unemployed }+ \text { working poor }}{\text { productively employed }}
\end{aligned}
$$

where:

non-working-age is the number of persons aged under 15 years or over 64 years;

outside the labour force is the population aged 15 to 64 years that is not engaged in the labour force;

unemployed is all persons aged 15 years and over who are seeking and are available to start working for pay or profit in specified reference periods;

working poor is the number of employed persons aged 15 years and over living in households with incomes below the international poverty line of US\$1.90 per day in purchasing power parity (PPP);

productively employed is the total number of employed persons minus the working poor.

When adding the working poor to the dependency measure, the dependency ratio increases substantially in developing and emerging economies compared to previous measures (see Table 4.2 and Figure 4.10). The largest increase is seen in developing countries, where the WPDR is estimated at 2.84 in 2024. Despite the fact that the WPDR has decreased considerably 
since the year 2000, when it was 5.76, it is on average about 2.7 times higher than the EBDR, which only considers persons outside the labour force and the unemployed as dependents.

In emerging countries, the convergence of the EBDR and the WPDR is much more pronounced, although the WPDR is still some 15 per cent higher. This means that the number of working poor has decreased in this group of countries $^{28}$ - mostly in China and India - and, consequently, so has its weight on the dependency measure. In emerging countries, the contribution of the child dependency ratio and the share of young and adult women outside the labour market are currently much higher than those of poverty and unemployment.

Since the working poverty rate, which is based on the international poverty line of US\$1.90 per day in purchasing power parity (PPP), tends to be zero in developed countries, the estimates for WPDR are practically identical to those for the EBDR.

Figure 4.10. Working poverty-based dependency ratio (WPDR), by income group, 2000-24

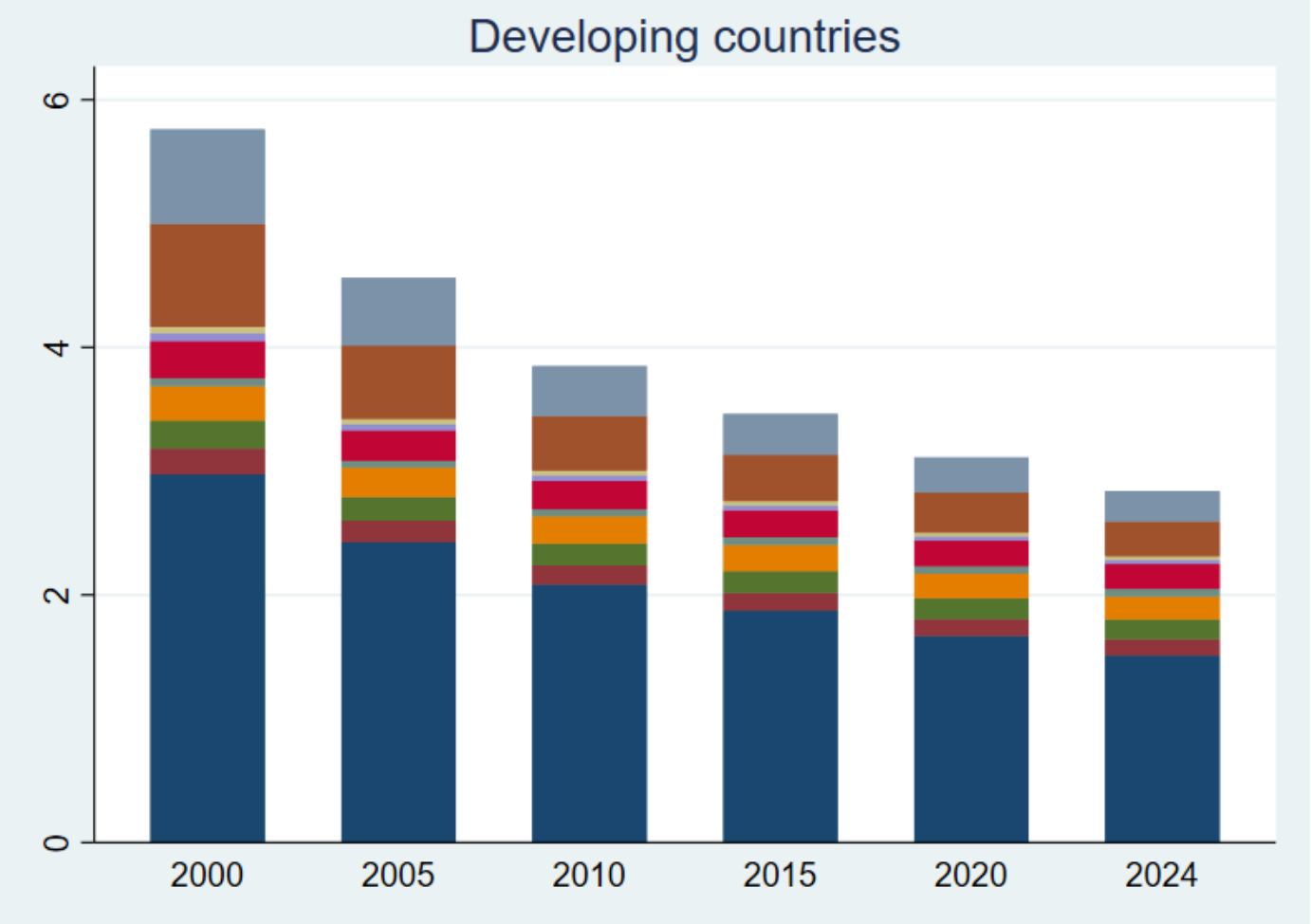

\footnotetext{
${ }^{28}$ Further information on the decline in working poverty can be found in ILO (ILO 2020c).
} 

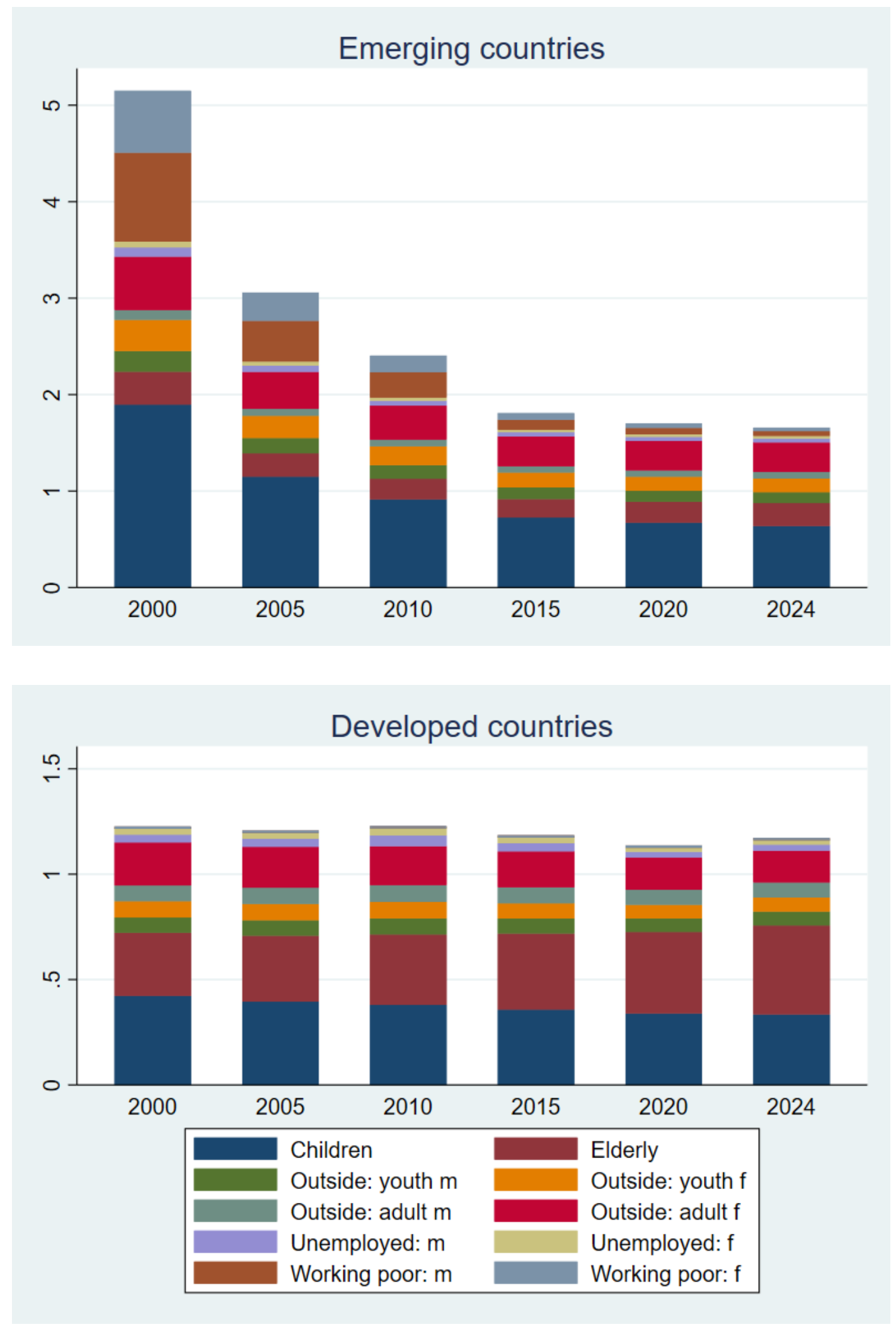

Source: calculations based on the ILO LFEP database, July 2019 update.

In developing countries, children will continue to contribute more than 50 per cent to the overall dependency rates, while the contribution of older persons remains relatively low at around 4.1 per cent (see Figure 4.11). The share of the working poor will continue to decrease; 
however, persons outside the labour force combined with the unemployed exceeded the share of the working poor in 2015 and will continue to gain in significance.

The picture is very different in emerging economies, where the contribution of older persons is strongly increasing, while the share of children is slowly declining. The weight of working poverty in total dependency rates has sharply decreased and, although its pace of reduction has slowed since 2015, it is the least important contributor to the overall dependency ratio since that year. At the same time, the contribution of persons outside the labour market and the unemployed, which had been equal to that of working poverty in the early 2000s, has risen sharply, to the extent that it overtook the child dependency ratio in 2016.

Figure 4.11. Breakdown of the WPDR over time, by income group, 2000-24

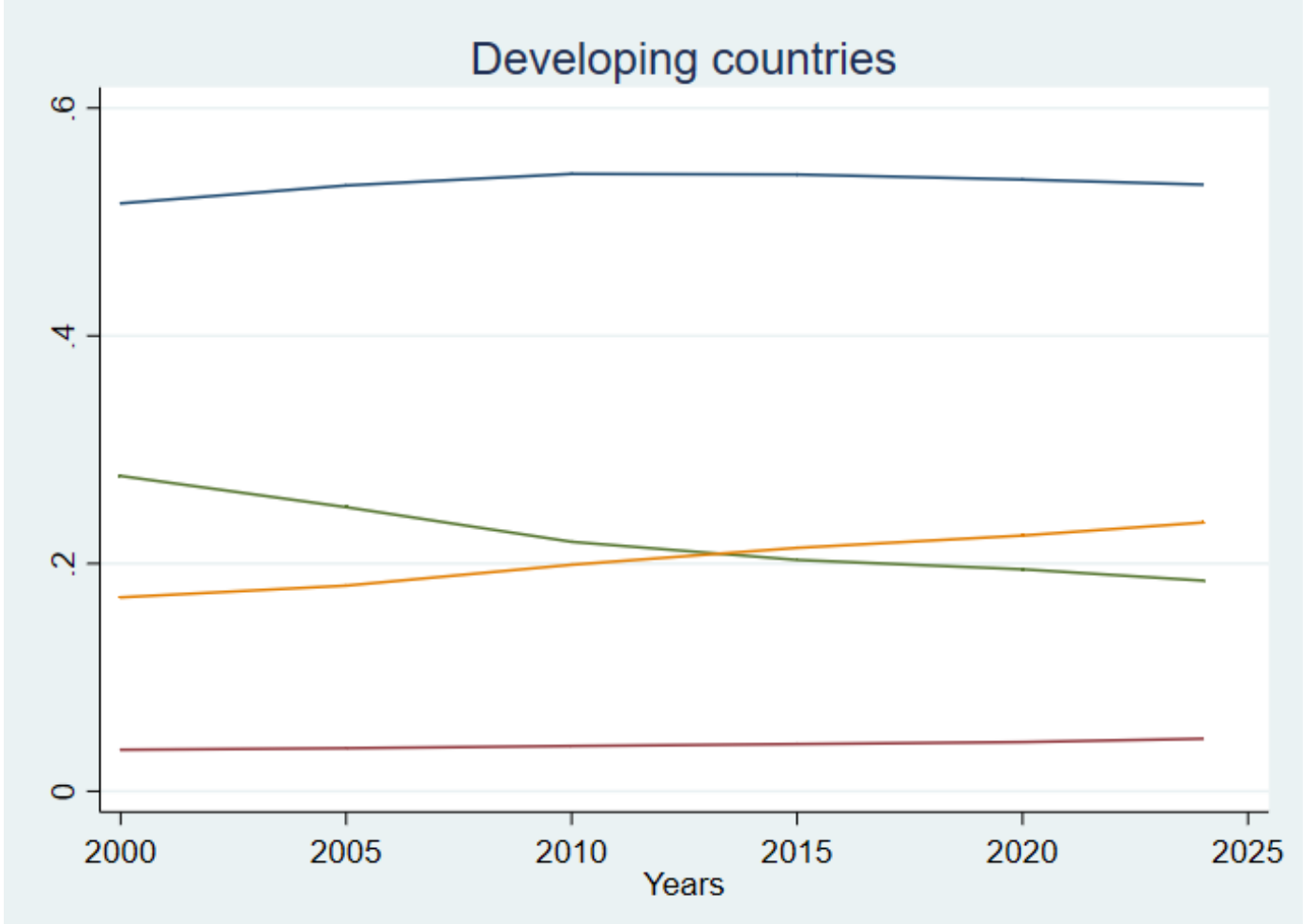



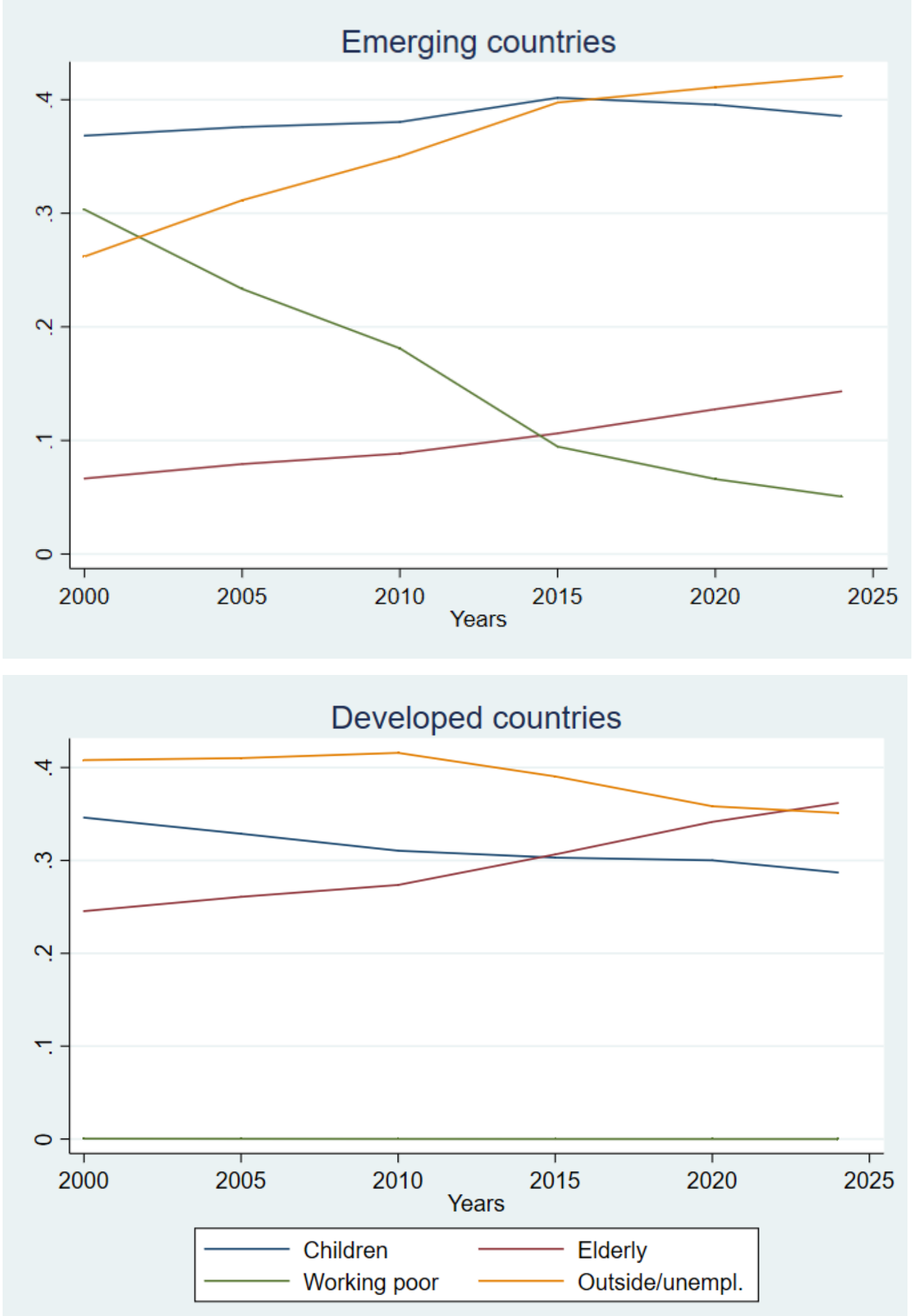

Source: calculations based on the ILO LFEP database, July 2019 update.

The working poverty-based dependency ratio adds an important element to the discussion on economic dependency by including a group that is very likely in need of support: workers who cannot lift themselves and their dependants above the poverty line. 
Although internationally comparable data is only available from the year 2000 onwards and predictions are limited to the near future, an intertemporal and cross-country analysis can be carried out for around 73 per cent of countries. However, the WPDR suffers from additional limitations similar to those discussed for the EBDR, especially with respect to the working poverty rate, which is a product of the poverty and employment rate. The working poverty rate is based on the headcount index, which does not take intrahousehold inequality or depth of poverty into account. Moreover, different approaches (microeconomic versus macroeconomic) are applied for the calculation, reflecting different data availability and risking compromise of cross-country comparisons (see ILO (2019b) and section 2.3). However, the working poverty-based dependency ratio adds a valuable indication of employment quality and is a proxy for a measure of dependency that relates to (un)productive employment.

The analysis shows that having a job is no guarantee of decent living conditions. Too many workers - especially women and youth - do not earn enough to lift themselves and their family members above the poverty threshold. Targeted policies are needed to further accelerate the progress made over recent decades. This includes ensuring adequate earnings, sufficient working hours, a certain level of job security and access to social protection.

\subsubsection{Vulnerable employment as a proxy for non-productive employment}

Another way to capture work that may not be sufficiently productive to enable those performing it to support their dependents is to take account of vulnerable employment. According to the ILO definition, vulnerable employment includes contributing family workers and own-account workers. In the context of developing countries, own-account workers are for the most part engaged in petty trading or farming for own-consumption, mostly in the informal economy. This is very different from self-employed workers in high value-added services, such as doctors and freelance IT specialists. In developed countries, own-account workers would ideally capture all self-employed persons who are performing task-based work (including on digital labour platforms), subcontracting to larger firms without an established employment relationship, or engaging in casual work; in other words, workers who are in nonstandard and precarious forms of employment (ILO 2016b). However, vulnerable employment 
so defined does not capture all those in precarious wage employment and involuntary parttime wage employment. ${ }^{29}$

The vulnerable employment dependency ratio (VEDR) integrates vulnerable workers as dependents and comprises: (a) children below the age of 15 years, (b) persons aged 15 to 64 years who are outside the labour force, (c) all unemployed persons aged 15 years and over, (d) older persons aged 65 years and over, and (e) vulnerable workers.

\section{$V E D R$ \\ $=\frac{\text { non working age }+ \text { outside the labour force }+ \text { unemployed }+ \text { vulnerable employment }}{\text { non vulnerable employment }}$}

where:

non-working-age is the number of persons aged under 15 years or over 64 years;

outside the labour force is the population aged 15 to 64 years that is not engaged in the labour force;

unemployed is all persons aged 15 years or older who are seeking and are available to start working for pay or profit in specified reference periods;

vulnerable employment is the sum of own-account workers (also known as selfemployed workers without employees) and contributing family workers (also known as unpaid family workers);

non-vulnerable employment is the total number of persons in employment minus those in vulnerable employment.

As shown in Table 4.2, dependency increases significantly across all income groups when vulnerable employment is taken into account. In developing countries, the VEDR rises sharply by a factor of 8.5 compared to the EBDR and is predicted to reach 11.40 in 2024 . This means that each non-vulnerable worker needs to provide support for more than 11 dependents. The total ratio has been decreasing constantly since 1991 (when it was 16.94, see Figure 4.12);

\footnotetext{
${ }^{29}$ Loichinger and Skirbekk (2016) calculate an alternative dependency ratio for European Union countries that is based on actual number of hours worked. This measure is very relevant but difficult to compute and less relevant for developing countries, where this data is not available and where wage employment is often less than 20 per cent of total employment.
} 
accordingly, the sub-ratio of vulnerable employment dependency will have more than halved by 2024 . While men are more often engaged as own-account workers, women are more than twice as likely to work as contributing family members.

In emerging countries, the overall dependency ratio is considerably smaller than in developing countries. It will decrease from 5.36 in 1991 to 3.73 in 2024, mainly due to a shrinking child dependency ratio, although the share of vulnerable employment also fell by around three quarters. Nevertheless, the VEDR is on average three times higher than the EBDR. As with developing countries, men are disproportionally represented among own-account workers and women among contributing family members. The shares of both activities were shrinking for women and men until 2015 and have been stagnating ever since.

In developed countries, the increase compared to the EBDR is much smaller, since comparatively fewer workers are engaged as own-account workers or contributing family members. The VEDR is on average 1.2 times higher than the EBDR. While the total VEDR has been decreasing over time, it is projected to rise again and reach 1.37 in 2024 as a result of population ageing. The distribution of vulnerable employment follows the same gender pattern as for developing and emerging countries, although the discrepancy between women and men is the highest for contributing family members. 
Figure 4.12. Vulnerable employment-based dependency ratio (VEDR), by income group, 1991-2024
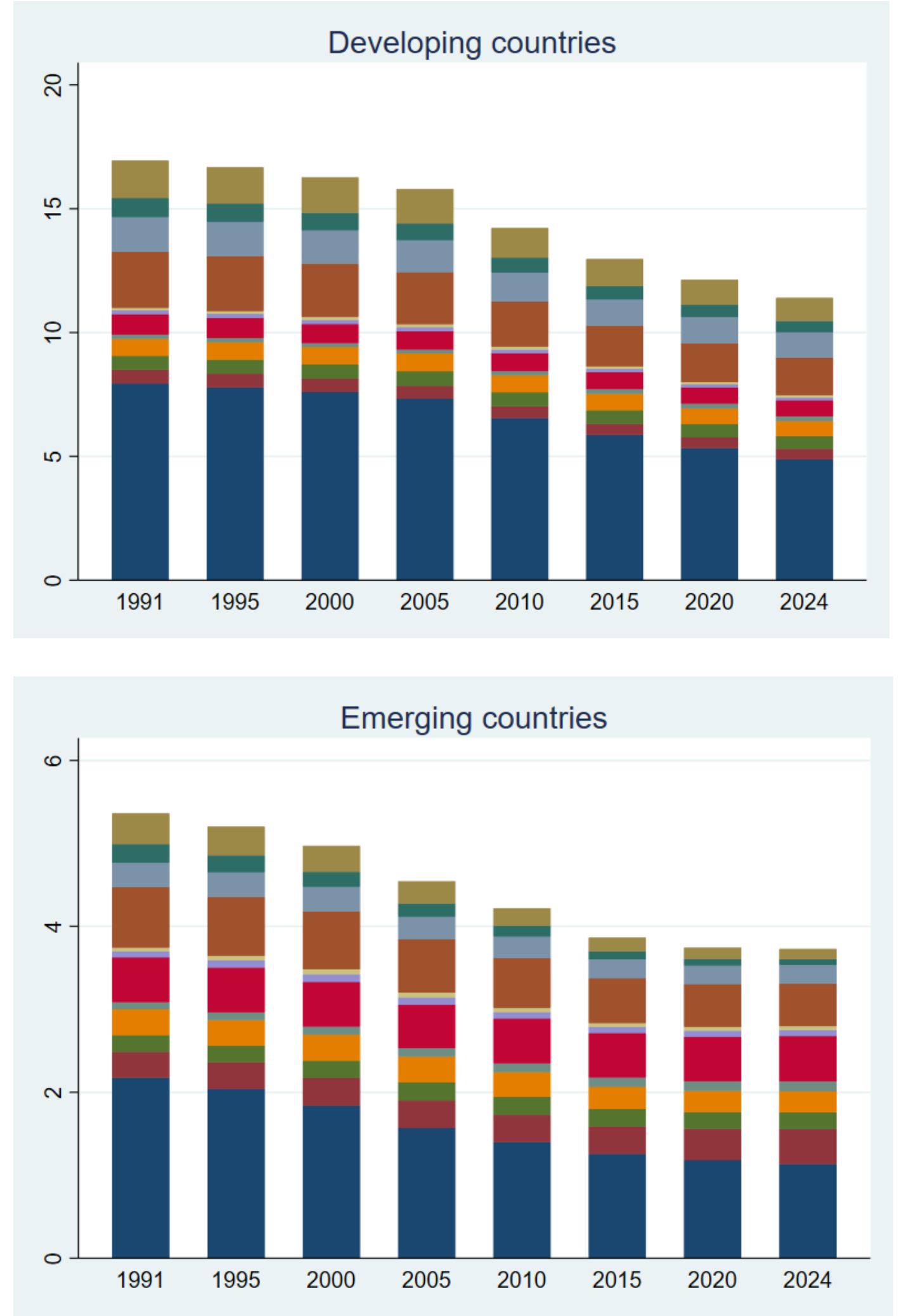


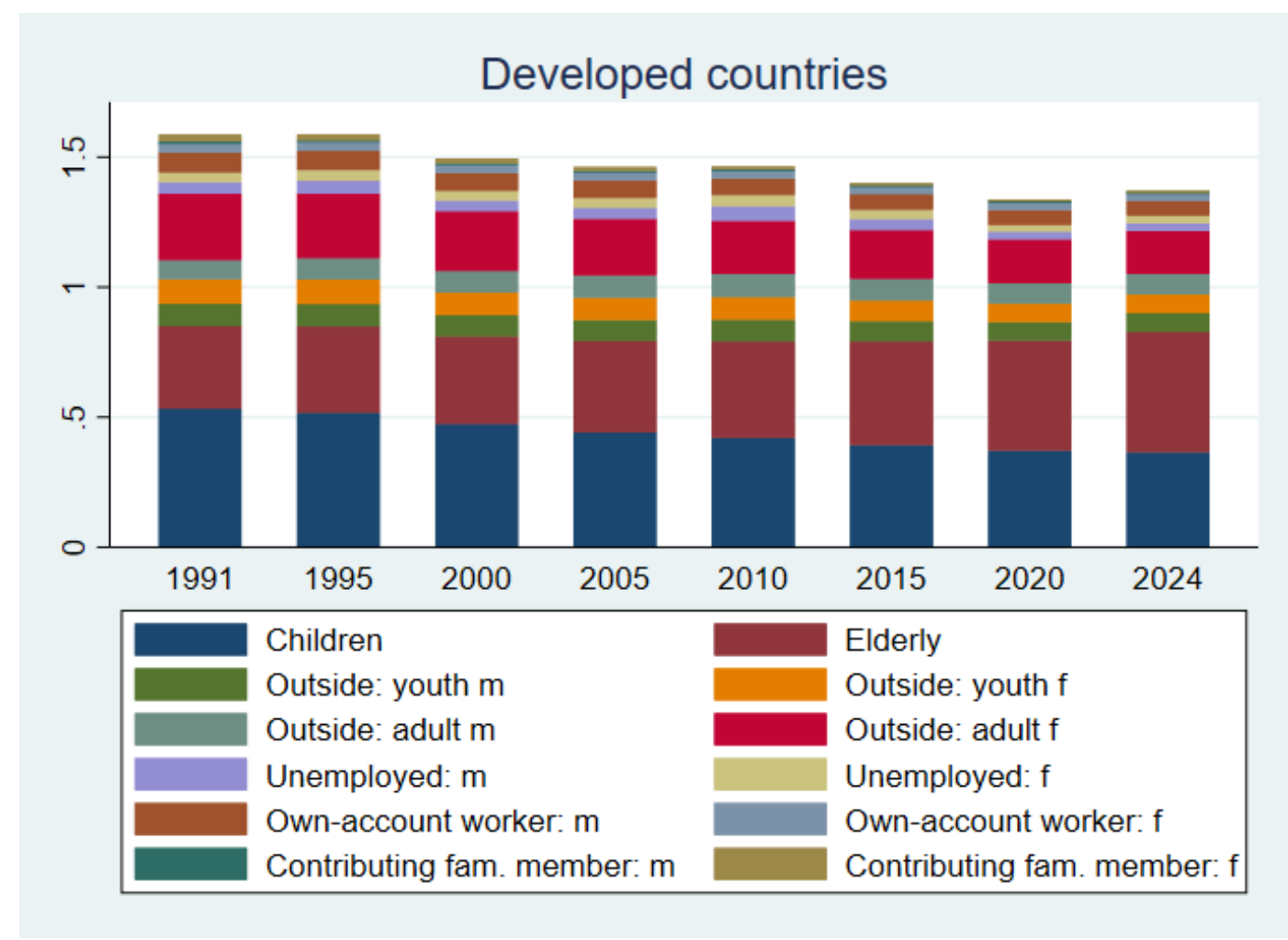

Source: calculations based on the ILO LFEP database, July 2019 update.

In developing countries, the vulnerable workers component of the total dependency ratio (34.4 per cent in 2024) is greater than that of persons outside the labour force and the unemployed (19 per cent in 2024) (see Figure 4.13). Clearly, many people have no other choice than to engage in non-productive work owing to a lack of more decent employment opportunities combined with a lack of social protection. Although the total VEDR is decreasing over time, the share of vulnerability in the total dependency ratio is at a persistently high level. The proportions of children and older persons remain the same as in the WPDR.

In emerging countries, persons outside the labour force and the unemployed account for one third, and those in vulnerable employment for one quarter, of the VEDR in 2024. The trend indicates a decreasing share of vulnerable employment and a strongly increasing share of persons outside the labour force and the unemployed between 1991 and 2024. The turning point came in 2010, when the latter cohort became the most important component of the VEDR.

In developed countries, the contribution of older persons increased significantly, surpassing that of children in 2015. The contribution of persons outside the labour force and the unemployed to the overall dependency rate remained at a fairly constant and high level 
(around 37 per cent) until 2010, when it began falling. Nevertheless, it is still the most important factor of the VEDR, although the elderly dependency ratio is expected to draw level by 2024 . The share of vulnerable employment has always been relatively low and has been slowly decreasing from 0.14 in 1991 to 0.09 in 2024.

Figure 4.13. Breakdown of the VEDR over time, by income group, 1991-2024

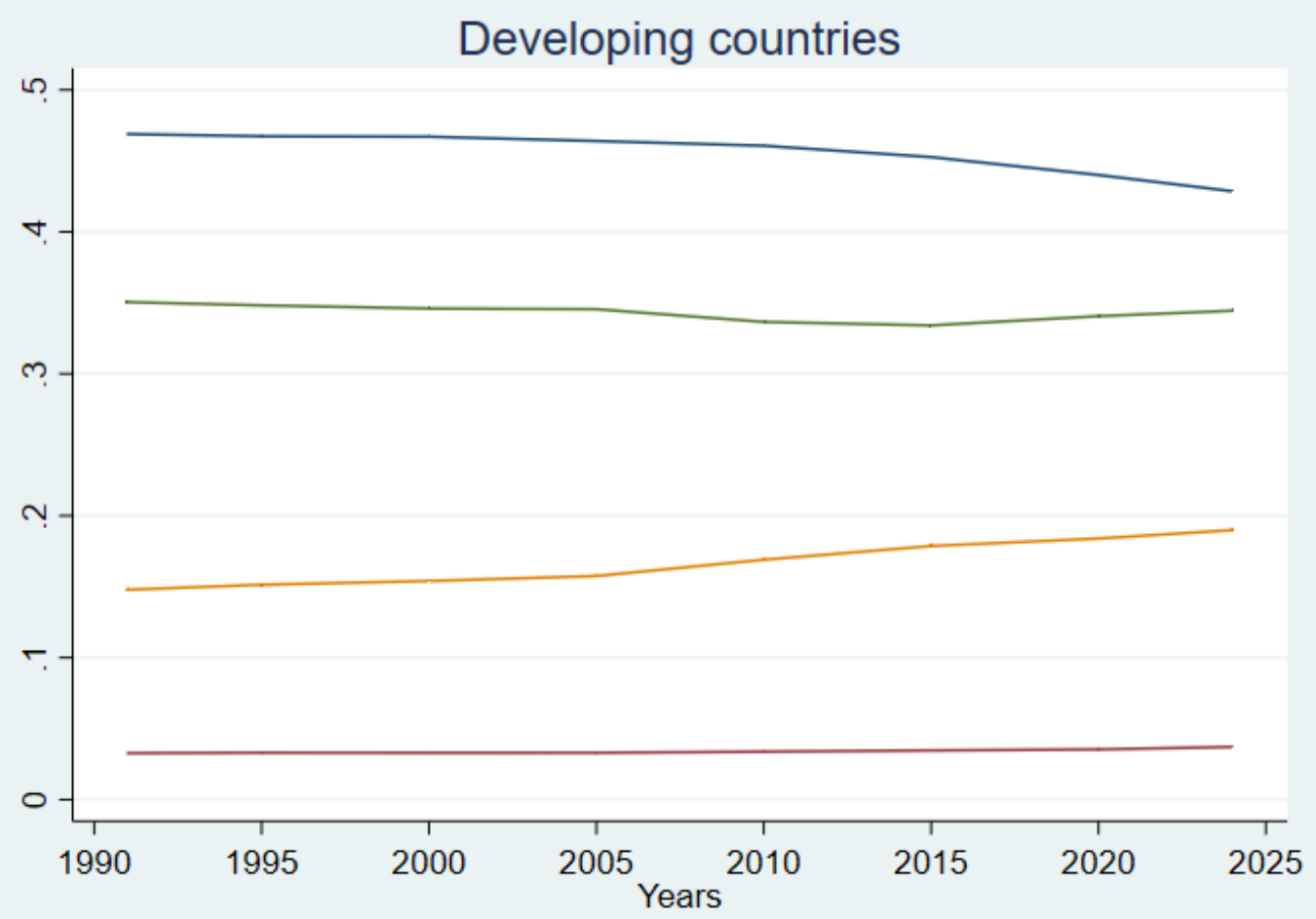



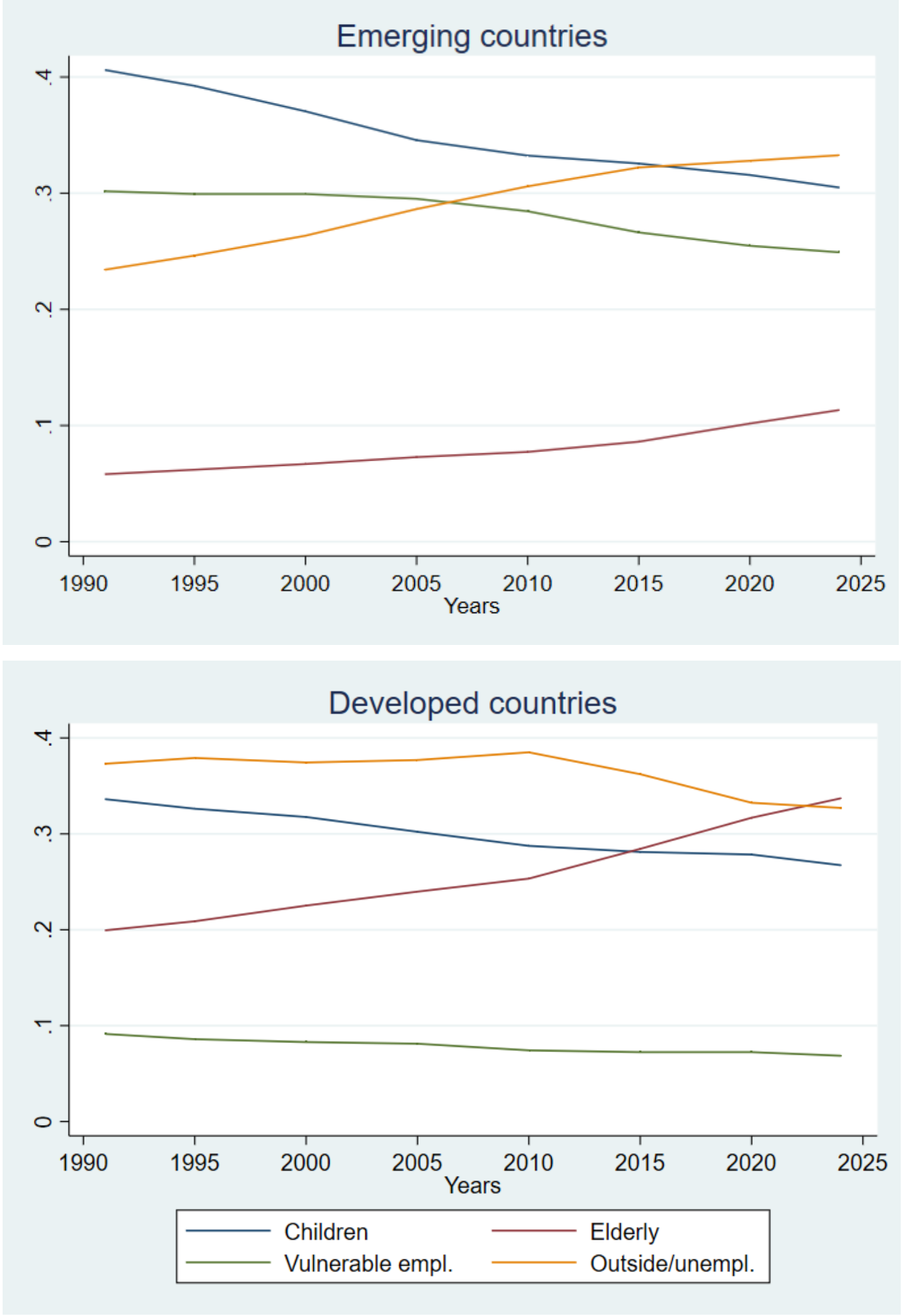

Source: calculations based on the ILO LFEP database, July 2019 update.

The VEDR benefits from excellent data availability both in terms of country coverage and time dimension, although projections are limited to the near future. However, the concept of vulnerability is based on strong assumptions which call into question the specificity and relevance of the indicator. First, own-account workers and contributing family members form 
a very diverse group, ranging from subsistence farmers to productive and profitable enterprises. At the same time, many wage workers are in precarious employment characterized by low levels of pay and employment protection, and by limitations on their freedom of association and collective bargaining - but are not captured by this indicator. The assumption that own-account workers and contributing family members are intrinsically more vulnerable than other persons is as questionable as the assumption that wage workers would by definition be less vulnerable. Thus, vulnerable employment could be more accurately defined on the basis of employment conditions rather than employment status (see section 2.3), which would then also allow vulnerable employees to be included.

Nevertheless, own-account workers and contributing family members represent a large part of the workforce - especially in developing and emerging economies - with the vast majority of these workers ( 85 per cent) engaged in the informal economy, which is often characterized by a lack of income security, access to labour rights and social protection (ILO 2018c). The vulnerable employment dependency ratio therefore adds another important dimension to dependency by including workers who are thought to be more vulnerable and hence more likely to be in need of support. 
Table 4.2. Comparison of different dependency ratios, by income group, 2000-30

\begin{tabular}{|c|c|c|c|c|c|c|c|}
\hline & & DDR & ABDR & EBDR & LUDR & WPDR & VEDR \\
\hline \multirow{3}{*}{2000} & $\begin{array}{l}\text { Developing } \\
\text { countries }\end{array}$ & 0.92 & 1.56 & 1.61 & . & 5.76 & 16.26 \\
\hline & $\begin{array}{l}\text { Emerging } \\
\text { countries }\end{array}$ & 0.59 & 1.30 & 1.40 & . & 5.15 & 4.97 \\
\hline & $\begin{array}{l}\text { Developed } \\
\text { countries }\end{array}$ & 0.49 & 1.11 & 1.22 & . & 1.22 & 1.49 \\
\hline \multirow{3}{*}{2010} & $\begin{array}{l}\text { Developing } \\
\text { countries }\end{array}$ & 0.88 & 1.58 & 1.63 & 2.01 & 3.85 & 14.22 \\
\hline & $\begin{array}{l}\text { Emerging } \\
\text { countries }\end{array}$ & 0.51 & 1.28 & 1.37 & 1.50 & 2.41 & 4.22 \\
\hline & $\begin{array}{l}\text { Developed } \\
\text { countries }\end{array}$ & 0.49 & 1.08 & 1.22 & 1.32 & 1.22 & 1.46 \\
\hline \multirow{3}{*}{2020} & $\begin{array}{l}\text { Developing } \\
\text { countries }\end{array}$ & 0.81 & 1.52 & 1.56 & 1.95 & 3.11 & 12.13 \\
\hline & $\begin{array}{l}\text { Emerging } \\
\text { countries }\end{array}$ & 0.50 & 1.34 & 1.43 & 1.54 & 1.70 & 3.74 \\
\hline & $\begin{array}{l}\text { Developed } \\
\text { countries }\end{array}$ & 0.54 & 1.09 & 1.13 & 1.20 & 1.13 & 1.34 \\
\hline \multirow{3}{*}{2024} & $\begin{array}{l}\text { Developing } \\
\text { countries }\end{array}$ & 0.77 & 1.47 & 1.52 & 1.90 & 2.84 & 11.40 \\
\hline & $\begin{array}{l}\text { Emerging } \\
\text { countries }\end{array}$ & 0.51 & 1.36 & 1.45 & 1.56 & 1.66 & 3.73 \\
\hline & $\begin{array}{l}\text { Developed } \\
\text { countries }\end{array}$ & 0.56 & 1.12 & 1.17 & 1.23 & 1.17 & 1.37 \\
\hline \multirow{3}{*}{2030} & $\begin{array}{l}\text { Developing } \\
\text { countries }\end{array}$ & 0.72 & 1.41 & . & . & . & . \\
\hline & $\begin{array}{l}\text { Emerging } \\
\text { countries }\end{array}$ & 0.51 & 1.40 & . & . & . & . \\
\hline & $\begin{array}{l}\text { Developed } \\
\text { countries }\end{array}$ & 0.60 & 1.18 & . & . & . & . \\
\hline
\end{tabular}

Notes: DDR: demographic dependency ratio; ABDR: Activity-based dependency ratio; EBDR: Employment-based dependency ratio; LUDR: Labour underutilization dependency ratio; WPDR: Working poverty-based dependency ratio; VEDR: Vulnerable employment dependency ratio. Projections of employment and unemployment figures based on econometric models are only available to the year 2024. Similarly, projections of time-related underemployment are only available from 2005. As a result, estimates for the EBDR, LUDR, WPDR and VEDR are not included for all years.

Source: calculations based on the ILO LFEP database, July 2019 update. 


\subsection{Conclusion}

The proportion of persons aged 55 years and over in the total population is set to increase significantly in all regions of the world over the coming decades. By 2050, more than three quarters of countries will either be ageing or already aged societies. As a direct consequence, the workforce will be ageing too. The number of workers aged 55 to 64 years will increase to represent between 12 per cent and 25 per cent of the total labour force by 2030 . What are the implications for the labour market? Will all these persons work, whether by choice or necessity? If they do, what conditions will they face?

This paper shows that, according to the latest forecasts, labour force participation rates (LFPRs) for persons aged 55 years and over differ across income levels. In developing countries, the progress made in terms of pension system coverage and other social transfers is giving older workers greater choice in deciding whether to remain in the labour market. Consequently, LFPRs in developing countries are decreasing significantly. In emerging countries, LFPRs are generally lower than in developing countries and are decreasing for persons aged 65 years or over. The situation is different in developed countries, where social protection systems are well developed, but where an ageing population is driving pension system reforms and active ageing policies that increase the labour force participation rates of older workers.

The gender gap in labour market participation is highest in emerging countries. As a result of targeted policies, it is slowly diminishing with age across all income levels, with the exception of workers aged 65 years or over in developed economies. Despite the progress that has been made, gaps remain that require decisive action in order to ensure equal opportunities in the labour market.

Clearly, ageing is impacting the labour market the world over. In countries that have already aged or are ageing rapidly - mostly developed economies - the contributions of workers to pension schemes are needed in order to cater for a growing group of retirees. In the light of a shrinking workforce at the lower age band, more women and men will have to work until, and most likely beyond, the age of 64 years. In countries that are still to enter their full demographic transition, providing decent employment to the young and adult labour force is a precondition for ensuring access to social protection by older workers and to education by large cohorts of children. These are issues that are commonly referred to in the literature as 
economic dependencies. Although these are useful indicators, their explanatory powers in terms of the functioning of the labour market are seriously limited. This paper therefore introduces an additional concept related to decent employment. If those who work are not productively employed - that is, engaged in an activity that provides them and their household with an income sufficient to be free from poverty - then they cannot contribute effectively to the education and retirement of others.

This paper therefore proposes a set of employment-based dependency ratios that realistically reflect the capacity of persons who work to support those who do not, based on different proxies for non-productive employment. Three main proxies are used: (i) the labour underutilization rate, (ii) the working poverty rate, and (iii) the vulnerable employment rate. These new employment-based dependency ratios are useful measures for probing into the causes of dependency and informing employment policy choices. They have different strengths and can therefore be used selectively for different country contexts, allowing policy makers to formulate better targeted and country specific policies. It has been possible to calculate them thanks to a very rich data set produced by the ILO that provides a consistent series of labour market data for all countries with forecasts to 2024 and beyond. The analysis shows the importance of age- and gender-specific employment levels and employment quality when discussing the challenges associated with population ageing. Including the employment quality dimension reveals important challenges for the future. As ageing becomes a worldwide reality, improving the quality of employment will become a necessity in order to avoid a steep increase in employment-based dependency ratios.

Further research is needed with regard to the design of the indicators' components. First, the poverty threshold of US\$1.90/day (PPP) does not account for the fact that achieving the same set of capabilities may require a different set of goods and services in different countries. In addition, it may become unsuited to tracking the evolution of poverty across and within countries as they continue to develop. Second, the upper age limit of 64 years for the workingage population requires further examination since the reality of "retiring" differs significantly across the world. Third, the concept of vulnerability is based on strong assumptions and its definition would benefit from new empirical evidence.

The consequences for dependency rates represented by high youth unemployment, low female labour force participation, high rates of labour underutilization, significant levels of 
vulnerable employment and the high incidence of working poverty lead to some key policy messages. Overall, absorbing more persons into productive employment should be a priority in order to respond to demographic change. Bringing people into productive employment removes them from the group of dependents and enables them to provide for those who are in need of support. Investing in key economic sectors that have a high employment creation potential can significantly transform economies and lead to the creation of millions of decent jobs (ILO 2019d). In addition, a number of policy initiatives may be considered:

Activating the potential labour force: The findings from the different dependency measures showed that persons outside the labour force weigh heavily on dependency rates. A large proportion of the youth population is not in education, employment or training (NEET); moreover, young and adult women, in particular, are disproportionally excluded from the labour market, often because of their involvement in family-related care responsibilities (Elder and Kring 2016). Setting clear objectives in terms of employment rates and adopting the right policies to achieve these targets would aid considerably in decreasing dependency levels in rapidly ageing and already aged developed and emerging countries. Transformative care policies would yield women's higher participation in the labour market and thus contribute to greater gender equality, better economic outcomes and improved health and care provision in a given country.

Promoting the employment of older workers: The results presented in this paper support a targeted policy approach to the challenges posed by ageing societies. Rising life expectancy coupled with diminishing fiscal space will require an extension of the working age of older workers. To enable the prolonged participation of workers in the labour market, several obstacles must be overcome. At the enterprise level, workplaces and the organization of work must be adapted to the needs of older workers, such as by providing flexible working arrangements and removing physical barriers. Launching public awareness campaigns, working closely with employers' organizations and providing financial incentives to promote the hiring or retention of older workers could support such efforts. Public employment services should offer training opportunities and career guidance services tailored to the needs of older workers.

Creating better and productive jobs: Simply raising the employment rates of women, youth and older workers will not be enough. As the dependency measures based on proxies for 
productive employment demonstrate, the productivity and quality of these jobs matter, as has been shown by the dependency ratios based on labour utilization, working poverty or vulnerable employment rates. Moreover, increasing the productive employment rate of those most impacted by inactivity, working poverty or vulnerable employment will effectively reduce future dependency rates. Policies aimed at ensuring a better match of labour demand and supply, decreasing vulnerable employment and working poverty, and creating quality employment are urgently needed.

Investing in training and education throughout the life cycle: Our dependency ratios show that it is important to bring more persons into the labour force, in particular youth and women, but labour force participation trends also show that it will be critical to retain older workers in the labour force. An important element for ensuring the employability of all workers is to provide the opportunity for continuous retraining and upskilling. Employers and public employment services could provide targeted training to help overcome the potential difficulties that older workers face when using new technologies. Moreover, employers could promote working in intergenerational teams, which would increase knowledge exchange between younger and older workers and also break down prejudices and stereotypes.

Making social protection systems sustainable: The paper shows that when we only take into account the productively employed as those in a position to support others, dependency ratios become very high. Unsustainable dependency ratios will make the funding of social protection impossible. If there are too few persons of working age, and if too few of those are productively employed, fiscal revenues, both direct (through income tax) and indirect (through consumption tax), will remain low and below potential. Low fiscal revenues mean that governments will not be able to finance public policies to support productive employment creation or to finance social protection schemes aimed at those who are inactive (children at school, pensioners, persons with disabilities) or who are unemployed, vulnerable or in a situation of working poverty (cash transfers, unemployment or sickness benefits, and public employment schemes). It is therefore necessary to adapt social protection systems to demographic change and enable them to continue to fulfil their key role in preventing and reducing poverty, enhancing income security and limiting inequality (Behrendt and Nguyen 2018). Ultimately, social protection systems will give older workers a real choice about whether to remain in employment and will lead to lifelong active societies (Seike 2016). 
Strengthening labour market information systems: Dependency measures based on productive employment should be used for long-term projections in order to inform policymakers and influence policy decisions, something that has not been the case before now. The paper has highlighted the data needs to produce these indicators and a clear methodology to calculate them, which can help all labour market observatories across the world produce the productive employment-based dependency ratios. 


\title{
5 Scarred Youth: School-to-work Transitions and Income Scars in Times of Crisis
}

\author{
Martin Ostermeier
}

\begin{abstract}
It has never been easy for young people to transition from school into the labour market even less so in times of economic recession. Global labour markets have yet to fully recover from the global financial crisis of 2007-08 but are already facing a new crisis triggered by the COVID-19 pandemic. The emerging "lockdown generation" is assumed to be disproportionately affected by the economic turmoil, especially when trying to gain a foothold in the labour market after finishing their education.

This paper analyses the scarring effect of an economic crisis. It derives estimates of the impact of a crisis on the school-to-work transition duration and on potential future income. It finds that youth entering the labour market in times of crisis suffer a significant increase in their transition time into their first job and a strong decrease in their labour income. Both effects appear to be long-lasting and could be classified as employment scars and income scars respectively.
\end{abstract}


"[I]n medical terms, the virus does not discriminate between its victims in its social and economic impact, it discriminates brutally against the poorest and the powerless."

Guy Ryder (2020) - Director-General of the International Labour Organization

\subsection{Introduction}

The global financial crisis of 2007-08 (GFC) triggered a major downturn in the global economy. A large number of companies were bankrupted and millions of workers were laid off or faced substantial cuts to their working hours, wages or other benefits. Twelve years on and the labour markets have yet to fully recover to pre-crisis levels. And now, even as traces of the GFC still remain visible, another global crisis has struck: the COVID-19 pandemic. The pandemic is, first and foremost, a public health emergency of international concern (WHO 2020) that poses an immediate threat to people's health and lives. However, it is also disrupting the global economy and threatening the livelihoods and well-being of millions of workers.

Young people $\mathrm{e}^{30}$ are particularly prone to suffering the consequences of a crisis. Indeed, past economic recessions, including the GFC, have hit youth much harder than adults. Even in times of economic prosperity, the unemployment rate is usually higher for youth than it is for adults owing to the fact that young people are lacking in skills and work experience (Verick 2011; Pastore 2018), but also have less access to finance in order to start their own business (O'Higgins 2001). However, youth unemployment rates only tell part of the story, as the labour market participation rate (LFPR) for youth is also around 25 percentage points lower compared to the rate for adults (Figure 5.1).

\footnotetext{
${ }^{30}$ The United Nations standard definition of "youth" suggests an age range of 15 to 24 years. To reflect the fact that today's youth spend more time in education and also face a prolonged transition into the labour market (see Ryan 2001), young people are defined in this paper as persons aged 15 to 29 years, unless stated otherwise. The terms "youth" and "young people" are therefore used interchangeably.
} 
Figure 5.1. Labour force participation rates (LFPR) and female-male ratio by income groups (1998-2018)

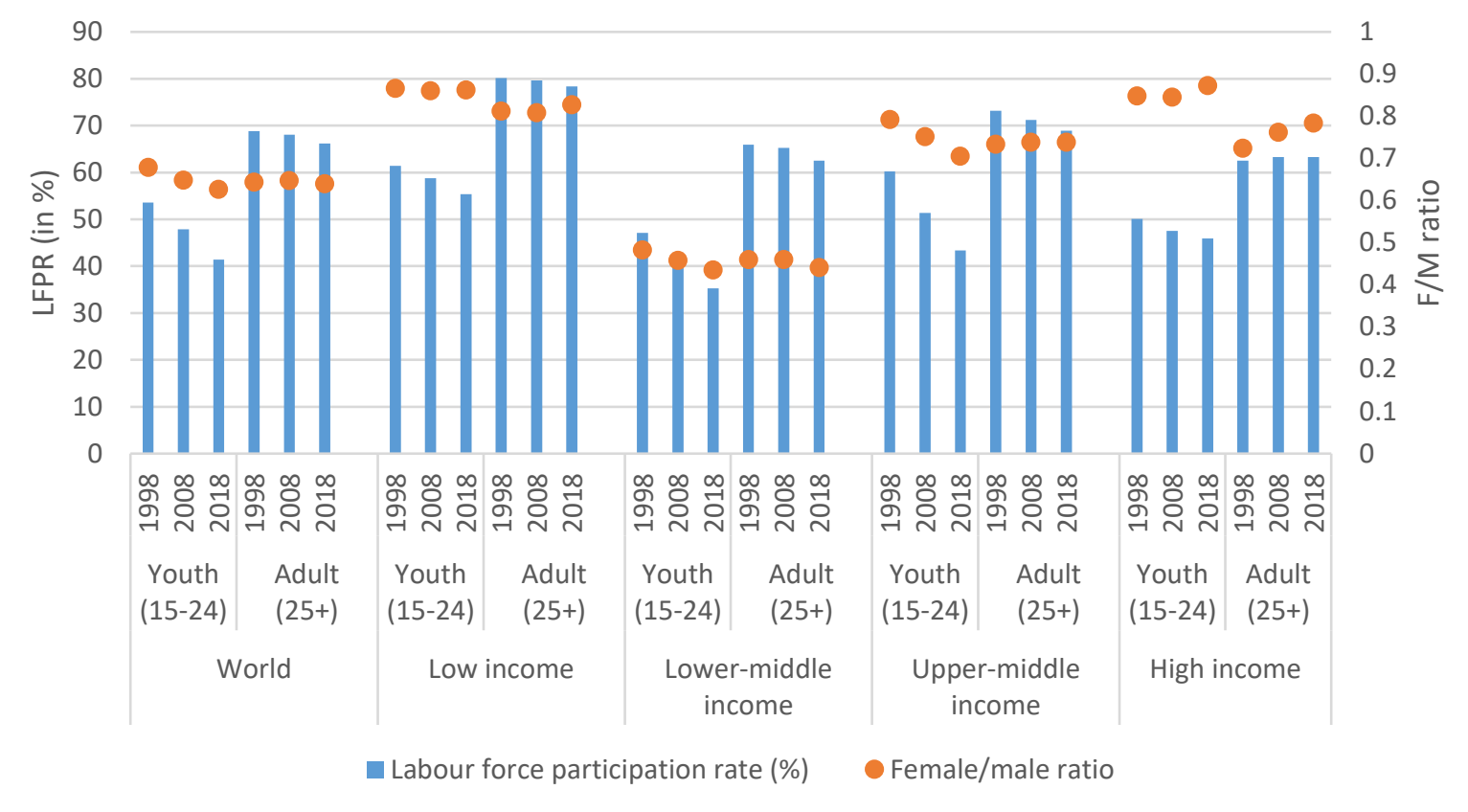

Source: ILO modelled estimates, July 2019.

Globally, only around four in ten young persons are in the labour force, while a similar share is either in education or training (40 per cent). The remaining 20 per cent form the group of youth not in employment, education or training (NEET) (ILO, 2020a). It would therefore be misleading to consider changes in unemployment rates as the sole indicator, since any rate variations would affect only a fraction of the youth population (O'Higgins 2010). For instance, it would exclude young persons who are not yet part of the labour force and who are still in the phase of transitioning from school to work.

This transition has become increasingly difficult and is exacerbated at times of economic turmoil. In general, young workers have yet to make the transition into stable employment and, instead, are particularly prone to ending up in non-standard forms of employment or in the informal economy (ILO, 2016b). In fact, young persons are on average 1.5 times more likely than adults to be in involuntary part-time employment and they account for a 14 per cent greater share of employment in the informal sector (ILO, 2020b). Both informal and nonstandard employment provide limited - if indeed any - social protection such as access to health care, paid sick leave and unemployment benefits. Following the last-in, first-out principle, youth are often the first to face reduced hours or even to be laid off. In addition, mass redundancies cause an excess supply of labour. This creates a situation in which young jobseekers and new entrants to the labour market are forced to compete with an increasing 
number of newly jobless older and more experienced workers for a smaller number of vacancies.

It is too early to assess the full impact of the COVID-19 pandemic on the situation of youth in the world of work. Nevertheless, the first indications are that this crisis may affect young people even more severely than the GFC. According to the ILO Monitor (2020f), some first data points suggest a massive rise in youth unemployment and a significant decline in their LFPR. In the US, for instance, the unemployment rate almost tripled for male youth and even quadrupled for female youth between February and April 2020. At the same time, the LFPR dropped by 7.5 percentage points. While these point estimates fall short of proving a general trend, a sectoral perspective reveals what may lie ahead. More than four in 10 young workers - particularly young women - were working in the four economic sectors that are now most adversely affected by the crisis, the vast majority of which are located in the informal economy. Although the GFC differed both in cause and nature from the crisis resulting from the COVID-19 pandemic, there may be some important parallels that could aid policymakers to develop targeted responses.

This paper seeks to add two main contributions to the academic discourse on the school-towork transition (SWT). First, studies on the SWT have largely concentrated on developed economies, which have provided important insights but which may not be applicable to lowand middle-income countries. This study fills this gap by deriving estimates for the SWT in middle-income countries. Second, the paper investigates the scarring effects of an economic crisis by analysing its impact on the SWT duration (employment scar) and on the potential labour income (income scar).

The paper is organized as follows: the first chapter discusses the theoretical background, clarifies the concepts of employment and income scars, and states the hypothesis. In the second part, we introduce the data set, conduct a descriptive analysis, and develop the framework for the empirical analysis. This is followed by actual analysis and the presentation of the empirical results. The last two chapters discuss the findings and conclude. 


\subsection{Conceptual framework}

\subsubsection{Definition of school-to-work transitions}

The journey from youth to adulthood is often marked by non-linear fluctuations until a stable job is found. After leaving the educational system, a young person may experience a change in their employment status (employed, unemployed) or employment type (wage worker, selfemployed), take on care responsibilities or household duties, become inactive or even return to the educational system. These transition stages are intertwined, and mastering one stage successfully may pave the way for the next phase.

The school-to-work transition (SWT) is a crucial stage in the life of a young person. However, there is no uniform definition of the SWT and, indeed, it varies between different countries and studies. In some cases, the transition's end point is reached once a person obtains a job any job - regardless of its nature or quality (c.f. Dolton, Makepeace, and Treble 1994; Guarcello et al. 2005). In other cases, the transition is only concluded if the respective job meets certain qualitative criteria, such as the nature or duration of the employment relationship (c.f. Elder and Kring 2016; ETF, 2008). The ILO offers a three-stage classification framework for young people aged 15 to 29 years (Table 5.1).

Table 5.1. Overview of school-to-work transition stages

\begin{tabular}{|c|c|}
\hline Transition stage & Description \\
\hline Transition not yet started & $\begin{array}{l}\text { - Still in school and outside the labour force or } \\
\text { - Not in school, outside the labour force and no intention of } \\
\text { looking for a job }\end{array}$ \\
\hline In transition & $\begin{array}{l}\text { - In school and currently employed or unemployed (i.e. in the } \\
\text { labour force) or } \\
\text { - Not in school and unemployed or } \\
\text { - Not in school and currently employed in a temporary and } \\
\text { unsatisfactory job or } \\
\text { - Not in school and not in employment but aiming to be } \\
\text { employed later }\end{array}$ \\
\hline Transited & $\begin{array}{l}\text { Not in school and } \\
\text { - Currently employed in a stable job or } \\
\text { - In satisfactory self-employment or } \\
\text { - In a satisfactory temporary job }\end{array}$ \\
\hline
\end{tabular}

Source: author's compilation based on ILOSTAT Glossary. 
Accordingly, the transition starts when a person becomes available to the labour market and ends when they either obtain a stable job (i.e. not time-bound) or are satisfied with their temporary job or entrepreneurial activity. The analysis in this paper is based on the more relaxed version of transition and applies the criterion of the ILO's "in transition" stage.

Any disruption or blockage of the SWT has severe consequences for both the individual and the wider society. Obviously, a prolonged transition due to spells of unemployment or inactivity directly results in a loss of personal income. Depending on the welfare regime, this could also burden society with direct public expenditure (social transfers and welfare benefits for the individual) and indirect resource costs due to missing contributions to the public treasury (income and consumption tax revenue) (Eurofound 2012b). However, a prolonged transition has further-reaching and longer-lasting consequences for an individual's future employment trajectory beyond the immediate income loss. These consequences have their theoretical foundation in human capital theory (Becker 1964) and signalling theory (Spence 1973). Human capital theory argues that a period of unemployment or inactivity interrupts the accumulation of work experience and depreciates any skills already acquired (Pissarides 1992). According to signalling theory, both outcomes are signals of lower productivity to a potential employer, leading to a lower probability of being hired or a lower wage being offered (Arulampalam, Gregg, and Gregory 2001). Moreover, candidates with assumed lower productivity may be more likely to obtain jobs of lower quality in terms of earnings, working hours, skills utilisation or social protection. From a labour supply perspective, tensions in the labour market can prompt youth to lower their personal reservation wage and hence begin their professional life at a lower income level (Christensen 2002). Once established, this gap between initial reservation wage and actual accepted wage may prove difficult to eliminate. A lack of decent wage-work opportunities can also push young people into involuntary selfemployment, sometimes characterized as low quality in terms of income, stability and prospects (Hughes 2006; Rissman 2003).

If the imposed income penalty or the reduced prospects for quality employment turn into more permanent features of an individual's employment history, they are commonly referred to as "scars", a term first coined by Ellwood (1979). More precisely, the income penalty imposed by spells of unemployment or inactivity is referred to as an "income scar", while the reduced probability of being re-employed or of obtaining (decent) work is referred to as an 
"employment scar". Just like physical scars, both are thought to be long-lasting, and traces may even remain throughout an individual's entire working life.

\subsubsection{Empirical literature review of scarring effects}

The following literature review summarises empirical findings on employment and income scars. Although there are considerable differences in the magnitude and persistence of employment and income scars, the findings highlight the relevance for analysing the impact of an economic crisis.

In a study of Peruvian youth, Cavero and Ruiz (2016) concluded that young people who had a high-quality first job increased their probability of getting a high-quality job later in life by 12 per cent compared to those who started out in a low-quality job. A factorial survey experiment amongst Swiss recruiters revealed that unemployment spells recorder in an applicants' CV decreases the perceived suitability of an applicant for a specific job (Shi et al. 2018). Petreski et al. (2016) found that North Macedonian youth who experienced unemployment spells early in their careers had a lower probability of finding employment than persons who had no (or fewer) unemployment spells. Depending on the number and duration of these periods of unemployment, the employment scar ranged from 28.4 per cent to 61.8 per cent. Similar results are derived in a study of unemployment, low pay and skills underutilisation in the Australian labour market (Mavromaras, Sloane, and Wei 2015). The authors find that skills underutilised workers as well as low-paid workers share a higher risk of future unemployment. Helbling and Sacchi (2014) demonstrated that an unemployment spell in the early stages of a person's career increased their probability of finding themselves not in employment, education or training (NEET) by around 9 per cent. An analysis of youth in New Zealand further revealed that individuals who had been NEET at least once were on average 23 per cent less likely to be in employment compared to those who had never been NEET (Samoilenko and Carter 2015). These results seem to have been confirmed by a similar UK-based study which estimated the difference in the employment probability between both groups at 27.5 percentage points after 5 years and 20 percentage points after 10 years (Crawford et al. 2011). In Mexico, however, the difference was 10 percentage points: less pronounced but still significant (Ranzani and Rosati 2013). A NEET spell also diminishes a young person's qualityemployment choices. A common occupational destination in the UK, for instance, appears to be the personal and protective service sector, which accommodates 40 per cent of former 
NEETs. Jobs in this sector include catering, security, domestic work and childcare and are often characterized by temporary employment contracts, low pay, a lack of social protection and limited career prospects (Bentley and Gurumurthy 1999).

In addition to the employment scar, young people are also assumed to sustain an income penalty induced by an economic crisis that could turn into a persistent income scar. One of the most prominent studies on income scars was based on the British Household Panel Survey and identified an inverted u-shaped pattern to the wage scar: in the first year of unemployment, workers were attributed an income scar of around 6 per cent, which rose to 14 per cent in the subsequent three years before dropping to 11 per cent (Arulampalam, Gregg, and Gregory 2001). The above-mentioned study by Helbling and Sacchi (2014) further demonstrated that when young persons with unemployment spells in their work history obtained a job, they suffered a wage scar of 7 per cent. Lupi and Ordine (2002) seemed to confirm this finding when they estimated a wage scar of around 8 per cent for Italian workers who experienced up to six months of unemployment. A study by Ruhm (1991) showed that displaced workers were twice as likely to suffer an income penalty of over 25 per cent compared to their non-displaced counterparts. The same study further revealed that while the employment scar slowly disappeared over time, the wage scar remained clearly visible. The long-lasting nature of wage scars was also confirmed by Gregg and Tominey (2005), who claim to have established a causal relationship between male youth unemployment and subsequent wage levels in later working life. Their estimates revealed a wage penalty of 13 to 21 per cent for individuals who experienced multiple spells of unemployment, and a slightly lower penalty of 9 to 11 per cent for individuals with only one unemployment experience. For both groups, a residual wage scar of around 8 per cent persists, even after 20 years. Cruces et al. (2012) estimated a wage penalty of around 11 per cent for Argentinian and Brazilian workers. While it tended to disappear quickly for some workers, it was larger and more persistent for low-skilled workers.

\subsubsection{Hypothesis and approach}

We are modelling the global financial crisis (GFC) as a shock to the labour market. In line with several descriptive assessments of the crisis' impact on youth labour markets (c.f. Verick 2009; O'Higgins 2010; R. Islam 2011; Kelly and McGuinness 2015; Carcillo et al. 2015), we assume that this shock will worsen the labour market prospects of new entrants, owing to, among other 
reasons, greater competition among jobseekers for fewer available jobs. This will make the transition into the labour market more difficult. Consequently, the SWT duration of individuals is expected to increase, leaving them with an employment scar on their work history. The assumed lower productivity of scarred individuals will cause a lower income level, resulting in an additional income scar.

Accordingly, this paper seeks to answer two main research questions (RQ):

$R Q$ 1: Does an economic crisis such as the global financial crisis affect the school-towork transition time of a young person (employment scar)? If so, which youth are most affected?

$R Q$ 2: Does an economic crisis affect future labour incomes (income scar)? If so, who is most affected and how persistent are these effects?

In order to address these employment and income scars, we first need to define the time span of the GFC. According to the literature, the GFC began as a US banking crisis in mid-2007 and evolved into a global crisis in September 2008 (c.f. Acharya et al. 2009; J. B. Foster and Magdoff 2009; Obstfeld and Rogoff 2009). The third quarter (Q3) of 2008 is therefore marked as the earliest potential starting point of the crisis for the countries in the sample. The quarterly growth rate of real gross domestic product (GDP) is then used to determine the beginning of the crisis for each individual country. More precisely, we identify two successive quarters with on average the smallest (i.e. most negative) GDP growth rates since Q3 2008.

The four consecutive quarters from that point onwards define the time span of the crisis in a given country. Based on this identification, we can select the treatment and control groups. Each person who finished formal education - and thus became available to the labour market - during the defined four quarters of the crisis is selected into the treatment group. Consequently, the control group comprises all those individuals who finished their formal education during the four quarters prior to the beginning of the crisis. In the simplified example of equation (i), the term in the middle identifies the treatment group and the term on the left the control group. The selection process can be formalized as follows: 


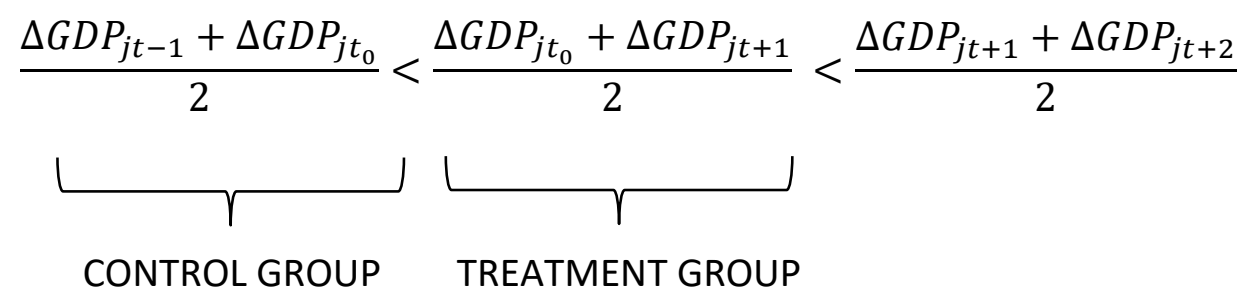

where $\triangle G D P_{j t}$ denotes the change in real GDP in country $y_{j}$ at time $_{t}$.

Table C 2 in Appendix C illustrates this identification strategy graphically.

In addition, Table C 2 shows the labour force participation rate (LFPR) and the unemployment rate for each country and quarter. These complementary indicators confirm the validity of the selection process. All countries show either a decrease in the LFPR or an increase in the unemployment rate over the four quarters of the treatment group compared to the respective quarters of the control group. In fact, most countries even show both. Moreover, these indicators reflect the slower labour market response rate in terms of the escalation of the crisis and the subsequent recovery. First, although GDP growth had already slowed in the quarter prior to the defined start of the crisis, both the LFPR and the unemployment rate remained mostly stable. In almost all countries, the situation in the labour market escalated in the quarter in which the crisis is determined to have begun. Second, although economic growth picked up during the time span for the treatment group in some countries, there seems not to have been any significant recovery in the labour market. These time lags are well-documented in the literature (c.f. Cazes, Heuer, and Verick 2011; Eichhorst et al. 2010) and confirm the inclusion of quarters with positive GDP growth rates following an economic recession.

\subsection{Analysis}

\subsubsection{Data}

The analysis draws on data from the ILO School-to-Work Transition Surveys (SWTS). These largely standardized SWTS were carried out in 33 low- and middle-income countries between 2012 and 2015. The resulting cross-sectional data set includes retrospective information on transitions into and within the labour market of individuals aged 15 to 29 years. The SWTS 
data has been chosen not only for the detailed activity history since leaving school but also the rich information provided on current employment at the time of the survey.

The scope of the analysis is restricted to middle-income countries for four main reasons: first, middle-income countries show comparable levels of poverty coupled with a basic level of social protection. Both factors combined give young people more choice when deciding whether to take up employment or pursue a different activity after finishing their formal education, which, in turn, influences the SWT duration significantly. Second, compared to lowincome counties, the labour market systems in middle-income countries are usually more advanced, including when it comes to the support offered by public employment services, thus facilitating the transition into employment. Third, there is a large knowledge gap around the nature and determinants of the SWT in middle-income countries. Lastly, the selection of countries was restricted by the availability of supplementing macroeconomic data (e.g. quarterly GDP growth rates) and by inconsistencies in the surveys' design. This sampling strategy resulted in the following 14 middle-income countries being selected:

- Armenia (2014)

- Brazil (2013)

- Dominican Republic (2015)

- $\quad$ Egypt (2014)

- El Salvador (2014)

- Jamaica (2015)

- Kyrgyzstan (2013)
- Moldova (2015)

- North Macedonia (2014)

- Montenegro (2015)

- Russian Federation (2015)

- Serbia (2015)

- Tunisia (2013)

- Ukraine (2015)

\subsubsection{Descriptive analysis}

Table C 1 in Appendix C contains the descriptive statistics for the full sample and the two subgroups (treatment and control):

\# of activities since school is a count variable which measures the number of activities a person has pursued since leaving school. These activities are categorized as (i) employment (wage work, self-employed, unpaid family work, apprenticeship or internship), (ii) unemployment, (iii) further training after formal education, (iv) home duties and caring for family members, and $(v)$ inactivity. The values range between zero (i.e. directly transitioned into current job) 
and 15 activities, with a mean of around 2.5 activities. The variable is mainly used as a predictor in the zero-inflated regression models (see 5.3.3).

Transition time to 1 st job is the SWT duration is the first dependent variable to assess the employment scar and calculated as the number of months between finishing formal education and obtaining a first job, i.e. it is the time a young person spends in categories (ii) $-(\mathrm{v})$ as defined above. The descriptive analysis shows that the average transition time in the control group (14.97 months) is some 16 per cent higher than in the treatment group (12.9 months). In other words, the descriptive analysis suggests that youth entering the labour market during the GFC transitioned into a job on average two months faster than a young person entering the labour market in the year before the crisis. This is contrary to our expectations, and the empirical analysis will demonstrate whether this conclusion holds true.

Labour income is the dependent variable of the income scar analysis. It is the employee's hourly wage or the self-employed person's hourly profit, expressed in international dollars with purchasing power parity (Int\$ PPP). The mean income is at a comparable level in both the treatment and control groups; the standard deviation is slightly higher in the treatment group. It should be noted that the minimum income is below zero since the negative profits (i.e. losses) of the self-employed are included. During the analysis, a constant value is added to the income variable which allows for a full log transformation of the data, including of negative observations (losses). This analytical constant is removed for all income values reported in this paper.

Finished school during GFC is the treatment dummy and takes the value 1 for young persons who finished their formal education during the GFC (treatment group), and the value 0 for those who finished a year prior to the crisis (control group). Across the full sample, individuals are equally distributed in the treatment and control group.

Sex is the gender dummy to distinguish between female (0) and male (1) survey respondents. Male youth are slightly overrepresented in both the full sample and the sub-samples.

Age at finishing formal education is the age when a person completed their formal education. On average, young people leave school at around 18 years of age. However, the minimum (around 10 years of age) shows that some youth obviously did not attend school or at least did not graduate (see Highest educational level). Sq. age is the age value, squared. 
Highest educational level is the educational attainment achieved at the time of the survey, defined as a categorical variable. It shows an average of 2.2 for both treatment and control groups, indicating that youth in the sample are at about an upper-secondary level. The distribution of primary education or less (15\%), completed secondary $(53 \%)$ and completed tertiary education (32\%) is similar in both treatment and control group.

Area dummy (urban/rural) is a dummy to differentiate between youth residing in urban or rural areas. Around 57 per cent of responses were recorded in urban areas.

Married is a dummy variable and indicates whether a respondent has ever been married. On average, around one third of respondents have been married. The share of married persons is slightly higher in the control group.

Informal employment indicates whether an employee works in a formally registered enterprise or whether an entrepreneur has a registered enterprise. About one third of all respondents worked in the informal economy.

One parent has tertiary education is a dummy which takes the value 1 if at least one parent has obtained tertiary education, otherwise it is 0 . Around one in five mothers or fathers have tertiary education, which accrues to a combined rate of about 31 per cent across the sample.

Distance between GFC and survey measures the number of months between the start of the GFC and the date of the survey.

\subsubsection{Empirical strategy}

The dependent variable for RQ1 is the predicted duration of the school-to-work transition. The general linear regression model to estimate this duration for an individual $i$ $\left(\right.$ SWT $\left._{\text {duration }}\right)$ can be stated as:

SWT duration $_{i}$

$$
=\beta_{0}+\beta_{1} G F C_{i}+\beta_{2} X_{i}+\beta_{3} G F C_{i} \times X_{i}+\beta_{j} C_{j}+\beta_{t} Q_{t}+\beta_{k} C_{j} \times Q_{t}+\epsilon_{i}
$$

where $G F C_{i}$ denotes the treatment dummy taking the value 1 for individuals who finished their formal education during the GFC, and 0 otherwise; $X_{i}$ is a vector of individual characteristics; $G F C_{i} \times X_{i}$ is the interaction between these characteristics and the treatment 
dummy; $C_{j}$ stands for country dummies; ${ }^{31} Q_{t}$ for time dummies (quarters); and $C_{j} \times Q_{t}$ for the interaction between countries and time. $\epsilon_{i}$ is the residual.

The dependent variable for RQ2 is the logarithmic labour income. The explicit form of the linear regression model to estimate the average potential labour income of an individual $i$ $\left(\right.$ income $\left._{i}\right)$ can be expressed as:

$$
\begin{aligned}
\ln (\text { income })_{i}= & \beta_{0}+\beta_{1} G F C_{i}+\beta_{2} X_{i}+\beta_{3} G F C_{i} \times X_{i}+\beta_{4} D_{i}+\beta_{5} G F C_{i} \times D_{i} \\
& +\beta_{6} G F C_{i} \times X_{i} \times D_{i}+\beta_{j} C_{j}+\beta_{q} Q_{t}+\beta_{k} C_{j} \times Q_{t}+\epsilon_{i}
\end{aligned}
$$

where $G F C_{i}$ denotes the treatment dummy; $X_{i}$ is a vector of individual characteristics; $D_{i}$ is the distance between the GFC and the survey date; $G F C_{i} \times X_{i}$ and $G F C_{i} \times D_{i}$ are two-way interaction terms between the treatment dummy and the individual characteristics and the distance respectively; and $G F C_{i} \times X_{i} \times D_{i}$ is the corresponding three-way interaction. The remaining components are the same as in equation (ii).

We are now turning to the model selection. The starting point of our analysis is an ordinary least squares (OLS) regression model for both research questions.

\section{Employment scar}

If we take a closer look at the distribution of the SWT duration in our sample, we note three characteristics. As shown in Figure 5.2, the SWT duration is a count variable, which only takes on non-negative values. Since count data is not normally distributed, OLS might not be the appropriate regression technique. Second, the outcome variables suffer from an excessive number of observations with a transition time of zero months; i.e. around 28 per cent of the respondents in our sample transitioned directly from school into employment. And third, we note a large variance $\left(\sigma^{2}\right)$ in the distribution, which is several times higher than the mean and indicates an over-dispersion of the observations.

\footnotetext{
${ }^{31}$ Throughout the analysis, Tunisia has been selected as a base country because it was least severely affected by the crisis in terms of $\triangle \mathrm{GDP}$ and had fairly constant growth rates during the time span for both the control and treatment groups.
} 
Figure 5.2. Zero-inflated and dispersed school-to-work transition duration

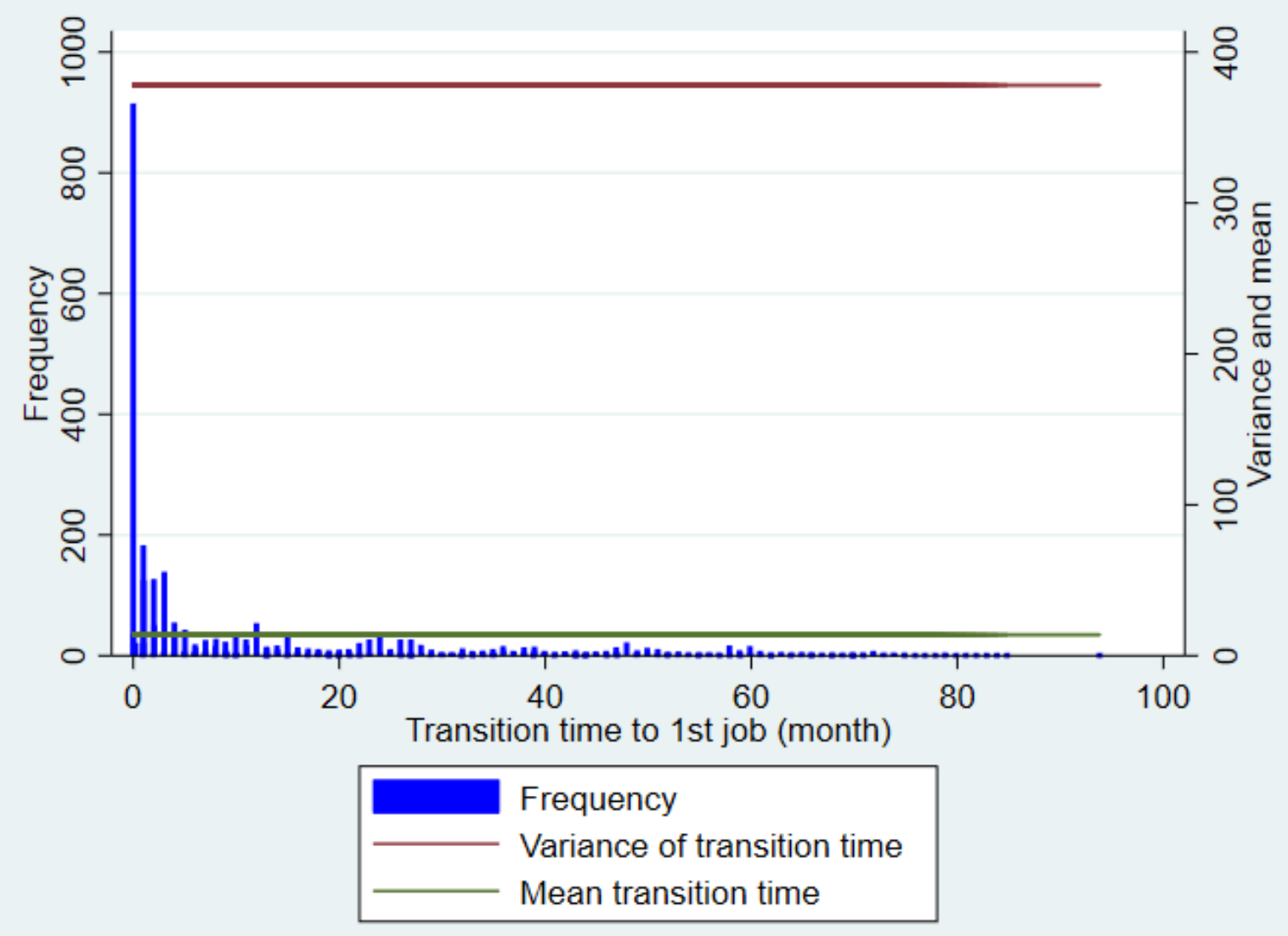

Source: authors' compilation.

Disregarding zero-inflation and over-dispersion can lead to inefficient, inconsistent and biased estimates of the outcome (Cameron and Trivedi 2013; Long and Freese 2006). One way of dealing with an excess number of zero observations is zero-inflation count models. First, we apply our data to a zero-inflated Poisson regression (ZIP), which combines a Poisson count model and a logit model to predict mass zeros. Then, we estimate a zero-inflated negative binomial regression (ZINB), which takes both zero-inflation and over-dispersion into account. The number of activities since finishing formal education is used as a predictor for zero values. The results of a likelihood ratio test indicate that the ZINB model seems to be more appropriate to account for both zero-inflation and over-dispersion of the outcome variable. In addition, and following Wilson (2015), the results are compared based on the Akaike and the Bayesian information criteria (AIC and BIC), which confirm that the ZINB better fits our data.

Another way to account for the mass of zeros are two-part models (TwoPM). In the first part, a binary response model is used to predict the probability of a zero outcome. The second part then estimates the outcome based on the predicted non-zero observations of the first part 
(Belotti et al. 2015; Dow and Norton 2003). We apply our data to the TwoPM in two specifications: we use a probit model for both specifications in the first stage; and we test both an OLS and a generalized linear model (GLM) in the second stage. After consulting the AIC and BIC criteria as well as supplementary goodness-of-fit indicators (e.g. pseudo $\mathrm{R}^{2}$ ), we select the probit-GLM specification.

To conclude the model selection, the analysis will use an OLS regression to define the baseline and then carry out the same estimation with a ZINB and a TwoPM (probit and GLM) to check the robustness of the findings. Although the remaining two models (ZIP and TwoPM with probit-OLS specification) discussed here are not used directly to derive the quantitative impact of the GFC on the SWT duration, their results are reported in the statistical Appendix C (Table C 3 and Table C 4 ) in order to further assess the robustness of the estimates.

The analysis of the impact of the GFC on the duration of the SWT will be conducted in two stages. First, we apply the model and estimate the variation of the SWT duration according to a number of key variables. The SWT duration may differ according to a young persons' individual characteristics and to their socio-economic background. In the second step, we are therefore analysing the heterogeneity of the average impact of the GFC by introducing interaction terms. This allows us to derive marginal effects, i.e. the effect of the GFC on the SWT duration for each of the key variables while holding the other covariates as fixed.

\section{$\underline{\text { Income scar }}$}

We are now turning to the impact of the GFC on labour incomes. Since both the prevalence of the GFC and the expected labour income may be affected by unobserved variables (e.g. the general macroeconomic climate or the quality of labour market institutions), the model is augmented by an endogenous treatment estimator. We estimate the average change in labour incomes using a maximum likelihood linear regression model, as suggested for linear regressions with endogenous treatment effects (Terza 1998; Wooldridge 2010). The explanatory variables include individual characteristics (age, gender, education, marital status) and socioeconomic characteristics (parents' education, geographic location, informal employment). The distance between the start of the GFC and the survey date is used to account for a potential discounting effect on the income scar over time. 
We run the model in three specifications. In the baseline specification (1), we estimate the average marginal effects without any interaction of the covariates. The second specification (2) introduces a two-way interaction term to allow for a variation of the distance between the GFC and the survey by the treatment level. In the last specification (3), a three-way interaction term is introduced to assess heterogeneity between key covariates (sex, education and area of residence) and the treatment (GFC) over time.

\subsubsection{Results}

We present our results in the following section.

\section{Employment scar}

Table 5.2 displays the regression results of our main determinates for the three models. The coefficients in the first column (1) are the marginal effects on the SWT duration. The coefficients of the ZINB (2) and the logistic regression model (3) cannot be interpreted directly. We therefore report the exponentiated values of the coefficients (odds ratios). In other words, while column 1 demonstrates the marginal effect of the independent variables on the SWT duration, columns 2 and 4 show the factorial change on the SWT duration and column 3 indicates the probability of a longer SWT duration.

All estimates reveal a similar trend but differ in terms of magnitude and statistical significance. Overall, we can predict an average transition duration into any first job of around 14 months. The GFC appears to have increased this duration for young persons by several months, but none of the coefficients are statistically significant. Overall, the SWT duration is significantly shorter for male than for female youth. Models (2) and (3) suggest a reduction by around one quarter for male youth, while model (1) quantifies this reduction to a bit more than four months. A higher level of education seems to lower the probability of a prolonged SWT (3). While young persons who have completed secondary education tend to transition into employment about 5 months faster than their counterparts who have no more than primarylevel education, youth with tertiary education see an even larger reduction of more than 8.5 months in their SWT transition. Moreover, labour markets in urban areas seem to absorb young people more quickly than they do in rural areas, with a predicted transition time that is around 1.5 months shorter. 
In conclusion, young men with higher educational attainment residing in urban areas appear to have a shorter transition duration than their less educated female counterparts in rural areas.

Table 5.2. Estimated change in the school-to-work transition

\begin{tabular}{|c|c|c|c|c|}
\hline \multirow{2}{*}{$\begin{array}{c}\text { Dependent variable: } \\
\text { SWT duration } \\
\text { (month) }\end{array}$} & \multirow[t]{2}{*}{$\begin{array}{l}\text { (1) } \\
\text { OLS }\end{array}$} & \multirow[t]{2}{*}{$\begin{array}{l}(2) \\
\text { ZINB }\end{array}$} & \multicolumn{2}{|c|}{$\begin{array}{c}\text { (3) } \\
\text { TwoPM }\end{array}$} \\
\hline & & & Probit & GLM \\
\hline GFC & & & & \\
\hline Sex $\quad$ GFC & $\begin{array}{c}6.72 \\
(5.413)\end{array}$ & $\begin{array}{c}1.49 \\
(0.511)\end{array}$ & $\begin{array}{c}0.17 \\
(0.313)\end{array}$ & $\begin{array}{c}1.59 \\
(0.536)\end{array}$ \\
\hline $\begin{array}{c}\text { Male } \\
\text { Education }\end{array}$ & $\begin{array}{c}-4.15^{* * *} \\
(0.743)\end{array}$ & $\begin{array}{l}0.72 * * * \\
(0.039)\end{array}$ & $\begin{array}{l}-0.12^{* *} \\
(0.059)\end{array}$ & $\begin{array}{l}0.76^{* * *} \\
(0.039)\end{array}$ \\
\hline Secondary & $\begin{array}{c}-4.86^{* * *} \\
(1.468)\end{array}$ & $\begin{array}{l}0.67^{* * *} \\
(0.083)\end{array}$ & $\begin{array}{c}-0.53^{* * *} \\
(0.105)\end{array}$ & $\begin{array}{c}1.11 \\
(0.116)\end{array}$ \\
\hline Area & $\begin{array}{c}-8.53 * * * \\
(1.511)\end{array}$ & $\begin{array}{l}0.56 * * * \\
(0.085)\end{array}$ & $\begin{array}{c}-1.01^{* * *} \\
(0.112)\end{array}$ & $\begin{array}{l}1.25^{*} \\
(0.149)\end{array}$ \\
\hline Urban & $\begin{array}{l}-1.46^{*} \\
(0.760)\end{array}$ & $\begin{array}{c}0.92 \\
(0.053)\end{array}$ & $\begin{array}{c}-0.02 \\
(0.059)\end{array}$ & $\begin{array}{c}0.93 \\
(0.049)\end{array}$ \\
\hline Constant & $\begin{array}{l}-28.39 * \\
(14.674)\end{array}$ & $\begin{array}{c}0.30 \\
(0.491)\end{array}$ & $\begin{array}{c}-6.60 * * * \\
(1.126)\end{array}$ & $\begin{array}{r}218.39 * * * \\
(346.693)\end{array}$ \\
\hline \multicolumn{5}{|l|}{ Controls } \\
\hline Country dummies & YES & YES & YES & YES \\
\hline Time dummies & YES & YES & YES & YES \\
\hline \multicolumn{5}{|l|}{ Goodness of fit } \\
\hline$R$-squared & 0.1412 & & & \\
\hline McFadden's R2 & & 0.015 & & \\
\hline Pseudo $R^{2}$ & & & 0.1764 & \\
\hline$A I C$ & 24383.32 & 18726.59 & 18555.55 & 18555.55 \\
\hline$B I C$ & 24573.53 & 18934.63 & 18941.9 & 18941.9 \\
\hline Observations & 2,819 & 2,819 & 2,818 & 2,818 \\
\hline
\end{tabular}

Controls included but not reported: Marital status, parents' tertiary education, age, age ${ }^{2}$ and number of activities since finishing formal education (only model (2)).

Robust standard errors in parentheses $* * * p<0.01, * * p<0.05, * p<0.1$

In the second part of the employment scar analysis, we introduce the GFC as the shock and explore the heterogeneity of the average impact on the SWT. For this purpose, we allow for a two-way interaction of the treatment dummy with the three main independent variables (sex, education and area). This enables us to isolate the marginal effect of the GFC on the SWT for each of the covariates. We continue with the three models used in the previous analysis and apply the same metric for the coefficients. 
Table 5.3 reports the estimated average impact of the GFC. Once again, we note that the estimates across all models indicate the same general trend, albeit of different magnitudes and levels of statistical significance. Since we have introduced interaction terms, the overall increase of the GFC on the SWT duration is smaller than in the previous specification, and still not significant. However, the derived estimates must be read in conjunction with the respective interaction terms. First, we assess whether the impact of the GFC varies by gender. The coefficients of the interaction term point unanimously and significantly in the same direction and demonstrate that the GFC hit male youth much harder than females. More precisely, their SWT duration increases by more than a third (models (2) and (3)), or by almost 3 months (1). Even so, the gender premium for males is strong enough to offset the impact of the GFC, leaving them with an SWT duration that is still shorter than it is for female youth. One explanation for the stronger impact of the crisis on young men could be that they were overrepresented in the sectors worst affected by the crisis, such as manufacturing and construction, which therefore impeded their transition (Verick 2009).

The impact of the GFC may also differ when it comes to educational attainment. Compared to the previous specification, we find that education has an even stronger mitigating effect. In times of crisis, however, youth with tertiary education are particularly affected. Their SWT duration is projected to increase by an additional 38 per cent (2) compared to youth who have no more than a primary education. This is something of a surprise, since most studies suggest that a crisis has a bigger impact on lower-skilled youth (EC 2014; Sharma and Winkler 2018). However, once we factor in the other components, we find that the SWT duration of women and men with tertiary education was shorter by some 3.8 and 6.5 months respectively, compared to youth with primary education or less.

As noted by Islam (2011), the urban economy in low and middle income countries was severely affected by the crisis and led to a reversal in rural-urban migration, as many laid-off workers began to seek jobs in rural areas. When analysing the variations in how the crisis impacted the rural and urban areas used in our sample, we observe a slightly more pronounced effect in urban areas, although, statistically speaking, it is not a significant one.

The findings reported in this section are largely comparable to the estimates derived from the zero-inflated Poisson (ZIP) regression and the two-part model with probit-OLS specification (see Appendix C, Table C 3 and Table C 4). We do, however, note a considerable variation in 
terms of the size of the coefficients and their levels of significance across the models. The TwoPM probit-OLS model, in particular, estimates the effect of the GFC on the SWT duration as being much higher.

Table 5.3. Estimated impact of the GFC on the school-to-work transition

\begin{tabular}{|c|c|c|c|c|}
\hline \multirow{3}{*}{$\begin{array}{c}\text { Dependent } \\
\text { variable: SWT } \\
\text { duration (month) }\end{array}$} & \multirow{3}{*}{$\begin{array}{l}\text { (1) } \\
\text { OLS }\end{array}$} & \multirow{3}{*}{$\begin{array}{c}\text { (2) } \\
\text { ZINB }\end{array}$} & \multirow{2}{*}{\multicolumn{2}{|c|}{$\begin{array}{c}\text { (3) } \\
\text { TwoPM }\end{array}$}} \\
\hline & & & & \\
\hline & & & Probit & GLM \\
\hline \multicolumn{5}{|l|}{ GFC } \\
\hline GFC & 1.98 & 1.24 & -0.07 & 1.43 \\
\hline Sex & (6.124) & $(0.437)$ & $(0.352)$ & $(0.504)$ \\
\hline \multirow{2}{*}{ Male } & $-5.60 * * *$ & $0.62^{* * *}$ & -0.09 & $0.64^{* * *}$ \\
\hline & $(1.113)$ & $(0.049)$ & $(0.081)$ & $(0.047)$ \\
\hline Male X GFC & $2.87 * *$ & $1.33^{* * *}$ & -0.07 & $1.37^{* * *}$ \\
\hline Education & (1.425) & $(0.146)$ & $(0.113)$ & (0.139) \\
\hline \multirow[t]{2}{*}{ Secondary } & $-6.34 * * *$ & $0.68 * * *$ & $-0.64 * * *$ & 1.16 \\
\hline & (2.123) & (0.101) & (0.143) & $(0.156)$ \\
\hline \multirow[t]{2}{*}{ Tertiary } & $-11.36 * * *$ & $0.47 * * *$ & $-1.22 * * *$ & 1.16 \\
\hline & $(2.187)$ & $(0.083)$ & $(0.152)$ & $(0.175)$ \\
\hline \multirow[t]{2}{*}{ Secondary X GFC } & 3.08 & 0.99 & 0.20 & 0.94 \\
\hline & (2.661) & $(0.182)$ & (0.188) & $(0.162)$ \\
\hline Tertiary X GFC & $5.61^{* *}$ & $1.38^{*}$ & $0.40^{* *}$ & 1.15 \\
\hline Area & (2.727) & (0.269) & (0.194) & (0.209) \\
\hline \multirow[t]{2}{*}{ Urban } & -1.61 & 0.91 & -0.05 & 0.93 \\
\hline & (1.134) & $(0.074)$ & $(0.082)$ & $(0.068)$ \\
\hline \multirow[t]{2}{*}{ Urban X GFC } & 0.18 & 1.02 & 0.05 & 1.00 \\
\hline & $(1.422)$ & $(0.114)$ & $(0.113)$ & $(0.101)$ \\
\hline Constant & $-27.66^{*}$ & 0.28 & $-6.52 * * *$ & $197.32 * * *$ \\
\hline \multicolumn{5}{|l|}{ Controls } \\
\hline Country dummies & YES & YES & YES & YES \\
\hline Time dummies & YES & YES & YES & YES \\
\hline \multicolumn{5}{|l|}{ Goodness of fit } \\
\hline$R$-squared & 0.144 & & & \\
\hline McFadden's R2 & & 0.016 & & \\
\hline Pseudo $R^{2}$ & & & 0.1782 & \\
\hline$A I C$ & 24381.86 & 18724.71 & 20467.29 & 18550.66 \\
\hline$B I C$ & 24595.85 & 18956.54 & 20901.18 & 18984.56 \\
\hline Observations & 2,819 & 2,819 & 2,818 & 2,818 \\
\hline
\end{tabular}

In conclusion, these results disprove the finding of the descriptive analysis, namely that of a shorter transition time of youth in the treatment group. Instead, we find a significant prolongation of the SWT duration, in particular for male youth and for youth with higher 
educational attainment in urban areas. Despite the stronger increase for men, it should be noted that women have a longer average transition time overall (Elder and Kring 2016). The same can be said for young people with lower educational attainment. The size of the effect suggests that youth finishing their formal education during an economic crisis are not only penalized by a longer SWT duration but are indeed scarred.

\section{$\underline{\text { Income scar }}$}

We will now assess the impact of the GFC on the potential labour income. We begin with a linear regression on the log labour income per hour without interaction terms (1), which serves as the baseline. Similar to the analytical frameworks of the employment scar, we then model the shock of the crisis as a two-way interaction term between the treatment dummy and the three main independent variables (sex, education and area) in model (2). In the third specification (3), we allow for a three-way interaction of the treatment dummy with the main independent variables and with the distance between the beginning of the GFC and the survey date. As a result, we obtain the average treatment effect (ATE) of the GFC in relationship to the time elapsed since the crisis. The findings are reported in Table 5.4.

Across all three specifications, we find a strong and highly significant income penalty caused by the GFC. Young persons who finished their formal education during the GFC experience on average a 10 per cent reduction in labour income compared to youth who finished their formal education in the year prior to the crisis. Young men seem to be slightly worse affected than women, although the effect is very small $(<0.2$ per cent) and statistically not significant. The income penalty seems to abate with rising educational attainment. Compared to persons who have not obtained anything beyond primary education (baseline), the income penalty is around 0.4 per cent lower for those with secondary education. A young person with tertiary education suffers an income penalty that is on average almost 2 per cent lower than a person who has not completed any formal education. Although not significant, the income penalty is slightly more pronounced in urban areas. Whether a young person is employed in the formal or informal sector makes a comparably strong difference. The income penalty for workers in the informal economy is on average 1.8 per cent higher than for formal workers. This can be explained by the fact that informal workers are less protected from (one-sided) wage adjustments, and the lack of access to collective bargaining mechanisms is often an obstacle to be covered by collective agreements. 
The distance between the crisis and the survey allows us to further isolate the discount factor (marginal effect) over time, and thus to assess whether the income penalty could become an income scar. We find that a young person needs around 12.6 years (model (3)) to offset the 10 per cent income penalty, and that men recover their losses about six times faster than women. The strong income penalty in combination with a rather low recovery rate brings us to the conclusion that income penalties are indeed income scars due to their persisting nature. However, the estimated recovery rate has to be taken with a pinch of salt since the predictor variation is large. In model (2), for instance, it is much smaller and derives a total of 22 years to fully offset the income penalty. However, this does not change the persisting nature of the effect. 
Table 5.4. Results of the maximum likelihood estimation on labour income

Dependent variable:

(1)

(2)

(3)

Log labour income

No interaction 2-way interaction

3-way interaction

\begin{tabular}{|c|c|c|c|}
\hline & & $\left(G F C_{i} \times D_{i}\right)$ & $\left(G F C_{i} \times X_{i} \times D_{i}\right)$ \\
\hline \multicolumn{4}{|l|}{ Overall effect } \\
\hline GFC & $\begin{array}{c}-0.101 * * * \\
(0.0211)\end{array}$ & $\begin{array}{c}-0.103329 * * * \\
(0.021)\end{array}$ & $\begin{array}{c}-0.101015^{* * *} \\
(0.021)\end{array}$ \\
\hline \multicolumn{4}{|l|}{ Marginal effects } \\
\hline \multicolumn{4}{|l|}{ Sex } \\
\hline Male & $\begin{array}{l}-0.000725 \\
(0.00462)\end{array}$ & $\begin{array}{c}-0.000834 \\
(0.005)\end{array}$ & $\begin{array}{c}-0.001833 \\
(0.004)\end{array}$ \\
\hline \multicolumn{4}{|l|}{ Education } \\
\hline Secondary & $\begin{array}{c}0.00377 \\
(0.00496)\end{array}$ & $\begin{array}{c}0.003842 \\
(0.005)\end{array}$ & $\begin{array}{c}0.004655 \\
(0.005)\end{array}$ \\
\hline Tertiary & $\begin{array}{c}0.0195 * * * \\
(0.00576)\end{array}$ & $\begin{array}{c}0.019611^{* * *} \\
(0.006)\end{array}$ & $\begin{array}{c}0.018343 * * * \\
(0.006)\end{array}$ \\
\hline \multicolumn{4}{|l|}{ Area } \\
\hline Urban & $\begin{array}{l}-0.00259 \\
(0.00408)\end{array}$ & $\begin{array}{c}-0.002597 \\
(0.004)\end{array}$ & $\begin{array}{c}-0.002119 \\
(0.004)\end{array}$ \\
\hline Informal employment & $\begin{array}{c}-0.0182 * * * \\
(0.00534)\end{array}$ & $\begin{array}{c}-0.018134^{* * *} \\
(0.005)\end{array}$ & $\begin{array}{c}-0.018062 * * * \\
(0.005)\end{array}$ \\
\hline Distance crisis-survey & & $\begin{array}{c}0.000361 \\
(0.000572)\end{array}$ & $\begin{array}{c}0.000635 \\
(0.0006121)\end{array}$ \\
\hline _cons & $\begin{array}{c}4.527 * * * \\
(0.570)\end{array}$ & $\begin{array}{c}4.546 * * * \\
(0.580)\end{array}$ & $\begin{array}{c}4.517^{* * *} \\
(0.578)\end{array}$ \\
\hline $\begin{array}{l}\text { Geographic control } \\
\text { Time control }\end{array}$ & $\begin{array}{l}\text { YES } \\
\text { YES }\end{array}$ & $\begin{array}{l}\text { YES } \\
\text { YES }\end{array}$ & $\begin{array}{l}\text { YES } \\
\text { YES }\end{array}$ \\
\hline \multicolumn{4}{|l|}{ Goodness of fit } \\
\hline$A I C$ & -1467.5 & -1466.3 & -1451.9 \\
\hline$B I C$ & -1271.0 & -1264.5 & -1172.6 \\
\hline Observations & 1,303 & 1,303 & 1,303 \\
\hline
\end{tabular}

Controls included but not reported: Marital status, parents' tertiary education, age and age 2 .

Standard errors in parentheses. ${ }^{*} p<0.05 \quad * * p<0.01 \quad * * * p<0.001$ 


\subsubsection{Discussion of findings and further research}

As indicated in the descriptive analysis, the average transition time varies greatly between countries. Manacorda et al. (2017), for instance, estimated the average transition duration to range from 3.5 to 57 months (a mean of 23 months), using data from the ILO SWTS for 23 lowand middle-income countries. A simple comparison of the median transition duration confirms our findings of longer transition rates for women. The same study further found some (statistically not significant) evidence for a decreasing transition time in countries with positive economic growth and for individuals with higher educational attainment. Quintini et al. (2007) provided estimates of the expected length of the school-to-work transition derived from labour force surveys for selected Organisation for Economic Co-operation and Development (OECD) countries. Their estimates ranged from 14.3 to 58 months with a mean duration of 29.4 months in 2005 . The study also pointed to particular difficulties for young people with low educational attainment, which is in line with our findings. Another study indicated a faster transition process with a finding that around one third of youth in Serbia and two thirds in Ukraine had started their first job within six months of finishing formal education (ETF, 2008). Lastly, Guarcello et al. (2005) offered an overview of SWT durations in 13 countries in sub-Saharan Africa, where they ranged from 18 to 80 months.

In the absence of research with - to our knowledge - a similar analytical framework, the scale of the GFC's impact on the SWT duration and labour incomes is more difficult to compare. However, there is some evidence on which the validity of the findings can be approximated. First, we can observe changes in certain key labour market indicators. Rising unemployment and inactivity rates in the months following the GFC indicate a prolonged transition time for youth. Second, the direction of the derived effects is in line both with our own expectations and other research findings. Third, the income penalty of around 10 per cent is within the penalty range identified by other studies (e.g. Cruces, Ham, and Viollaz 2012; Helbling and Sacchi 2014; Lupi and Ordine 2002). Lastly, the scale of the prolonged transition duration as well as the scale and persistence of income penalty over time suggest an actual scarring effect which seems to be supported by other studies (e.g. Gregg and Tominey 2004; Helbling and Sacchi 2014; Ruhm 1991).

However, there are certain limitations to this study. Although we are using the best available macroeconomic indicator for this country sample (i.e. quarterly GDP growth rates) in order to 
determine the beginning of the crisis at the country level, it leaves us with a considerable amount of imprecision. In addition, a crisis may not hit all sectors simultaneously and on an equal scale. Both factors can cause an overlap of the treatment and the control group and dilute the effect size. As with most experimental research, the findings of this study may further suffer from a potential endemic selection bias. Although the number of independent variables used in the models was kept small, there may be unobserved personal attributes which correlate with both the outcome variables and the covariates. Lastly, further robustness checks must be carried out to substantiate the validity of the findings.

In concluding this assessment, we consider the derived effects of the GFC as valid in terms of their accuracy and explanatory power. Further research should be carried out on the schoolto-decent-work transition with a focus on policies that facilitate this transition. While the commonly applied criteria of a stable and/or satisfactory employment provide a good starting point, more dimensions of decent work could be incorporated. In terms of income scars, the prevalence of low-pay employment and their possibility to trap certain groups of workers should be examined in more detail. Moreover, the role of reservation wages and their possible adjustments in times of crisis would add another important puzzle piece to better understand the labour supply side.

\subsection{Conclusion}

This paper analysed some key determinates of the school-to-work transition duration as well as the potential labour outcome both prior to and during an economic crisis. We used data from the ILO's SWTS for 14 middle-income countries and applied it to different regression models.

We found that the average transition duration into any first job is around 14 months. On average, women's transition time is four months longer than men's. Overall, the transition time is longest for young persons with primary education or less, and decreases with increasing educational attainment. The SWT duration is shorter for youth in urban areas.

The global financial crisis had a very strong impact on both transition duration and projected labour income. It caused the average school-to-work transition duration to rise by several months and imposed a wage penalty of over 10 per cent on young persons. Although men were hit harder by the crisis, women continue to experience longer SWT durations. Similarly, 
while youth with high levels of education were more affected by the GFC, low-skilled workers continue to require the longest transition time. The income penalty was slightly stronger for male and urban youth, although it reduced significantly with increasing educational attainment. A very low recovery rate (especially for women) suggests a persisting trend in terms of income penalty. Although the derived estimates are considerably small (i.e. the recovery rate is low) to assume an income scar, we do not find significant empirical support to prove it.

Although at the moment it is not possible to predict the exact scope or duration of the economic recession, there are strong indications that the "lockdown generation" will be among the worst affected sections of society: in the short-term, because of their generally lower employment security; and in the longer-term, because of the employment and income scars with which they will be marked by the current crisis. 


\section{Appendix A}

Table A 1. Labor intensity for different crops

\begin{tabular}{|c|c|c|c|c|}
\hline Crop & $\begin{array}{l}\text { Labor intensity (workers } \\
\text { per hectare) }\end{array}$ & Region & Comment & Source \\
\hline \multirow[t]{5}{*}{ Banana } & 0.16 & Philippines & 2007 & \multirow{5}{*}{$\begin{array}{l}\text { Bathan and Lantican } \\
\text { (2010); Arias et al. } \\
\text { (2003); Bagamba et al. } \\
\text { (2007) }\end{array}$} \\
\hline & 0.67 & Costa Rica & 1999 & \\
\hline & $1.00-5.00$ & Ecuador & 1999 & \\
\hline & $1.08-1.75$ & Uganda & 2007 & \\
\hline & 3.64 & Côte d'Ivoire & 1999 & \\
\hline \multirow[t]{3}{*}{ Barley } & $0.04-0.11$ & Ethiopia & 1996-2002 & \multirow{3}{*}{$\begin{array}{l}\text { Simpson and Cheong } \\
\text { (2014); García Bendezú } \\
\text { (2011); Abreha (2007) }\end{array}$} \\
\hline & $0.04-0.69$ & Peru & 2004-2008 & \\
\hline & 0.06 & Tanzania & 2008 & \\
\hline \multirow[t]{5}{*}{ Cassava } & $0.06-0.13$ & Colombia & 2000 & \multirow{5}{*}{$\begin{array}{l}\text { Pimentel (2009); FAO } \\
\text { (1977); Gray (1982); } \\
\text { Ospina Patiño et al. } \\
\text { (2007) }\end{array}$} \\
\hline & $0.12-0.21$ & Brazil & 1982 & \\
\hline & $0.41-0.43$ & Congo (DRC) & 1977 & \\
\hline & 0.85 & Nigeria & 1996 & \\
\hline & $0.97-1.15$ & Uganda & 1977 & \\
\hline \multirow[t]{3}{*}{ Corn (Maize) } & $0.04-0.68$ & Ghana & 2009 & Pimentel (2009); García \\
\hline & 0.17 & Cameroon & Unknown & Bendezú (2011); Dutch \\
\hline & 0.19 & Mozambique & 2005 & Jatropha Consortium \\
\hline
\end{tabular}




\begin{tabular}{|c|c|c|c|c|}
\hline & 0.33 & Indonesia & 1996 & (2009); Deininger and \\
\hline & $0.41-1.10$ & Peru & $2004-2008$ & $\begin{array}{l}\text { Byerlee (2011); Ngeleza } \\
\text { et al. (2011) }\end{array}$ \\
\hline \multirow[t]{6}{*}{ Cotton } & $0.03-0.17$ & Benin & 1998 & \multirow{6}{*}{$\begin{array}{l}\text { Minot and Daniels } \\
\text { (2005); Tschirley et al } \\
(2009)\end{array}$} \\
\hline & $0.04-0.28$ & Uganda & Unknown & \\
\hline & $0.05-0.60$ & Mozambique & Unknown & \\
\hline & $0.11-0.45$ & Zambia & Unknown & \\
\hline & $0.16-0.46$ & Tanzania & Unknown & \\
\hline & $0.19-0.38$ & Zimbabwe & Unknown & \\
\hline \multirow[t]{2}{*}{ Cocoa } & 0.30 & Unknown & 2013 & \multirow{2}{*}{$\begin{array}{l}\text { Tiffen \& Mortimor } \\
(1990,59) ; \text { ICCO }(2013)\end{array}$} \\
\hline & 3.25 & Malaysia & 1983 & \\
\hline Coconut & 4.50 & Sri Lanka & 1984 & $\begin{array}{l}\text { Tiffen \& Mortimor } \\
(1990,59)\end{array}$ \\
\hline Coffee & 1.83 & Java & 1983 & $\begin{array}{l}\text { Tiffen \& Mortimor } \\
(1990,59)\end{array}$ \\
\hline \multirow[t]{2}{*}{ Grains (cereals) } & 0.01 & Unknown & Unknown & \multirow{2}{*}{$\begin{array}{l}\text { World Bank (2011) } \\
\text { Bustos et al. (2016) }\end{array}$} \\
\hline & 0.02 & Brazil & 2006 & \\
\hline \multirow[t]{3}{*}{ Jatropha } & $0.04-0.49$ & Mozambique & 2005 & \multirow{3}{*}{$\begin{array}{l}\text { Deininger and Byerlee } \\
\text { (2011); Scharschmidt } \\
\text { (2010); Dutch Jatropha }\end{array}$} \\
\hline & $0.13-0.27$ & Tanzania & 2001 & \\
\hline & 0.42 & Unknown & Unknown & \\
\hline
\end{tabular}




\begin{tabular}{|c|c|c|c|c|c|}
\hline & & & & & Consortium (2009); \\
\hline & & & & & Arndt et al. (2008) \\
\hline \multirow[t]{5}{*}{ Oil palm } & 0.11 & Indonesia & 2012 & \multirow[t]{5}{*}{ Smallholder } & World Bank (2011); \\
\hline & 0.35 & Unknown & Unknown & & Schwarze et al. (2015); \\
\hline & $3.60-4.00$ & Malaysia & $1976 / 1983$ & & Tiffen \& Mortimor \\
\hline & 3.80 & Nigeria & 1987 & & $(1990,59)$ \\
\hline & $5.00-7.50$ & Africa & 1977 & & \\
\hline \multirow[t]{2}{*}{ Rice } & $0.20-0.71$ & China/India & 1995 & & \multirow{2}{*}{$\begin{array}{l}\text { Hossain (1998); Ngeleza } \\
\text { et al. (2011) }\end{array}$} \\
\hline & $0.39-1.17$ & Ghana & 2009 & & \\
\hline \multirow[t]{4}{*}{ Rubber } & 0.33 & Cambodia & 2007 & \multirow{4}{*}{ Smallholder } & World Bank (2011); \\
\hline & 0.42 & Unknown & Unknown & & Schwarze et al. (2015); \\
\hline & 0.48 & Indonesia & 2012 & & Tiffen \& Mortimor \\
\hline & $2.10-2.85$ & Malaysia & $1978 / 1983$ & & $\begin{array}{l}(1990,59) \text {; Dararath et } \\
\text { al. (2011) }\end{array}$ \\
\hline \multirow[t]{2}{*}{ Sorghum } & 0.05 & Unknown Uganda & Unknown & \multirow[b]{2}{*}{ Smallholder } & World Bank (2011); \\
\hline & $0.83-1.09$ & & $2000-2001$ & & $\begin{array}{l}\text { Ainembabazi et al. } \\
(2005,950)\end{array}$ \\
\hline \multirow[t]{3}{*}{ Soya bean } & 0.02 & Unknown & Unknown & & World Bank (2011); \\
\hline & 0.02 & Brazil & 2006 & & Bustos et al. (2016); \\
\hline & 0.39 & Philippines & 1996 & & (Pimentel 2009) \\
\hline
\end{tabular}




\begin{tabular}{|c|c|c|c|c|c|}
\hline \multirow[t]{3}{*}{ Sugar cane } & $0.14-0.66$ & Brazil & 1982 & Different & Deininger and Byerlee \\
\hline & $0.15-0.34$ & Mozambique & Unknown & production & (2011); Gray (1982); \\
\hline & 0.70 & Tanzania & Unknown & schemes & Arndt et al. (2008) \\
\hline Sunflower & 0.19 & Mozambique & 2005 & & (2009) \\
\hline \multirow[t]{4}{*}{ Wheat } & $0.04-0.05$ & Ethiopia & 1996-2002 & & García Bendezú (2011); \\
\hline & 0.06 & Tanzania & 2008 & & Pimentel \\
\hline & $0.20-1.05$ & Peru & 2004-2008 & & Abreha (2007); Simpson \\
\hline & 0.36 & Kenya & 1996 & & and Cheong (2014) \\
\hline \multirow[t]{4}{*}{ Tea } & $0.20-0.80$ & Sri Lanka & 1984 & & Tiffen \& Mortimor \\
\hline & 0.52 & Kenya & 1983 & & $(1990,59)$ \\
\hline & 0.63 & Java & 1983 & & \\
\hline & 0.80 & Malaysia & 1983 & & \\
\hline
\end{tabular}


Table A 2. Different scenarios and actual areas under contract in hectares

\begin{tabular}{|c|c|c|c|c|c|c|c|}
\hline \multirow{3}{*}{\multicolumn{3}{|c|}{ Former land use }} & \multicolumn{4}{|c|}{ Large-scale farm } & \multirow{3}{*}{\begin{tabular}{|c} 
\\
Total \\
$(n=1,031)$
\end{tabular}} \\
\hline & & & \multicolumn{2}{|c|}{ Labor intensive $(3,188,127)$} & \multicolumn{2}{|c|}{ Capital intensive $(9,390,727)$} & \\
\hline & & & no $C F$ & $\mathrm{CF}$ & no $\mathrm{CF}$ & $\mathrm{CF}$ & \\
\hline 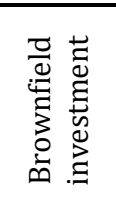 & $\begin{array}{l}\text { Large-scale } \\
\text { agriculture }\end{array}$ & $\begin{array}{l}\text { Size under contract (in } \\
\text { ha) }\end{array}$ & $\begin{array}{c}2 a \\
341,181\end{array}$ & $\begin{array}{c}2 b \\
232,977\end{array}$ & $\begin{array}{c}2 c \\
3,522,884\end{array}$ & $\begin{array}{c}2 \mathrm{~d} \\
1,460,318\end{array}$ & $5,557,360$ \\
\hline \multirow{4}{*}{ 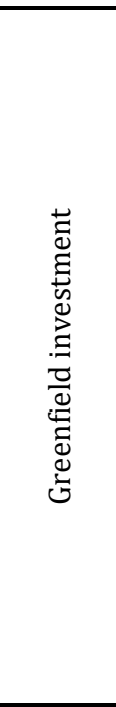 } & $\begin{array}{l}\text { Smallholder } \\
\text { agriculture }\end{array}$ & $\begin{array}{l}\text { Size under contract (in } \\
\text { ha) }\end{array}$ & $\begin{array}{c}1 \mathrm{a} \\
1,511,032\end{array}$ & $\begin{array}{c}1 \mathrm{~b} \\
154,730\end{array}$ & $\begin{array}{c}1 c \\
2,075,338\end{array}$ & $\begin{array}{c}1 \mathrm{~d} \\
485,182\end{array}$ & $4,226,282$ \\
\hline & Pastoralists & $\begin{array}{l}\text { Size under contract (in } \\
\text { ha) }\end{array}$ & $\begin{array}{c}a \\
202,069\end{array}$ & $\begin{array}{c}3 b \\
2,952\end{array}$ & $\begin{array}{c}3 c \\
426,773\end{array}$ & $\begin{array}{c}3 d \\
20,550\end{array}$ & 652,344 \\
\hline & Forestry & $\begin{array}{l}\text { Size under contract (in } \\
\text { ha) }\end{array}$ & $\begin{array}{c}\mathrm{a} \\
693,060\end{array}$ & $\begin{array}{c}4 b \\
10,711\end{array}$ & $\begin{array}{c}4 c \\
743,480\end{array}$ & $\begin{array}{c}4 d \\
181,905\end{array}$ & $1,629,156$ \\
\hline & Conservation & $\begin{array}{l}\text { Size under contract (in } \\
\text { ha) }\end{array}$ & $\begin{array}{c}5 a \\
37,477\end{array}$ & $\begin{array}{c}5 b \\
1,939\end{array}$ & $\begin{array}{c}5 c \\
422,970\end{array}$ & $\begin{array}{c}5 d \\
51,327\end{array}$ & 513,713 \\
\hline & & Total & $2,784,818$ & 403,309 & $7,191,445$ & $2,199,282$ & $12,578,854$ \\
\hline
\end{tabular}

Source: author's calculation based on the Land Matrix Global Observatory (2016). 


\section{Appendix B}

Table B 1. Ranking of countries and territories by ageing status (population aged 65 and over as \% of total population) in 2020, 2030 and 2050

\begin{tabular}{|c|c|c|c|c|c|c|c|c|c|c|c|}
\hline $\begin{array}{l}\text { Rank } \\
\text { (regional) }\end{array}$ & \begin{tabular}{|l} 
Rank \\
(global) \\
\end{tabular} & Country & 2020 & \begin{tabular}{|l|} 
Rank \\
(regional) \\
\end{tabular} & $\begin{array}{l}\text { Rank } \\
\text { (global) }\end{array}$ & Country & 2030 & $\begin{array}{l}\text { Rank } \\
\text { (regional) } \\
\end{array}$ & $\begin{array}{l}\text { Rank } \\
\text { (global) } \\
\end{array}$ & Country & 2050 \\
\hline \multicolumn{12}{|c|}{ East Asia \& Pacific } \\
\hline 1 & 1 & Japan & 28.4 & 1 & 1 & Japan & 30.87 & 1 & 1 & South Korea & 38.07 \\
\hline 2 & 29 & Hong Kong & 18.2 & 2 & 8 & Hong Kong & 25.84 & 2 & 2 & Japan & 37.69 \\
\hline 3 & 38 & New Zealand & 16.37 & 3 & 15 & South Korea & 24.75 & 3 & 6 & Taiwan & 34.99 \\
\hline 4 & 39 & Australia & 16.21 & 4 & 23 & Taiwan & 23.37 & 4 & 8 & Hong Kong & 34.68 \\
\hline 5 & 41 & Taiwan & 15.85 & 5 & 29 & Singapore & 22.49 & 5 & 9 & Singapore & 33.27 \\
\hline 6 & 42 & South Korea & 15.79 & 6 & 41 & New Zealand & 20.54 & 6 & 18 & Thailand & 29.64 \\
\hline 7 & 55 & Singapore & 13.35 & 7 & 45 & Macao & 20.25 & 7 & 21 & Macao & 28.91 \\
\hline 8 & 56 & Thailand & 12.96 & 8 & 48 & Thailand & 19.61 & 8 & 37 & China & 26.07 \\
\hline 9 & 61 & Macao & 11.97 & 9 & 50 & Australia & 19.32 & 9 & 54 & New Zealand & 23.85 \\
\hline 10 & 62 & China & 11.97 & 10 & 62 & China & 16.87 & 10 & 60 & Australia & 22.78 \\
\hline 11 & 67 & Guam & 10.54 & 11 & 66 & Guam & 14.64 & 11 & 65 & Fr. Polynesia & 21.92 \\
\hline 12 & 72 & New Caledonia & 9.7 & 12 & 71 & Fr. Polynesia & 13.44 & 12 & 67 & Brunei & 21.75 \\
\hline 13 & 74 & North Korea & 9.35 & 13 & 73 & New Caledonia & 13.38 & 13 & 75 & New Caledonia & 20.49 \\
\hline 14 & 77 & Fr. Polynesia & 9.07 & 14 & 76 & North Korea & 12.7 & 14 & 76 & Vietnam & 20.45 \\
\hline 15 & 87 & Vietnam & 7.87 & 15 & 83 & Vietnam & 11.95 & 15 & 81 & North Korea & 19.7 \\
\hline 16 & 95 & Malaysia & 7.18 & 16 & 93 & Brunei & 10.2 & 16 & 82 & Guam & 19.19 \\
\hline 17 & 98 & Micronesia & 6.94 & 17 & 97 & Micronesia & 10.07 & 17 & 93 & Malaysia & 17 \\
\hline 18 & 104 & Indonesia & 6.26 & 18 & 98 & Malaysia & 10.03 & 18 & 102 & Indonesia & 15.86 \\
\hline 19 & 105 & Myanmar & 6.24 & 19 & 101 & Indonesia & 9.17 & 19 & 114 & Myanmar & 13.18 \\
\hline 20 & 107 & \begin{tabular}{|l} 
Tonga \\
\end{tabular} & 5.92 & 20 & 106 & Myanmar & 8.52 & 20 & 115 & Micronesia & 13.13 \\
\hline 21 & 109 & Fiji & 5.82 & 21 & 107 & Fiji & 8.13 & 21 & 125 & Mongolia & 12 \\
\hline
\end{tabular}




\begin{tabular}{|c|c|c|c|c|c|c|c|c|c|c|c|}
\hline 22 & 111 & Brunei & 5.57 & 22 & 110 & Philippines & 7.6 & 22 & 127 & Philippines & 11.8 \\
\hline 23 & 112 & Philippines & 5.51 & 23 & 119 & Mongolia & 6.86 & 23 & 128 & Cambodia & 11.68 \\
\hline 24 & 117 & Samoa & 5.08 & 24 & 120 & Samoa & 6.84 & 24 & 129 & Fiji & 11.16 \\
\hline 25 & 123 & Cambodia & 4.85 & 25 & 122 & Cambodia & 6.69 & 25 & 133 & Laos & 10.41 \\
\hline 26 & 133 & Mongolia & 4.31 & 26 & 123 & Tonga & 6.68 & 26 & 138 & Samoa & 9.14 \\
\hline 27 & 134 & Timor-Leste & 4.28 & 27 & 130 & Kiribati & 6.17 & 27 & 139 & Tonga & 8.93 \\
\hline 28 & 135 & Laos & 4.26 & 28 & 135 & Laos & 5.64 & 28 & 140 & Kiribati & 8.72 \\
\hline 29 & 136 & Kiribati & 4.21 & 29 & 142 & Timor-Leste & 4.97 & 29 & 147 & Solomon Is. & 7.02 \\
\hline 30 & 140 & Solomon Is. & 3.67 & 30 & 145 & Solomon Is. & 4.41 & 30 & 150 & Papua New Guinea & 6.57 \\
\hline 31 & 141 & Vanuatu & 3.61 & 31 & 146 & Papua New Guinea & 4.37 & 31 & 152 & Timor-Leste & 6.48 \\
\hline 32 & 144 & Papua New Guinea & 3.57 & 32 & 148 & Vanuatu & 4.25 & 32 & 153 & Vanuatu & 6.45 \\
\hline \multicolumn{12}{|l|}{ South Asia } \\
\hline 1 & 66 & Sri Lanka & 11.23 & 1 & 64 & Sri Lanka & 15.43 & 1 & 62 & Sri Lanka & 22.58 \\
\hline 2 & 102 & India & 6.57 & 2 & 104 & India & 8.57 & 2 & 72 & Maldives & 20.88 \\
\hline 3 & 106 & Bhutan & 6.2 & 3 & 109 & Bhutan & 7.82 & 3 & 103 & Bhutan & 15.84 \\
\hline 4 & 108 & Nepal & 5.83 & 4 & 113 & Bangladesh & 7.45 & 4 & 104 & Bangladesh & 15.81 \\
\hline 5 & 115 & Bangladesh & 5.23 & 5 & 116 & Nepal & 7.07 & 5 & 112 & India & 13.75 \\
\hline 6 & 132 & Pakistan & 4.35 & 6 & 121 & Maldives & 6.72 & 6 & 118 & Nepal & 12.85 \\
\hline 7 & 142 & Maldives & 3.59 & 7 & 139 & Pakistan & 5.21 & 7 & 142 & Pakistan & 7.87 \\
\hline 8 & 177 & Afghanistan & 2.65 & 8 & 172 & Afghanistan & 3.14 & 8 & 164 & Afghanistan & 5.42 \\
\hline \multicolumn{12}{|c|}{ Europe and Central Asia } \\
\hline 1 & 2 & Italy & 23.3 & 1 & 2 & Italy & 27.89 & 1 & 3 & Spain & 36.81 \\
\hline 2 & 3 & Portugal & 22.77 & 2 & 3 & Portugal & 27.05 & 2 & 4 & Greece & 36.23 \\
\hline 3 & 4 & Finland & 22.55 & 3 & 4 & Greece & 26.51 & 3 & 5 & Italy & 36.01 \\
\hline 4 & 5 & Greece & 22.28 & 4 & 5 & Lithuania & 26.38 & 4 & 7 & Portugal & 34.81 \\
\hline 5 & 6 & Germany & 21.69 & 5 & 6 & Germany & 26.18 & 5 & 11 & Slovenia & 32.14 \\
\hline
\end{tabular}




\begin{tabular}{|c|c|c|c|c|c|c|c|c|c|c|c|}
\hline 6 & 7 & Bulgaria & 21.47 & 6 & 7 & Finland & 25.99 & 6 & 12 & Poland & 31.13 \\
\hline 7 & 9 & Croatia & 21.25 & 7 & 9 & Slovenia & 25.46 & 7 & 13 & Croatia & 30.87 \\
\hline 8 & 11 & France & 20.75 & 8 & 12 & Croatia & 25.08 & 8 & 14 & Bosnia and Herz. & 30.39 \\
\hline 9 & 12 & Slovenia & 20.74 & 9 & 13 & Spain & 25.04 & 9 & 16 & Germany & 30.01 \\
\hline 10 & 13 & Latvia & 20.69 & 10 & 14 & Latvia & 24.97 & 10 & 19 & Austria & 29.39 \\
\hline 11 & 14 & Lithuania & 20.62 & 11 & 16 & Netherlands & 24.61 & 11 & 20 & Lithuania & 28.98 \\
\hline 12 & 15 & Estonia & 20.37 & 12 & 17 & France & 24.13 & 12 & 22 & Czechia & 28.86 \\
\hline 13 & 16 & Sweden & 20.33 & 13 & 18 & Bosnia and Herz. & 24.09 & 13 & 23 & Slovakia & 28.86 \\
\hline 14 & 17 & Denmark & 20.16 & 14 & 19 & Austria & 23.69 & 14 & 24 & Estonia & 28.73 \\
\hline 15 & 18 & Hungary & 20.16 & 15 & 20 & Estonia & 23.55 & 15 & 25 & Switzerland & 28.65 \\
\hline 16 & 19 & Czechia & 20.14 & 16 & 21 & Bulgaria & 23.43 & 16 & 26 & Bulgaria & 28.63 \\
\hline 17 & 20 & Netherlands & 20.03 & 17 & 22 & Switzerland & 23.39 & 17 & 27 & Netherlands & 28 \\
\hline 18 & 21 & Spain & 19.98 & 18 & 24 & Poland & 23.22 & 18 & 28 & Hungary & 28 \\
\hline 19 & 22 & Belgium & 19.25 & 19 & 25 & Belgium & 22.97 & 19 & 29 & France & 27.83 \\
\hline 20 & 23 & Romania & 19.23 & 20 & 28 & Denmark & 22.6 & 20 & 30 & Latvia & 27.81 \\
\hline 21 & 24 & Austria & 19.2 & 21 & 30 & Czechia & 22.22 & 21 & 32 & Romania & 27.67 \\
\hline 22 & 25 & Switzerland & 19.1 & 22 & 31 & Sweden & 22.15 & 22 & 33 & Finland & 27.57 \\
\hline 23 & 26 & Serbia & 19.06 & 23 & 33 & Hungary & 21.98 & 23 & 34 & Belgium & 26.92 \\
\hline 24 & 27 & Poland & 18.74 & 24 & 35 & United Kingdom & 21.52 & 24 & 35 & Serbia & 26.64 \\
\hline 25 & 28 & United Kingdom & 18.65 & 25 & 36 & Serbia & 21.18 & 25 & 36 & Ireland & 26.62 \\
\hline 26 & 31 & Bosnia and Herz. & 17.92 & 26 & 37 & Romania & 21.04 & 26 & 38 & Cyprus & 26 \\
\hline 27 & 33 & Norway & 17.53 & 27 & 38 & Slovakia & 20.99 & 27 & 39 & Macedonia & 25.65 \\
\hline 28 & 34 & Ukraine & 16.95 & 28 & 40 & Albania & 20.73 & 28 & 40 & Ukraine & 25.52 \\
\hline 29 & 36 & Slovakia & 16.7 & 29 & 42 & Belarus & 20.5 & 29 & 41 & Albania & 25.44 \\
\hline 30 & 43 & Montenegro & 15.77 & 30 & 43 & Norway & 20.27 & 30 & 42 & United Kingdom & 25.34 \\
\hline 31 & 44 & Iceland & 15.62 & 31 & 46 & Iceland & 20.11 & 31 & 43 & Iceland & 25.17 \\
\hline
\end{tabular}




\begin{tabular}{|c|c|c|c|c|c|c|c|c|c|c|c|}
\hline 32 & 45 & Belarus & 15.58 & 32 & 47 & Ukraine & 20.01 & 32 & 47 & Sweden & 24.58 \\
\hline 33 & 46 & Russia & 15.51 & 33 & 49 & Russia & 19.6 & 33 & 48 & Luxembourg & 24.5 \\
\hline 34 & 47 & Georgia & 15.25 & 34 & 51 & Montenegro & 19.22 & 34 & 50 & Denmark & 24.23 \\
\hline 35 & 49 & Albania & 14.7 & 35 & 52 & Georgia & 18.54 & 35 & 52 & Belarus & 24 \\
\hline 36 & 51 & Ireland & 14.58 & 36 & 53 & Macedonia & 18.24 & 36 & 53 & Norway & 23.95 \\
\hline 37 & 52 & Macedonia & 14.48 & 37 & 54 & Cyprus & 18.21 & 37 & 55 & Montenegro & 23.78 \\
\hline 38 & 53 & Cyprus & 14.41 & 38 & 55 & Ireland & 18.14 & 38 & 58 & Moldova & 23.03 \\
\hline 39 & 54 & Luxembourg & 14.39 & 39 & 56 & Luxembourg & 18.04 & 39 & 59 & Russia & 22.86 \\
\hline 40 & 58 & Moldova & 12.49 & 40 & 60 & Moldova & 16.96 & 40 & 66 & Georgia & 21.78 \\
\hline 41 & 63 & Armenia & 11.8 & 41 & 61 & Armenia & 16.9 & 41 & 69 & Armenia & 21.39 \\
\hline 42 & 79 & Turkey & 8.98 & 42 & 80 & Turkey & 12.34 & 42 & 73 & Turkey & 20.86 \\
\hline 43 & 86 & Kazakhstan & 7.9 & 43 & 85 & Azerbaijan & 11.78 & 43 & 88 & Azerbaijan & 17.5 \\
\hline 44 & 101 & Azerbaijan & 6.74 & 44 & 89 & Kazakhstan & 11.07 & 44 & 111 & Kazakhstan & 14.15 \\
\hline 45 & 124 & Uzbekistan & 4.79 & 45 & 112 & Uzbekistan & 7.56 & 45 & 123 & Uzbekistan & 12.18 \\
\hline 46 & 126 & Turkmenistan & 4.77 & 46 & 114 & Kyrgyzstan & 7.23 & 46 & 131 & Turkmenistan & 10.6 \\
\hline 47 & 127 & Kyrgyzstan & 4.73 & 47 & 117 & Turkmenistan & 7.07 & 47 & 134 & Kyrgyzstan & 10.08 \\
\hline 48 & 153 & Tajikistan & 3.18 & 48 & 141 & Tajikistan & 5.06 & 48 & 144 & Tajikistan & 7.5 \\
\hline
\end{tabular}

\section{Middle East and North Africa}

\begin{tabular}{|c|c|c|c|c|c|c|c|c|c|c|c|}
\hline 1 & 8 & Malta & 21.32 & 1 & 10 & Malta & 25.32 & 1 & 15 & Malta & 30.37 \\
\hline 2 & 59 & Israel & 12.41 & 2 & 69 & Israel & 13.64 & 2 & 71 & Lebanon & 20.94 \\
\hline 3 & 80 & Tunisia & 8.87 & 3 & 78 & Tunisia & 12.5 & 3 & 77 & Tunisia & 20.2 \\
\hline 4 & 90 & Morocco & 7.61 & 4 & 81 & Lebanon & 11.99 & 4 & 78 & Iran & 20.16 \\
\hline 5 & 92 & Lebanon & 7.55 & 5 & 88 & Morocco & 11.16 & 5 & 80 & Kuwait & 19.73 \\
\hline 6 & 100 & Algeria & 6.74 & 6 & 100 & Iran & 9.55 & 6 & 89 & Morocco & 17.46 \\
\hline 7 & 103 & Iran & 6.56 & 7 & 102 & Algeria & 8.94 & 7 & 91 & Saudi Arabia & 17.24 \\
\hline 8 & 114 & Egypt & 5.33 & 8 & 111 & Kuwait & 7.58 & 8 & 95 & Israel & 16.58 \\
\hline
\end{tabular}




\begin{tabular}{|c|c|c|c|c|c|c|c|c|c|c|c|}
\hline 9 & 122 & Syria & 4.87 & 9 & 126 & Djibouti & 6.4 & 9 & 96 & Libya & 16.35 \\
\hline 10 & 128 & Djibouti & 4.71 & 10 & 127 & Egypt & 6.38 & 10 & 99 & $\begin{array}{l}\text { United Arab } \\
\text { Emirates }\end{array}$ & 16.11 \\
\hline 11 & 129 & Libya & 4.53 & 11 & 128 & Libya & 6.33 & 11 & 101 & Algeria & 15.89 \\
\hline 12 & 138 & Jordan & 3.95 & 12 & 132 & Saudi Arabia & 6.05 & 12 & 110 & Qatar & 14.17 \\
\hline 13 & 147 & Saudi Arabia & 3.5 & 13 & 133 & Syria & 6.05 & 13 & 113 & Syria & 13.5 \\
\hline 14 & 148 & Iraq & 3.44 & 14 & 136 & Bahrain & 5.56 & 14 & 116 & Bahrain & 12.95 \\
\hline 15 & 152 & Palestine & 3.22 & 15 & 138 & Jordan & 5.55 & 15 & 117 & Oman & 12.86 \\
\hline 16 & 160 & Kuwait & 3.04 & 16 & 140 & $\begin{array}{l}\text { United Arab } \\
\text { Emirates }\end{array}$ & 5.14 & 16 & 124 & Djibouti & 12.13 \\
\hline 17 & 165 & Yemen & 2.93 & 17 & 143 & Qatar & 4.71 & 17 & 126 & Jordan & 11.84 \\
\hline 18 & 176 & Bahrain & 2.65 & 18 & 144 & Oman & 4.44 & 18 & 137 & Egypt & 9.42 \\
\hline 19 & 182 & Oman & 2.51 & 19 & 152 & Palestine & 4.14 & 19 & 143 & Palestine & 7.56 \\
\hline 20 & 192 & Qatar & 1.69 & 20 & 159 & Iraq & 3.78 & 20 & 146 & Iraq & 7.08 \\
\hline 21 & 193 & $\begin{array}{l}\text { United Arab } \\
\text { Emirates }\end{array}$ & 1.26 & 21 & 168 & Yemen & 3.38 & 21 & 158 & Yemen & 5.91 \\
\hline \multicolumn{12}{|c|}{ Latin America and Caribbean } \\
\hline 1 & 10 & Puerto Rico & 32.65 & 1 & 10 & Puerto Rico & 20.83 & 1 & 11 & Puerto Rico & 25.16 \\
\hline 2 & 17 & Cuba & 29.83 & 2 & 32 & Curaçao & 17.67 & 2 & 26 & Curaçao & 22.88 \\
\hline 3 & 31 & Barbados & 27.74 & 3 & 35 & Barbados & 16.7 & 3 & 32 & Barbados & 22.06 \\
\hline 4 & 45 & Chile & 24.9 & 4 & 40 & Cuba & 15.89 & 4 & 34 & Cuba & 21.66 \\
\hline 5 & 46 & Curaçao & 24.73 & 5 & 48 & Uruguay & 15.09 & 5 & 39 & Aruba & 20.74 \\
\hline 6 & 51 & Saint Lucia & 24.06 & 6 & 50 & Aruba & 14.6 & 6 & 58 & Chile & 17.15 \\
\hline 7 & 56 & Costa Rica & 23.66 & 7 & 60 & Chile & 12.24 & 7 & 59 & Uruguay & 17.15 \\
\hline 8 & 57 & $\begin{array}{l}\text { Trinidad and } \\
\text { Tobago }\end{array}$ & 23.05 & 8 & 64 & $\begin{array}{l}\text { Trinidad and } \\
\text { Tobago }\end{array}$ & 11.51 & 8 & 63 & $\begin{array}{l}\text { Trinidad and } \\
\text { Tobago }\end{array}$ & 16.14 \\
\hline 9 & 61 & Brazil & 22.72 & 9 & 65 & Argentina & 11.37 & 9 & 65 & Costa Rica & 15.11 \\
\hline 10 & 64 & Aruba & 22.32 & 10 & 68 & Saint Lucia & 10.3 & 10 & 67 & Saint Lucia & 14.64 \\
\hline
\end{tabular}




\begin{tabular}{|c|c|c|c|c|c|c|c|c|c|c|c|}
\hline 11 & 68 & Uruguay & 21.67 & 11 & 69 & Costa Rica & 10.25 & 11 & 68 & Antigua and Barb. & 13.67 \\
\hline 12 & 70 & Colombia & 21.01 & 12 & 70 & St. Vin. and Gren. & 9.91 & 12 & 70 & Brazil & 13.59 \\
\hline 13 & 74 & Antigua and Barb. & 20.79 & 13 & 71 & Grenada & 9.79 & 13 & 72 & St. Vin. and Gren. & 13.39 \\
\hline 14 & 83 & St. Vin. and Gren. & 18.94 & 14 & 73 & Brazil & 9.59 & 14 & 74 & Colombia & 13.03 \\
\hline 15 & 84 & Peru & 18.93 & 15 & 75 & Antigua and Barb. & 9.33 & 15 & 75 & Argentina & 12.74 \\
\hline 16 & 85 & Jamaica & 18.47 & 16 & 76 & Jamaica & 9.08 & 16 & 79 & Grenada & 12.45 \\
\hline 17 & 86 & Panama & 17.82 & 17 & 78 & Colombia & 9.06 & 17 & 82 & Jamaica & 11.96 \\
\hline 18 & 87 & Bahamas & 17.64 & 18 & 81 & Peru & 8.73 & 18 & 84 & Bahamas & 11.79 \\
\hline 19 & 90 & Argentina & 17.28 & 19 & 82 & El Salvador & 8.65 & 19 & 86 & Peru & 11.44 \\
\hline 20 & 92 & Mexico & 17.03 & 20 & 83 & Panama & 8.54 & 20 & 87 & Panama & 11.3 \\
\hline 21 & 94 & Grenada & 16.69 & 21 & 85 & Venezuela & 7.97 & 21 & 90 & El Salvador & 10.65 \\
\hline 22 & 97 & El Salvador & 16.27 & 22 & 88 & Bahamas & 7.75 & 22 & 91 & Guyana & 10.31 \\
\hline 23 & 98 & Ecuador & 16.19 & 23 & 89 & Mexico & 7.62 & 23 & 92 & Dominican Rep. & 10.24 \\
\hline 24 & 100 & Dominican Rep. & 16.02 & 24 & 91 & Ecuador & 7.59 & 24 & 94 & Mexico & 10.2 \\
\hline 25 & 105 & Venezuela & 15.33 & 25 & 93 & Dominican Rep. & 7.53 & 25 & 95 & Venezuela & 10.13 \\
\hline 26 & 106 & Nicaragua & 14.93 & 26 & 94 & Bolivia & 7.49 & 26 & 96 & Ecuador & 10.1 \\
\hline 27 & 108 & Guyana & 14.82 & 27 & 96 & Suriname & 7.14 & 27 & 99 & Suriname & 9.97 \\
\hline 28 & 109 & Suriname & 14.37 & 28 & 97 & Guyana & 7 & 28 & 103 & Bolivia & 8.78 \\
\hline 29 & 119 & Honduras & 12.84 & 29 & 99 & Paraguay & 6.81 & 29 & 105 & Paraguay & 8.52 \\
\hline 30 & 120 & Paraguay & 12.77 & 30 & 110 & Nicaragua & 5.68 & 30 & 108 & Nicaragua & 7.99 \\
\hline 31 & 121 & Belize & 12.76 & 31 & 116 & Haiti & 5.17 & 31 & 118 & Belize & 7.06 \\
\hline 32 & 122 & Bolivia & 12.72 & 32 & 118 & Guatemala & 5.04 & 32 & 125 & Honduras & 6.66 \\
\hline 33 & 130 & Guatemala & 10.95 & 33 & 119 & Belize & 5.01 & 33 & 129 & Haiti & 6.31 \\
\hline 34 & 135 & Haiti & 10.08 & 34 & 120 & Honduras & 4.97 & 34 & 131 & Guatemala & 6.12 \\
\hline \multicolumn{12}{|c|}{ North America } \\
\hline 1 & 30 & Canada & 18.1 & 1 & 27 & Canada & 22.82 & 1 & 44 & Canada & 25.04 \\
\hline
\end{tabular}




\begin{tabular}{|c|c|c|c|c|c|c|c|c|c|c|c|}
\hline 2 & 37 & $\begin{array}{l}\text { United States of } \\
\text { America }\end{array}$ & 16.63 & 2 & 44 & $\begin{array}{l}\text { United States of } \\
\text { America }\end{array}$ & 20.26 & 2 & 63 & $\begin{array}{l}\text { United States of } \\
\text { America }\end{array}$ & 22.35 \\
\hline \multicolumn{12}{|c|}{ Sub-Saharan Africa } \\
\hline 1 & 57 & Mauritius & 12.52 & 1 & 57 & Mauritius & 17.99 & 1 & 49 & Mauritius & 24.46 \\
\hline 2 & 84 & Seychelles & 8.07 & 2 & 77 & Seychelles & 12.6 & 2 & 79 & Seychelles & 20.02 \\
\hline 3 & 113 & South Africa & 5.51 & 3 & 115 & Cabo Verde & 7.16 & 3 & 107 & Cabo Verde & 14.83 \\
\hline 4 & 121 & Lesotho & 4.95 & 4 & 124 & South Africa & 6.68 & 4 & 132 & South Africa & 10.49 \\
\hline 5 & 125 & Cabo Verde & 4.79 & 5 & 134 & Botswana & 5.65 & 5 & 136 & Botswana & 9.98 \\
\hline 6 & 130 & Botswana & 4.51 & 6 & 137 & Lesotho & 5.55 & 6 & 141 & Lesotho & 8.06 \\
\hline 7 & 131 & Eritrea & 4.51 & 7 & 147 & Rwanda & 4.37 & 7 & 145 & Gabon & 7.43 \\
\hline 8 & 137 & eSwatini & 4.01 & 8 & 149 & Eritrea & 4.23 & 8 & 148 & Rwanda & 6.91 \\
\hline 9 & 139 & Sudan & 3.67 & 9 & 150 & Sudan & 4.2 & 9 & 149 & Kenya & 6.72 \\
\hline 10 & 143 & Namibia & 3.59 & 10 & 151 & Ghana & 4.19 & 10 & 151 & Namibia & 6.5 \\
\hline 11 & 145 & Ethiopia & 3.54 & 11 & 153 & Namibia & 4.13 & 11 & 154 & Ghana & 6.44 \\
\hline 12 & 146 & Gabon & 3.53 & 12 & 154 & Gabon & 3.91 & 12 & 155 & eSwatini & 6.25 \\
\hline 13 & 149 & S. Sudan & 3.35 & 13 & 155 & $\begin{array}{l}\text { São Tomé and } \\
\text { Principe }\end{array}$ & 3.9 & 13 & 156 & $\begin{array}{l}\text { São Tomé and } \\
\text { Principe }\end{array}$ & 6.18 \\
\hline 14 & 150 & Liberia & 3.32 & 14 & 156 & eSwatini & 3.83 & 14 & 157 & Ethiopia & 6.05 \\
\hline 15 & 151 & Benin & 3.28 & 15 & 157 & Ethiopia & 3.83 & 15 & 159 & Comoros & 5.74 \\
\hline 16 & 154 & Mauritania & 3.18 & 16 & 158 & Comoros & 3.82 & 16 & 160 & Sudan & 5.68 \\
\hline 17 & 155 & Ghana & 3.14 & 17 & 160 & Liberia & 3.78 & 17 & 161 & Madagascar & 5.63 \\
\hline 18 & 156 & Rwanda & 3.12 & 18 & 161 & Madagascar & 3.73 & 18 & 162 & Mauritania & 5.56 \\
\hline 19 & 157 & Senegal & 3.11 & 19 & 162 & Mauritania & 3.68 & 19 & 163 & Liberia & 5.53 \\
\hline 20 & 158 & Comoros & 3.11 & 20 & 163 & Benin & 3.6 & 20 & 165 & Zimbabwe & 5.42 \\
\hline 21 & 159 & Madagascar & 3.1 & 21 & 164 & S. Sudan & 3.57 & 21 & 166 & Eritrea & 5.39 \\
\hline 22 & 161 & Dem. Rep. Congo & 3.02 & 22 & 165 & Congo & 3.45 & 22 & 167 & Congo & 5.35 \\
\hline 23 & 162 & Zimbabwe & 3.01 & 23 & 166 & Kenya & 3.43 & 23 & 168 & Senegal & 5.22 \\
\hline
\end{tabular}




\begin{tabular}{|c|c|c|c|c|c|c|c|c|c|c|c|}
\hline 24 & 163 & $\begin{array}{l}\text { São Tomé and } \\
\text { Principe }\end{array}$ & 3.01 & 24 & 167 & Senegal & 3.38 & 24 & 169 & Togo & 5.12 \\
\hline 25 & 164 & Guinea & 2.95 & 25 & 169 & Zimbabwe & 3.33 & 25 & 170 & Sierra Leone & 4.92 \\
\hline 26 & 166 & Sierra Leone & 2.93 & 26 & 170 & Togo & 3.27 & 26 & 171 & Benin & 4.84 \\
\hline 27 & 167 & Togo & 2.91 & 27 & 171 & Dem. Rep. Congo & 3.18 & 27 & 172 & S. Sudan & 4.69 \\
\hline 28 & 168 & Somalia & 2.9 & 28 & 173 & Sierra Leone & 3.13 & 28 & 173 & Malawi & 4.59 \\
\hline 29 & 169 & Guinea-Bissau & 2.89 & 29 & 174 & Guinea & 3.08 & 29 & 174 & Tanzania & 4.51 \\
\hline 30 & 170 & Côte d'Ivoire & 2.88 & 30 & 175 & Côte d'Ivoire & 3.05 & 30 & 175 & Cameroon & 4.51 \\
\hline 31 & 171 & Mozambique & 2.86 & 31 & 176 & Tanzania & 3 & 31 & 176 & Guinea-Bissau & 4.45 \\
\hline 32 & 172 & Central African Rep. & 2.8 & 32 & 177 & Guinea-Bissau & 2.98 & 32 & 177 & Zambia & 4.17 \\
\hline 33 & 173 & Congo & 2.76 & 33 & 178 & Somalia & 2.94 & 33 & 178 & Burkina Faso & 4.1 \\
\hline 34 & 174 & Nigeria & 2.74 & 34 & 179 & Nigeria & 2.9 & 34 & 179 & Dem. Rep. Congo & 4.1 \\
\hline 35 & 175 & Cameroon & 2.72 & 35 & 180 & Central African Rep. & 2.9 & 35 & 180 & Uganda & 4.03 \\
\hline 36 & 178 & Tanzania & 2.64 & 36 & 181 & Cameroon & 2.89 & 36 & 181 & Côte d'Ivoire & 3.98 \\
\hline 37 & 179 & Malawi & 2.64 & 37 & 182 & Burundi & 2.88 & 37 & 182 & Nigeria & 3.96 \\
\hline 38 & 180 & Niger & 2.6 & 38 & 183 & Mozambique & 2.84 & 38 & 183 & Burundi & 3.94 \\
\hline 39 & 181 & Gambia & 2.53 & 39 & 184 & Malawi & 2.83 & 39 & 184 & Guinea & 3.93 \\
\hline 40 & 183 & Kenya & 2.51 & 40 & 185 & Burkina Faso & 2.69 & 40 & 185 & Gambia & 3.91 \\
\hline 41 & 184 & Chad & 2.5 & 41 & 186 & Gambia & 2.68 & 41 & 186 & Mozambique & 3.88 \\
\hline 42 & 185 & Mali & 2.48 & 42 & 187 & Niger & 2.6 & 42 & 187 & Mali & 3.55 \\
\hline 43 & 186 & Burkina Faso & 2.41 & 43 & 188 & Chad & 2.55 & 43 & 188 & Central African Rep. & 3.5 \\
\hline 44 & 187 & Eq. Guinea & 2.38 & 44 & 189 & Angola & 2.49 & 44 & 189 & Chad & 3.38 \\
\hline 45 & 188 & Burundi & 2.38 & 45 & 190 & Zambia & 2.46 & 45 & 190 & Angola & 3.35 \\
\hline 46 & 189 & Angola & 2.19 & 46 & 191 & Mali & 2.42 & 46 & 191 & Eq. Guinea & 3.27 \\
\hline 47 & 190 & Zambia & 2.13 & 47 & 192 & Uganda & 2.34 & 47 & 192 & Somalia & 3.08 \\
\hline 48 & 191 & Uganda & 1.99 & 48 & 193 & Eq. Guinea & 2.21 & 48 & 193 & Niger & 2.71 \\
\hline
\end{tabular}


Table B 2. Income groupings

\begin{tabular}{|c|c|c|c|}
\hline $\begin{array}{l}\text { Developed countries } \\
\text { (high income) }\end{array}$ & $\begin{array}{l}\text { Taivan, China } \\
\text { Trinidad and Tobago }\end{array}$ & $\begin{array}{l}\text { Lebanon } \\
\text { Lesotho }\end{array}$ & $\begin{array}{l}\text { Developing countries } \\
\text { (low income) }\end{array}$ \\
\hline Andorra & United Arab Emirates & Libya & Afghanistan \\
\hline Antigua and Barbuda & United Kingdom & Macedonia, the former & Benin \\
\hline Argentina & $\begin{array}{l}\text { United States } \\
\text { United States Virojin lslands }\end{array}$ & Yugoslav Republic of & Burkina Faso \\
\hline Australia & $\begin{array}{l}\text { United States Virgin Islands } \\
\text { Uruguay }\end{array}$ & $\begin{array}{l}\text { Malaysia } \\
\text { Maldives }\end{array}$ & Burundi \\
\hline Austria & Uruguay & $\begin{array}{l}\text { Maldives } \\
\text { Marshall Islands }\end{array}$ & Central African Republic \\
\hline Bahamas & & $\begin{array}{l}\text { Marshall Islands } \\
\text { Mauritania }\end{array}$ & Chad \\
\hline Bahrain & Emerging countries & $\begin{array}{l}\text { Mauritania } \\
\text { Mauritius }\end{array}$ & Comoros \\
\hline Barbados & (middle income) & Mexico & Congo, Democratic \\
\hline $\begin{array}{l}\text { Belgium } \\
\text { Brunei Darussalam }\end{array}$ & Albania & Micronesia, Federated & Republic of the \\
\hline $\begin{array}{l}\text { Canada } \\
\text { Cassalam }\end{array}$ & Algeria & States of & Eritrea \\
\hline Channel Islands & Angola & Moldova, Republic of & Ethiopia \\
\hline Chile & Armenia & Mongolia & $\begin{array}{l}\text { The Gambia } \\
\text { Guinea }\end{array}$ \\
\hline Croatia & Azerbaijan & Montenegro & Guinea-Bissau \\
\hline Cyprus & Bangladesh & Morocco & Haiti \\
\hline Czech Republic & Belarus & Myanmar & Korea, Democratic People's \\
\hline Denmark & Belize & Namibia & Republic of \\
\hline Estonia & Bhutan & Nauru & Liberia \\
\hline Finland & Bolivia, Plurinational State of & Nicaragua & Madagascar \\
\hline France & & Nigeria & Malawi \\
\hline French Polynesia & $\begin{array}{l}\text { Botswana } \\
\text { Brazil }\end{array}$ & Occupied Palestinian Territory & Mali \\
\hline Germany & $\begin{array}{l}\text { Brazil } \\
\text { Bulgaria }\end{array}$ & Pakistan & Mozambique \\
\hline Greece & $\begin{array}{l}\text { Bulgaria } \\
\text { Cabo Verde }\end{array}$ & Palau & Nepal \\
\hline Guam & Cabo Verde & Panama & Niger \\
\hline Hong Kong, China & $\begin{array}{l}\text { Cambodia } \\
\text { Cameroon }\end{array}$ & Papua New Guinea & Rwanda \\
\hline Hungary & Cameroon & Paraguay & Senegal \\
\hline Iceland & China & Peru & Sierra Leone \\
\hline Ireland & Colombia & Philippines & Somalia \\
\hline Israel & Congo & Romania & Tanzania, United Republic of \\
\hline Italy & Cook Islands & Russian Federation & Togo \\
\hline Japan & Costa Rica & Saint Lucia & Uganda \\
\hline $\begin{array}{l}\text { Kuwait } \\
\text { Latvia }\end{array}$ & $\begin{array}{l}\text { Cuba } \\
\text { Djibouti }\end{array}$ & $\begin{array}{l}\text { the Grenadines } \\
\text { Samoa }\end{array}$ & \\
\hline Liechtenstein & Dominica & Sao Tome and Principe & \\
\hline Lithuania & Dominican Republic & Serbia & \\
\hline Luxembourg & Ecuador & Solomon Islands & \\
\hline Macau, China & Egypt & South Africa & \\
\hline Malta & El Salvador & Sri Lanka & \\
\hline Monaco & Equatorial Guinea & Sudan & \\
\hline Netherlands & Fiji & Suriname & \\
\hline Netherlands Antilles & Gabon & Swaziland & \\
\hline New Caledonia & Georgia & Syrian Arab Republic & \\
\hline New Zealand & Ghana & Tajikistan & \\
\hline Norway & Grenada & Thailand & \\
\hline Oman & Guatemala & Timor-Leste & \\
\hline Poland & Guyana & Tonga & \\
\hline Portugal & Honduras & Tunisia & \\
\hline Puerto Rico & India & Turkey & \\
\hline Qatar & Indonesia & Turkmenistan & \\
\hline Saint Kitts and Nevis & Iran, Islamic Republic of & Tuvalu & \\
\hline San Marino & Iraq & Ukraine & \\
\hline Saudi Arabia & Jamaica & Uzbekistan & \\
\hline Seychelles & Jordan & Vanuatu & \\
\hline Singapore & Kazakhstan & Venezuela, Bolivarian & \\
\hline Slovakia & Kenya & Republic of & \\
\hline Slovenia & Kiribati & Viet Nam & \\
\hline Spain & Kyrgyzstan & Western Sahara & \\
\hline Sweden & Lao People's & Yemen & \\
\hline Switzerland & Democratic Republic & Zambia & \\
\hline
\end{tabular}




\section{Appendix C}

Table C 1. Descriptive statistics

\begin{tabular}{|c|c|c|c|c|c|c|c|c|c|c|c|c|c|c|c|}
\hline \multirow[b]{2}{*}{ Variable } & \multicolumn{5}{|c|}{$\begin{array}{c}\text { Full sample } \\
(n=4,795)\end{array}$} & \multicolumn{5}{|c|}{$\begin{array}{c}\text { Treatment group } \\
(n=2,451)\end{array}$} & \multicolumn{5}{|c|}{$\begin{array}{c}\text { Control group } \\
(n=2,344)\end{array}$} \\
\hline & $\mathrm{N}$ & Mean & SD & Min & Max & $\mathrm{N}$ & Mean & SD. & Min & Max & $\mathrm{N}$ & Mean & SD & Min & Max \\
\hline $\begin{array}{l}\text { Transition time to } \\
\text { 1st job (month) }\end{array}$ & 3177 & 13.92 & 19.45 & 0 & 93.8 & 1616 & 12.9 & 17.83 & 0 & 78.79 & 1561 & 14.97 & 20.95 & 0 & 93.8 \\
\hline $\begin{array}{l}\text { Labour income } \\
\text { (Int\$ PPP) }\end{array}$ & 2155 & 4.77 & 8.69 & -7.86 & $\begin{array}{c}195.2 \\
1\end{array}$ & 1119 & 4.77 & 8.74 & -7.86 & $\begin{array}{c}161.5 \\
3\end{array}$ & 1036 & 4.76 & 8.65 & -0.96 & $\begin{array}{c}195.2 \\
1\end{array}$ \\
\hline $\begin{array}{l}\text { \# of activities } \\
\text { since school }\end{array}$ & 4795 & 2.57 & 2.52 & 0 & 15 & 2451 & 2.53 & 2.47 & 0 & 15 & 2344 & 2.6 & 2.58 & 0 & 15 \\
\hline $\begin{array}{l}\text { Finished school } \\
\text { during GFC }\end{array}$ & 4795 & 0.51 & 0.5 & 0 & 1 & 2451 & 1 & 0 & 1 & 1 & 2344 & 0 & 0 & 0 & 0 \\
\hline Sex & 4795 & 0.51 & 0.5 & 0 & 1 & 2451 & 0.51 & 0.5 & 0 & 1 & 2344 & 0.51 & 0.5 & 0 & 1 \\
\hline $\begin{array}{l}\text { Sq. age at ending } \\
\text { formal education }\end{array}$ & 4771 & $\begin{array}{c}355.8 \\
1\end{array}$ & $\begin{array}{c}105.9 \\
7\end{array}$ & $\begin{array}{c}100.8 \\
8\end{array}$ & $\begin{array}{c}683.4 \\
3\end{array}$ & 2445 & 358.3 & 111.8 & $\begin{array}{c}100.9 \\
3\end{array}$ & $\begin{array}{c}683.4 \\
3\end{array}$ & 2326 & 353.2 & 99.42 & $\begin{array}{c}100.8 \\
8\end{array}$ & $\begin{array}{c}627.8 \\
8\end{array}$ \\
\hline $\begin{array}{l}\text { Highest } \\
\text { educational level }\end{array}$ & 4698 & 2.18 & 0.66 & 1 & 3 & 2408 & 2.19 & 0.66 & 1 & 3 & 2290 & 2.17 & 0.66 & 1 & 3 \\
\hline Married & 4794 & 0.34 & 0.47 & 0 & 1 & 2451 & 0.32 & 0.47 & 0 & 1 & 2343 & 0.36 & 0.48 & 0 & 1 \\
\hline
\end{tabular}




\begin{tabular}{|c|c|c|c|c|c|c|c|c|c|c|c|c|c|c|c|}
\hline $\begin{array}{l}\text { Informal } \\
\text { employment }\end{array}$ & 2068 & 0.32 & 0.47 & 0 & 1 & 1062 & 0.31 & 0.46 & 0 & 1 & 1006 & 0.34 & 0.47 & 0 & 1 \\
\hline $\begin{array}{l}\text { One parent has } \\
\text { tertiary education }\end{array}$ & 4300 & 0.31 & 0.46 & 0 & 1 & 2203 & 0.31 & 0.46 & 0 & 1 & 2097 & 0.31 & 0.46 & 0 & 1 \\
\hline $\begin{array}{l}\text { Area dummy } \\
\text { (urban/rural) }\end{array}$ & 4795 & 0.43 & 0.5 & 0 & 1 & 2451 & 0.43 & 0.5 & 0 & 1 & 2344 & 0.43 & 0.5 & 0 & 1 \\
\hline $\begin{array}{l}\text { Distance between } \\
\text { GFC and survey }\end{array}$ & 4795 & 71.74 & 9.66 & 52.82 & 85.28 & 2451 & 71.71 & 9.53 & 52.82 & 85.28 & 2344 & 71.78 & 9.8 & 52.82 & 85.28 \\
\hline
\end{tabular}

Table C 2. Selection of treatment and control group based on real GDP growth

\begin{tabular}{|c|c|c|c|c|c|c|c|c|c|c|c|c|}
\hline $\begin{array}{l}\text { Country name } \\
\text { (survey date) }\end{array}$ & $\begin{array}{l}\text { Indicator } \\
\text { (in \%) }\end{array}$ & Q3 2007 & Q4 2007 & Q1 2008 & Q2 2008 & Q3 2008 & Q4 2008 & Q1 2009 & Q2 2009 & Q3 2009 & Q4 2009 & Q1 2010 \\
\hline \multirow{3}{*}{$\begin{array}{l}\text { Armenia } \\
\text { (Sep-0ct 2014) }\end{array}$} & Real $\Delta$ GDP & 52.9 & -1.7 & -51.2 & 56.8 & 58.7 & -19.5 & -49.5 & 30.8 & 58.0 & -4.3 & -44.4 \\
\hline & LFPR & . & & 58.9 & 59.6 & 61.9 & 57.8 & 57.5 & 56.7 & 61.9 & 60.7 & 58.1 \\
\hline & Unemployment & . & & 17.7 & 17.3 & 15.6 & 14.7 & 19.9 & 19.1 & 19.3 & 16.8 & 18.1 \\
\hline \multirow[t]{3}{*}{$\begin{array}{l}\text { Brazil } \\
\text { (Jun 2013) }\end{array}$} & Real $\Delta$ GDP & 2.8 & 0.5 & -1.6 & 4.6 & 3.5 & -5.1 & -4.9 & 4.8 & 4.6 & 1.1 & -1.4 \\
\hline & LFPR* & . & 65.7 & 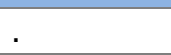 & & . & 65.6 & & . & . & 65.9 & . \\
\hline & Unemployment* & . & 8.3 & . & & . & 7.3 & & . & . & 8.5 & . \\
\hline \multirow[t]{3}{*}{$\begin{array}{l}\text { Dominican Rep. } \\
\text { (Jul-Sep 2015) }\end{array}$} & Real $\Delta$ GDP & 0.8 & 3.0 & 1.9 & 1.8 & -6.4 & 1.4 & 0.5 & 2.4 & -1.9 & 6.1 & 2.2 \\
\hline & LFPR & . & 57.3 & . & 57.8 & . & 57.4 & & 55.0 & . & 55.9 & . \\
\hline & Unemployment & . & 5.0 & . & 4.7 & . & 4.8 & & 5.1 & . & 5.8 & . \\
\hline \multirow[t]{2}{*}{$\begin{array}{l}\text { Egypt } \\
\text { (Nov-Dec 2014) }\end{array}$} & Real $\triangle$ GDP & 0.2 & 4.9 & 2.3 & 4.6 & 1.7 & -2.1 & 0.1 & 4.9 & 1.8 & -1.8 & 0.7 \\
\hline & LFPR & & & 47.6 & 47.1 & 47.7 & 47.9 & 47.9 & 47.7 & 47.9 & 48.1 & 49.3 \\
\hline
\end{tabular}




\begin{tabular}{|c|c|c|c|c|c|c|c|c|c|c|c|c|}
\hline & Unemployment & 8.9 & 9.1 & 9.2 & 8.1 & 8.3 & 8.4 & 9.1 & 9.0 & 9.0 & 9.1 & 8.8 \\
\hline \multirow{3}{*}{$\begin{array}{l}\text { El Salvador } \\
\text { (Oct-Dec 2014) }\end{array}$} & Real $\Delta$ GDP & 1.0 & 7.8 & -9.2 & 5.9 & -2.4 & 4.3 & -8.8 & 5.2 & -2.8 & 5.2 & -4.5 \\
\hline & LFPR* $^{*}$ & . & 61.9 & . & . & . & 61.7 & & & & 61.6 & \\
\hline & Unemployment* & . & 6.4 & . & . & . & 5.9 & & & & 7.3 & \\
\hline \multirow{3}{*}{$\begin{array}{l}\text { Jamaica } \\
\text { (Jun-Sep 2015) }\end{array}$} & Real $\Delta$ GDP & -0.5 & -1.0 & -0.1 & 1.0 & -1.2 & -1.2 & -2.5 & 0.4 & 1.0 & -1.6 & -1.4 \\
\hline & LFPR & . & . & 65.7 & 64.9 & 65.2 & 65.4 & 64.1 & 63.5 & 63.7 & 62.9 & 63.0 \\
\hline & Unemployment & 9.7 & 9.4 & 10.1 & 11.7 & 10.2 & 10.3 & 11.1 & 11.4 & 11.3 & 11.6 & 13.5 \\
\hline \multirow{3}{*}{$\begin{array}{l}\text { Kyrgyzstan } \\
\text { (Jul-Sep 2013) }\end{array}$} & Real $\Delta$ GDP & 75.8 & -21.6 & -34.6 & 19.3 & 73.7 & -16.5 & -43.3 & 22.0 & 81.2 & -15.9 & -36.3 \\
\hline & LFPR & 67.2 & 64.7 & 64.5 & 64.7 & 67.3 & 65.1 & 63.0 & 64.5 & 66.2 & 63.8 & \\
\hline & Unemployment & 6.3 & 7.1 & 11.1 & 6.9 & 7.4 & 7.6 & 10.9 & 7.9 & 6.9 & 8.0 & \\
\hline \multirow{3}{*}{$\begin{array}{l}\text { Moldova } \\
\text { (Mar 2015) }\end{array}$} & Real $\Delta$ GDP & 25.4 & -6.5 & -15.1 & 23.2 & 17.1 & -6.7 & -22.3 & 9.7 & 16.9 & -3.8 & -9.1 \\
\hline & LFPR & 46.5 & 42.6 & 41.7 & 47.5 & 46.1 & 41.8 & 39.9 & 45.9 & 44.8 & 40.4 & 37.9 \\
\hline & Unemployment & 5.1 & 5.4 & 5.5 & 3.0 & 3.6 & 3.9 & 7.7 & 6.1 & 5.7 & 6.2 & \\
\hline \multirow{3}{*}{$\begin{array}{l}\text { North Macedonia } \\
\text { (Jul-Oct 2014) }\end{array}$} & Real $\Delta$ GDP & 7.0 & 6.1 & -11.8 & 9.1 & 2.0 & 3.6 & -10.7 & 4.2 & -0.2 & 9.0 & -6.8 \\
\hline & LFPR & 54.6 & 54.6 & 55.1 & 55.0 & 55.5 & 54.8 & 55.0 & 55.8 & 56.1 & 54.9 & 55.1 \\
\hline & Unemployment & 34.2 & 34.8 & 34.8 & 33.9 & 33.0 & 33.5 & 32.8 & 31.9 & 31.7 & 32.4 & 33.5 \\
\hline \multirow{3}{*}{$\begin{array}{l}\text { Montenegro } \\
\text { (Sep-Oct 2015) }\end{array}$} & Real $\Delta \mathrm{GDP}$ & 9.4 & 0.8 & 18.1 & 13.2 & 7.1 & -5.7 & 9.2 & -10.9 & -6.7 & -10.1 & 9.9 \\
\hline & LFPR* & . & 48.5 & . & . & . & 48.6 & & & & 48.5 & \\
\hline & Unemployment* & . & 19.4 & . & . & . & 17.1 & & & & 19.1 & \\
\hline \multirow{3}{*}{$\begin{array}{l}\text { Russia } \\
\text { (Mar 2015) }\end{array}$} & Real $\Delta \mathrm{GDP}$ & 8.7 & 4.9 & -12.9 & 8.7 & 7.2 & -2.7 & -19.9 & 6.4 & 10.2 & 3.7 & -14.4 \\
\hline & LFPR & 67.8 & 67.0 & 66.8 & 67.6 & 68.5 & 67.8 & 66.9 & 67.8 & 68.7 & 67.8 & 66.9 \\
\hline & Unemployment & 5.6 & 5.6 & 7.1 & 5.4 & 5.8 & 7.0 & 9.4 & 8.5 & 7.8 & 8.0 & 8.7 \\
\hline \multirow{3}{*}{$\begin{array}{l}\text { Serbia } \\
\text { (Mar-Apr 2015) }\end{array}$} & Real $\Delta \mathrm{GDP}$ & 4.7 & 7.4 & . & 7.2 & 3.6 & 3.1 & -14.5 & 5.7 & 4.5 & 3.2 & -12.4 \\
\hline & LFPR & . & . & . & 51.6 & . & 51.4 & & 49.3 & & 48.9 & \\
\hline & Unemployment & . & . & . & 13.4 & . & 14.0 & & 15.6 & & 16.7 & \\
\hline
\end{tabular}




\begin{tabular}{|c|c|c|c|c|c|c|c|c|c|c|c|c|}
\hline $\begin{array}{l}\text { Tunisia } \\
\text { (Feb-Mar 2013) }\end{array}$ & Real $\Delta \mathrm{GDP}$ & 1.6 & 0.6 & 1.3 & 0.4 & 2.4 & 0.9 & -0.9 & 1.7 & 1.5 & 1.7 & -0.8 \\
\hline & LFPR* $^{*}$ & . & 45.7 & & & & 45.9 & & & & 45.3 & \\
\hline & Unemployment* & . & 12.4 & & & & 12.4 & & & & 13.3 & \\
\hline \multirow{3}{*}{$\begin{array}{l}\text { Ukraine } \\
\text { (Apr-May 2015) }\end{array}$} & Real $\Delta \mathrm{GDP}$ & 17.5 & -1.8 & -15.6 & 9.0 & 15.3 & -13.2 & -26.3 & 12.1 & 17.6 & -3.9 & -17.5 \\
\hline & LFPR & 63.9 & 61.5 & 63.0 & 64.0 & 64.7 & 61.6 & 63.2 & 63.7 & 64.3 & 62.1 & 63.7 \\
\hline & Unemployment & 5.4 & 6.9 & 7.1 & 5.4 & 5.5 & 7.5 & 9.5 & 8.6 & 7.8 & 9.4 & 9.0 \\
\hline
\end{tabular}

Sources: Real $\triangle$ GDP (\%): IMF (2020). $\left({ }^{1}\right)$ Statistica Moldovei. $\left({ }^{2}\right)$ Montstat.

LFPR (\%) and Unemployment (\%): ILOSTAT (2020b). (*) Annual data.

Notes: This table reports real gross domestic growth rates from one quarter to the next. Blue cells indicate the control group, orange cells the treatment group. 
Table C 3. Estimated change in the school-to-work transition (full output, model comparison)

\begin{tabular}{|c|c|c|c|c|c|c|c|}
\hline \multirow[b]{2}{*}{ Dependent variable: SWT duration (month) } & \multirow[t]{2}{*}{$\begin{array}{l}\text { (1) } \\
\text { OLS }\end{array}$} & \multirow[t]{2}{*}{$\begin{array}{c}\text { (2) } \\
\text { ZINB }\end{array}$} & \multirow[t]{2}{*}{$\begin{array}{l}\text { (3) } \\
\text { ZIP }\end{array}$} & \multicolumn{2}{|c|}{$\begin{array}{c}\text { (4) } \\
\text { TwoPM }\end{array}$} & \multicolumn{2}{|c|}{$\begin{array}{c}\text { (5) } \\
\text { TwoPM }\end{array}$} \\
\hline & & & & Probit & OLS & Probit & GLM \\
\hline \multicolumn{8}{|l|}{ r r c } \\
\hline GFC & 6.72 & 1.49 & 1.46 & 0.17 & $12.10 * *$ & 0.17 & 1.59 \\
\hline Sex & $(5.413)$ & $(0.511)$ & $(0.347)$ & $(0.313)$ & $(5.704)$ & $(0.313)$ & $(0.536)$ \\
\hline Male & $-4.15 * * *$ & $0.72 * * *$ & $0.79 * * *$ & $-0.12 * *$ & $-4.69 * * *$ & $-0.12 * *$ & $0.76 * * *$ \\
\hline Education & $(0.743)$ & (0.039) & $(0.035)$ & $(0.059)$ & $(0.864)$ & $(0.059)$ & $(0.039)$ \\
\hline \multirow[t]{2}{*}{ Secondary } & $-4.86 * * *$ & $0.67^{* * *}$ & 1.05 & $-0.53 * * *$ & 1.19 & $-0.53 * * *$ & 1.11 \\
\hline & $(1.468)$ & $(0.083)$ & $(0.083)$ & $(0.105)$ & $(1.735)$ & $(0.105)$ & $(0.116)$ \\
\hline Tertiary & $-8.53 * * *$ & $0.56 * * *$ & 1.16 & $-1.01 * * *$ & 2.69 & $-1.01 * * *$ & $1.25^{*}$ \\
\hline Area & $(1.511)$ & $(0.085)$ & $(0.112)$ & $(0.112)$ & $(1.994)$ & $(0.112)$ & $(0.149)$ \\
\hline Urban & $-1.46 *$ & 0.92 & $0.89 * *$ & -0.02 & $-2.45 * * *$ & -0.02 & 0.93 \\
\hline Controls & $(0.760)$ & $(0.053)$ & $(0.041)$ & $(0.059)$ & $(0.888)$ & $(0.059)$ & $(0.049)$ \\
\hline \multirow[t]{2}{*}{ Married } & -0.20 & 0.99 & 1.00 & -0.04 & -0.00 & -0.04 & 1.01 \\
\hline & $(0.850)$ & $(0.064)$ & $(0.051)$ & $(0.069)$ & $(0.978)$ & $(0.069)$ & $(0.059)$ \\
\hline \multirow[t]{2}{*}{ One parent has tertiary education } & -0.57 & 1.00 & 1.00 & -0.05 & -0.12 & -0.05 & 1.01 \\
\hline & $(0.860)$ & $(0.070)$ & $(0.058)$ & $(0.069)$ & $(1.047)$ & $(0.069)$ & $(0.063)$ \\
\hline \multirow[t]{2}{*}{ Age at finishing formal education } & $3.93 * * *$ & $1.47^{* * *}$ & 0.94 & $0.46 * * *$ & -2.73 & $0.46 * * *$ & 0.90 \\
\hline & $(1.140)$ & $(0.205)$ & $(0.091)$ & (0.099) & $(1.970)$ & $(0.099)$ & $(0.106)$ \\
\hline \multirow[t]{2}{*}{ Sq. age at finishing formal education } & $-0.11 * * *$ & $0.99 * * *$ & 1.00 & $-0.01 * * *$ & 0.04 & $-0.01 * * *$ & 1.00 \\
\hline & $(0.031)$ & $(0.004)$ & $(0.003)$ & $(0.003)$ & $(0.052)$ & $(0.003)$ & $(0.003)$ \\
\hline \multirow[t]{2}{*}{ Constant } & $-28.39 *$ & 0.30 & $134.67 * * *$ & $-6.60 * * *$ & $80.44 * * *$ & $-6.60 * * *$ & $218.39 * * *$ \\
\hline & $(14.674)$ & $(0.491)$ & $(122.768)$ & $(1.126)$ & $(26.566)$ & $(1.126)$ & (346.693) \\
\hline \multicolumn{8}{|l|}{ Inflate } \\
\hline \multirow[t]{2}{*}{ Number of activities since school } & & $1.62 * * *$ & $1.13^{* * *}$ & & & & \\
\hline & & $(0.127)$ & $(0.024)$ & & & & \\
\hline \multicolumn{8}{|l|}{ Controls } \\
\hline Country dummies & YES & YES & YES & YES & YES & YES & YES \\
\hline Time dummies & YES & YES & YES & YES & YES & YES & YES \\
\hline
\end{tabular}

\section{Goodness of fit}

$R$-squared 


\begin{tabular}{|c|c|c|c|c|c|c|c|}
\hline McFadden's R2 & & 0.015 & 0.156 & & & & \\
\hline Pseudo $R^{2}$ & & & & 0.1764 & & 0.1764 & \\
\hline$A I C$ & 24383.32 & 18726.59 & 45416.27 & 20468.11 & 20468.11 & 18555.55 & 18555.55 \\
\hline$B I C$ & 24573.53 & 18934.63 & 45618.37 & 20854.45 & 20854.45 & 18941.9 & 18941.9 \\
\hline
\end{tabular}

GLM: log link and gamma distribution.

Robust standard errors in parentheses ${ }^{* * *} p<0.01,{ }^{* *} p<0.05, * p<0.1$

Table C 4. Estimated impact of the GFC (full output, model comparison)

\begin{tabular}{|c|c|c|c|c|c|c|c|}
\hline \multirow{2}{*}{$\begin{array}{l}\text { Dependent variable: } \\
\text { SWT duration (month) }\end{array}$} & \multirow{2}{*}{$\begin{array}{l}\text { (1) } \\
\text { OLS }\end{array}$} & \multirow{2}{*}{$\begin{array}{c}(2) \\
\text { ZINB }\end{array}$} & \multirow{2}{*}{$\begin{array}{l}\text { (3) } \\
\text { ZIP }\end{array}$} & \multicolumn{2}{|c|}{$\begin{array}{c}\text { (4) } \\
\text { TwoPM }\end{array}$} & \multicolumn{2}{|c|}{$\begin{array}{c}\text { (5) } \\
\text { TwoPM }\end{array}$} \\
\hline & & & & Probit & OLS & Probit & GLM \\
\hline \multicolumn{8}{|l|}{ GFC } \\
\hline GFC & 1.98 & 1.24 & 1.27 & -0.07 & 8.11 & -0.07 & 1.43 \\
\hline Sex & $(6.124)$ & $(0.437)$ & $(0.323)$ & $(0.352)$ & $(6.016)$ & $(0.352)$ & $(0.504)$ \\
\hline \multirow[t]{2}{*}{ Male } & $-5.60 * * *$ & $0.62 * * *$ & $0.71 * * *$ & -0.09 & $-7.24 * * *$ & -0.09 & $0.64 * * *$ \\
\hline & $(1.113)$ & $(0.049)$ & $(0.044)$ & $(0.081)$ & $(1.219)$ & $(0.081)$ & $(0.047)$ \\
\hline Male X GFC & $2.87 * *$ & $1.33^{* * *}$ & $1.24 * *$ & -0.07 & $4.92 * * *$ & -0.07 & $1.37 * * *$ \\
\hline Education & $(1.425)$ & $(0.146)$ & $(0.104)$ & $(0.113)$ & $(1.678)$ & $(0.113)$ & (0.139) \\
\hline \multirow[t]{2}{*}{ Secondary } & $-6.34 * * *$ & $0.68 * * *$ & 1.02 & $-0.64 * * *$ & -0.06 & $-0.64 * * *$ & 1.16 \\
\hline & $(2.123)$ & $(0.101)$ & $(0.098)$ & $(0.143)$ & $(2.183)$ & $(0.143)$ & $(0.156)$ \\
\hline \multirow[t]{2}{*}{ Tertiary } & $-11.36 * * *$ & $0.47 * * *$ & 1.07 & $-1.22 * * *$ & 0.21 & $-1.22 * * *$ & 1.16 \\
\hline & $(2.187)$ & $(0.083)$ & $(0.122)$ & $(0.152)$ & $(2.466)$ & $(0.152)$ & $(0.175)$ \\
\hline \multirow[t]{2}{*}{ Secondary X GFC } & 3.08 & 0.99 & 1.09 & 0.20 & 2.71 & 0.20 & 0.94 \\
\hline & $(2.661)$ & $(0.182)$ & $(0.143)$ & $(0.188)$ & $(2.856)$ & $(0.188)$ & $(0.162)$ \\
\hline Tertiary X GFC & $5.61 * *$ & $1.38^{*}$ & 1.20 & $0.40 * *$ & 4.87 & $0.40 * *$ & 1.15 \\
\hline Area & $(2.727)$ & $(0.269)$ & $(0.172)$ & $(0.194)$ & (3.018) & $(0.194)$ & (0.209) \\
\hline \multirow[t]{2}{*}{ Urban } & -1.61 & 0.91 & $0.88 * *$ & -0.05 & $-2.74 * *$ & -0.05 & 0.93 \\
\hline & $(1.134)$ & $(0.074)$ & $(0.056)$ & $(0.082)$ & $(1.239)$ & $(0.082)$ & $(0.068)$ \\
\hline Urban X GFC & 0.18 & 1.02 & 1.03 & 0.05 & 0.40 & 0.05 & 1.00 \\
\hline Controls & (1.422) & $(0.114)$ & $(0.089)$ & $(0.113)$ & $(1.693)$ & $(0.113)$ & $(0.101)$ \\
\hline Married & -0.19 & 0.98 & 1.01 & -0.04 & 0.03 & -0.04 & 1.00 \\
\hline
\end{tabular}




\begin{tabular}{|c|c|c|c|c|c|c|c|}
\hline & $(0.848)$ & $(0.063)$ & $(0.051)$ & (0.069) & $(0.977)$ & (0.069) & $(0.059)$ \\
\hline \multirow[t]{2}{*}{ One parent has tertiary education } & -0.54 & 1.01 & 1.01 & -0.05 & 0.00 & -0.05 & 1.03 \\
\hline & $(0.857)$ & $(0.071)$ & $(0.058)$ & $(0.070)$ & $(1.047)$ & $(0.070)$ & $(0.064)$ \\
\hline \multirow[t]{2}{*}{ Age at finishing formal education } & $4.08^{* * *}$ & $1.48^{* * *}$ & 0.94 & $0.47^{* * *}$ & -2.79 & $0.47^{* * *}$ & 0.90 \\
\hline & (1.147) & $(0.206)$ & $(0.092)$ & (0.099) & $(1.971)$ & (0.099) & $(0.106)$ \\
\hline \multirow[t]{2}{*}{ Squared age at finishing formal education } & $-0.11^{* * *}$ & $0.99 * * *$ & 1.00 & $-0.01 * * *$ & 0.04 & $-0.01 * * *$ & 1.00 \\
\hline & $(0.031)$ & $(0.004)$ & $(0.003)$ & $(0.003)$ & $(0.052)$ & $(0.003)$ & $(0.003)$ \\
\hline Constant & $-27.66^{*}$ & 0.28 & $127.80^{* * *}$ & $-6.52^{* * *}$ & $80.66^{* * *}$ & $-6.52 * * *$ & $197.32^{* * *}$ \\
\hline Inflate & (14.597) & (0.448) & (117.196) & (1.131) & $(26.573)$ & (1.131) & (312.585) \\
\hline \multirow[t]{2}{*}{ Number of activities since school } & & $1.615^{* * *}$ & $1.132^{* * *}$ & & & & \\
\hline & & $(-0.128)$ & $(-0.024)$ & & & & \\
\hline \multirow[t]{2}{*}{ _cons } & & $0.007 * * *$ & $0.286^{* * *}$ & & & & \\
\hline & & $(-0.006)$ & $(-0.02)$ & & & & \\
\hline \multicolumn{8}{|l|}{ I } \\
\hline \multirow{2}{*}{ Inalpha } & & $2.476^{* * *}$ & & & & & \\
\hline & & $(-0.106)$ & & & & & \\
\hline Country dummies & YES & YES & YES & YES & YES & YES & YES \\
\hline Time dummies & YES & YES & YES & YES & YES & YES & YES \\
\hline \multicolumn{8}{|l|}{ Goodness of fit } \\
\hline$R$-squared & 0.144 & & & & 0.1957 & & \\
\hline McFadden's R2 & \multirow{2}{*}{\multicolumn{2}{|c|}{0.016}} & 0.159 & & & & \\
\hline Pseudo $R^{2}$ & & & & \multicolumn{2}{|l|}{0.1782} & \multicolumn{2}{|l|}{0.1782} \\
\hline$A I C$ & 24381.862 & 18724.71 & 45290.68 & 20467.29 & 20467.29 & 18550.66 & 18550.66 \\
\hline$B I C$ & 24595.851 & 18956.54 & 45516.56 & 20901.18 & 20901.18 & 18984.56 & 18984.56 \\
\hline Observations & 2,819 & 2,819 & 2,819 & 2,818 & 2,818 & 2,818 & 2,818 \\
\hline
\end{tabular}




\section{References}

Aaronson, Stephanie, Bruce Fallick, Andrew Figura, Jonathan Pingle, and William Wascher. 2006. "The Recent Decline in the Labor Force Participation Rate and Its Implications for Potential Labor Supply." Brookings Papers on Economic Activity 37 (1): 69-154.

Abreha, Nigist Haile. 2007. "An economic analysis of farmers' risk attitudes and farm households' responses to rainfall risk in Tigray Northern Ethiopia." Wageningen: Ponsen \& Looijen.

Acharya, Viral, Thomas Philippon, Matthew Richardson, and Nouriel Roubini. 2009. "The Financial Crisis of 2007-2009: Causes and Remedies." Financial Markets, Institutions \& Instruments 18 (2): 89-137. https://doi.org/10.1111/j.1468-0416.2009.00147_2.x.

Adamopoulos, Tasso, and Diego Restuccia. 2014. "The Size Distribution of Farms and International Productivity Differences." American Economic Review 104 (6): 1667-97. http://dx.doi.org/10.1257/aer.104.6.1667.

Ainembabazi, J. H., B. Bashaasha, J. Mugisha, J. Pender, and T. S. Hyuha. 2005. "Technological Change in Sorghum Production in Eastern Uganda." African Crop Science Conference Proceedings 7 (pt. 2 of 3): 947-54.

Ali, Daniel Ayalew, Klaus Deininger, and Anthony Harris. 2017. "Using National Statistics to Increase Transparency of Large Land Acquisition: Evidence from Ethiopia." World Development 93 (May): 62-74. https://doi.org/10.1016/j.worlddev.2016.12.027.

Araujo, Julia P., and Mauro Rodrigues. 2016. "Taxation, Credit Constraints and the Informal Economy." EconomiA 17 (1): 43-55. https://doi.org/10.1016/j.econ.2016.03.003.

Arezki, R., K. Deininger, and H. Selod. 2015. "What Drives the Global 'Land Rush'?" The World Bank Economic Review 29 (2): 207-33. https://doi.org/10.1093/wber/lht034.

Arias, Pedro, Cora Dankers, Pascal Liu, and Paul Pilkauskas, eds. 2003. The World Banana Economy: 1985 - 2002. FAO Commodity Studies 1. Rome: Food and Agriculture Organization of the United Nations.

Arndt, Channing, Rui Benfica, Finn Tarp, James Thurlow, and Rafael Uaiene. 2008. "Biofuels, Poverty, and Growth: A Computable General Equilibrium Analysis of Mozambique." IFPRI discussion paper 803. International Food Policy Research Institute (IFPRI). https://ideas.repec.org/p/fpr/ifprid/803.html.

Arulampalam, Wiji, Paul Gregg, and Mary Gregory. 2001. "Unemployment Scarring." The Economic Journal 111 (475): F577-84. https://doi.org/10.1111/1468-0297.00663.

Asian Development Bank (ADB). 2014. Key Indicators for Asia and the Pacific 2014. Asian Development Bank.

Azevedo, Joao Pedro, Gabriela Inchauste, Sergio Olivieri, Jaime Saavedra, and Hernan Winkler. 2013. "Is Labor Income Responsible for Poverty Reduction? A Decomposition Approach." Policy Research Working Paper, no. 6414. http://papers.ssrn.com/sol3/papers.cfm?abstract_id=2253784.

Bagamba, Fredrick, Ruerd Ruben, and Mariana Rufino. 2007. "Chapter 8 Determinants of Banana Productivity and Technical Efficiency in Uganda." In An Economic Assessment 
of Banana Genetic Improvement and Innovation in the Lake Victoria Region of Uganda and Tanzania. Intl Food Policy Res Inst.

Barrett, Christopher B., Shane M. Sherlund, and Akinwumi A. Adesina. 2007. "Shadow Wages, Allocative Inefficiency, and Labor Supply in Smallholder Agriculture." Agricultural Economics 38 (1): 21-34. https://doi.org/10.1111/j.15740862.2007.00278.x.

Bates-Earner, Nicole, Barry Carin, Min Ha Lee, Wonhyuk Lim, and Mukesh Kapila. 2012. "Post-2015 Development Agenda: Goals, Targets and Indicators - Special Report." Waterloo: CIGI, KDI. https://www.cigionline.org/sites/default/files/MDG_Post_2015v3.pdf.

Bathan, B. M., and F. A. Lantican. 2010. "Factors Affecting Yield Performance of Banana Farms in Oriental Mindoro, Philippines." Journal of the International Society for Southeast Asian Agricultural Sciences 16 (1): 110-20.

Baumann, Pari. 2000. Equity and Efficiency in Contract Farming Schemes: The Experience of Agricultural Tree Crops. Vol. 111. Overseas development institute. https://www.odi.org/sites/odi.org.uk/files/odi-assets/publications-opinionfiles/2730.pdf.

Baumgartner, Philipp, Joachim von Braun, Degnet Abebaw, and Marc Müller. 2015. "Impacts of Large-Scale Land Investments on Income, Prices, and Employment: Empirical Analyses in Ethiopia." World Development 72 (C): 175-90.

Becker, Gary Stanley. 1964. Human Capital: A Theoretical and Empirical Analysis with Special Reference to Education. General Series (National Bureau of Economic Research); No. 80. New York: National Bureau of Economic Research; distributed by Columbia University Press.

Behrendt, Christina, and Quynh Anh Nguyen. 2018. "Innovative Approaches for Ensuring Universal Social Protection for the Future of Work." ILO Future of Work Research Paper Series 1. Geneva: International Labour Organization. https://www.ilo.org/global/topics/future-of-work/publications/WCMS_629864/lang-en/index.htm.

Belotti, Federico, Partha Deb, Willard Manning, and Edward Norton. 2015. "Twopm: TwoPart Models." The Stata Journal 15 (1): 3-20.

Bentley, Tom, and Ravi Gurumurthy. 1999. Destination Unknown: Engaging with the Problems of Marginalised Youth. London: Demos. https://www.demos.co.uk/files/destinationunknown.pdf.

Bijman, Jos. 2008. "Contract Farming in Developing Countries. An Overview of the Literature." Policy Brief. Wageningen: Wageningen UR. http://www.wur.nl/upload_mm/5/c/b/79333121-6f4b-4f86-9e8e0a1782e784d6_ReviewContractFarming.pdf.

Blanchard, Olivier, Eugenio Cerutti, and Lawrence Summers. 2015. "Inflation and Activity Two Explorations and Their Monetary Policy Implications." Working Paper 21726. National Bureau of Economic Research. https://doi.org/10.3386/w21726.

Blimpo, Moussa Pouguinimpo, Michael Minges, Wilfried Anicet Kouakou Kouame, Theophile Thomas Azomahou, Emmanuel Kwasi Koranteng Lartey, Christelle Meniago, Mapi M. 
Buitano, and Albert G. Zeufack. 2017. "Leapfrogging : The Key to Africa's Development - from Constraints to Investment Opportunities." 119849. The World Bank.

http://documents.worldbank.org/curated/en/121581505973379739/Leapfroggingthe-key-to-Africas-development-from-constraints-to-investment-opportunities.

Bräutigam, Deborah, and Haisen Zhang. 2013. "Green Dreams: Myth and Reality in China's Agricultural Investment in Africa." Third World Quarterly 34 (9): 1676-96. https://doi.org/10.1080/01436597.2013.843846.

Burchell, B., K. Sehnbruch, A. Piasna, and N. Agloni. 2014. "The Quality of Employment and Decent Work: Definitions, Methodologies, and Ongoing Debates." Cambridge Journal of Economics 38 (2): 459-77. https://doi.org/10.1093/cje/bet067.

Bussolo, Maurizio, Johannes Koettl, and Emily Sinnott. 2015. Golden Aging: Prospects for Healthy, Active, and Prosperous Aging in Europe and Central Asia. The World Bank. https://doi.org/10.1596/978-1-4648-0353-6.

Bustos, Paula, Bruno Caprettini, and Jacopo Ponticelli. 2016. "Agricultural Productivity and Structural Transformation: Evidence from Brazil." American Economic Review 106 (6): 1320-65. http://dx.doi.org/10.1257/aer.20131061.

Cameron, A., and Pravin Trivedi. 2013. "Regression Analysis of Count Data." Cambridge Books. Cambridge University Press.

Carcillo, Stéphane, Rodrigo Fernández, Sebastian Königs, Andreea Minea, and Labour and Social Affairs (ELS) Directorate for Employment. 2015. NEET Youth in the Aftermath of the Crisis: Challenges and Policies. OECD Social, Employment and Migration Working Papers.

Cavero, Denice, and Claudia Ruiz. 2016. Do Working Conditions in Young People's First Jobs Affect Their Employment Trajectories? The Case of Peru. Work4Youth Publication Series, No. 33. Geneva: ILO. http://www.ilo.org/public/libdoc/ilo/2016/116B09_6_engl.pdf.

Cazes, S., C. Heuer, and S. Verick. 2011. "Labour Market Policies in Times of Crisis." In From the Great Recession to Labour Market Recovery: Issues, Evidence and Policy Options, edited by Iyanatul Islam and Sher Verick, 196-226. London: Palgrave Macmillan UK. https://doi.org/10.1057/9780230295186_8.

Chen, Martha Alter, and Joann Vanek. 2013. "Informal Employment Revisited: Theories, Data \& Policies." Indian Journal of Industrial Relations 48 (3): 390-401.

Chen, Shaohua, and Martin Ravallion. 2008. "The Developing World Is Poorer than We Thought, but No Less Successful in the Fight against Poverty." 4703. Policy Research Working Paper Series. The World Bank. https://ideas.repec.org/p/wbk/wbrwps/4703.html.

Chenery, Hollis Burnley, and Moises Syrquin. 1975. Patterns of Development, 1950-1970. Oxford University Press for the World Bank.

Christensen, Björn. 2002. "Reservation Wages, Offered Wages, and Unemployment Duration: New Empirical Evidence." Kiel Working Paper No. 1095. Kiel Institute of World Economics. https://www.econstor.eu/handle/10419/17749. 
Clark, R., and R. Anker. 1990. "Labour Force Participation Rates of Older Persons: An International Comparison," Population and Labour Policies Programme working paper, ILO-WEP 2-21 (171). https://www.ilo.org/public/libdoc/ilo/1990/90B09_25_engl.pdf.

Collier, Paul, and Stefan Dercon. 2014. "African Agriculture in 50 Years: Smallholders in a Rapidly Changing World?" World Development 63: 92-101. http://dx.doi.org/10.1016/j.worlddev.2013.10.001.

Collier, Paul, and Anthony J. Venables. 2012. "Land Deals in Africa: Pioneers and Speculators." Journal of Globalization and Development 3 (1). https://doi.org/10.1515/1948-1837.1228.

Cotula, Lorenzo. 2013. The Great African Land Grab: Agricultural Investments and the Global Food System. Zed Books Ltd.

Cotula, Lorenzo, Sonja Vermeulen, Rebeca Leonard, and James Keeley. 2009. Land Grab or Development Opportunity? Agricultural Investment and International Land Deals in Africa. London; Rome: IIED / FAO / IFAD.

Crawford, Claire, Kathryn Duckworth, Anna Vignoles, and Gill Wyness. 2011. "Young People's Education and Labour Market Choices Aged 16/17 to 18/19." Research Report DFERR182. UK Department for Education. https://www.gov.uk/government/uploads/system/uploads/attachment_data/file/18 3355/DFE-RR182.pdf.

Cruces, Guillermo, Andrés Ham, and Mariana Viollaz. 2012. Scarring Effects of Youth Unemployment and Informality Evidence from Argentina and Brazil. Centre for Distributive, Labor and Social Studies.

Dao, Nga. 2016. "Agrarian Change and Gendered Livelihoods in Northern Uplands Vietnam." In Workshop on Land Transactions at the University of Michigan (April 20-21, 2016). Ann Arbor.

Dararath, Yem, Neth Top, and Vuthy Lic. 2011. "Rubber Plantation Development in Cambodia: At What Cost?" https://surumer.unihohenheim.de/fileadmin/einrichtungen/surumer/Rubber_Plantation_Development_i n_Cambodia.pdf.

De Schutter, Olivier. 2011. "How Not to Think of Land-Grabbing: Three Critiques of LargeScale Investments in Farmland." Journal of Peasant Studies 38 (2): 249-79. https://doi.org/10.1080/03066150.2011.559008.

Deininger, Klaus. 2013. "Global Land Investments in the Bio-Economy: Evidence and Policy Implications: K. Deininger." Agricultural Economics 44 (s1): 115-27. https://doi.org/10.1111/agec.12056.

Deininger, Klaus, and Derek Byerlee. 2011. Rising Global Interest in Farmland: Can It Yield Sustainable and Equitable Benefits? The World Bank. http://elibrary.worldbank.org/doi/book/10.1596/978-0-8213-8591-3.

- - . 2012. "The Rise of Large Farms in Land Abundant Countries: Do They Have a Future?" World Development 40 (4): 701-14. https://doi.org/10.1016/j.worlddev.2011.04.030. 
Deininger, Klaus, and Fang Xia. 2016. "Quantifying Spillover Effects from Large Land-Based Investment: The Case of Mozambique." World Development 87 (November): 227-41. https://doi.org/10.1016/j.worlddev.2016.06.016.

Dolton, Peter J., Gerald H. Makepeace, and John G. Treble. 1994. "The Youth Training Scheme and the School-to-Work Transition." Oxford Economic Papers 46 (4): 629-57.

Dorward, Andrew. 2013. "Agricultural Labour Productivity, Food Prices and Sustainable Development Impacts and Indicators." Food Policy 39: 40-50.

Dow, William H., and Edward C. Norton. 2003. "Choosing Between and Interpreting the Heckit and Two-Part Models for Corner Solutions." Health Services and Outcomes Research Methodology 4 (1): 5-18. https://doi.org/10.1023/A:1025827426320.

Dutch Jatropha Consortium. 2009. "Dutch Jatropha Consortium." 2009. http://www.dutchjatropha.nl/.

Eaton, Charles, and Andrew W. Shepherd. 2001. Contract Farming: Partnerships for Growth. FAO Agricultural Services Bulletin 145. Rome: FAO. http://www.fao.org/docrep/014/y0937e/y0937e00.pdf.

Edelman, Marc. 2013. "Messy Hectares: Questions about the Epistemology of Land Grabbing Data." The Journal of Peasant Studies 40 (3): 485-501. https://doi.org/10.1080/03066150.2013.801340.

Eichhorst, Werner, Verónica Escudero, Paul Marx, and Steven Tobin. 2010. The Impact of the Crisis on Employment and the Role of Labour Market Institutions. Discussion Paper, DP/202/2010. Geneva: ILO/IILS.

Elder, Sara. 2015. What Does NEETs Mean and Why Is the Concept so Easily Misinterpreted? Technical Brief ; 1. Geneva: ILO. http://www.ilo.org/public/libdoc//ilo/2015/115B09_11_engl.pdf.

Elder, Sara, and Sriani Kring. 2016. Young and Female - a Double Strike? Gender Analysis of School-to-Work Transition Surveys in 32 Developing Economies. Work4Youth Publication Series, No. 32. Geneva: ILO.

Ellwood, David T. 1979. "Teenage Unemployment: Permanent Scars or Temporary Blemishes?" Working Paper No. 399. National Bureau of Economic Research. https://doi.org/10.3386/w0399.

Eurofound. 2012a. Income from Work after Retirement in the EU. EF, 12/59 EN. Luxembourg: Publ. Off. of the Europ. Union [u.a.].

- - - 2012b. NEETs - Young People Not in Employment, Education or Training: Characteristics, Costs and Policy Responses in Europe. EF, 12/54 EN. Luxembourg: Publications Office of the European Union.

European Commission (EC). 2004. "Aid Delivery Methods: Volume 1 - Project Cycle Management Guidelines."

http://ec.europa.eu/europeaid/sites/devco/files/methodology-aid-deliverymethods-project-cycle-management-200403_en_2.pdf.

- - . 2014. "European Vacancy and Recruitment Report 2014." https://op.europa.eu/en/publication-detail/-/publication/4dd66948-a82f-46d393b1-57f5a5b6029c. 
European Training Foundation (ETF). 2008. Transition from Education to Work in EU Neighbouring Countries: Results of an EFT Innovation and Learning Project. Luxembourg: Office for Official Publications of the European Communities.

Feder, Jade, and Derek Yu. 2020. "Employed yet Poor: Low-Wage Employment and Working Poverty in South Africa." Development Southern Africa 37 (3): 363-81. https://doi.org/10.1080/0376835X.2019.1597682.

Fields, Gary S. 2007. "Economic Development, Labor Markets, and Poverty Reduction." 24. ILR Impact Brief. http://digitalcommons.ilr.cornell.edu/briefs/38.

Food and Agriculture Organization (FAO). 1977. "Cassava Processing." Rome. http://www.fao.org/docrep/x5032e/x5032e01.htm.

- - . 2016. "Decent Rural Employment, Productivity Effects and Poverty Reduction in SubSaharan Africa." Technical Papers Series 5. Rural Transformation. Rome: Food and Agriculture Organization of the United Nations (FAO). http://www.fao.org/3/ai5432e.pdf.

Foster, Andrew D., and Mark R. Rosenzweig. 2007. “Chapter 47 Economic Development and the Decline of Agricultural Employment." In Handbook of Development Economics, 4:3051-83. Elsevier.

http://linkinghub.elsevier.com/retrieve/pii/S1573447107040478.

Foster, John Bellamy, and Fred Magdoff. 2009. The Great Financial Crisis: Causes and Consequences. New York: NYU Press.

Gallup, John Luke, and Jeffrey D. Sachs. 2000. "Agriculture, Climate, and Technology: Why Are the Tropics Falling Behind?" American Journal of Agricultural Economics 82 (3): 731-37.

García Bendezú, Sady Javier GARCÍA. 2011. “Evaluating the Biophysical Resource Management Strategies of the Agro-Ecosystems in Farm Communities of the Mantaro Valley, Central Andes of Peru." Gent: Universiteit Gent. https://lirias.kuleuven.be/handle/123456789/289126.

German, Laura, George Schoneveld, and Esther Mwangi. 2013. "Contemporary Processes of Large-Scale Land Acquisition in Sub-Saharan Africa: Legal Deficiency or Elite Capture of the Rule of Law?" World Development 48 (August): 1-18. https://doi.org/10.1016/j.worlddev.2013.03.006.

Giger, Markus, Kerstin Nolte Ward Anseeuw, Thomas Michael Breu, Wytske O. Chamberlain, Peter Messerli, Christoph Oberlack, and Tobias Haller. 2019. "Impacts of Large-Scale Land Acquisitions on Common-Pool Resources: Evidence from the Land Matrix." In The Commons in a Glocal World: Global Connections and Local Responses, edited by Tobias Haller, Thomas Breu, Tine De Moor, Christian Rohr, and Heinzpeter Znoj. London: Routledge. https://www.crcpress.com/The-Commons-in-a-Glocal-WorldGlobal-Connections-and-Local-Responses/Haller-Breu-Moor-RohrZnoj/p/book/9781138484818.

Gindling, T. H., and David Newhouse. 2014. "Self-Employment in the Developing World." World Development 56 (April): 313-31. https://doi.org/10.1016/j.worlddev.2013.03.003. 
Gollin, Douglas, David Lagakos, and Michael E. Waugh. 2014. "Agricultural Productivity Differences across Countries." American Economic Review: Papers \& Proceedings 104 (5): 165-70. http://dx.doi.org/10.1257/aer.104.5.165.

Gray, Cheryl Williamson. 1982. "Food Consumption Parameters for Brazil and Their Application to Food Policy:" Research reports 32. International Food Policy Research Institute (IFPRI). https://ideas.repec.org/p/fpr/resrep/32.html.

Gregg, Paul, and Emma Tominey. 2004. "The Wage Scar from Youth Unemployment." No. 04/097. CMPO Working Paper Series. Department of Economics, University of Bristol. https://www.bristol.ac.uk/media-library/sites/cmpo/migrated/documents/wp97.pdf.

- - . 2005. "The Wage Scar from Male Youth Unemployment." Labour Economics 12 (4): 487-509.

Grimshaw, Damian. 2011. "What Do We Know about Low Wage Work and Low Wage Workers?: Analysing the Definitions, Patterns, Causes and Consequences in International Perspective." ILO Working Paper. International Labour Organization. https://www.ilo.org/travail/whatwedo/publications/WCMS_157253/lang-en/index.htm.

Guarcello, L., M. Manacorda, F. C. Rosati, S. Lyon, and C. Valdivia. 2005. "School to Work Transition in Sub-Saharan Africa: An Overview." UCW Working Paper 43933. The World Bank. http://documents.worldbank.org/curated/en/665461468193751257/School-towork-transition-in-Sub-Saharan-Africa-an-overview.

Guerzoni, Benedetta, and Fabian Zuleeg. 2011. "Working Away at the Cost of Ageing: The Labour Market Adjusted Dependency Ratio." EPC Issue Paper, no. 64. https://wms.flexious.be/editor/plugins/imagemanager/content/2140/PDF/2011/EPC _Issue_Paper_64_-_Working_away_at_the_cost_of_ageing.pdf.

Günther, Isabel, and Andrey Launov. 2012. "Informal Employment in Developing Countries: Opportunity or Last Resort?" Journal of Development Economics 97 (1): 88-98. https://doi.org/10.1016/j.jdeveco.2011.01.001.

Haggblade, Steven, Peter Hazell, and Thomas Reardon. 2010. "The Rural Non-Farm Economy: Prospects for Growth and Poverty Reduction." World Development, The Future of Small Farms Including Special Section: Impact Assessment of PolicyOriented International Agricultural Research (pp. 1453-1526), 38 (10): 1429-41. https://doi.org/10.1016/j.worlddev.2009.06.008.

Headey, Derek, Dirk Bezemer, and Peter Hazell. 2010. "Agricultural Employment Trends in Asia and Africa." World Bank Research Observer 25 (1): 57-89. https://doi.org/10.1093/wbro/lkp028.

Helbling, Laura A., and Stefan Sacchi. 2014. "Scarring Effects of Early Unemployment among Young Workers with Vocational Credentials in Switzerland." Empirical Research in Vocational Education and Training 6 (1): 12. https://doi.org/10.1186/s40461-0140012-2.

Herrmann, Raoul T. 2017. "Large-Scale Agricultural Investments and Smallholder Welfare: A Comparison of Wage Labor and Outgrower Channels in Tanzania." World 
Development 90 (February): 294-310.

https://doi.org/10.1016/j.worlddev.2016.10.007.

High Level Panel of Experts on Food Security and Nutrition (HLPE). 2013. "Investing in Smallholder Agriculture for Food Security." Report by the High Level Panel of Experts on Food Security and Nutrition of the Committee on World Food Security 6. Rome. http://www.fao.org/3/a-i2953e.pdf.

Hossain, M. 1998. "Sustaining Food Security in Asia: Economic, Social, and Political Aspects." In Sustainability of Rice in the Global Food System, 19-44. Davis/Manila. http://books.irri.org/9712201074_content.pdf.

Hughes, Karen D. 2006. "Exploring Motivation and Success Among Canadian Women Entrepreneurs." Journal of Small Business \& Entrepreneurship 19 (2): 107-20. https://doi.org/10.1080/08276331.2006.10593362.

International Cocoa Organisation (ICCO). 2013. "How Much Time and Money Would Have to Be Invested to Get a Cocoa Farm Operational and What Are the On-Going Production Costs?" 2013. http://www.icco.org/faq/57-cocoa-production/125-how-much-timeand-money-would-have-to-be-invested-to-get-a-cocoa-farm-operational-and-whatare-the-on-going-production-costs.html.

International Labour Organization (ILO). 1994. Recent Developments in the Plantations Sector. Report International Labour Organisation, Sectoral Activities Programme, Committee on Work on Plantations, Sess. 10,1. Geneva: ILO.

- - . 1999. "Decent Work - Report of the Director-General." 87th Session. International Labour Conference. Geneva: ILO. http://www.ilo.org/public/libdoc/ilo/P/09605/09605(1999-87).pdf.

- - . 2003. "Decent Work in Agriculture." Background Paper IWSDWA/2003. Geneva: International Labour Organization. http://www.ilo.org/wcmsp5/groups/public/--ed_dialogue/---sector/documents/publication/wcms_161567.pdf.

- - . 2009. Guide to the New Millennium Development Goals Employment Indicators: Including the Full Decent Work Indicator Set. Geneva: ILO.

- - - 2012. "Jobs and Livelihoods at the Heart of the Post-2015 Development Agenda." ILO Concept Note for the Post-2015 Development Agenda, no. 1. http://www.ilo.org/wcmsp5/groups/public/---dgreports/--dcomm/documents/statement/wcms_205641.pdf.

- - . 2012. Understanding Deficits of Productive Employment and Setting Targets: $A$ Methodological Guide. Geneva: ILO. https://www.ilo.org/wcmsp5/groups/public/--ed_emp/documents/publication/wcms_177149.pdf.

- - . 2013. "Jobs and Livelihoods in the Post-2015 Development Agenda: Meaningful Ways to Set Targets and Monitor Progress." ILO Concept Note for the Post-2015 Development Agenda, no. 2. http://www.ilo.org/wcmsp5/groups/public/--dgreports/---dcomm/documents/genericdocument/wcms_213309.pdf.

- - . 2013a. "Resolution Concerning Statistics of Work, Employment and Labour Underutilization, Adapted Py the 19th International Conference of Labour Statisticians." 
- - . 2013b. The Informal Economy and Decent Work: A Policy Resource Guide Supporting Transitions to Formality. http://www.ilo.org/emppolicy/pubs/WCMS_212688/lang-en/index.htm.

- - . 2014. "Social Protection." 2014. http://www.ilo.org/global/about-the-ilo/decentwork-agenda/social-protection/lang--en/index.htm.

- - . 2016a. Women at Work: Trends 2016. Geneva: International Labour Office.

- - . 2016. "Indicator: Employment by Sex and Economic Activity." ILOSTAT Database, January. http://www.ilo.org/ilostat.

- - . 2016b. "Non-Standard Employment around the World: Understanding Challenges, Shaping Prospects." Report. Geneva: International Labour Office. http://www.ilo.org/wcmsp5/groups/public/---dgreports/---dcomm/--publ/documents/publication/wcms_534326.pdf.

- - . 2017a. "Labour Force Estimates and Projections: 1990-2030 (2017 Edition). Methodological Description." Geneva. https://www.ilo.org/ilostatfiles/Documents/LFEP.pdf.

- - - 2017b. World Social Protection Report 2017-19 Universal Social Protection to Achieve the Sustainable Development Goals. Geneva: ILO. https://labordoc.ilo.org/view/delivery/41ILO_INST/1251629030002676.

- - . 2018a. "Care Work and Care Jobs for the Future of Decent Work." Geneva: International Labour Office. https://www.ilo.org/wcmsp5/groups/public/--dgreports/---dcomm/---publ/documents/publication/wcms_633135.pdf.

- - . 2018b. Global Wage Report 2018/19: What Lies behind Gender Pay Gaps. Geneva. https://labordoc.ilo.org/discovery/delivery/41ILO_INST:41ILO_V2/125599888000267 6.

- - . 2018c. Women and Men in the Informal Economy: A Statistical Picture. Geneva.

- - . 2019a. "G20 Recent Employment Trends 2019." Presented at the 1st Employment Working Group (EWG) meeting. https://www.ilo.org/wcmsp5/groups/public/--dgreports/---cabinet/documents/presentation/wcms_713351.pdf.

- - . 2019b. "The Working Poor or How a Job Is No Guarantee of Decent Living Conditions. A Study Based on ILO's Global Estimates of Employment by Economic Class." Spotlight on Work Statistics 6. Geneva. https://ilo.org/wcmsp5/groups/public/---dgreports/--stat/documents/publication/wcms_696387.pdf.

- - . 2019c. "Time to Act for SDG 8: Integrating Decent Work, Sustained Growth and Environmental Integrity." Geneva. https://www.ilo.org/wcmsp5/groups/public/--dgreports/---inst/documents/publication/wcms_712685.pdf.

- - . 2019d. Work for a Brighter Future. Report of the Director-General (International Labour Conference) 108. Geneva: ILO.

- - . 2019e. World Employment and Social Outlook Trends 2019. Geneva: ILO.

- - . 2019f. "Labour Force by Sex and Age (Thousands) -- ILO Modelled Estimates, July 2019." ILOSTAT. July 3, 2019. https://ilostat.ilo.org/data/. 
- - . 2020a. Global Employment Trends for Youth 2020. Technology and the Future of Jobs. Geneva: ILO.

https://labordoc.ilo.org/view/delivery/41ILO_INST/1267519890002676.

- - . 2020b. "ILO Modelled Estimates." ILOSTAT Database. Accessed 20/05/2020. 2020. Available at: https://ilostat.ilo.org/data/.

- - . 2020c. World Employment and Social Outlook Trends 2020. Geneva: ILO.

- - . 2020d. "Measuring Job Quality: Difficult but Necessary." ILOSTAT Blog (blog). January 27, 2020. https://ilostat.ilo.org/2020/01/27/measuring-job-quality-difficultbut-necessary/.

- - . 2020e. "Social Protection Responses to the COVID-19 Pandemic in Developing Countries: Strengthening Resilience by Building Universal Social Protection." Social Protection Spotlight. Geneva. https://www.ilo.org/wcmsp5/groups/public/--ed_protect/---soc_sec/documents/publication/wcms_744612.pdf.

- - . 2020f. "ILO Monitor: COVID-19 and the World of Work. Fourth Edition. Updated Estimates and Analysis." Geneva.

International Monetary Fund (IMF). 2020. "Indicator: National Accounts, Expenditure, Gross Domestic Product, Real, Percent Change, Previous Period, Percent." Database. International Financial Statistics (IFS). April 14, 2020. https://data.imf.org.

Irz, Xavier, Lin Lin, Colin Thirtle, and Steve Wiggins. 2001. "Agricultural Productivity Growth and Poverty Alleviation." Development Policy Review 19 (4): 449-66. https://doi.org/10.1111/1467-7679.00144.

Islam, R. 2011. "The Employment Challenge in Developing Countries during Economic Downturn and Recovery." In From the Great Recession to Labour Market Recovery: Issues, Evidence and Policy Options, edited by lyanatul Islam and Sher Verick, 78-118. London: Palgrave Macmillan UK. https://doi.org/10.1057/9780230295186_4.

Jinghong Liu. 2017. "Working Poor in Mainland China: Concept and Life Trajectory of Its Main Working Groups." Journal of US-China Public Administration 14 (2). https://doi.org/10.17265/1548-6591/2017.02.004.

Joshi, Anuradha, Wilson Prichard, and Christopher Heady. 2014. "Taxing the Informal Economy: The Current State of Knowledge and Agendas for Future Research." The Journal of Development Studies 50 (10): 1325-47. https://doi.org/10.1080/00220388.2014.940910.

Julia, and Ben White. 2012. "Gendered Experiences of Dispossession: Oil Palm Expansion in a Dayak Hibun Community in West Kalimantan." The Journal of Peasant Studies 39 (34): 995-1016. https://doi.org/10.1080/03066150.2012.676544.

Kabeer, Naila. 2005. "Gender Equality and Women's Empowerment: A Critical Analysis of the Third Millennium Development Goal." Gender \& Development 13 (1): 13-24. https://doi.org/10.1080/13552070512331332273.

Kapsos, Steven. 2011. "Working Poverty." In Towards Decent Work in Sub-Saharan Africa: Monitoring MDG Employment Indicators, edited by Theo Sparreboom and Alana Albee. Geneva: ILO. https://www.ilo.org/public/libdoc/ilo/2011/111B09_157_engl.pdf. 
Kelly, Elish, and Seamus McGuinness. 2015. "Impact of the Great Recession on Unemployed and NEET Individuals' Labour Market Transitions in Ireland." Economic Systems, Symposium: Youth Labour Market and the Great Recession, 39 (1): 59-71. https://doi.org/10.1016/j.ecosys.2014.06.004.

Klasen, Stephan, and Francesca Lamanna. 2009. "The Impact of Gender Inequality in Education and Employment on Economic Growth: New Evidence for a Panel of Countries." Feminist Economics 15 (3): 91-132. https://doi.org/10.1080/13545700902893106.

Kleemann, Linda, and Rainer Thiele. 2015. "Rural Welfare Implications of Large-Scale Land Acquisitions in Africa: A Theoretical Framework." Economic Modelling 51: 269-79. https://doi.org/10.1016/j.econmod.2015.08.016.

Kolm, Ann-Sofie, and Birthe Larsen. 2003. "Wages, Unemployment, and the Underground Economy." 1086. CESifo Working Paper Series. CESifo Group Munich. https://ideas.repec.org/p/ces/ceswps/_1086.html.

Kouser, Shahzad, Abedullah, and Martin Qaim. 2015. "Bt Cotton and Employment Effects for Female Agricultural Laborers in Pakistan." New Biotechnology (forthcoming).

Krause, Eleanor, and Isabel Sawhill. 2017. "What We Know and Don't Know about Declining Labor Force Participation: A Review." Center on Children and Families, Brookings Institution, Washington, $D C$.

Kuznets, Simon. 1957. "Quantitative Aspects of the Economic Growth of Nations: II. Industrial Distribution of National Product and Labor Force." Economic Development and Cultural Change 5 (4): 1-111.

Lagakos, David, and Michael E. Waugh. 2013. "Selection, Agriculture, and Cross-Country Productivity Differences." American Economic Review 103 (2): 948-80. http://dx.doi.org/10.1257/aer.103.2.948.

Lambin, E. F., and P. Meyfroidt. 2011. "Global Land Use Change, Economic Globalization, and the Looming Land Scarcity." Proceedings of the National Academy of Sciences 108 (9): 3465-72. https://doi.org/10.1073/pnas.1100480108.

Larson, Donald W., and Thomas K. Shaw. 2001. "Issues of Microenterprise and Agricultural Growth: Do Opportunities Exist through Forward and Backward Linkages?" Journal of Developmental Entrepreneurship, December. https://www.highbeam.com/doc/1P3101574928.html.

Lay, Jann, and Kerstin Nolte. 2018. "Determinants of Foreign Land Acquisitions in Low- and Middle-Income Countries." Journal of Economic Geography 18 (1): 59-86. https://doi.org/10.1093/jeg/lbx011.

Li, Tania Murray. 2011. "Centering Labor in the Land Grab Debate." The Journal of Peasant Studies 38 (2): 281-98. https://doi.org/10.1080/03066150.2011.559009.

Loayza, Norman V. 2016. "Informality in the Process of Development and Growth." The World Economy 39 (12): 1856-1916. https://doi.org/10.1111/twec.12480.

Loayza, Norman V., Ana Maria Oviedo, and Luis Serven. 2005. The Impact Of Regulation On Growth And Informality - Cross-Country Evidence, Vol. 1 Of 1. Policy Research Working Papers. The World Bank. https://doi.org/10.1596/1813-9450-3623. 
Loichinger, Elke, Bernhard Hammer, Alexia Prskawetz, Michael Freiberger, and Joze Sambt. 2014. "Economic Dependency Ratios: Present Situation and Future Scenarios." 02/2014. ECON WPS - Vienna University of Technology Working Papers in Economic Theory and Policy. Vienna University of Technology, Institute for Mathematical Methods in Economics, Research Group Economics (ECON). https://ideas.repec.org/p/zbw/tuweco/022014.html.

Loichinger, Elke, and Vegard Skirbekk. 2016. "International Variation in Ageing and Economic Dependency: A Cohort Perspective." Comparative Population Studies 41 (2). https://www.comparativepopulationstudies.de/index.php/CPoS/article/view/156.

Long, J. Scott, and Jeremy Freese. 2006. "Regression Models for Categorical Dependent Variables Using Stata, 2nd Edition." Stata Press books. StataCorp LP. https://econpapers.repec.org/bookchap/tsjspbook/long2.htm.

Lowder, Sarah K., Jakob Skoet, and Terri Raney. 2016. "The Number, Size, and Distribution of Farms, Smallholder Farms, and Family Farms Worldwide." World Development, February. https://doi.org/10.1016/j.worlddev.2015.10.041.

Luebker, Malte. 2011. "Labour Productivity." In Towards Decent Work in Sub-Saharan Africa: Monitoring MDG Employment Indicators, edited by Theo Sparreboom and Alana Albee. Geneva, Switzerland: ILO.

Lupi, Claudio, and Patrizia Ordine. 2002. "Unemployment Scarring in High Unemployment Regions." Economics Bulletin 10 (2): 1-8.

Maertens, Miet, and Johan F. M. Swinnen. 2009. "Trade, Standards, and Poverty: Evidence from Senegal." World Development 37 (1): 161-78. https://doi.org/10.1016/j.worlddev.2008.04.006.

Maloney, William F. 2004. "Informality Revisited." World Development 32 (7): 1159-78. https://doi.org/10.1016/j.worlddev.2004.01.008.

Manacorda, Marco, Furio Camillo Rosati, Marco Ranzani, and Giuseppe Dachille. 2017. "Pathways from School to Work in the Developing World." IZA Journal of Labor \& Development 6 (1): 1. https://doi.org/10.1186/s40175-016-0067-5.

Martins, Pedro, and Laura Rodriguez Takeuchi. 2013. "Employment in a Post-2015 Framework." ODI Working Paper. http://kms2.isn.ethz.ch/serviceengine/Files/ESDP/167996/ipublicationdocument_sin gledocument/40b07431-0765-4443-8a2b-40a143378825/en/8503.pdf.

Mavromaras, Kostas, Peter Sloane, and Zhang Wei. 2015. "The Scarring Effects of Unemployment, Low Pay and Skills under-Utilization in Australia Compared." Applied Economics 47 (23): 2413-29. https://doi.org/10.1080/00036846.2015.1008762.

McBride, Jo, Andrew Smith, and Marcell Mbala. 2018. "YYou End Up with Nothing': The Experience of Being a Statistic of 'In-Work Poverty' in the UK." Work, Employment and Society 32 (1): 210-18. https://doi.org/10.1177/0950017017728614.

Meghir, Costas, Renata Narita, and Jean-Marc Robin. 2015. "Wages and Informality in Developing Countries." American Economic Review 105 (4): 1509-46. https://doi.org/10.1257/aer.20121110. 
Melamed, Claire, Renate Hartwig, and Ursula Grant. 2011. "Jobs, Growth and Poverty: What Do We Know, What Don't We Know, What Should We Know?" Background Note.

Overseas Development Institute (ODI).

https://www.odi.org/sites/odi.org.uk/files/odi-assets/publications-opinionfiles/7121.pdf.

Messerli, Peter, Markus Giger, Michael B. Dwyer, Thomas Breu, and Sandra Eckert. 2014.

"The Geography of Large-Scale Land Acquisitions: Analysing Socio-Ecological Patterns of Target Contexts in the Global South." Applied Geography 53 (September): 449-59. https://doi.org/10.1016/j.apgeog.2014.07.005.

Minot, Nicholas. 2007. "Contract Farming in Developing Countries: Patterns, Impact, and Policy Implications. Case Study \#6-3." In Food Policy for Developing Countries: Case Studies. Cornell. http://cip.cornell.edu/dns.gfs/1200428173.

Minot, Nicholas, and Lisa Daniels. 2005. "Impact of Global Cotton Markets on Rural Poverty in Benin." Agricultural Economics 33 (November): 453-66. https://doi.org/10.1111/j.1574-0864.2005.00415.x.

Ngeleza, Guyslain K., Rebecca Owusua, Kipo Jimah, and Shashidhara Kolavalli. 2011. "Cropping Practices and Labor Requirements in Field Operations for Major Crops in Ghana: What Needs to Be Mechanized?" IFPRI Discussion Paper 01074. International Food Policy Research Institute (IFPRI). http://www.ifpri.org/cdmref/p15738coll2/id/124900/filename/124901.pdf.

Nolte, Kerstin, Wytske Chamberlain, and Markus Giger. 2016. "International Land Deals for Agriculture. Fresh Insights from the Land Matrix: Analytical Report II." Bern, Montpellier, Hamburg, Pretoria: Centre for Development and Environment, University of Bern; Centre de coopération internationale en recherche agronomique pour le développement; German Institute of Global and Area Studies; University of Pretoria. http://www.landmatrix.org/media/filer_public/ab/c8/abc8b563-9d744a47-9548-cb59e4809b4e/land_matrix_2016_analytical_report_draft_ii.pdf.

Nolte, Kerstin, and Mitelo Subakanya. 2016. "Relationship between Large-Scale Agricultural Investors and Local Communities: Lessons from Two Investments In Zambia." Indaba Agricultural Policy Research Institute Policy Brief, no. 79 (April). http://wwwaec.msu.edu/agecon/fs2/zambia/index.htm.

Notestein, Frank Wallace, Irene B. Taeuber, Dudley Kirk, Ansley J. Coale, and Louise K. Kiser. 1944. The Future Population of Europe and the Soviet Union; Population Projections, 1940-1970,. Geneva: League of Nations.

Oberlack, Christoph, Laura Tejada, Peter Messerli, Stephan Rist, and Markus Giger. 2016. "Sustainable Livelihoods in the Global Land Rush? Archetypes of Livelihood Vulnerability and Sustainability Potentials." Global Environmental Change 41 (November): 153-71. https://doi.org/10.1016/j.gloenvcha.2016.10.001.

Obstfeld, Maurice, and Kenneth Rogoff. 2009. "Global Imbalances and the Financial Crisis: Products of Common Causes." CEPR Discussion Paper No. DP7606. Rochester, NY: Social Science Research Network. Available at SSRN: https://papers.ssrn.com/abstract=1533211. 
O'Hare, Bernadette, and Mark Curtis. 2017. "Lost Revenues in Low Income Countries." SSRN Scholarly Paper ID 3069383. Rochester, NY: Social Science Research Network. https://papers.ssrn.com/abstract=3069383.

O’Higgins, Niall. 2001. "Youth Unemployment and Employment Policy: A Global Perspective." 23698. MPRA Paper. University Library of Munich, Germany. https://ideas.repec.org/p/pra/mprapa/23698.html.

- - . 2010. The Impact of the Economic and Financial Crisis on Youth Employment: Measures for Labour Market Recovery in the European Union, Canada and the United States. Employment Working Paper 70. Geneva: ILO. http://www.ilo.org/public/libdoc/ilo/2010/110B09_332_engl.pdf.

Oizumi, Keiichiro, Hirokazu Kajiwara, and Natsumi Aratame. 2006. "Facing up to the Problem of Population Aging in Developing Countries. New Perspectives for Assistance and Cooperation." Institute for International Cooperation. Japan International Cooperation Agency. https://openjicareport.jica.go.jp/pdf/11844420.pdf.

Organisation for Economic Cooperation and Development (OECD). 2017. Pensions at a Glance 2017: OECD and G20 Indicators. Paris: OECD Publishing. http://dx.doi.org/10.1787/pension_glance-2017-en.

Osabuohien, Evans S. 2014. "Large-Scale Agricultural Land Investments and Local Institutions in Africa: The Nigerian Case." Land Use Policy 39 (July): 155-65. https://doi.org/10.1016/j.landusepol.2014.02.019.

Ospina Patiño, B., L. F. Cadavid López, M. L. García González, and C. A. Alcalde Torres. 2007. "Mechanization of Cassava Production in Colombia." In . Centro Internacional de Agricultura Tropical (CIAT), Cassava Office for Asia. https://cgspace.cgiar.org/handle/10568/56116.

Oya, Carlos. 2013. "Methodological Reflections on 'Land Grab' Databases and the 'Land Grab' Literature 'Rush.'” The Journal of Peasant Studies 40 (3): 503-20. https://doi.org/10.1080/03066150.2013.799465.

Pastore, Francesco. 2018. "Why Is Youth Unemployment so High and Different across Countries?" IZA World of Labor, January. https://doi.org/10.15185/izawol.420.

Petreski, Marjan, Nikica Mojsoska-Blazevski, and Marcelo Bergolo. 2016. "Labor-Market Scars When Youth Unemployment Is Extremely High: Evidence from Macedonia." IZA Discussion Paper No. 10342. Institute for the Study of Labor (IZA). http://econpapers.repec.org/paper/izaizadps/dp10342.htm.

Pimentel, David. 2009. "Energy Inputs in Food Crop Production in Developing and Developed Nations." Energies 2 (1). http://econpapers.repec.org/article/gamjeners/v_3a2_3ay_3a2009_3ai_3a1_3ap_3a 1-24_3ad_3a3869.htm.

Pissarides, Christopher A. 1992. "Loss of Skill During Unemployment and the Persistence of Employment Shocks." The Quarterly Journal of Economics 107 (4): 1371-91. https://doi.org/10.2307/2118392.

Quintini, Glenda, John P. Martin, and Sébastien Martin. 2007. "The Changing Nature of the School-to-Work Transition Process in OECD Countries." IZA Discussion Papers 2582. Institute of Labor Economics (IZA). https://ideas.repec.org/p/iza/izadps/dp2582.html. 
Ranzani, Marco, and Furio C. Rosati. 2013. "The NEET Trap: A Dynamic Analysis for Mexico." UCW Working Paper Series. http://www.ucw-

project.org/attachment/Youth_Empl_NEET_TRAP_MEXICO20130328_160056.pdf.

Rissman, Ellen. 2003. "Self-Employment as an Alternative to Unemployment." FRB of Chicago Working Paper 2003-34. Rochester, NY: Social Science Research Network. Available at SSRN: https://papers.ssrn.com/abstract=486988.

Robertson, Beth, and Per Pinstrup-Andersen. 2010. "Global Land Acquisition: NeoColonialism or Development Opportunity?" Food Security 2 (3): 271-83. https://doi.org/10.1007/s12571-010-0068-1.

Rosenzweig, Mark R. 1988. "Risk, Implicit Contracts and the Family in Rural Areas of LowIncome Countries." The Economic Journal 98 (393): 1148. https://doi.org/10.2307/2233724.

Ruhm, Christopher J. 1991. “Are Workers Permanently Scarred by Job Displacements?" The American Economic Review 81 (1): 319-24.

Ryan, Paul. 2001. "The School-to-Work Transition: A Cross-National Perspective." Journal of Economic Literature 39 (1): 34-92.

Ryder, Guy. 2020. "New Normal? Better Normal!" International Labour Organization, May 1, 2020, sec. Op-Ed. http://www.ilo.org/global/about-theilo/newsroom/news/WCMS_743326/lang--en/index.htm.

Samoilenko, Anton, and Kristie Carter. 2015. Economic Outcomes of Youth Not in Education, Employment or Training (NEET). Treasury Working Paper Series.

Samorodov, Alexander T. 1999. Ageing and Labour Markets for Older Workers. Employment and Training Papers, 33. Geneva: ILO.

Sanderson, Warren C., and Sergei Scherbov. 2015. "Are We Overly Dependent on Conventional Dependency Ratios?" Population and Development Review 41 (4): $687-$ 708. https://doi.org/10.1111/j.1728-4457.2015.00091.x.

Satchi, Mathan, and Jonathan Temple. 2009. "Labor Markets and Productivity in Developing Countries." Review of Economic Dynamics 12 (1): 183-204. https://doi.org/10.1016/j.red.2008.09.001.

Scharschmidt, Anna Sophia. 2010. "Macro-economic Impacts of Large Scale Jatropha Cultivation and Biodiesel Production in Tanzania." Utrecht: Utrecht University. https://www.dub.uu.nl/sites/default/files/legacy/other/08.13.\%20final\%20version.p df.

Scheidel, Arnim, and Alevgul H. Sorman. 2012. "Energy Transitions and the Global Land Rush: Ultimate Drivers and Persistent Consequences." Global Environmental Change 22 (3): 588-95. https://doi.org/10.1016/j.gloenvcha.2011.12.005.

Schlyter, Charlotta. 2002. "International Labour Standards and the Informal Sector : Developments and Dilemmas." 993541743402676. ILO Working Papers. International Labour Organization. https://ideas.repec.org/p/ilo/ilowps/993541743402676.html.

Schnabel, Claus. 2016. "Low-Wage Employment." IZA World of Labor, July. https://doi.org/10.15185/izawol.276. 
Schneider, Friedrich, and Dominik H. Enste. 2000. "Shadow Economies: Size, Causes, and Consequences." Journal of Economic Literature 38 (1): 77-114. https://doi.org/10.1257/jel.38.1.77.

Schwarze, Stefan, Michael Euler, Marcel Gatto, J. Hein, Elisabeth Hettig, Anna Mareike Holtkamp, Lutfi Izhar, et al. 2015. "Rubber vs. Oil Palm: An Analysis of Factors Influencing Smallholders' Crop Choice in Jambi, Indonesia." EFForTS Discussion Paper Series 11. Collaborative Research Centre 990 "EFForTS, Ecological and Socioeconomic Functions of Tropical Lowland Rainforest Transformation Systems (Sumatra, Indonesia)", University of Goettingen. https://ideas.repec.org/p/zbw/crc990/11.html.

Seike, Atsushi. 2016. "Towards a Lifelong Active Society: Coping with Japan's Changing Population." Asia \& the Pacific Policy Studies 3 (3): 533-39. https://doi.org/10.1002/app5.153.

Sharma, Siddharth, and Hernan Winkler. 2018. "The Labour Market Effects of Financial Crises: The Role of Temporary Contracts in Central and Western Europe." Economics of Transition 26 (1): 35-60. https://doi.org/10.1111/ecot.12141.

Shi, Lulu P., Christian Imdorf, Robin Samuel, and Stefan Sacchi. 2018. "How Unemployment Scarring Affects Skilled Young Workers: Evidence from a Factorial Survey of Swiss Recruiters." Journal for Labour Market Research 52 (1): 7. https://doi.org/10.1186/s12651-018-0239-7.

Simmons, Phillip Ray. 2002. "Overview of Smallholder Contract Farming in Developing Countries." Working Paper 02-04. ESA Working Paper. Rome: Agricultural and Development Economics Division of the Food and Agriculture Organization of the United Nations (FAO - ESA). http://www.fao.org/docrep/007/ae023e/ae023e00.HTM.

Simpson, John Y., and Qing Yang Cheong. 2014. "Commercial Agricultural Production in Tanzania: Mountainside Farms Limited." International Food and Agribusiness Management Review 17 (B). https://ideas.repec.org/a/ags/ifaamr/179582.html.

Slonimczyk, Fabián. 2014. "Informal Employment in Emerging and Transition Economies." IZA World of Labor, May. https://doi.org/10.15185/izawol.59.

Sparreboom, Theo. 2011. "Vulnerable Employment." In Towards Decent Work in SubSaharan Africa: Monitoring MDG Employment Indicators, edited by Theo Sparreboom and Alana Albee. Geneva: ILO.

Spence, Michael. 1973. “Job Market Signaling.” The Quarterly Journal of Economics 87 (3): 355-374. https://doi.org/10.2307/1882010.

Stewart, Mark B. 2007. "The Interrelated Dynamics of Unemployment and Low-Wage Employment." Journal of Applied Econometrics 22 (3): 511-31. https://doi.org/10.1002/jae.922.

Taylor, J. Edward, and Philip L. Martin. 2001. "Human Capital: Migration and Rural Population Change." Handbook of Agricultural Economics. Elsevier. http://econpapers.repec.org/bookchap/eeehagchp/1-09.htm. 
Terza, Joseph V. 1998. "Estimating Count Data Models with Endogenous Switching: Sample Selection and Endogenous Treatment Effects." Journal of Econometrics 84 (1): 12954. https://doi.org/10.1016/S0304-4076(97)00082-1.

The Land Matrix Global Observatory. 2016. "Get the Detail." Database. Get the Detail. 2016. http://landmatrix.org/en/.

Tiffen, Mary, and Michael Mortimore. 1990. "Theory and Practice in Plantation Agriculture: An Economic Review." ODI Development Policy Studies. http://www.odi.org/sites/odi.org.uk/files/odi-assets/publications-opinionfiles/8008.pdf.

Timmer, Charles Peter. 1988. "Chapter 8: The Agricultural Transformation." In Handbook of Development Economics, 1:275-331. Elsevier. http://linkinghub.elsevier.com/retrieve/pii/S1573447188010113.

Timmer, Marcel P., Abdul Azeez Erumban, Bart Los, Robert Stehrer, and Gaaitzen J. de Vries. 2014. "Slicing Up Global Value Chains." Journal of Economic Perspectives 28 (2): 99118. https://doi.org/10.1257/jep.28.2.99.

Tsani, Stella, Leonidas Paroussos, Costas Fragiadakis, Ioannis Charalambidis, and Pantelis Capros. 2013. "Female Labour Force Participation and Economic Growth in the South Mediterranean Countries." Economics Letters 120 (2): 323-28. https://doi.org/10.1016/j.econlet.2013.04.043.

Tscharntke, Teja, Yann Clough, Thomas C. Wanger, Louise Jackson, Iris Motzke, Ivette Perfecto, John Vandermeer, and Anthony Whitbread. 2012. "Global Food Security, Biodiversity Conservation and the Future of Agricultural Intensification." Biological Conservation 151 (1): 53-59. https://doi.org/10.1016/j.biocon.2012.01.068.

Tschirley, David Lawrence, Colin Poulton, and Patrick Labaste. 2009. Organization and Performance of Cotton Sectors in Africa: Learning from Reform Experience. World Bank Publications.

Turnham, David, and Deniz Eröcal. 1990. "Unemployment in Developing Countries: New Light on an Old Problem," July. https://doi.org/10.1787/665867303478.

UNESCO Institute for Statistics (UIS). 2020. “Indicator: Gross Enrolment Ratio by Level of Education." Database. May 31, 2020. http://data.uis.unesco.org/\#.

Üngör, Murat. 2013. "De-Agriculturalization as a Result of Productivity Growth in Agriculture." Economics Letters 119 (2): 141-45.

United Nations, Department of Economic and Social Affairs, Population Division (UNDESA). 2019a. "World Population Prospects 2019: Highlights." ST/ESA/SER.A/423. New York. https://population.un.org/wpp/Publications/Files/WPP2019_Highlights.pdf.

- - - 2019b. “World Population Prospects 2019, Online Edition. Rev. 1." 2019. https://population.un.org/wpp/.

United Nations Development Programme (UNDP), ed. 2009. "Handbook on Planning, Monitoring and Evaluating for Development Results."

http://web.undp.org/evaluation/handbook/documents/english/pme-handbook.pdf. 
United Nations Economic and Social Council (ECOSOC). 2014. "Millennium Development Goals and Post-2015 Development Agenda." 2014.

http://www.un.org/en/ecosoc/about/mdg.shtml.

United Nations General Assembly (UNGA). 2015. "Transforming Our World: The 2030 Agenda for Sustainable Development." Resolution adopted by the General Assembly on 25 September 2015. A/RES/70/1. New York.

https://www.un.org/ga/search/view_doc.asp?symbol=A/RES/70/1\&Lang=E.

United Nations Statistics Division (UNSTATS). 2008. "Official List of MDG Indicators." https://unstats.un.org/unsd/mdg/Resources/Attach/Indicators/OfficialList2008.pdf.

Van den Broeck, Goedele, Johan Swinnen, and Miet Maertens. 2017. "Global Value Chains, Large-Scale Farming, and Poverty: Long-Term Effects in Senegal." Food Policy 66 (C): 97-107.

Verick, Sher. 2009. "Who Is Hit Hardest during a Financial Crisis? The Vulnerability of Young Men and Women to Unemployment in an Economic Downturn." IZA Discussion Paper No. 4359. http://ftp.iza.org/dp4359.pdf.

- - . 2011. "The Impact of the Global Financial Crisis on Labour Markets in OECD Countries: Why Youth and Other Vulnerable Groups Have Been Hit Hard." In From the Great Recession to Labour Market Recovery: Issues, Evidence and Policy Options, edited by Iyanatul Islam and Sher Verick, 119-45. London: Palgrave Macmillan UK. https://doi.org/10.1057/9780230295186_5.

- - . 2014. "Female Labor Force Participation in Developing Countries." IZA World of Labor. https://doi.org/10.15185/izawol.87.

Vogel, Edgar, Alexander Ludwig, and Axel Börsch-Supan. 2017. “Aging and Pension Reform: Extending the Retirement Age and Human Capital Formation." Journal of Pension Economics and Finance 16 (1): 81-107. https://doi.org/10.1017/S1474747215000086.

Warren, Tracey. 2015. "Work-Time Underemployment and Financial Hardship: Class Inequalities and Recession in the UK." Work, Employment and Society 29 (2): 191212. https://doi.org/10.1177/0950017014559264.

Wilson, Paul. 2015. "The Misuse of the Vuong Test for Non-Nested Models to Test for ZeroInflation." Economics Letters 127 (February): 51-53. https://doi.org/10.1016/j.econlet.2014.12.029.

Wooldridge, Jeffrey. 2010. "Econometric Analysis of Cross Section and Panel Data." MIT Press Books. The MIT Press.

https://econpapers.repec.org/bookchap/mtptitles/0262232588.htm.

World Bank. 2009. “Awakening Africa's Sleeping Giant : Prospects for Commercial Agriculture in the Guinea Savannah Zone and Beyond." World Bank Publications. The World Bank. https://ideas.repec.org/b/wbk/wbpubs/2640.html.

- - - 2010. "Poverty Trends in Uganda - Who Gained and Who Was Left Behind?" Inclusive Growth Policy Note 1.

http://siteresources.worldbank.org/INTUGANDA/Resources/uganda-poverty-andinequality-trends-full-policy-note.pdf. 
- - . 2012. World Development Report 2013: Jobs. World Development Report 2013. Washington, D.C.: World Bank.

- - - 2016. "World Development Indicators." Database. 2016. http://databank.worldbank.org/data/reports.aspx?source=world-developmentindicators\&preview=on.

- - . 2019. "How Does the World Bank Classify Countries?” Data Help Desk. 2019. https://datahelpdesk.worldbank.org/knowledgebase/articles/378834-how-does-theworld-bank-classify-countries.

World Health Organization (WHO). 2020. "WHO Director-General's Statement on IHR Emergency Committee on Novel Coronavirus (2019-NCoV)." Speech. https://www.who.int/dg/speeches/detail/who-director-general-s-statement-on-ihremergency-committee-on-novel-coronavirus-(2019-ncov).

Wöss, Josef, and Erik Türk. 2011. "Dependency Ratios and Demographic Change. The Labour Market as a Key Element." ETUI Policy Brief, no. 4. https://www.etui.org/content/download/3860/42211/file/Policy+Brief-Blue-Issue42011-EN.pdf.

Zuleeg, Fabian. 2007. "How to Grow Old without Going Bust: The Need for Efficient EU Labour Markets." Policy Brief. Brussels: European Policy Centre. https://www.files.ethz.ch/isn/45588/PB_Nov_07_Grow_Old.pdf. 


\section{Versicherung bei Zulassung zur Promotionsprüfung}

Ich versichere,

1. dass ich die eingereichte Dissertation

“KEY LABOUR MARKET ISSUES AND DECENT WORK IN DEVELOPING AND EMERGING COUNTRIES"

selbstständig angefertigt habe und nicht die Hilfe Dritter in einer dem Prüfungsrecht und wissenschaftlicher Redlichkeit widersprechenden Weise in Anspruch genommen habe,

2. dass ich das Prüfungsrecht einschließlich der wissenschaftlichen Redlichkeit - hierzu gehört die strikte Beachtung des Zitiergebots, so dass die Übernahme fremden Gedankenguts in der Dissertation deutlich gekennzeichnet ist - beachtet habe,

3. dass beim vorliegenden Promotionsverfahren kein Vermittler gegen Entgelt eingeschaltet worden ist sowie im Zusammenhang mit dem Promotionsverfahren und seiner Vorbereitung

- kein Entgelt gezahlt oder entgeltgleiche Leistungen erbracht worden sind

- keine Dienste unentgeltlich in Anspruch genommen wurden, die dem Sinn und

- Zweck eines Prüfungsverfahrens widersprechen

4. dass ich eine entsprechende Promotion nicht anderweitig beantragt und hierbei die eingereichte Dissertation oder Teile daraus vorgelegt habe.

Mir ist bekannt, dass Unwahrheiten hinsichtlich der vorstehenden Versicherung die Zulassung zur Promotionsprüfung ausschließen und im Falle eines späteren Bekanntwerdens die Promotionsprüfung für ungültig erklärt werden oder der Doktorgrad aberkannt werden kann.

Datum Unterschrift 


\section{Erklärung über den geleisteten Eigenanteil der Arbeit}

Die vorgelegte kumulative Dissertation besteht aus vier Artikeln, welche in den Kapiteln 2 bis 5 angeführt werden. Die Artikel sind thematisch miteinander verknüpft und bauen aufeinander auf, können jedoch unabhängig voneinander gelesen und verstanden werden.

Kapitel 2 entstand in Ko-Autorenschaft mit Sarah Linde, Jann Lay und Sebastian Prediger. Die Idee und das Konzept zu diesem Artikel basiert auf meiner Masterarbeit und wurde gemeinschaftlich weiterentwickelt. Sarah Linde und ich waren für die Datenaufbereitung und die empirische Analyse zuständig. Das eigentliche Paper wurde im Kollektiv erstellt, wobei ich sowohl in der Entwurfsphase, als auch in der Revisions- und Veröffentlichungsphase substantielle Beiträge geleistet habe.

Der Artikel in Kapitel 3 wurde in Zusammenarbeit mit Kerstin Nolte verfasst. Gemeinsam haben wir die Idee und das Konzept entwickelt. Während ich den größten Teil der Datenaufbereitung und -analyse übernommen hatte, hat Kerstin Nolte den Großteil des ersten Entwurfs ausgearbeitet. An der Revision, finalen Ausarbeitung und Vorbereitung zur Veröffentlichung waren wir zu gleichen Teilen beteiligt.

Kapitel 4 ist in Zusammenarbeit mit Claire Harasty entstanden, der die ursprüngliche Forschungsidee zu verdanken ist und sie hat einen ersten Entwurf dazu entwickelt. Basierend auf diesem Entwurf habe ich das Konzept stärker in die wissenschaftlichen Debatten eingebettet und um einen zusätzlichen Indikator erweitert. Zudem habe ich die Datenanalyse aktualisiert und nach aktuellsten Methoden durchgeführt. Während ich alleine mit der Überarbeitung des Entwurfs betraut war, haben wir den Artikel gemeinsam für die Veröffentlichung finalisiert.

Ich bin Alleinautor von Kapitel 5.

Hiermit bestätige ich, alle Personen, die sich für eine Autorenschaft qualifizieren, hier genannt zu haben.

$\underline{04.06 .2020}$

Datum Unterschrift 